This report was prepared as an account of work sponsored by the United States Government. Neither the United States nor the United States Atomic Energy Commission, nor any of their employees, nor any of Commission, hor any of theirs, or their employees, their contractors, subcontractors, or the makes any warranty, express or for the accuracy, com-

legal liability or responsibility for the accuracy, com-

pleteness or useralness of any informanion, apparatus,

product or process disclosed, or represents that its use

would not infringe privately owned rights.

\title{
THE \\ JOSHUA \\ SYSTEM
}

\section{Vol. 9.3 OPERATING SYSTEM}

Approved by

J. R. Hilley, Research Manager

Computer Applications Division

\section{NOTICE}

This document contains descriptions JUSHUA oprating System and Aprofletions

Modules. The aromentepared as a set of loosezear notebooks whithwil be periodily updated. A11 of the materiat is preliminary and should not be referenced.

JUNE 1974

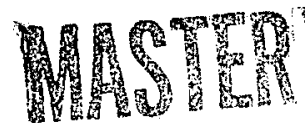

DISTRIBUTION OF THIS DOCUMENT IS UNLIMITED

E. I. du Pont de Nemours \& Co. Savannah River Laboratory

Aiken, S. C. 29801 


\section{DISCLAIMER}

This report was prepared as an account of work sponsored by an agency of the United States Government. Neither the United States Government nor any agency Thereof, nor any of their employees, makes any warranty, express or implied, or assumes any legal liability or responsibility for the accuracy, completeness, or usefulness of any information, apparatus, product, or process disclosed, or represents that its use would not infringe privately owned rights. Reference herein to any specific commercial product, process, or service by trade name, trademark, manufacturer, or otherwise does not necessarily constitute or imply its endorsement, recommendation, or favoring by the United States Government or any agency thereof. The views and opinions of authors expressed herein do not necessarily state or reflect those of the United States Government or any agency thereof. 


\section{DISCLAIMER}

Portions of this document may be illegible in electronic image products. Images are produced from the best available original document. 


\section{NOTICE}

This report was prepared as an account of work sponsored by the United States Government. Neither the United States nor the United States Atomic Energy Commission, nor any of their employees, nor any of their contractors, subcontractors, or their employees, makes any warranty, express or implied, or assumes any legal liability or responsibility for the accuracy, completeness or usefulness of any information, apparatus, product or process disclosed, or represents that its use would not infringe privately owned rights. 


\begin{tabular}{|l|l|l|l|l|}
\hline \multirow{2}{\text{JPSTM-500}}{} & Title Part E-Modules and Subprograms (Cont.) & $\begin{array}{c}\text { Vol. } \\
\text { IX }\end{array}$ & $\begin{array}{l}\text { Page } \\
\text { E.0.1.4 }\end{array}$ \\
\cline { 3 - 4 } & Rev. & $\begin{array}{c}\text { Date } \\
6 / 73\end{array}$ \\
\hline
\end{tabular}

(BIank) 


\begin{tabular}{|l|l|l|l|l|}
\hline$\underbrace{}_{\text {DPSTM-500 }}$ Title Part E - Modules and Subprograms (cont.) & $\begin{array}{c}\text { Vol. } \\
\text { Ix }\end{array}$ & $\begin{array}{c}\text { Page } \\
\text { E.1.2.5 }\end{array}$ \\
\cline { 3 - 5 } & & Rev. 1 & $\begin{array}{c}\text { Date } \\
6 / 73\end{array}$ \\
\hline
\end{tabular}

\begin{tabular}{|c|c|c|}
\hline 4.142 & JTVARY & E. 1.429 \\
\hline 4.143 & JTVIEWQ & E. 1.435 \\
\hline 4.144 & JTVQACCT & E. 1.439 \\
\hline 4.145 & JTWSTATS & E. 1.443 \\
\hline 4.146 & JTXBCHEK & E. 1.445 \\
\hline 4.147 & LIST & E. 1.447 \\
\hline 4.148 & LISTB & E. 1.451 \\
\hline \multirow[t]{3}{*}{4.149} & LSTSQR & E. 1.453 \\
\hline & 4.149 .1 & E. 1.456 \\
\hline & 4.149.2 MINVS & E. 1.460 \\
\hline 4.150 & MATHERRX & E. 1.463 \\
\hline 4.151 & MTDIRECT & E. 1.467 \\
\hline 4.152 & MTPAGE & E. 1.469 \\
\hline \multirow[t]{4}{*}{4.153} & NTERPRET & E. 1.473 \\
\hline & 4.153 .1 INVER & E. 1.478 \\
\hline & 4.153 .2 OVFLO & E. 1.484 \\
\hline & 4.153.3 PEELPG & E. 1.487 \\
\hline 4.154 & PRECOP & E. 1.489 \\
\hline 4.155 & PROC & E. 1.491 \\
\hline 4.156 & RENAME & E. 1.495 \\
\hline 4.157 & RMEND & E. 1.497 \\
\hline \multirow[t]{2}{*}{4.158} & RMSTART & E. 1.501 \\
\hline & 4.158.1 RMREAD & E. 1.504 \\
\hline 4.159 & SETJOB & E. 1.507 \\
\hline 4.160 & SUPSCRTH & E. 1.509 \\
\hline 4.161 & SYSMSG & E. 1.513 \\
\hline \multirow[t]{4}{*}{ 4. 162} & TDISPLAY & E. 1.515 \\
\hline & 4.162 .1 CRPAGE & E. 1.518 \\
\hline & 4.162 .2 CTYPE & E. 1.520 \\
\hline & 4.162 .3 FLDPIX & E. 1.522 \\
\hline 4.163 & TEMPEXIT & E. 1.525 \\
\hline 4.164 & TEMP INIT & E. 1.529 \\
\hline \multirow[t]{4}{*}{4.165} & TEMPLIST & E. 1.533 \\
\hline & 4.165 .1 STRIF & E. 1.536 \\
\hline & $4.165 .2 \quad$ XLIMIT & E. 1.538 \\
\hline & 4.165.3 ХTYPE & E. 1.540 \\
\hline 4.166 & TEMPNEST & E. 1.543 \\
\hline \multirow[t]{5}{*}{4.167} & TEMPPAGE & E. 1.545 \\
\hline & 4.167 .1 SKIP & E. 1.548 \\
\hline & 4.167 .2 XPAGE & E. 1.550 \\
\hline & 4.167 .3 XPTRS & E. 1.553 \\
\hline & $4.167 .4 \quad$ XTMP IT & E. 1.555 \\
\hline 4.168 & VERIFY & E. 1.557 \\
\hline 4.169 & ZONK1 & E. 1.559 \\
\hline
\end{tabular}




\begin{tabular}{|c|c|c|c|c|}
\hline 1. & \multirow{2}{*}{\multicolumn{2}{|c|}{ Title Part E - Modules and Subprograms (Cont.) }} & \begin{tabular}{|r|} 
Vol. \\
IX \\
\end{tabular} & \begin{tabular}{|l|} 
Page \\
E.1.2.6 \\
\end{tabular} \\
\hline DPSTM- 500 & & & Rev. & $\begin{array}{c}\text { Date } \\
6 / 73\end{array}$ \\
\hline
\end{tabular}

(Blank) 


\begin{tabular}{|c|l|l|l|}
\hline $\begin{array}{c}\text { JOSHUA } \\
\text { DPSTM-500 }\end{array}$ & Title Module: JTVARY & $\begin{array}{l}\text { Vol. } \\
\text { IX }\end{array}$ & $\begin{array}{c}\text { Page } \\
\text { E.1.429 }\end{array}$ \\
\cline { 3 - 5 } & & $\begin{array}{c}\text { Rev. } \\
\text { Date } \\
6 / 73\end{array}$ \\
\hline
\end{tabular}

Purpose:

Attribute:

JOS Main Progran Name: JTVARY

Arguments:

Parameter

$\mathrm{CCB}$

External References:

Objective:

Program Logic:

$\mathrm{D}$
To initiate the activating or deactivating of a terminal, the allocation or deallocation of a terminal unit, the activating or deactivating of a function, or the issuing of a message.

Nonreusable

Type
Description

CCBMCB - Monitor Control Block

CCBUSER - User data set name

DAR, CLOSE, LINK, GALLOC, OPEN, SAEC, SPAR, GETMAIN, FREEMAN

The module has the following objectives:

(1) To activate or deactivate a terminal.

(2) To allocate or deallocate a terminal unit.

(3) To activate or deactivate functions.

(4) To issue general messages.

The address of the communication control block (CCB) is received via the argument list. A check is made on the third double word of argument 1 (WCBARG1) to see if a control request is indicated (indicated by there not being a third name). If it is a special. request, the terminal is checked to see if it is a control terminal. If the terminal is not a control terminal, an appropriate code is set up, and a return is issued (this is called an invalid procedure). If the terminal was a control terminal (MCFCNTRL flag on), a check is made to see if it is a function request. If a function request is indicated and it is valid (proper authorization necessary or invalid procedure is followed), the function offline flag (FCLFCTOF) is either set on or off depending on the request and a return is issued. If no function existed for the one indicated, the invalid procedure is followed.

If the request has been concerned with a message for all terminals, the message area for all terminal (RCBMSG) would be obtained via GETMAIN (if not already available) and the message moved in or the message area would have been freed up via FREEMAIN depending on the request. A return is issued after performing the desired action.

If an external terminal request is desired, the terminal is located and the request is analyzed. If the terminal is to be varied on-line or off-line, the proper flags are set and a return is issued. If a message is to be put to a terminal, the terminal message area (WCBMSG) is obtained via a GETMAIN (if not already available), the message moved in, and a return is issued. If the terminal message is to be removed, the area is freed via FREEMAIN and a return is issued.

If a unit is to be allocated, a LINK is issued to GALLOC 


\begin{tabular}{|c|l|l|l|}
\hline JOSHUA & Title Module: JTVARY & Vol. & $\begin{array}{l}\text { Page } \\
\text { E.1.430 }\end{array}$ \\
& & Rev. & $\begin{array}{c}\text { Date } \\
6 / 73\end{array}$ \\
\hline
\end{tabular}

with the proper arguments and the return code is checked. If the return code is nonzero, the invalid proredure is followed; otherwise, the data control block for the unit (GALDCBG) is OPENED, the graphic attention routines are set up via SAEC and SPAR macros, and a return is issued.

If the deallocation of a unit is indicated, the graphic attention routine is deleted via the DAR macro, the data control block (DCB) is CLOSED, a LINK is issued to GALLOC for deallocation, and a return is issued. If there are any errors obtained in any of the above operations, the invalid procedure is followed.

If the request had not been special, the terminal would not have had to be a control one.

Terminating Conditions: Upon obtaining some error upon allocating or deallocating or fullfilling some other request, an appropriate code is set up, and a return is issued.

Referenced by: $\quad$ JTMON

Language:

Assembler

Author:

R. L. Boyce, Jr. 


\begin{tabular}{|c|c|c|c|}
\hline & \multirow[t]{2}{*}{ Title Module: JTVARY } & Vol. $_{\text {IX }}$ & \begin{tabular}{|l|} 
Page \\
E.1.431
\end{tabular} \\
\hline DPSTM. 500 & & $\begin{array}{r}\text { Rev. } \\
1\end{array}$ & \begin{tabular}{|c|} 
Date \\
$6 / 73$ \\
\end{tabular} \\
\hline
\end{tabular}

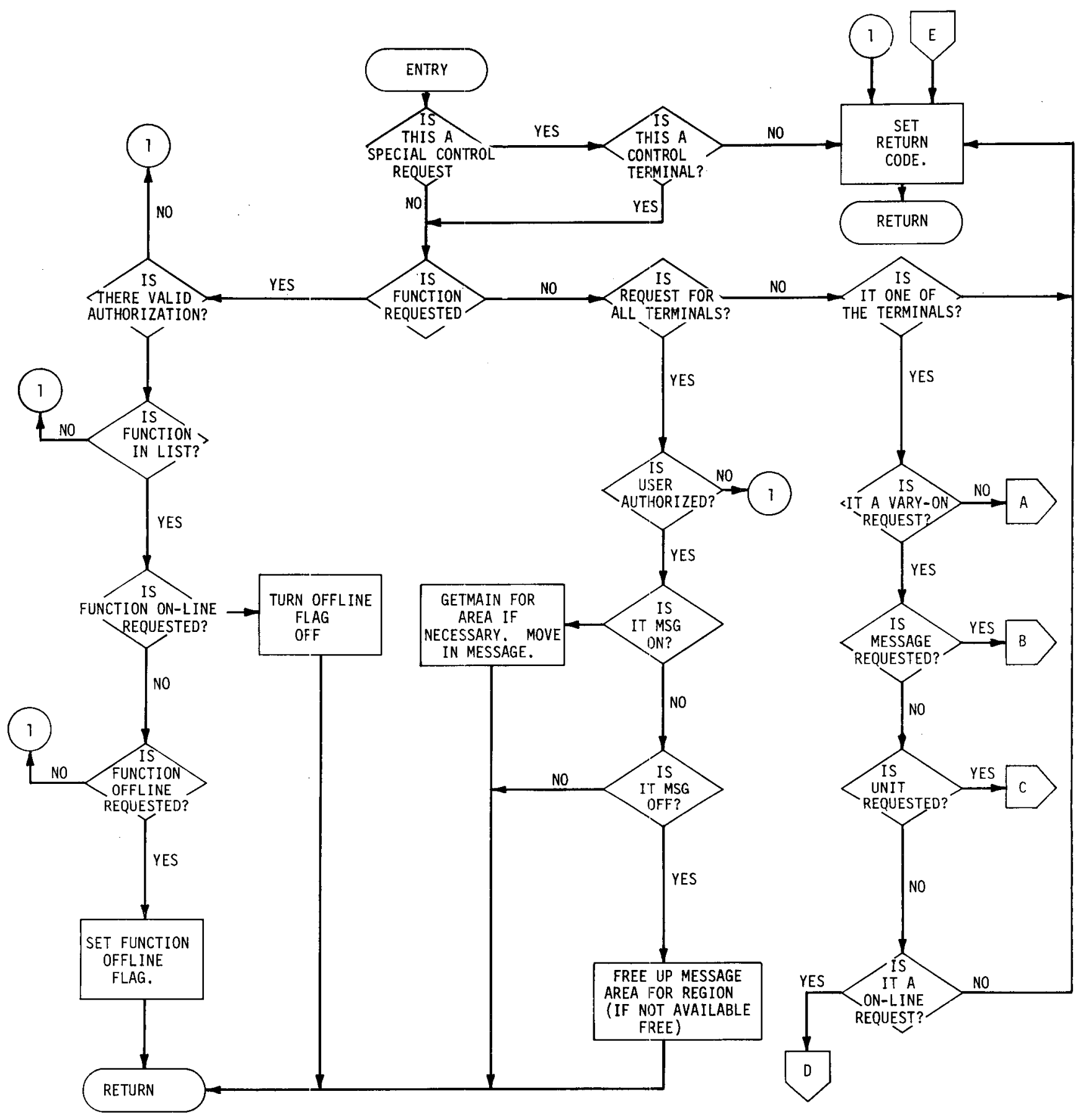




\begin{tabular}{|c|c|c|c|}
\hline & Title Module: JTVARY & Vol. IX & \begin{tabular}{|l} 
Page \\
E.I.432
\end{tabular} \\
\hline DPSTM-500 & & Rev. $_{1}$ & $\begin{array}{l}\text { Date } \\
6 / 73\end{array}$ \\
\hline
\end{tabular}

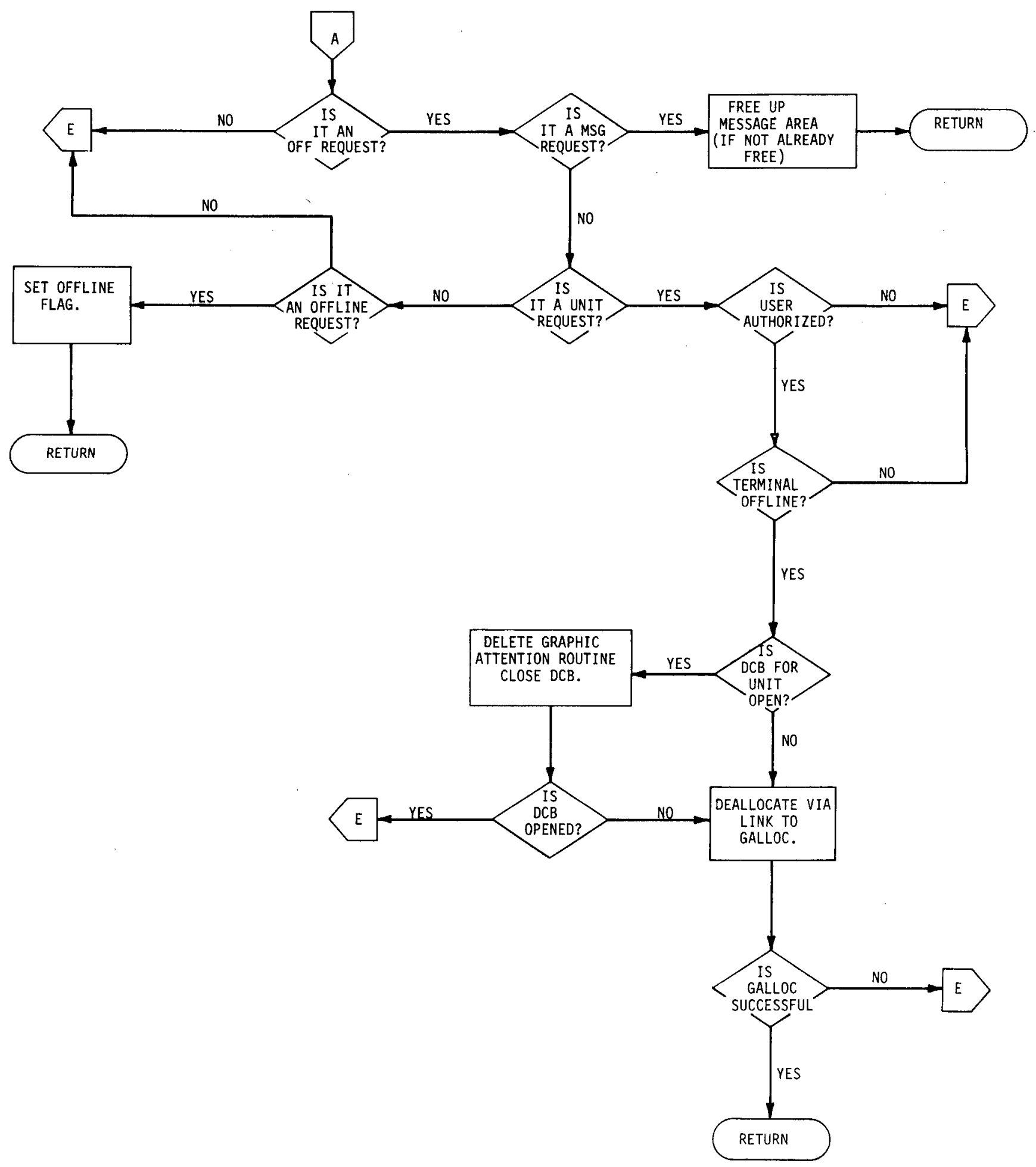




\begin{tabular}{|c|c|c|c|}
\hline 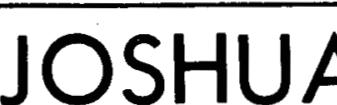 & Title Module: JTVARY & Vol. IX & \begin{tabular}{|l|} 
Page \\
E.1.433
\end{tabular} \\
\hline DPSTM. 500 & & Rev. 1 & Date \\
\hline
\end{tabular}
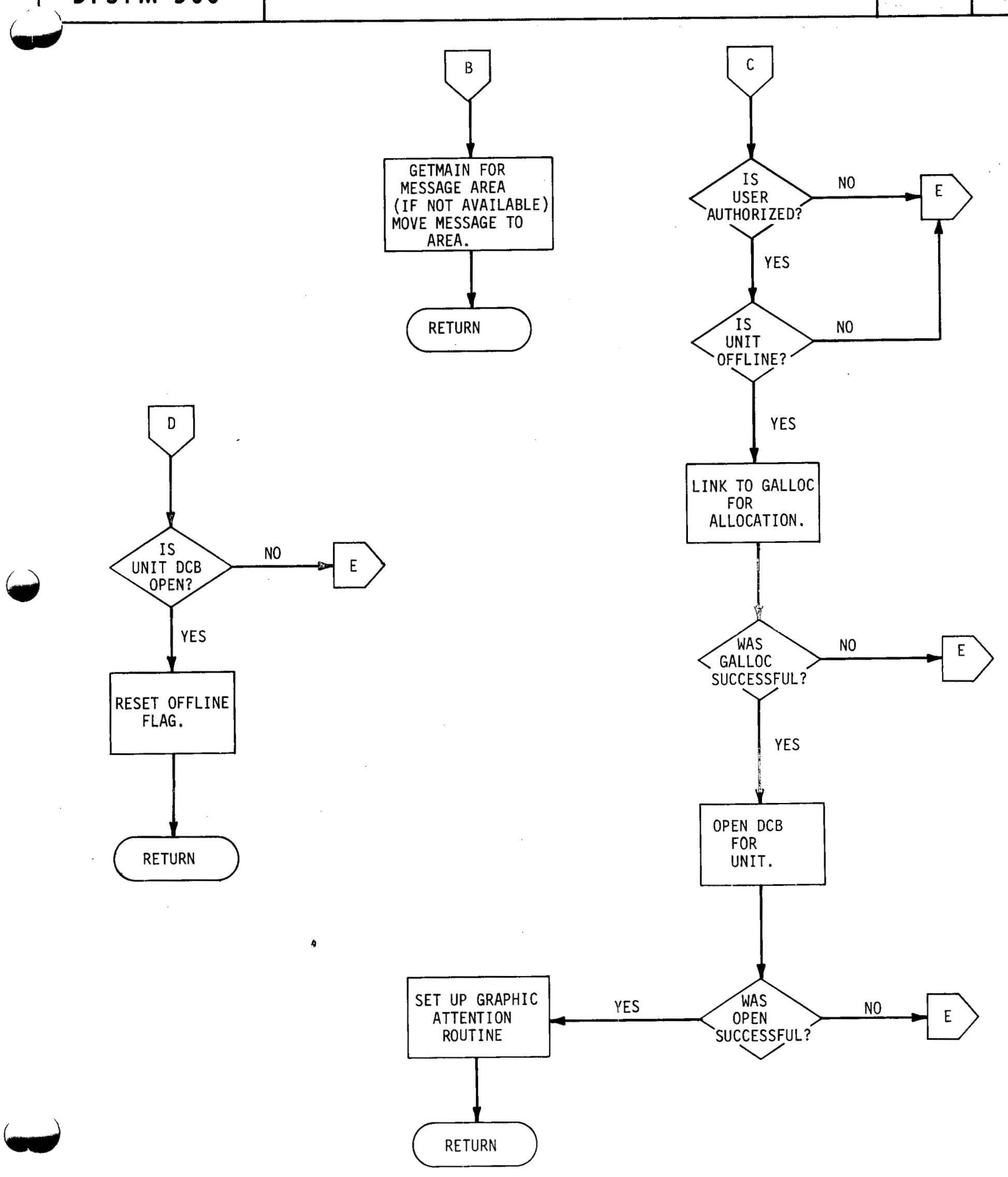


\begin{tabular}{|c|c|c|c|}
\hline | & \multirow{2}{*}{ Title $\quad$ Module: JTVARY } & Vol. & $\begin{array}{l}\text { Page } \\
\text { E.1.434 }\end{array}$ \\
\hline DPSTM. 500 & & Rev. & $\begin{array}{l}\text { Date } \\
6 / 73\end{array}$ \\
\hline
\end{tabular}

(Blank) 


\begin{tabular}{|c|c|c|c|}
\hline 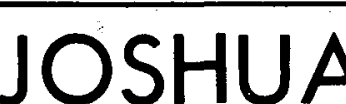 & \multirow{2}{*}{\multicolumn{2}{|c|}{ Title Module: JTVIEWQ }} & $\begin{array}{l}\text { Page } \\
\text { E.1.435 }\end{array}$ \\
\hline DPSTM. 500 & & & \begin{tabular}{|c} 
Date \\
$6 / 73$ \\
\end{tabular} \\
\hline
\end{tabular}

Purpose:

Attribute:

JOS Main Program Name:

Arguments:

$\underline{\text { Parameter }}$

$\mathrm{CCB}$

External References:

Data Sets:

Objective:

Program Logic:
To initiate the display of the job hold queue.

Nonreusable

JTVIEWQ

\section{Description \\ CCBMCB - Monitor Control Block}

GETMAIN, FREEMAIN, OPEN, READ, WAIT, CLOSE

Job hold queue data set; communication data set.

To initiate the display of the job hole queue by transferring the hold queue to the communication data set.

The address of the CCB is received via the argument list. The hold queue data set is OPENED. The control record is READ and a check is made to see if there are any records in the queue. If there are none, the next subfunction is set to a blank (to skip it), a CLOSE is issued on the data set and a return is issued; otherwise, the areas are set up for reading. The records are read and put into the display buffer until it is filled up or until the end of the job is reached at which time a link is made to WPAGE. WPAGE will put them into the communication data set. This is done until the end of the records is reached. A CLOSE is then issued on the data set and a return is issued.

Termination Condition: If a READ error is encountered, the module will abend.

Referenced By: $\quad$ JTMON

Language: $\quad$ Assembler

Author:

W. H. Brotherton, Jr. 


\begin{tabular}{|c|l|l|l|}
\hline JOSHUA & Title Module: JTVIEWQ & $\begin{array}{l}\text { Vol. } \\
\text { Ix }\end{array}$ & $\begin{array}{l}\text { Page } \\
\text { E.1.436 }\end{array}$ \\
\cline { 3 - 3 } & Rev. & $\begin{array}{c}\text { Date } \\
6 / 73\end{array}$ \\
\hline
\end{tabular}

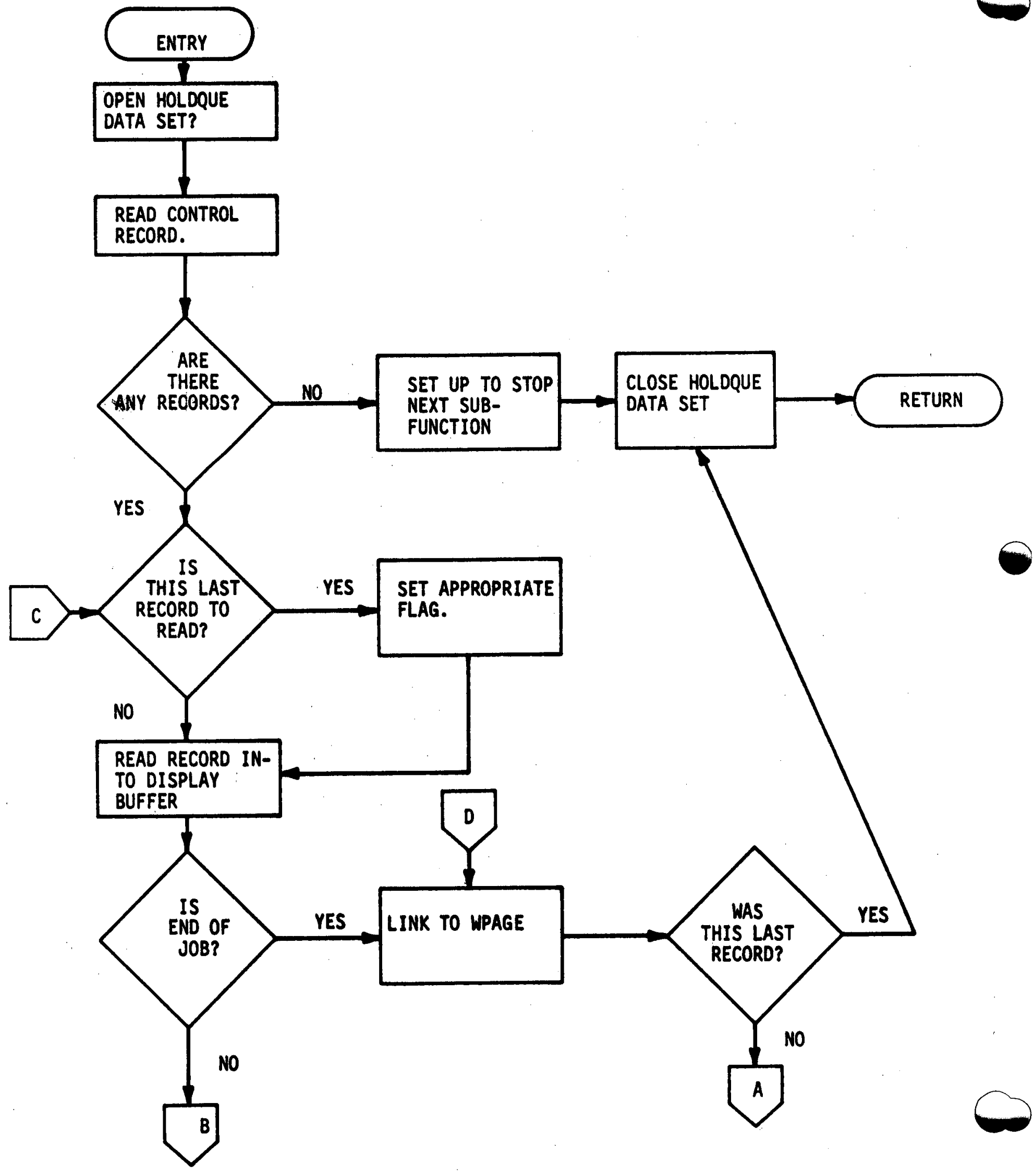




\begin{tabular}{|c|l|l|l|l|}
\hline JOSHUA & Title Module: JTVIEWQ & Vol. & $\begin{array}{l}\text { Page } \\
\text { E.1.437 }\end{array}$ \\
& & Revi & $\begin{array}{l}\text { Date } \\
6 / 73\end{array}$ \\
\hline
\end{tabular}
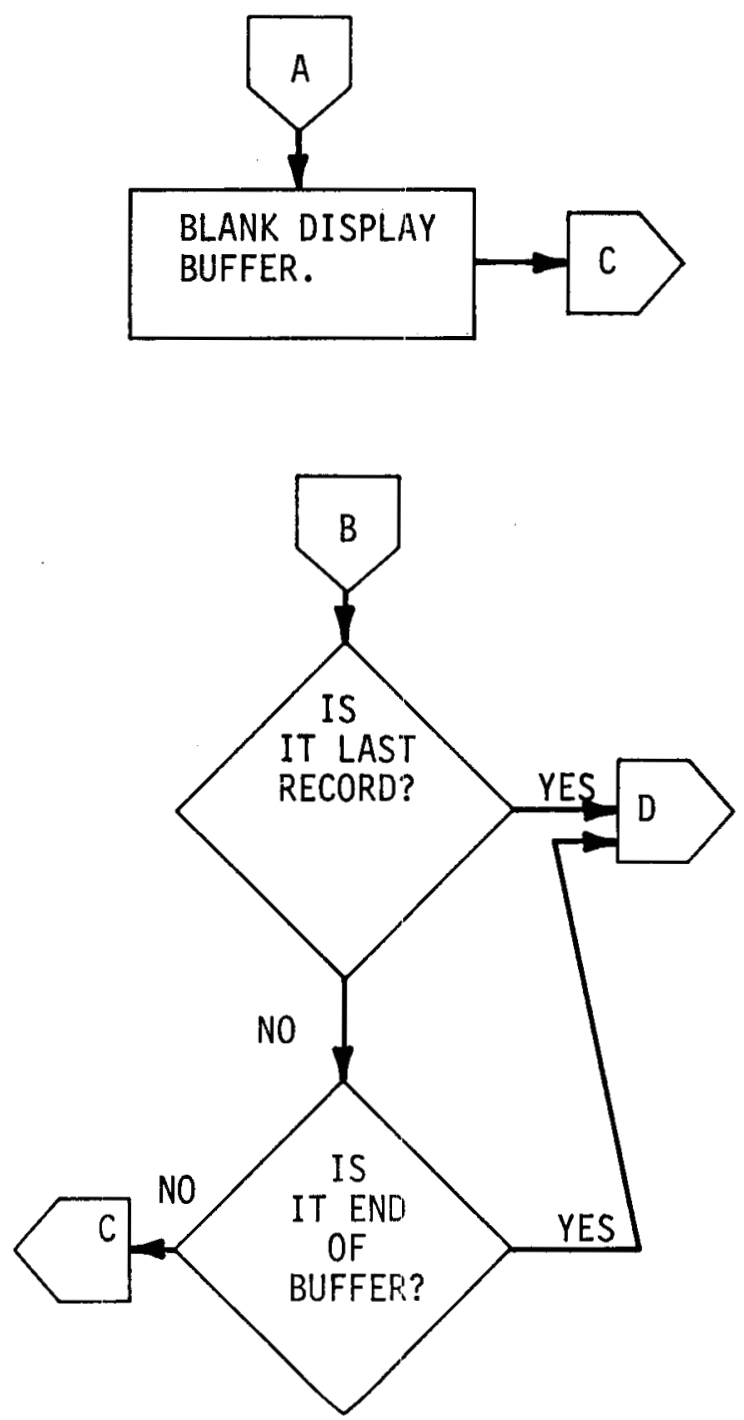


\begin{tabular}{|c|c|c|c|}
\hline & Title Module: JTVIEWQ & Vol. & $\begin{array}{l}\text { Page } \\
\text { E.1.438 }\end{array}$ \\
\hline DPSTM-500 & & ${ }_{1}$ & \begin{tabular}{|l|} 
Date \\
$6 / 73$
\end{tabular} \\
\hline
\end{tabular}

(B1ank) 


\begin{tabular}{|c|c|c|c|c|}
\hline & \multirow{2}{*}{\multicolumn{2}{|c|}{ Title $\quad$ Module: JTVQACCT }} & Vol. & $\begin{array}{l}\text { Page } \\
\text { E.1.439 }\end{array}$ \\
\hline DPSTM. & & & Rev. $_{1}$ & $\begin{array}{l}\text { Date } \\
6 / 73\end{array}$ \\
\hline
\end{tabular}

Purpose:

Attribute:

JOS Main Program Name:

Arguments:

Parameter

CCB

External References:

Data Sets:

Objective:

Program Logic:
To allow display of accounting information.

Nonreus able

JTVQACCT $\frac{\text { Type }}{\text { D }} \quad \frac{\text { Description }}{\text { CCBMCB - Monitor Control Block }}$

GETMAIN, FREEMAIN, READ, WAIT, ABEND

Accounting data set.

Communication data set.

The objective is to display the accounting data where the data consists of the following:

1) the data accumulated by a user during a terminal session.

2) the data stored on encountering a protection violation.

The address of the CCB is received via the argument list. The accounting control record (QCBACB) is read and the proper areas are set up. After reading the record, the function control table flag is examined to see if violations are desired or if accounting records are.

The appropriate flag (ACTVLTN) in the record will tell which type record has been read. After this is determined and a desired records is read, the data is edited. After two records are encountered and edited, the edited information is written to the communication data set via BALR to WPAGE. When all records have been read, examined, etc., a return is issued.

Terminating Conditions: An appropriate code is issued when an $1 / 0$ error is encountered.

\section{Referenced By: $\quad$ JTMON}

Language:

Assembler

Author:

W. H. Brotherton, Jr.

Restrictions:
The module is restricted to system and operation personnel us age. 


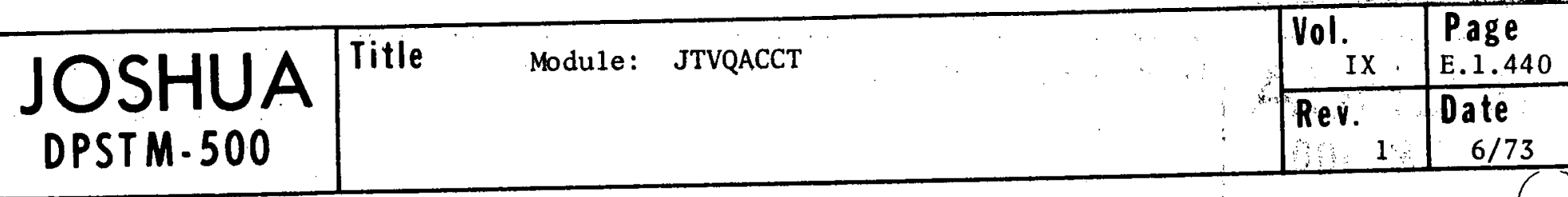

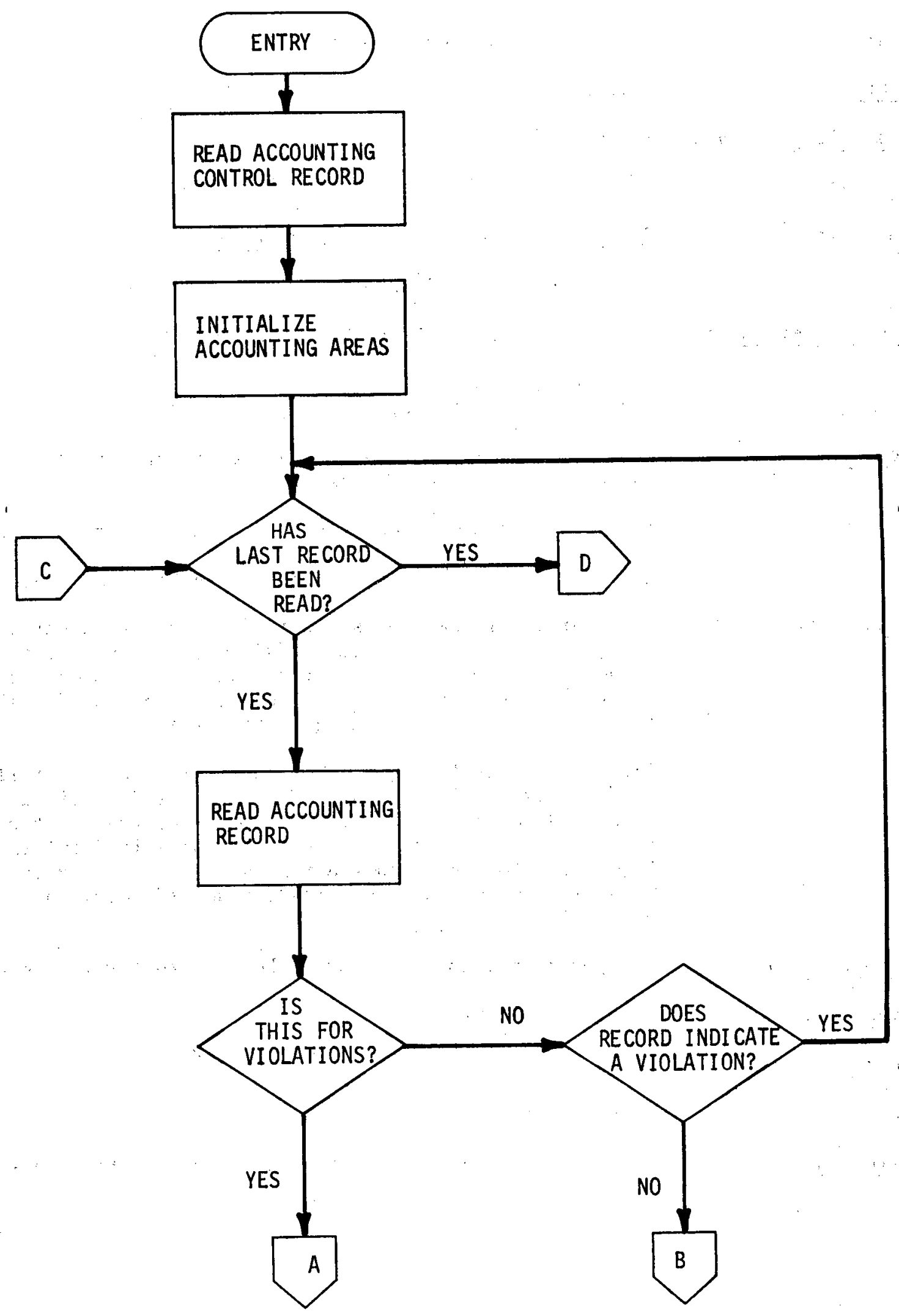




\begin{tabular}{|c|l|l|l|l|}
\hline $\begin{array}{c}\text { JOSHUA } \\
\text { DPSTM-500 }\end{array}$ & Title Module: JTVQACCT & $\begin{array}{l}\text { Vol. } \\
\text { IX }\end{array}$ & $\begin{array}{l}\text { Page } \\
\text { E.1.441 }\end{array}$ \\
\cline { 3 - 5 } & & $\begin{array}{c}\text { Rate } \\
6 / 73\end{array}$ \\
\hline
\end{tabular}

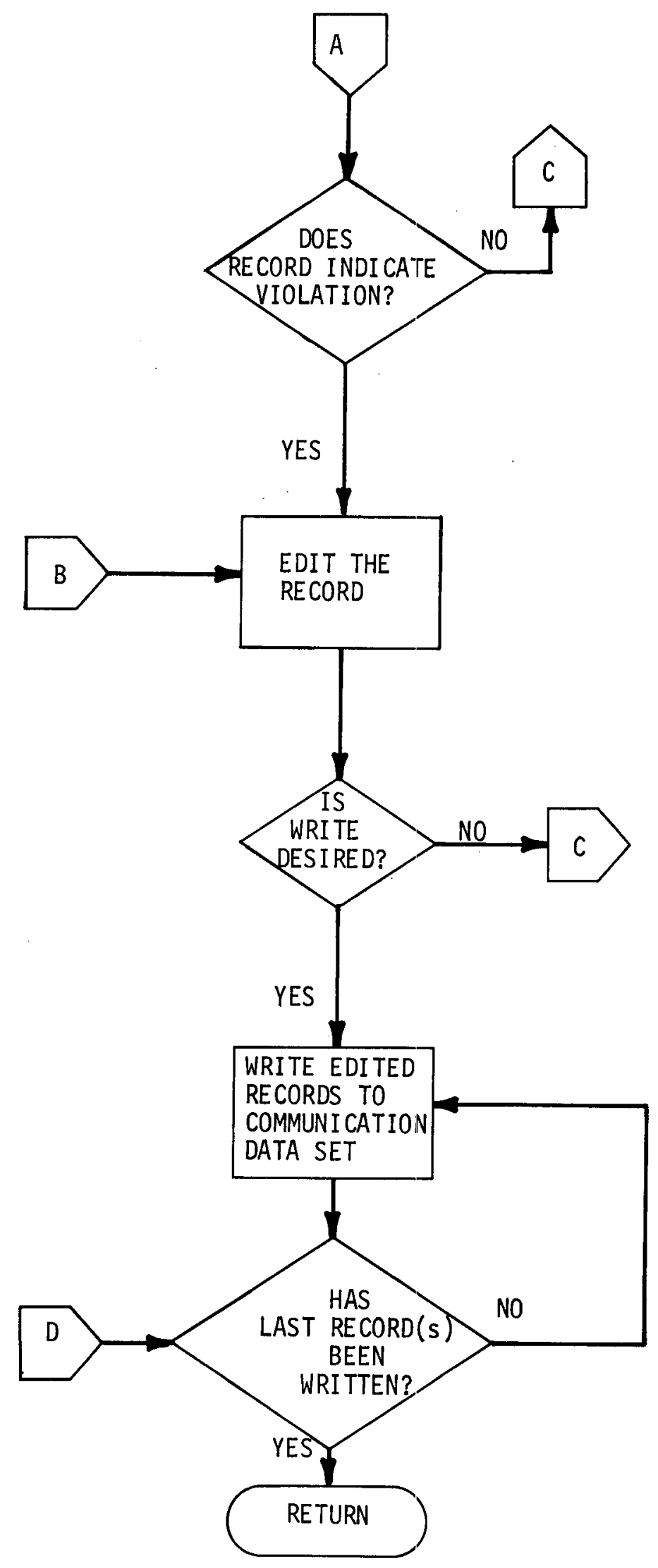




\begin{tabular}{|l|l|l|l|}
\hline JOSHUA & Title Module: JTVQACCT & $\begin{array}{l}\text { Vol. } \\
\text { IX }\end{array}$ & Page \\
\\
\cline { 3 - 5 }
\end{tabular}

(Blank) 


\begin{tabular}{|c|c|c|c|c|}
\hline & \multirow[t]{2}{*}{ Title } & \multirow[t]{2}{*}{ Module: JTWSTATS } & $\begin{array}{r}\text { Vol. } \\
\text { IX }\end{array}$ & $\begin{array}{l}\text { Page } \\
\text { E.1.443 }\end{array}$ \\
\hline DPSTM. 500 & & & Rev. & \begin{tabular}{|l} 
Date \\
$6 / 73$
\end{tabular} \\
\hline
\end{tabular}

Purpose:

To handle the logging out of BNAM statistics.

Attribute:

Nonreusable

JOS Main Program Name:

JTWSTATS

Arguments:

Parameter

$\mathrm{CCB}$

External References:

Data Sets:

Program Logic:
Type

D
Description

CCBMCE - Monitor Control Block

\$CBMONF - Monitor Mode Flag

GETMAIN, FREEMAIN, ENQ, SVC 252, READ, WAIT, WRITE, DEQ, TIME

Accounting data set

The address of the CCB is received via the argument list. The BNAM statistics table is located and then the type of record to be written is determined. If the monitor mode flag (\$CBMONF) indicates computational, the EM record is built and written to the accounting data set via the WRITE macro. After this write, the BNAM statistics are reset to zero. If it was not the computational mode, the EOJ (End of Job) record is build and written to the accounting data set provided there is a sufficient amount of data to warrant it. If an I/O error is encountered, a return code is set up; otherwise, a normal return is issued. An enq is provided for the accounting data set to protect from concurrent usage.

The records built will consist of a particular code (determines type record), badge number, date, member name, and BNAM statistics. The badge number is obtained via SVC 252 and the date via the TIME macro. On moving the statistics into the record, halfword overflow is indicated by making data negative.

Terminating Conditions: Module terminates on an $\mathrm{I} / 0$ error.

Enq Name:

JOSYSTEM JOSQUEUE

Referenced By:

JTMON

Language:

Assembler

Author:

W. H. Brotherton, Jr. 


\begin{tabular}{|c|l|l|l|l|}
\hline JOSHUA & Title & Module: JTWSTATS & $\begin{array}{l}\text { Vol. } \\
\text { IX }\end{array}$ & $\begin{array}{l}\text { Page } \\
\text { E.1.444 }\end{array}$ \\
& & Rev. 1 & $\begin{array}{c}\text { Date } \\
6 / 73\end{array}$ \\
\hline
\end{tabular}

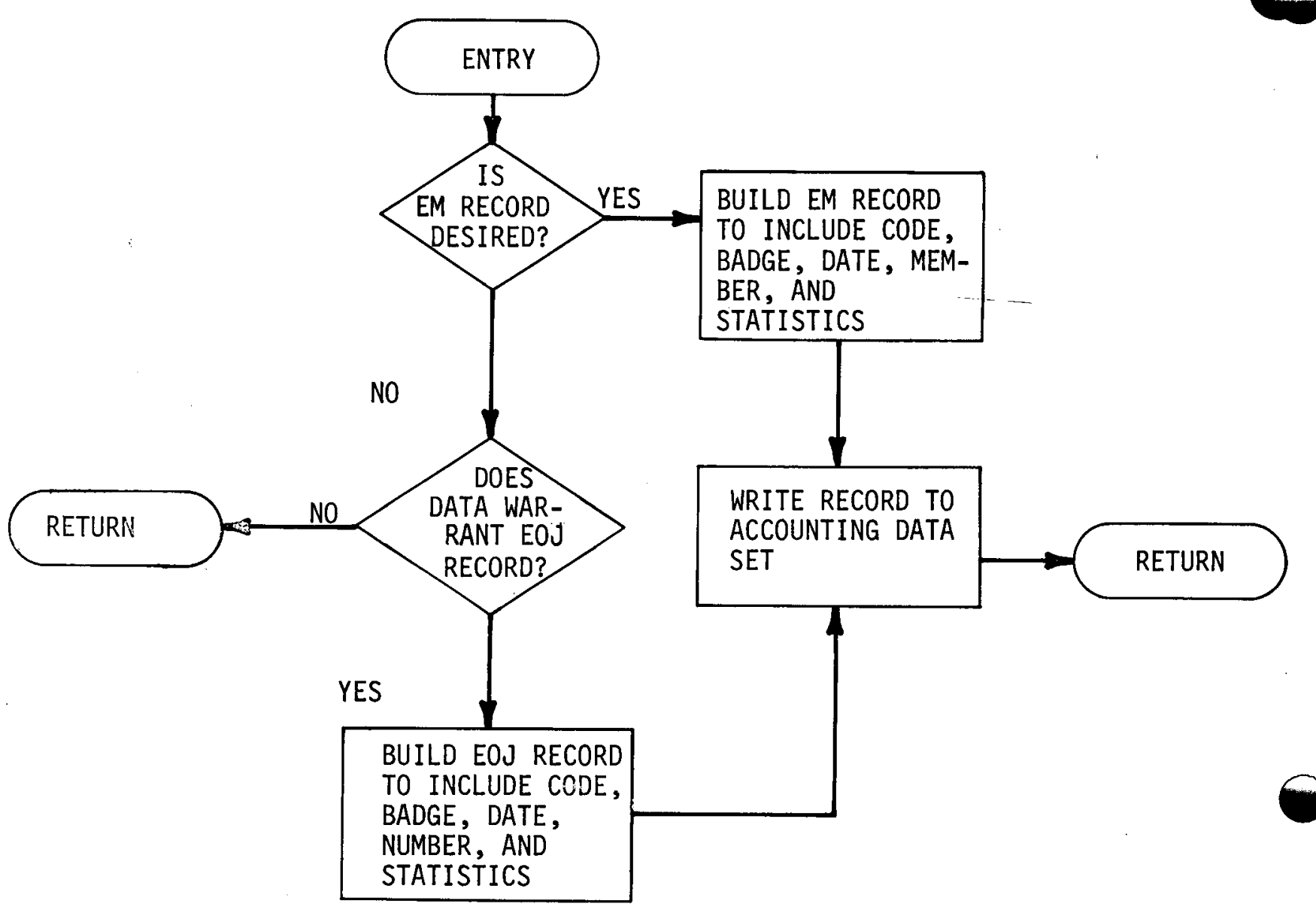




\begin{tabular}{|c|c|c|c|c|}
\hline 1 & \multirow{2}{*}{\multicolumn{2}{|c|}{\begin{tabular}{|ll} 
Title & Module: $\quad$ JTXBCHEK
\end{tabular}}} & Vol. IX & \begin{tabular}{|l} 
Page \\
E.1.445
\end{tabular} \\
\hline DPSTM. 500 & & & Rev. $_{1}$ & $\begin{array}{l}\text { Date } \\
6 / 73\end{array}$ \\
\hline
\end{tabular}

Purpose:

Attribute:

JOS Main Program Name:

Arguments:

Parameter

$\mathrm{CCB}$

External References:

Program Logic:

Referenced by:

Language:

Author:
To check for proper authorization in presenting hold queue jobs to HASP.

Nonreusable

JTXBCHEK
Type

D

\section{Description \\ CCBMCB - Monitor Control Block CCBBADGE - User Badge Number}

GETMAIN, FREEMAIN

The address of the CCB is received via the argument list. The user badge number (CCBBADGE) is checked for on the authorized badge list. If the user's badge number is found, a return is issued; otherwise, the next subfunctren is set up to be skipped before issuing the return.

JTMOM

Assembler

W. H. Brotherton, Jr. 


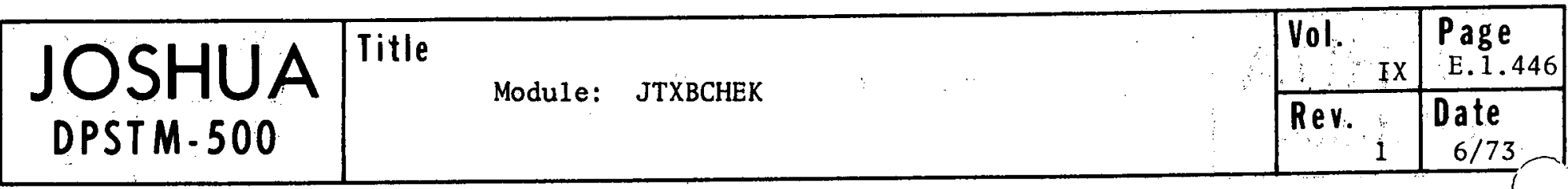

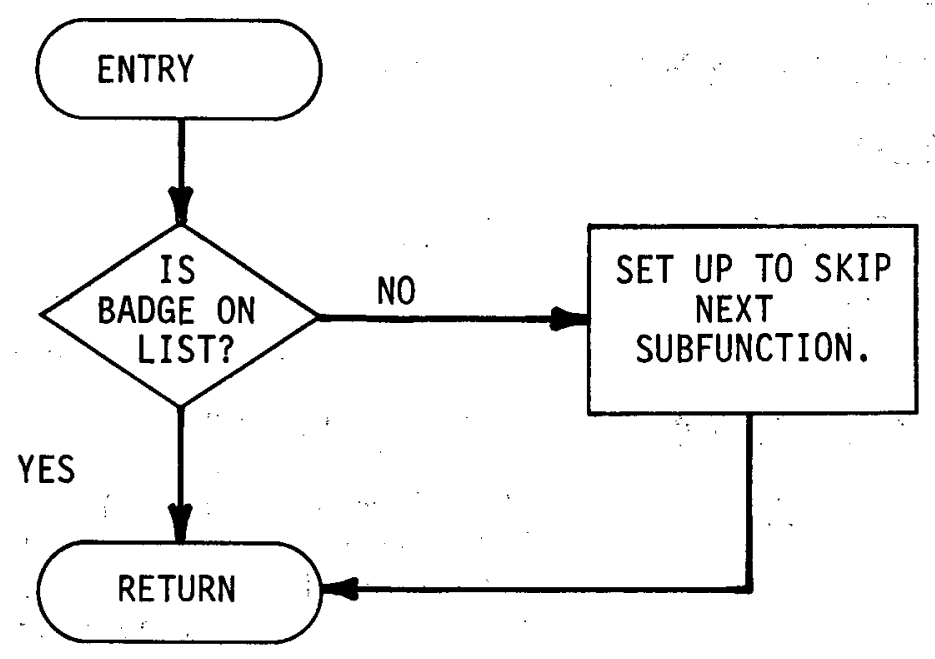




\begin{tabular}{|c|l|l|l|l|}
\hline JOSHUA & Title Module: LIST & Vol. & $\begin{array}{c}\text { Page } \\
\text { EPSTM-1.447 }\end{array}$ \\
\cline { 3 - 5 } & & Rev. & Date \\
& $6 / 73$ \\
\hline
\end{tabular}

Purpose:

Attribute:

JOS Main Program:

Arguments:
To place in the communication data set an edited list of all fully-qualified names in a BNAM-catalogued tree or subtree.

Nonreusable

LIST

\begin{tabular}{lll} 
Mnemonic & \multicolumn{1}{c}{ Type } & \multicolumn{1}{c}{ Description } \\
A1 & $\begin{array}{l}\text { Rea1*8 } \\
\text { Real*8 }\end{array}$ & $\begin{array}{l}\text { CCB } \\
\text { WCBARG1. Specifies the subtree to } \\
\text { be listed. }\end{array}$ \\
A8 & Integer*4 & $\begin{array}{l}\text { WXTNTGR. Defines the number of } \\
\text { qualifiers in A2. }\end{array}$ \\
A4 & Logical*1 & $\begin{array}{l}\text { Area pointed to by MCBBUFF. Used } \\
\text { as a buffer by WPAGE. }\end{array}$
\end{tabular}

Subprograms:

Data Sets:

Program Logic:

\begin{tabular}{|c|c|}
\hline Control Section & Entry Point \\
\hline$\$$ TERR & \$TER \\
\hline LCDINT & $\$ C D I N T$, HCDINT \\
\hline LINK & BNAM, WPAGE \\
\hline MOVEIT & MOVEIT \\
\hline
\end{tabular}

Communication Data Set (CDS)

- Initialize edit controls.

- Call BNAM (functional request 12) to retrieve each fully qualified name in the subtree designated by A2. A separate call to BNAM is required for each name. A2 may be null in which case the first data set located from the search sequence will be listed. Failure to locate a subtree results in termination via \$TERR.

- The subordinate portion of the name is edited in A4. This includes:

1. specifying data classification level if other than zero;

2. providing the relative record number of the data record;

3. replacing deleted qualifiers with the literal 'DELETED. ';

4. replacing a qualifier with blanks unless it introduces a new subtree or is part of the first record being listed on any page.

- Write out each page as it is completed and any partial page when the list is complete. 


\begin{tabular}{|l|ll|l|l|}
\hline JOSHUA & Title Module: LIST & Vol. & Page \\
DPSTM.500 & & E.1.448 \\
\cline { 3 - 5 } & & Rev. & Date \\
$6 / 73$
\end{tabular}

Terminating Conditions: BNAM error - via a call to \$TERR.

Comments:

Data are entered into $A 4$ on the basis of a ten line, six hundred forty character page.

Language:

FORTRAN IV

Author:

R. C. Haywood - J. C. Jensen 


\section{JOSHUA ${ }^{\text {Title }}$ Module: LIST

\begin{tabular}{|c|l|}
\hline $\begin{array}{c}\text { Vol. } \\
\text { IX }\end{array}$ & $\begin{array}{l}\text { Page } \\
\text { E.1.449 }\end{array}$ \\
\hline Rev. & $\begin{array}{l}\text { Date } \\
6 / 73\end{array}$ \\
\end{tabular}

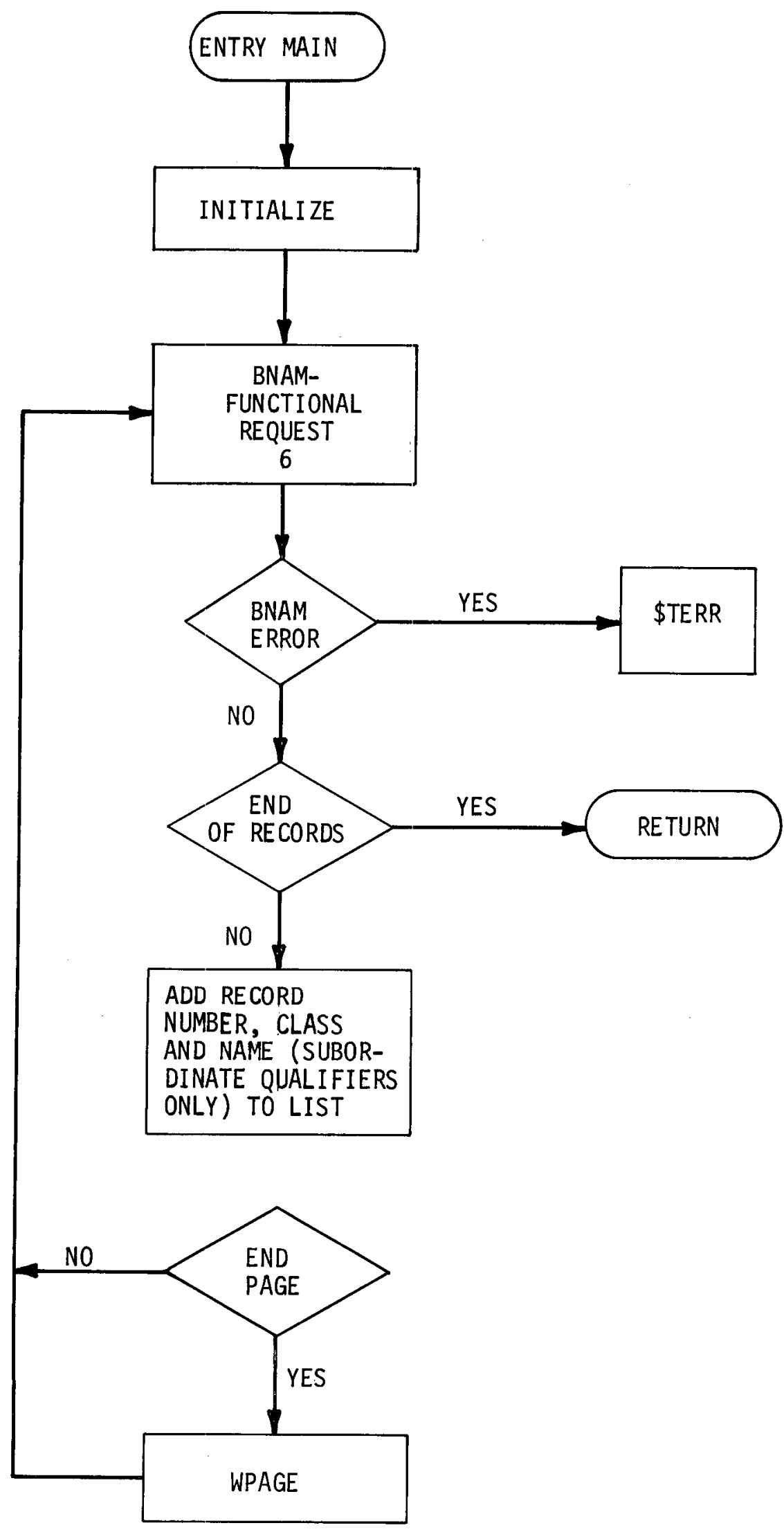




\begin{tabular}{|c|c|c|c|}
\hline & Title Module: LIST & \begin{tabular}{|r|} 
Vol. \\
IX
\end{tabular} & \begin{tabular}{|l|} 
Page \\
E.1.450 \\
\end{tabular} \\
\hline DPSTM -500 & & Rev. $_{1}$ & $\begin{array}{l}\text { Date } \\
6 / 73\end{array}$ \\
\hline
\end{tabular}

(B1 ank) 


\begin{tabular}{|c|l|l|l|}
\hline $\begin{array}{c}\text { JOSHUA } \\
\text { DPSTM-500 }\end{array}$ & Title Module: LISTB & $\begin{array}{l}\text { Vol. } \\
\text { Ix }\end{array}$ & $\begin{array}{c}\text { Page } \\
\text { E.1.451 }\end{array}$ \\
\cline { 3 - 5 } & & $\begin{array}{c}\text { Rev. } \\
\text { Date } \\
6 / 73\end{array}$ \\
\hline
\end{tabular}

Purpose:

Attribute:

JOS Main Program:

Arguments:
Given an incomplete record name, to list the son node and all the brother nodes of that son.

Nonreusable

MAIN

\begin{tabular}{lll} 
Mnemonic & \multicolumn{1}{c}{ Type } & \multicolumn{1}{c}{ Description } \\
A1 & $\begin{array}{l}\text { Rea1*8 } \\
\text { Real*8 }\end{array}$ & $\begin{array}{l}\text { CCB. } \\
\text { WCBARG1 - contains the record } \\
\text { name. }\end{array}$ \\
A4 & Rea1*8 & $\begin{array}{l}\text { Area pointed to by MCBBUFFG and } \\
\text { used as WPAGE buffer. } \\
\text { A8 }\end{array}$ \\
Integer*4 & $\begin{array}{l}\text { WXTTGR - specifies the number } \\
\text { of qualifiers in A2. }\end{array}$
\end{tabular}

Subprograms:

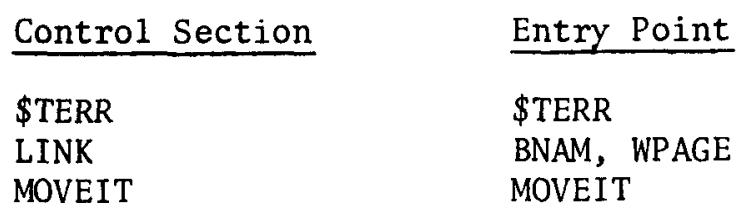

Data Sets:

Communication data set (CDS)

Program Logic:

- Functional symbol ' $\$ ? \$$ ' is added as a final qualifier to A2. This marks the level from which the nodes are to be listed.

- A series of functional request 11 's is made to BNAM retrieving on each call a number of brothers up to the number sufficient to complete a formatted CDS record which is written thru a call to WPAGE.

- When a BNAM error is encountered, execution is terminated thru a call to \$TERR.

Language:

FORTRAN IV

Author:

R. C. Haywood. 


\begin{tabular}{|c|c|c|c|c|}
\hline & \multirow{2}{*}{\multicolumn{2}{|c|}{ Title $\quad$ Module: LISTB }} & $\begin{array}{l}\text { Vol. } \\
\text { IX }\end{array}$ & $\begin{array}{l}\text { Page } \\
\text { E.1.452 }\end{array}$ \\
\hline DPSTM-500 & & & Rev. & $\begin{array}{c}\text { Date } \\
6 / 73\end{array}$ \\
\hline
\end{tabular}

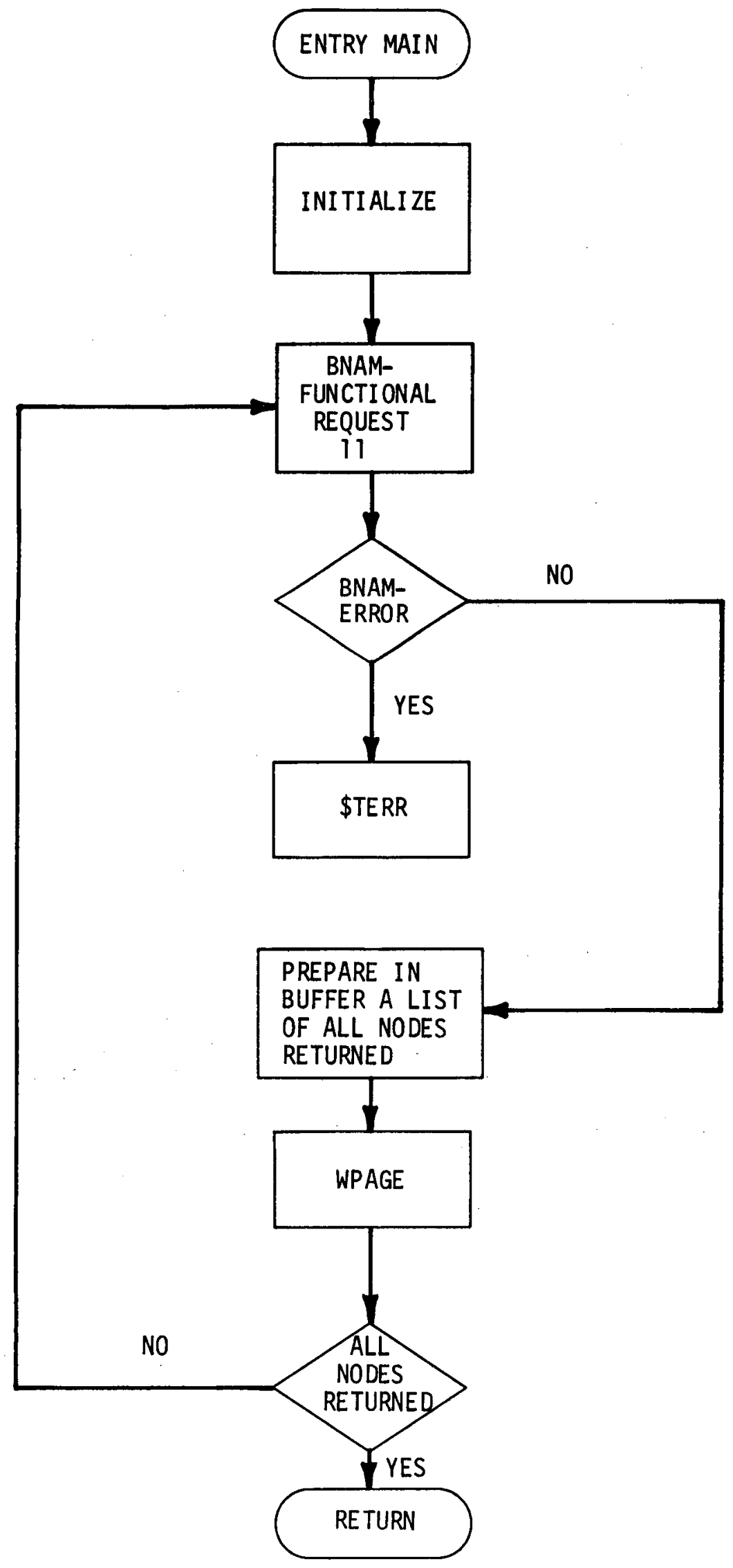




\begin{tabular}{|c|c|c|c|c|}
\hline & \multirow{2}{*}{\multicolumn{2}{|c|}{ Title Module: LSTSQR }} & $\begin{array}{l}\text { Vol. } \\
\text { IX }\end{array}$ & \begin{tabular}{|l} 
Page \\
E.1.453
\end{tabular} \\
\hline DPSTM. 500 & & & Rev. & $\begin{array}{l}\text { Date } \\
6 / 73\end{array}$ \\
\hline
\end{tabular}

Purpose:

Attribute:

JOS Main Program:
Arguments:

To fit a specified mathematical function to a set of data points by the least squares method.

Nonreusable

MAIN

\begin{tabular}{lll} 
Mnemonic & Type & \multicolumn{1}{c}{ Description } \\
A1 & Rea1*8 & CCB. \\
A2 & Rea1*8 & $\begin{array}{l}\text { WCBARG1 - enters with the name of } \\
\text { the input record; returns the name } \\
\text { of the output record. }\end{array}$ \\
A8 & Real*8 & $\begin{array}{l}\text { WXTNTGR - the number of qualifier } \\
\text { in A2. }\end{array}$
\end{tabular}

Subprograms:

$\begin{array}{ll}\text { Control Section } & \text { Entry Point } \\ \text { \$TERR } & \text { \$TERR } \\ \text { IPUT } & \text { IPUT, JPUT } \\ \text { JSREAD } & \text { JSREAD } \\ \text { LINK } & \text { BNAM, JTREE } \\ \text { LSTSQR* } & \text { LSTSQR } \\ \text { MINVS* } & \text { MINVS }\end{array}$

Program Logic:

- The name of the input record is ascertained to be of form LSTSQR. INPIJT.?.?

with or without an explicit data set reference. Failure to meet this criteria results in a call to \$TERR.

- The input data is read. If the limits of the modules arrays would be exceeded, \$TERR is called.

- The data is passed to subroutine LSTSQR to obtain a fit; from this a ratio of calculated to observed data is determined as a goodness-of-fit indication.

- The results are written to a record LSTSQR.OUTPUT.?.? where the variable qualifiers are the same as specified for the input record. A BNAM close follows the write.

- The name of the output record is loaded into A2 and A8 set to reflect the number of qualifiers. 


\begin{tabular}{|c|l|l|l|l|}
\hline JOSHUA & Title Module: LSTSQR & Vol. & Page \\
DPSTM.500 & & IX & E.1.454 \\
\cline { 3 - 4 } & & Rev. & Date \\
& & $6 / 73$ \\
\hline
\end{tabular}

Terminating Conditions:

- Invalid form for the input record.

- Nonexistence of specified input record.

- Program data areas exceeded by input record requirements.

- Error in writing the output record.

Language:

FORTRAN IV

Author:

R. C. Haywood - F. D. Knight 


\begin{tabular}{|c|c|c|c|c|}
\hline 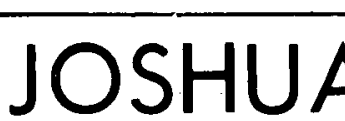 & & \multirow[t]{2}{*}{ Module: LSTSQR } & $\begin{array}{|ll|}\text { Vol. } & \\
& \text { IX } \\
\end{array}$ & \begin{tabular}{|l|} 
Page \\
E.1.455 \\
\end{tabular} \\
\hline DPSTM.500 & & & $\operatorname{Rev.}_{1}$ & $\begin{array}{l}\text { Date } \\
6 / 73\end{array}$ \\
\hline
\end{tabular}

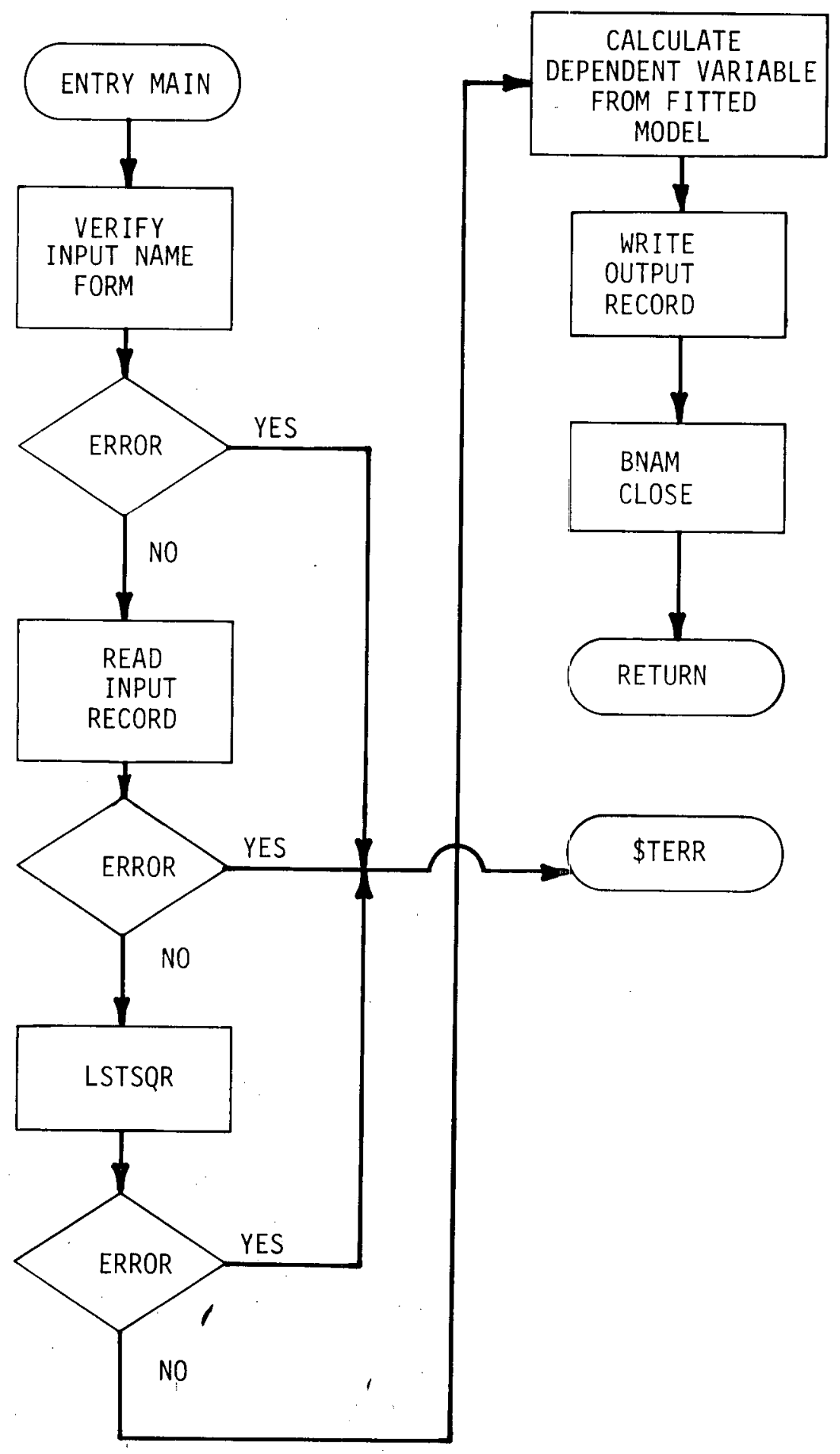




\begin{tabular}{|c|c|c|c|}
\hline & Title Module: LSTSQR & Vol. $_{\text {IX }}$ & $\begin{array}{l}\text { Page } \\
\text { E.1.456 }\end{array}$ \\
\hline DPSTM -500 & Subroutine: LSTSQR & Rev. $_{1}$ & $\begin{array}{l}\text { Date } \\
6 / 73\end{array}$ \\
\hline
\end{tabular}

Purpose:

Usage:

Arguments:

\begin{tabular}{|c|c|c|}
\hline Parameter & Type & Description \\
\hline L & Integer*4 & Number of data points. \\
\hline M & Integer*4 & $\begin{array}{l}\text { Number of terms in function } \\
\text { excluding constant term. }\end{array}$ \\
\hline $\mathrm{X}$ & $\operatorname{Real} 1 * 8$ & $\begin{array}{l}\text { LXM matrix of the functions of } \\
\text { the independent variables. }\end{array}$ \\
\hline Y & $\operatorname{Rea} 1 * 8$ & $\begin{array}{l}\text { L-dimensioned vector of the } \\
\text { dependent variable. }\end{array}$ \\
\hline W & $\operatorname{Rea} I^{* 8}$ & $\begin{array}{l}\text { L-dimensioned vector of the } \\
\text { weighting factors to be used } \\
\text { ( } W=0 \text { or } 1 \text { if equal weighting } \\
\text { desired). }\end{array}$ \\
\hline A & $\operatorname{Real} * 8$ & $\begin{array}{l}\mathrm{A}=0 \text { to specify no constant term } \\
\mathrm{A}=1 \text { to specify a constant term } \\
\text { (On returning from this routine, } \\
\text { A will contain the fitted constant } \\
\text { if applicable.) }\end{array}$ \\
\hline B & $\operatorname{Real} * 8$ & $\begin{array}{l}\text { M-dimensioned vector of the } \\
\text { independent fitted parameters. }\end{array}$ \\
\hline MPI & Integer*4 & $\begin{array}{c}\text { MPL }=0 \text { - Functions of independent } \\
\text { variables are set up by } \\
\text { calling program. } \\
\text { MPI }=1 \text { - Polynomial fit is to be } \\
\text { set up by the LSTSQR } \\
\text { routine in which case only } \\
\text { X(L,I) must be specified } \\
\text { for the array } X .\end{array}$ \\
\hline STAT & $\operatorname{Rea}{ }^{*} 8$ & $\begin{array}{l}\text { STAT(1) - Square of multiple } \\
\text { correlation coefficient. } \\
\text { STAT (2) - Variance of estimate. } \\
\text { STAT (3) - F ratio for variances. }\end{array}$ \\
\hline $\mathrm{MX}$ & Intege $* 4$ & $\begin{array}{l}\text { Value to which the first subscript } \\
\text { of } X \text { has been dimensioned }(>I) \text {. }\end{array}$ \\
\hline
\end{tabular}

To fit a specified mathematical function to a set of data points by the least squares criterion ard to calculate statistics for a goodness of fit determination.

CALL LSTSQR( L, M, X, Y, W, A, B, MPL, STAT , MX, \&SN) 


\begin{tabular}{|l|l|l|l|l|}
\hline $\begin{array}{l}\text { JOSHUA } \\
\text { DPSTM.500 }\end{array}$ & $\begin{array}{l}\text { Title Module: LSTSQR } \\
\text { Subroutine: LSTSQR }\end{array}$ & $\begin{array}{l}\text { Pol. } \\
\text { IX }\end{array}$ & $\begin{array}{l}\text { E.1.457 } \\
\text { E. }\end{array}$ \\
\cline { 3 - 5 } & & Rev. & $\begin{array}{l}\text { Date } \\
6 / 73\end{array}$ \\
\hline
\end{tabular}

Subprogram Jsed:

Ob.jective:
Program Logic:

\section{MINVS}

To fit a mathematical function to a set of data points by the least squares criterion. The routine has the capability of fitting any function in which the relationship is linear in the parameters to be calculated. Several. options are available for use with this routine. The function can be fitted with or without a constant intercept (i.e., the intercept can be determined from the data or set to o); specified data points can be weighted in the fitting calculation; and for polynomial fits, the routine generates the higher powered terms $\left(\mathrm{X}^{2}, \mathrm{X}^{3}\right.$ etc.). The program obtains the fitting parameters by the least squares criterion given below in matrix form.

$$
B=\left(X^{T} W X\right)^{-1} x^{T} W Y ; A=\bar{Y}-B \vec{X}
$$

where:

$$
\begin{aligned}
& \text { X - matrix of independent variables } \\
& \text { shifted by respective means } \\
& y \text { - vector of dependent variable shifted } \\
& \text { by its mean } \\
& W \text { - diagonal matrix of weighting factors } \\
& \text { (stored and used as vector) } \\
& \text { A - vector of fitted parameters } \\
& \bar{Y} \text { - mean of the dependent variable } \\
& \bar{X} \text { - vector of means for the independent } \\
& \text { - variables. }
\end{aligned}
$$

It calculates the square of the multiple correlation coefficient, the variance of estimate, and the $F$ ratio for variance.

The degrees of freedom are determined and a switch set based on whether a constant is or is not requested. The work areas are zero initialized and the weighting vector is set to 1 if initialized to zero by the user. The higher power terms are generated from the 


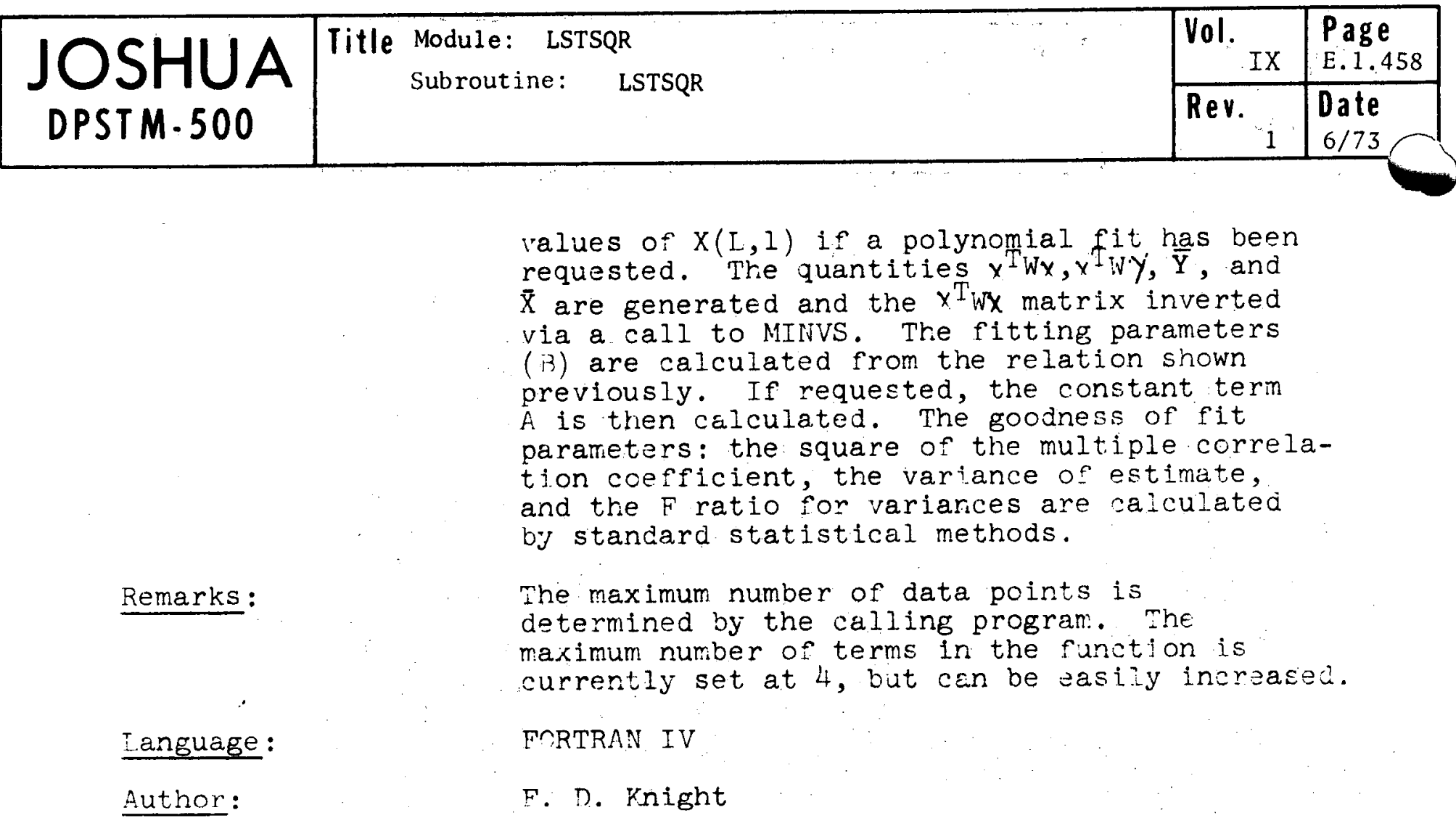




\begin{tabular}{|c|c|c|c|}
\hline & \multirow{2}{*}{ 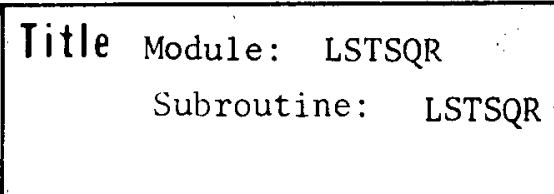 } & $\operatorname{Vol}_{\text {IX }}$ & \begin{tabular}{|l|} 
Page \\
E.1.459
\end{tabular} \\
\hline DPST M. 500 & & Rev. & \begin{tabular}{|c|} 
Date \\
$6 / 73$
\end{tabular} \\
\hline
\end{tabular}

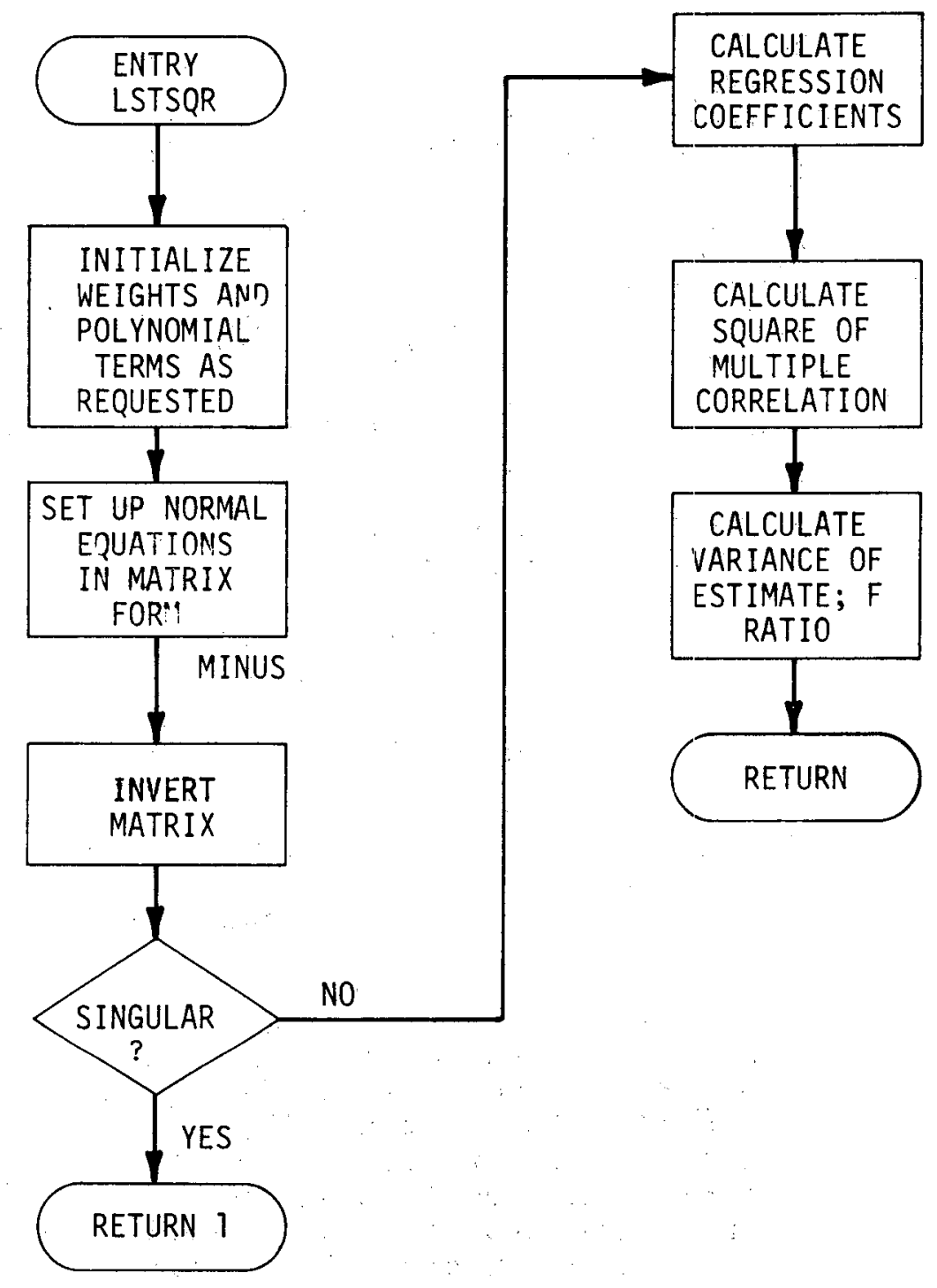


Purpose:

Usage:

Parameter

1

Parameter
A
NN
D
3

$\mathrm{N}: 3$

Objective:
To find the inverse and determinant of an NXN matrix $A$ and the solution vector, $X$, for the matrix problem $\Lambda X=$.

CALI MINVS $(A, N, N N, D, B, K)$

Type

Description

Real*8 Matrix to bo inverted.

Integer*4 Size of matrix to be inverted.

Integer*4 Value to which the first subscript of array $A$ has been dimensioned $(\geq N)$.

$\operatorname{Real*8}$

Determinant of A (returned as output).

Real*'s

Only used if solution to $A X=3$ requested.

on input, 3 contains the righthand side vector.

on output, 3 contains the solution vector $X$.

Integer*4 NB=0 - find inverse of $\mathrm{A}$

$N B=1-$ find inverse of $A$ and solve $A X=B$ for $X$.

To determine the inverse of an NXN matrix $A$ which is a subset of a KXL matrix where $\mathrm{N} \leq \mathrm{K}=\mathrm{NN}$ and $\mathrm{N} \leq \mathrm{L}$. This routine is a modification of the IBM/350 SSP routine MINV and allows for the inversion of matrices stored in normal row-column form $A(I, J)$. The inversion procedure is standard Gauss-Jordan with both row and column searching for next pivot. The inverse is generated in place, hence destroying the original A matrix. The routine also calculates the solution vector $X$ to $A X=B$ if requested. This result is stored in the vector $B$, thus destroying its original contents. 


\begin{tabular}{|l|l|l|l|l|}
\hline Jitle & Module: LSTSQR & Vol. & Page \\
DPSTM.500 & & Subroutine: MINVS & IX & E.1.461 \\
\cline { 3 - 5 } & & & Rev $_{i}$ & $\begin{array}{l}\text { Date } \\
6 / 73\end{array}$ \\
\hline
\end{tabular}

\section{Program Logic:}

Language:

Author:
The program utilizes the standard GaussJordan inversion procedure whereby an implied identify matrix is transformed into the desired inverse through a series of row operations. Superimposed upon this are row and/or column interchanges for placing the maximum value of the reduced matrix as the pivot element. At the conclusion of the Gauss-Jordan procedure, reverse row/column interchanges are made to give the desired inverse. The determinant is calculated at each matrix recluction as $\prod_{i} P_{i}$ where $P_{i}$ is the pivot of the $i^{\text {th }}$ reduced matrix. If the solution vector $X$ to $A X=B$ is requested, appropriate Gauss-Jordan row operations are performed on the vector $B$, as the inversion proceeds.

FORTRAN IV

F. D. Knight 


\begin{tabular}{|c|c|c|c|c|}
\hline DPSTM. 500 & Title & $\begin{aligned} \text { Module: } & \text { LSTSQR } \\
\text { Subroutine: } & \text { MINVS }\end{aligned}$ & Rev. & $\begin{array}{l}\text { Date } \\
6 / 73\end{array}$ \\
\hline
\end{tabular}

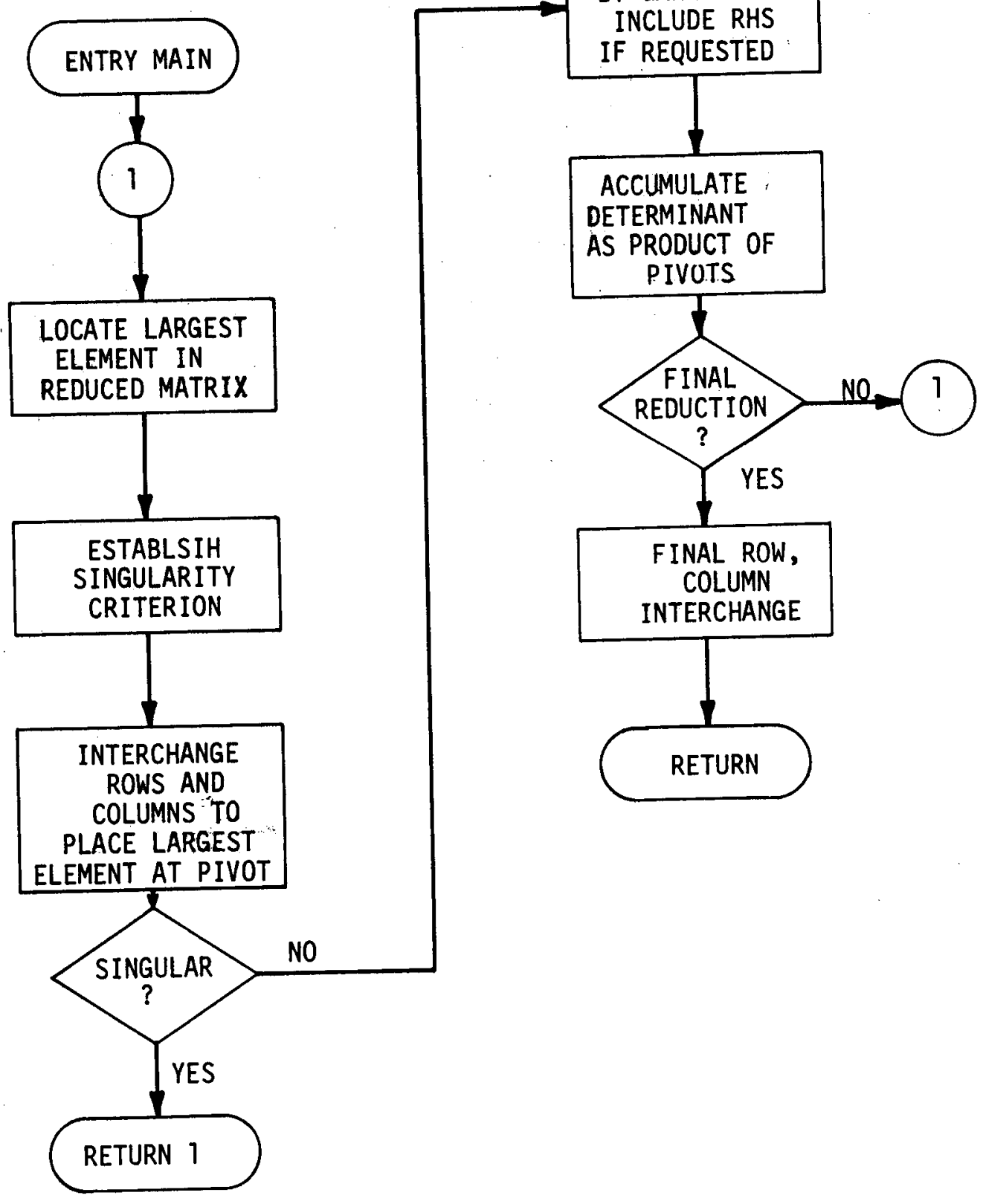

RED'JCE MATRIX

BY GANN-JORDAN

INCLUDE RHS

IF REQUESTED

DETERMINANT

AS PRODUCT OF

LOCATE LARGEST

FINAL

REDUCTION

INAL ROW,

SINGULARITY

INTERCHANG 


\begin{tabular}{|l|l|l|l|l|}
\hline JOSHIUA & Title & Module: MATHERRX & $\begin{array}{l}\text { Vol. } \\
\text { IX }\end{array}$ & $\begin{array}{l}\text { Page } \\
\text { E.1.463 }\end{array}$ \\
& & & Rev. & $\begin{array}{c}\text { Date } \\
6 / 73\end{array}$ \\
\hline
\end{tabular}

Purpose:

To provide traceback routine for mathematical errors.

Attribute: Nonreusable

JOS Main Program Name: MATHERRX

External Reference: SVC 13, OPEN, WRITE, CHECK

Data Sets:

FTO6FO01 (Printer)

Program Logic:

The program is entered via the LOAD macro instruction from the \$LINK routine. The function that the math error occurred in is retrieved from the save area along with the subroutine in which it occurred. The return address for the particular math function is also retrieved. This information is then put in message 1 which is written to the printer (FTO6FOOI) by issuing a WRITE macro instruction. An abend code of 29 is then set up before 'abending' via the OS 360 SVC 13.

MESSAGE I: 'ABEND OCCURRED IN FUNCTION FFFFFF CALLED FROM SUBROUTINE SSSSSS AT ISN NNNNNNNN'

where:

$\begin{array}{ll}\text { FFFFFF } & =\text { function name } \\ \text { SSSSSS } & \equiv \text { subroutine name } \\ \text { NNNNNNNN } & =\text { internal statement } \\ & \text { number (return address) }\end{array}$

Referenced By: $\quad$ \$LINK

Language: Assembler

Author: $\quad$ R. L. Boyce, Jr. 


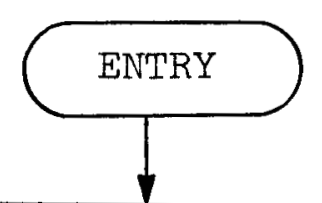

OBTAIN AND MOVE FUNCTION ROUTINE

NAME TO MESSAGE

AREA.

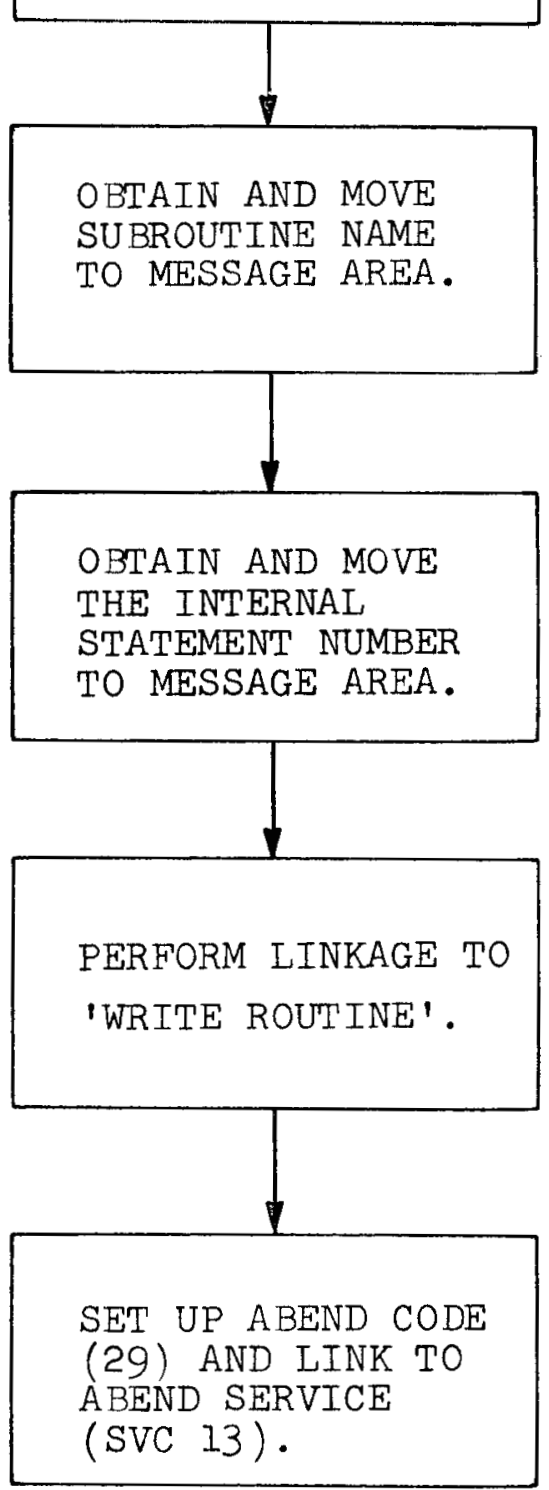




\begin{tabular}{|c|c|c|c|c|}
\hline & Title & Module: MATHERRX & \begin{tabular}{|lll} 
Vol. & \\
& IX \\
\end{tabular} & \begin{tabular}{|l|} 
Page \\
E.1.465 \\
\end{tabular} \\
\hline DPSTM.500 & & & $\begin{array}{r}\text { Rev. } \\
\\
1\end{array}$ & \begin{tabular}{|c|} 
Date \\
$6 / 73$ \\
\end{tabular} \\
\hline
\end{tabular}

\section{'WRITE ROUTINE':}

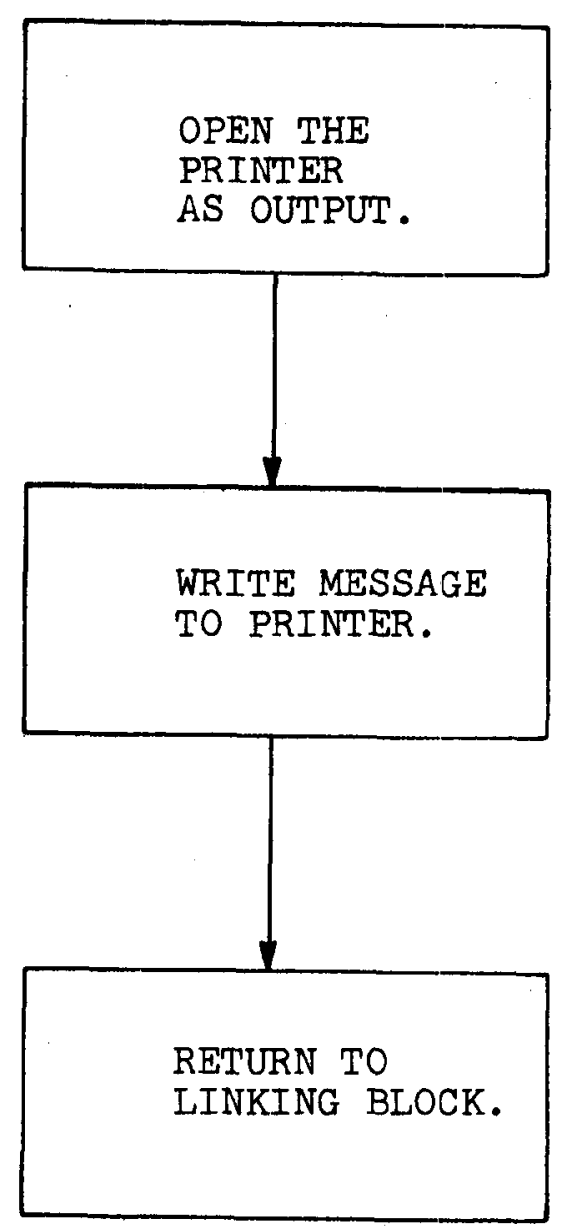




\begin{tabular}{|c|c|c|c|c|}
\hline 1 & \multirow{2}{*}{\multicolumn{2}{|c|}{ Title Module: MATHERRX }} & Vol. & $\begin{array}{l}\text { Page } \\
\text { E.1.466 }\end{array}$ \\
\hline DPSTM. 500 & & & $\begin{aligned} \text { Rev. } \\
1\end{aligned}$ & \begin{tabular}{|l} 
Date \\
$6 / 73$ \\
\end{tabular} \\
\hline
\end{tabular}

(Bank) 


\begin{tabular}{|l|l|l|l|l|}
\hline JOSHUA & Title Module: MTDIRECT & Vol. & $\begin{array}{l}\text { Page } \\
\text { E.1.467 }\end{array}$ \\
\cline { 3 - 4 } & & Rev. & Date \\
1 & $6 / 73$ \\
\hline
\end{tabular}

Purpose:

Attribute:

JOS Main Program:

Arguments:

Subprograms:

Program Logic:

Language:

Author:
In the MT function, to direct function execution to the proper module for disposition of the template page type.

Nonreusable

MAIN

Mnemonic Type

A1 $\quad$ Real*

CCB.

Area pointed to by MCBBUFFG - buffer area containing page-type display and user-specified indicators.

A13

Integer *2

WXTWORK3 - A13(162) is set to the page count of the next CDS record to be read.

A15 Integer*4 MCBCFCT.

\section{Control Section}

MOVEIT

RHAR

\section{Entry Point}

MOVEIT

CHAR

- If a numeric character is found in either the first or eight hundred eighty-first position of $A 4$, it is used to define the number of the next CDS page to be read. A page one specification is always reset to page two.

- Positions 707, 787, and 867 of A4 are checked for indicated dispositions of delete, insert, or process, respectively. Multiple indications or no indication results in the display being returned for proper specification.

- Any required change to $A 13(162)$ and $A 15$ as a result of the specified disposition is made.

FORTRAN IV

R. C. Haywood 


\begin{tabular}{|c|c|c|c|c|}
\hline & Title & Module: MTDIRECT & $\begin{array}{l}\text { Vol. } \\
\text { IX }\end{array}$ & $\begin{array}{l}\text { Page } \\
\text { E.1.468 }\end{array}$ \\
\hline DPST M- 500 & & & Rev: $_{1}$ & $\begin{array}{l}\text { Date } \\
6 / 73\end{array}$ \\
\hline
\end{tabular}

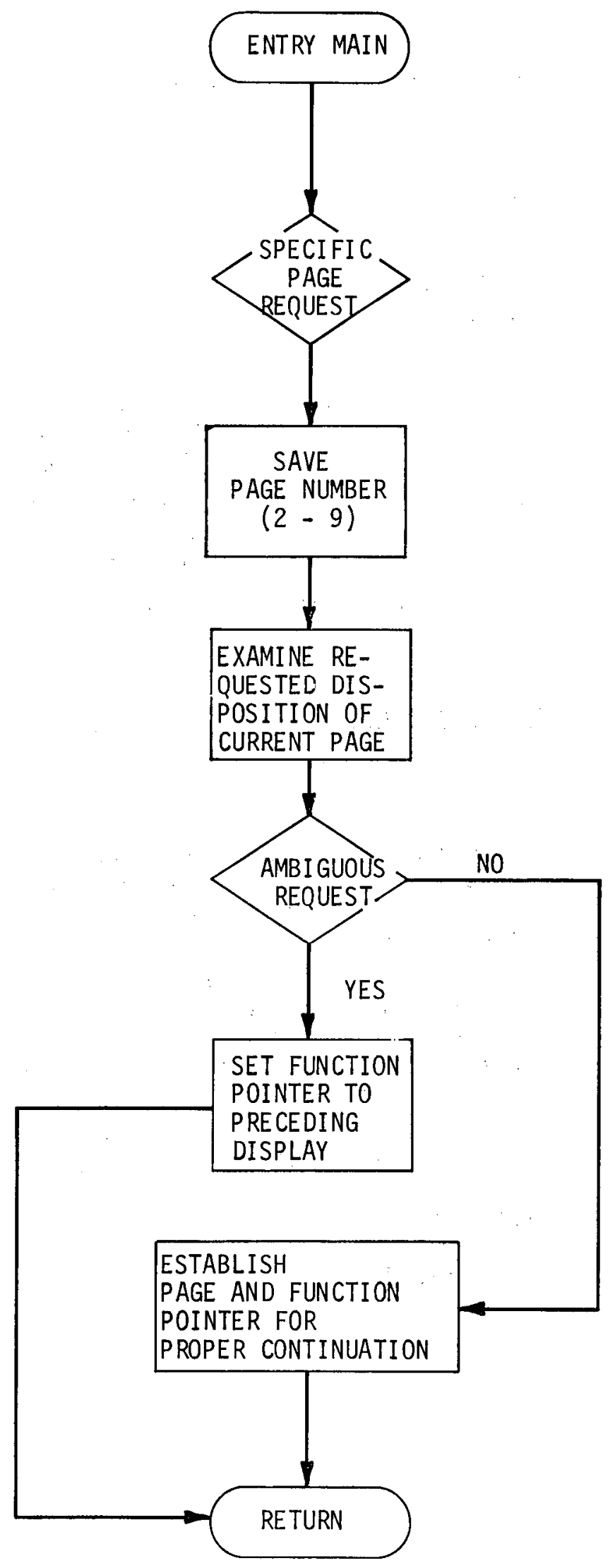




\begin{tabular}{|l|l|l|l|l|}
\hline JOSHUA & Title Module: MTPAge & Vol. & Page \\
DPSTM.500 & E.1.469 \\
\cline { 3 - 5 } & & Rev. & $\begin{array}{c}\text { Date } \\
6 / 73\end{array}$ \\
\hline
\end{tabular}

Purpose:

In the MT function to read from the CDS and place in the display buffer the specified template page type so that modifications may be made.

Attribute: ... Nonreusable

JOS Main Program: MAIN

Arguments:

\begin{tabular}{|c|c|c|}
\hline Mnemonic & Type & \\
\hline $\mathrm{A} 1$ & Real $* 8$ & CСB. \\
\hline A4 & Rea $1 * 8$ & $\begin{array}{l}\text { Area pointed to by MCBBUFFG - used } \\
\text { as the CDS buffer and the terminal } \\
\text { buffer. }\end{array}$ \\
\hline A13 & Integer $* 2$ & 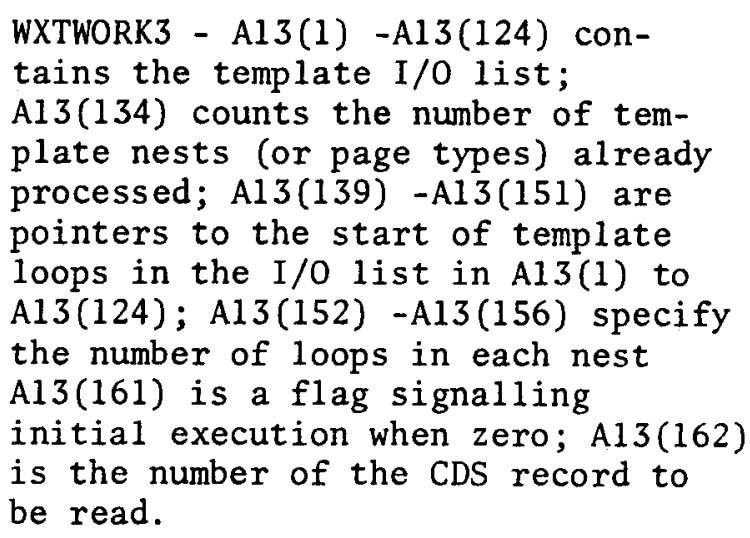 \\
\hline
\end{tabular}

Subprograms:

Control Section Entry Point

LINK

MOVEIT

XNSTID

\$LINK, RPAGE

MOVEIT

XNSTID

External References: JTRSTPGE - referenced via call to \$LINK.

Data Sets:

Communication Data Set (CDS) - via call to RPAGE.

Program Logic:

- A call to \$LINK is made to execute JTRSTPGE thus repositioning to the start of the CDS.

- To retrieve the specified page (two on initial execution), the CDS is read sequentially until the desired page is read into $A 4$ or the end of the CDS is reached. In the latter case, the area of A4 which would normally contain the page type display is initialized to question marks. 


\begin{tabular}{|c|c|c|c|c|}
\hline \multirow{2}{*}{$\begin{array}{l}\text { OSAUA } \\
\text { DPSTM-500 }\end{array}$} & \multirow[t]{2}{*}{ Title } & \multirow[t]{2}{*}{ MTPAGE } & $\begin{array}{l}\text { Vol. } \\
\text { IX }\end{array}$ & $\begin{array}{l}\text { Page } \\
\text { E. } 1.470\end{array}$ \\
\hline & & & Rev. & $\begin{array}{c}\text { Date } \\
6 / 73\end{array}$ \\
\hline
\end{tabular}

Language:

- XNSTID is called to place the page type's associated nest from the I/O list on the last line of the buffer.

- Instructions for indicating the options of delete, insert, or process in bytes 707,787 , and 867 , respectively, are loaded into the buffer.

Author:

FORTRAN IV

R. C. Haywood 


\begin{tabular}{|c|l|l|l|l|}
\hline JOSHUA & Title Module: MTPAGE & Vol. & $\begin{array}{l}\text { Page } \\
\text { DPSTM.1.471 }\end{array}$ \\
\cline { 3 - 5 } & & Rev. & $\begin{array}{c}\text { Date } \\
6 / 73\end{array}$ \\
\hline
\end{tabular}

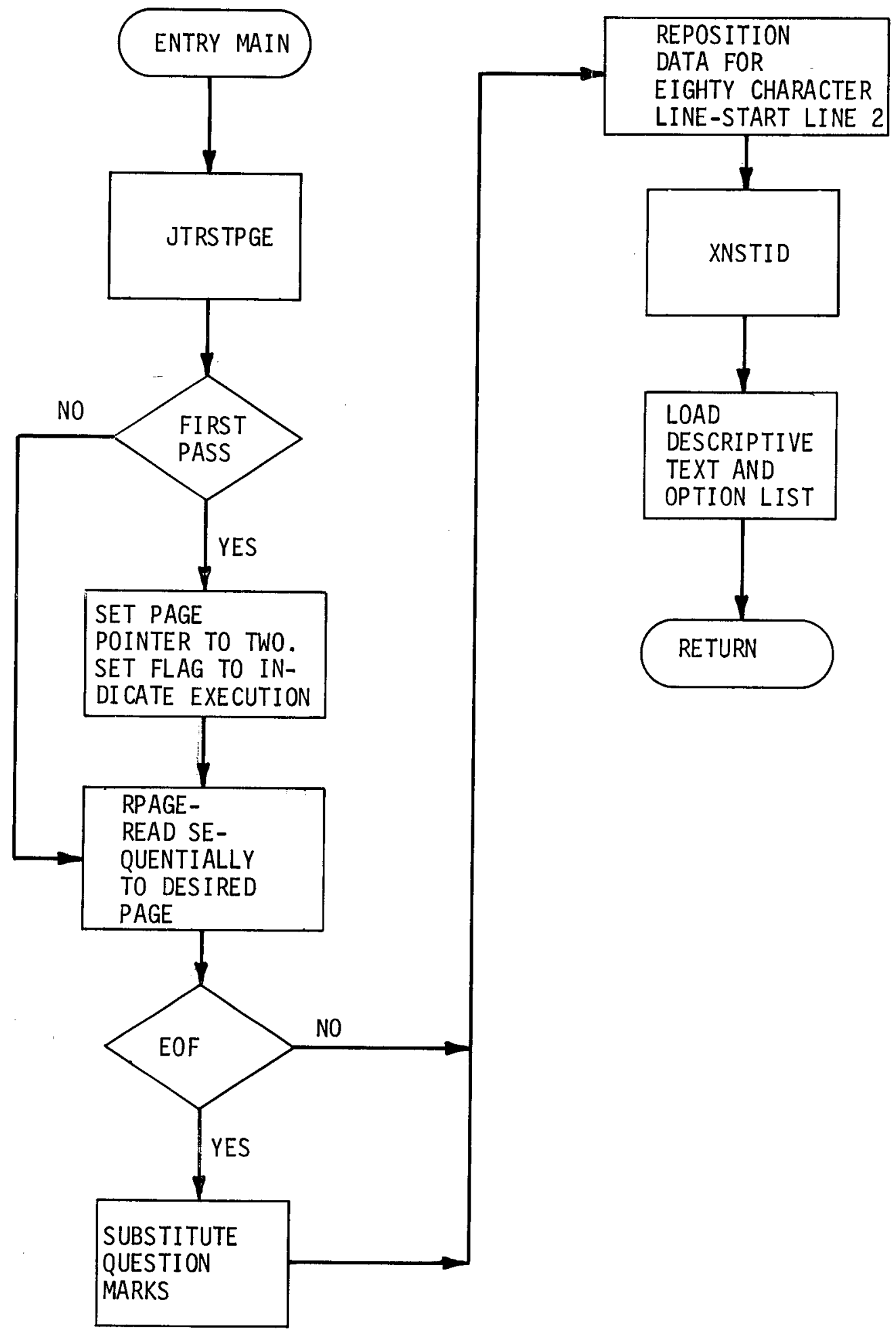




\begin{tabular}{|c|c|c|c|}
\hline 10 & Title Module: MTPAGE & ${ }_{\text {IX }}^{\text {Vol. }}$ & \begin{tabular}{|l} 
Page \\
E.1.472
\end{tabular} \\
\hline DPSTM.500 & & $\begin{array}{l}\text { Rev. } \\
1\end{array}$ & $\begin{array}{c}\text { Date } \\
6 / 73\end{array}$ \\
\hline
\end{tabular}

(Blank) 


\begin{tabular}{|c|c|c|c|c|}
\hline $1 \cap c 1$ & \multirow{2}{*}{\multicolumn{2}{|c|}{ Title $\quad$ Module: NTERPRET }} & \begin{tabular}{|l|} 
Vol. \\
\\
IX \\
\end{tabular} & $\begin{array}{l}\text { Page } \\
\text { E.1.473 }\end{array}$ \\
\hline DPSTM-500 & & & Rev. & $\begin{array}{l}\text { Date } \\
6 / 73\end{array}$ \\
\hline
\end{tabular}

Purpose :

Attribute:

JOS Main Program:

Arguments:
To create unformatted data records from formatted input.

Nonreusable

MAIN

Mnemonic

Al

A2

Rea $1 * 8$

A3

$\operatorname{Real} * 8$

A4

Logical*1

A8

Integer $* 4$

A10

Integer ${ }^{\star} 4$

CCB. data record written except when conditions indicate a lownam is in progress.

WCBARG2 - specifies the name of the data record to be written. as CDS buffer by RPAGE.

WXTNTGR - returns the number of qualifiers placed in $A 2$.

WXTWORKI - assumed to have been
Description

WCBARG1 - returns the name of the

Area addressed by MCBBUFFG - used used as the COMTEM array in an earlier BNAM reference. The relative values of $A 10(4)$ and AlO(7) are used to determine if a lownam is in progress. When no lownam is indicated, $A 10(3)$ is set to zero.

Subprograms:

\section{Entry Point}

\$TERR

BCDFIX

BCDFLT

INVER

BNAM, JTREE, RPAGE

MOVEIT

OVFLO

PEELPG

TRNSLT 
- The number of qualifiers in $\mathrm{A} 3$ is determined by locating the delimiting qualifier, hexadecimal $55^{\prime} \mathrm{s}$.

- The template for the record type being created or modified is located by means of a read (functional request 2) request to BNAM. The template is sought first in the output data set and then according to the default search sequence. The qualifiers defined in A3 are prefixed by the qualifier 'TEMPLATE'. If the initial qualifier in $A 3$ was of the form of a job or user data set, that qualifier is eliminated for the search. The node corresponding to BNAM's COMTEM( 8 ) must be set to hexadecimal 4's.

- The template record is read and used to strip the data from formatted pages (in subroutine PEELPG) which are retrieved from the communication data set to create the output data record. Processing continues until the template is satisfied. When an end-of-file situation exists on the CDS, A4 is loaded with blanks.

- When the last physical record of data has been written (output is performed by subroutine OVFLO) a final call is made to OVFLO to assure the proper record length is cataloged.

- When a lownam is not in process, the name of the record written is placed in $A 2, A 8$ set to indicate the number of qualifiers, and $A 10(3)$ set to zero.

Terminating Conditions:

The following errors result in calls to \$TERR:

- Failure to locate a template.

- Invalid data in the template record.

- Failure in BNAM write of the data record.

Language:

FORTRAN IV

Author:

R. C. Haywood - J. E. Suich 


\begin{tabular}{|l|l|l|l|}
\hline \multirow{2}{\text{DPSTM}-500}{} & Title Module: NTERPRET & Vol. & Page \\
IX & E.1.475 \\
\cline { 3 - 5 } & & Rev. & $\begin{array}{c}\text { Date } \\
6 / 73\end{array}$ \\
\hline
\end{tabular}

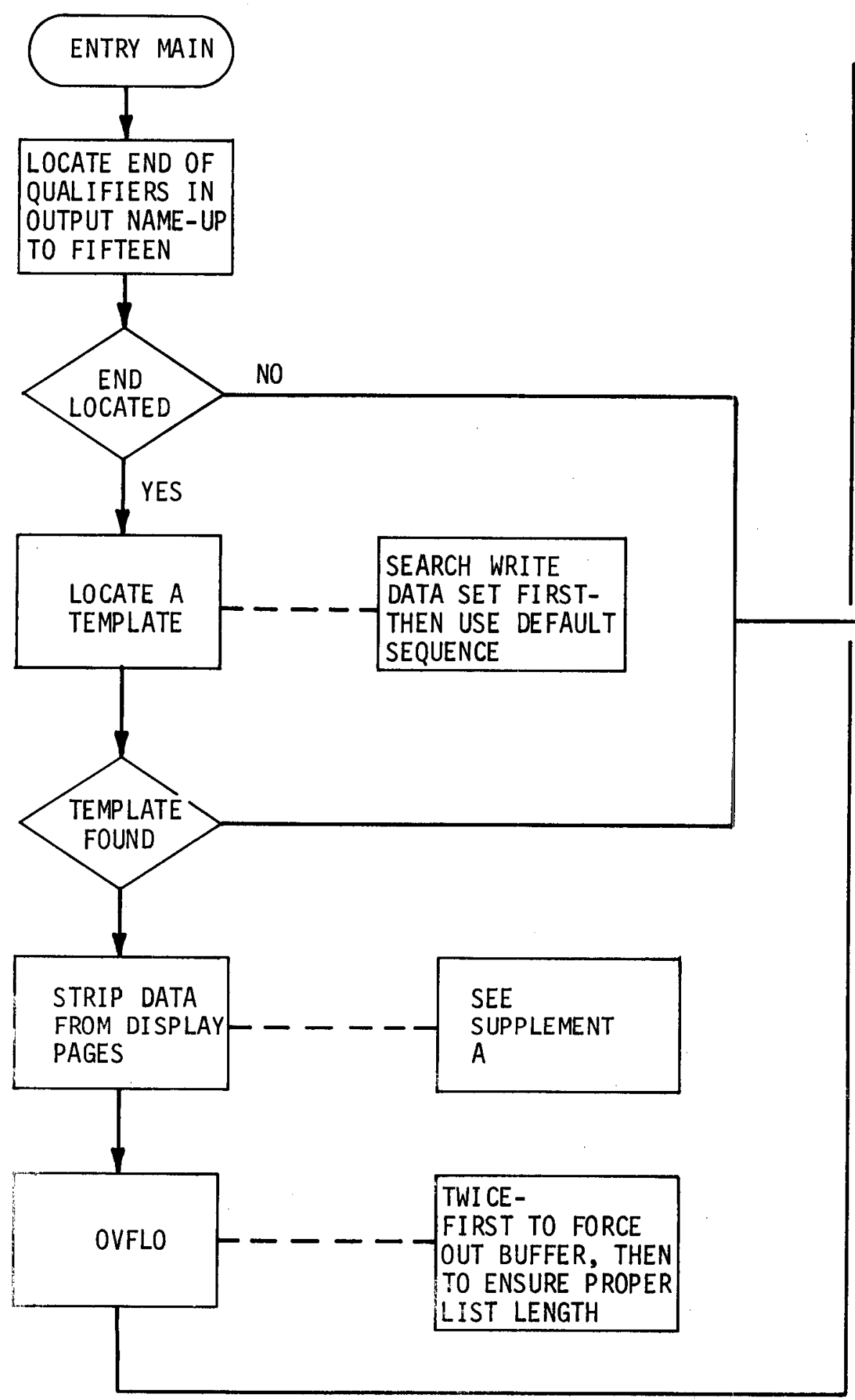




\begin{tabular}{|c|l|l|l|l|}
\hline JOSHUA & Title Module: NTERPRET & $\begin{array}{l}\text { Vol. } \\
\text { Ix }\end{array}$ & Page \\
DPST M-500 & & & Rev. & Date \\
& & & $6 / 73$ \\
\hline
\end{tabular}

Supplement A:

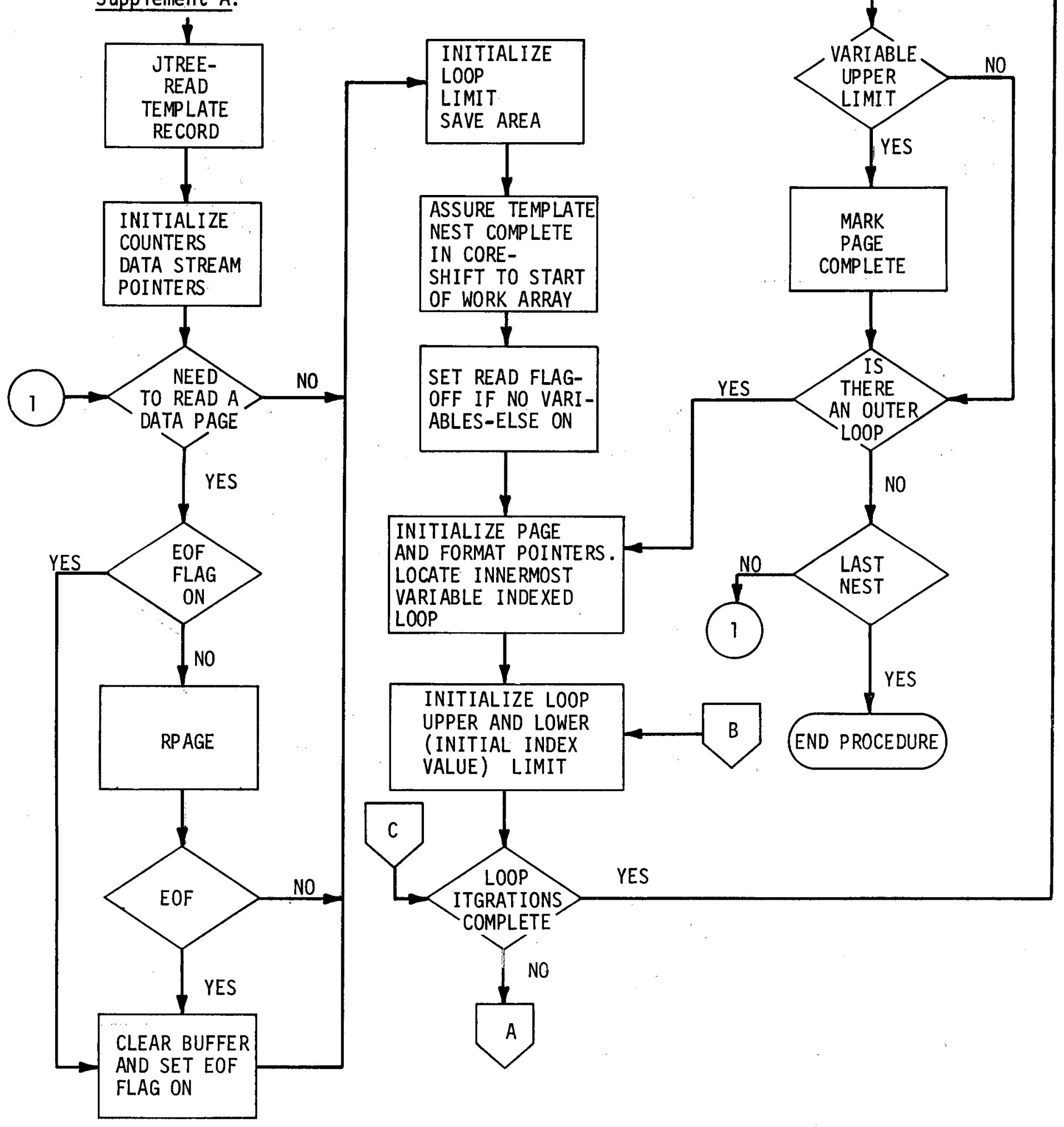




\begin{tabular}{|c|c|c|c|c|}
\hline 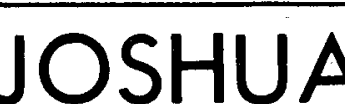 & \multirow{2}{*}{\multicolumn{2}{|c|}{ Title Module: NTERPRET }} & $\begin{array}{l}\text { Vol. } \\
\text { IX }\end{array}$ & $\begin{array}{l}\text { Page } \\
\text { E.1.477 }\end{array}$ \\
\hline DPSTM -500 & & & Rev. & $\begin{array}{l}\text { Date } \\
6 / 73\end{array}$ \\
\hline
\end{tabular}

Supplement A (contd):

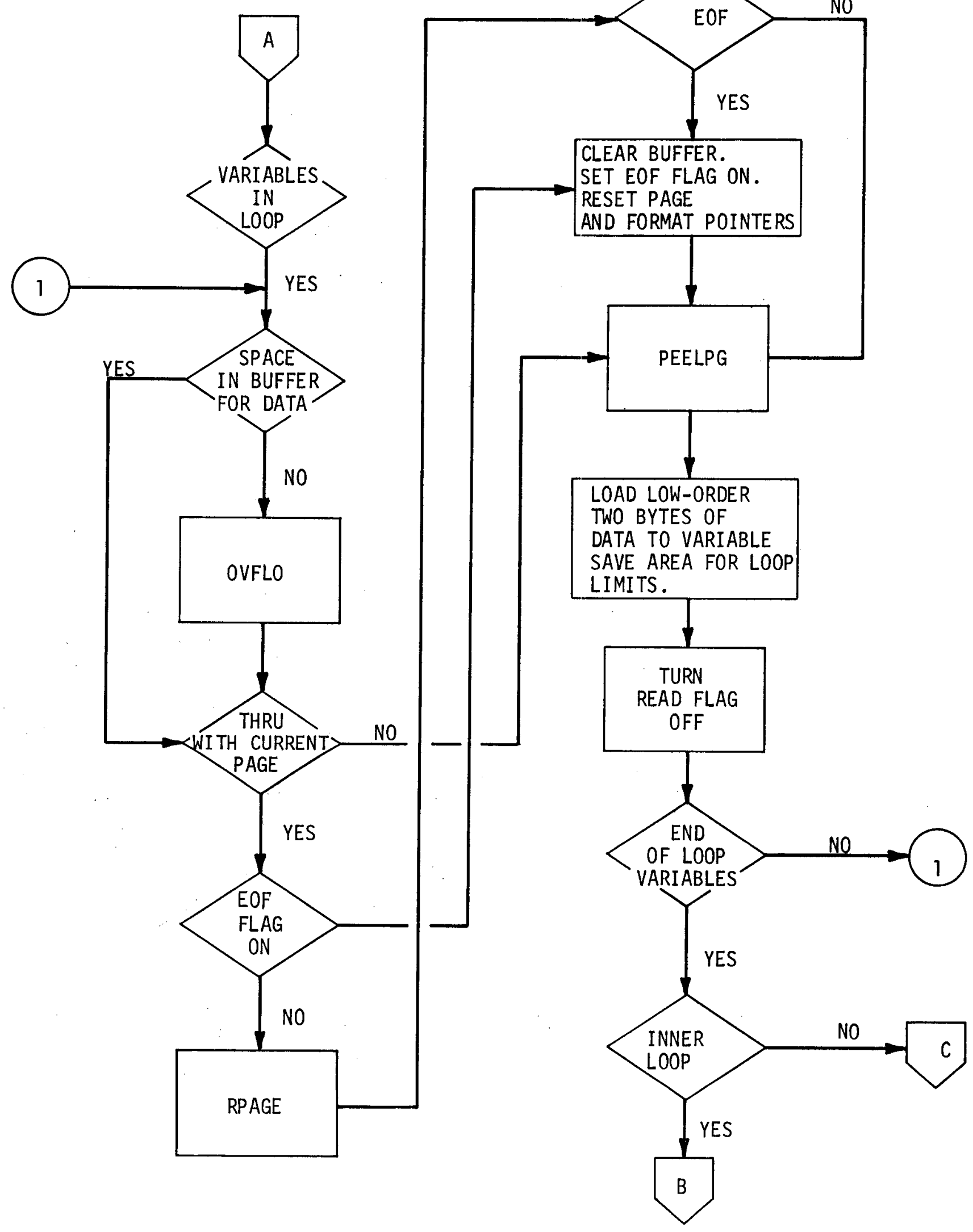


Purpose:

Usage:

Arguments:

Subprograms:

Program Logic:

Language:

Author:
To convert an EBCDIC display of data to the prescribed internal format.

CALL INVER(FMT, VAR, OUT, DATA)

\begin{tabular}{|c|c|c|}
\hline Mnemonic & Type & Description \\
\hline FMT & Logical*1 & Two-byte template format code. \\
\hline VAR & Logical*1 & $\begin{array}{l}\text { Two-byte template variable } \\
\text { description. }\end{array}$ \\
\hline OUT & Logical*1 & Receives the converted data. \\
\hline DATA & Logical*1 & EBCDIC display. \\
\hline
\end{tabular}

BCDFIX

BCDFLT

MOVEIT

TRNSLT

- The conversion is based on the format code FMT; the length of the converted data is defined by the second byte of VAR.

- Hexadecimal - Converted data is justified right in OUT; when necessary DATA is truncated from the left. Valid EBCDIC characters appearing in DATA are all numerics and the alphabetic characters $A$ through $F$; invalid characters are considered as EBCDIC zeros. One hundred eighty-three is subtracted from alphabetic representations, two hundred forty is subtracted from numeric representations. Grouping by sets of twos from the 'right, the high-order remainder is multiplied by sixteen and added to the low-order remainder to complete the conversion.

- Alphameric - No conversion is made. Truncation of DATA takes place on the right; OUT is justified left and, when necessary, filled out with blanks.

- Fixed-point - Any uncleared format descriptors are set to blanks. The data to be converted, the first group of nonblank characters in DATA, is passed to BCDFIX for conversion and the result moved to OUT.

- Floating-point - DATA is scanned for the first occurrence of the character E; all other occurrences of $E$ and all occurrences of $F$ are replaced by blanks. BCDFLT is called to convert the data and the result placed in OUT.

FORTRAN IV

R. C. Haywood 


\begin{tabular}{|l|l|l|l|l|}
\hline JOSHUA & Title & $\begin{array}{l}\text { Module: NTERPRET } \\
\text { Subrout ine: INVER }\end{array}$ & $\begin{array}{l}\text { Pol. } \\
\text { Ix }\end{array}$ & $\begin{array}{l}\text { Page } \\
\text { E. } 1.479\end{array}$ \\
\cline { 3 - 5 } & & Rev. & $\begin{array}{c}\text { Date } \\
6 / 73\end{array}$ \\
\hline
\end{tabular}

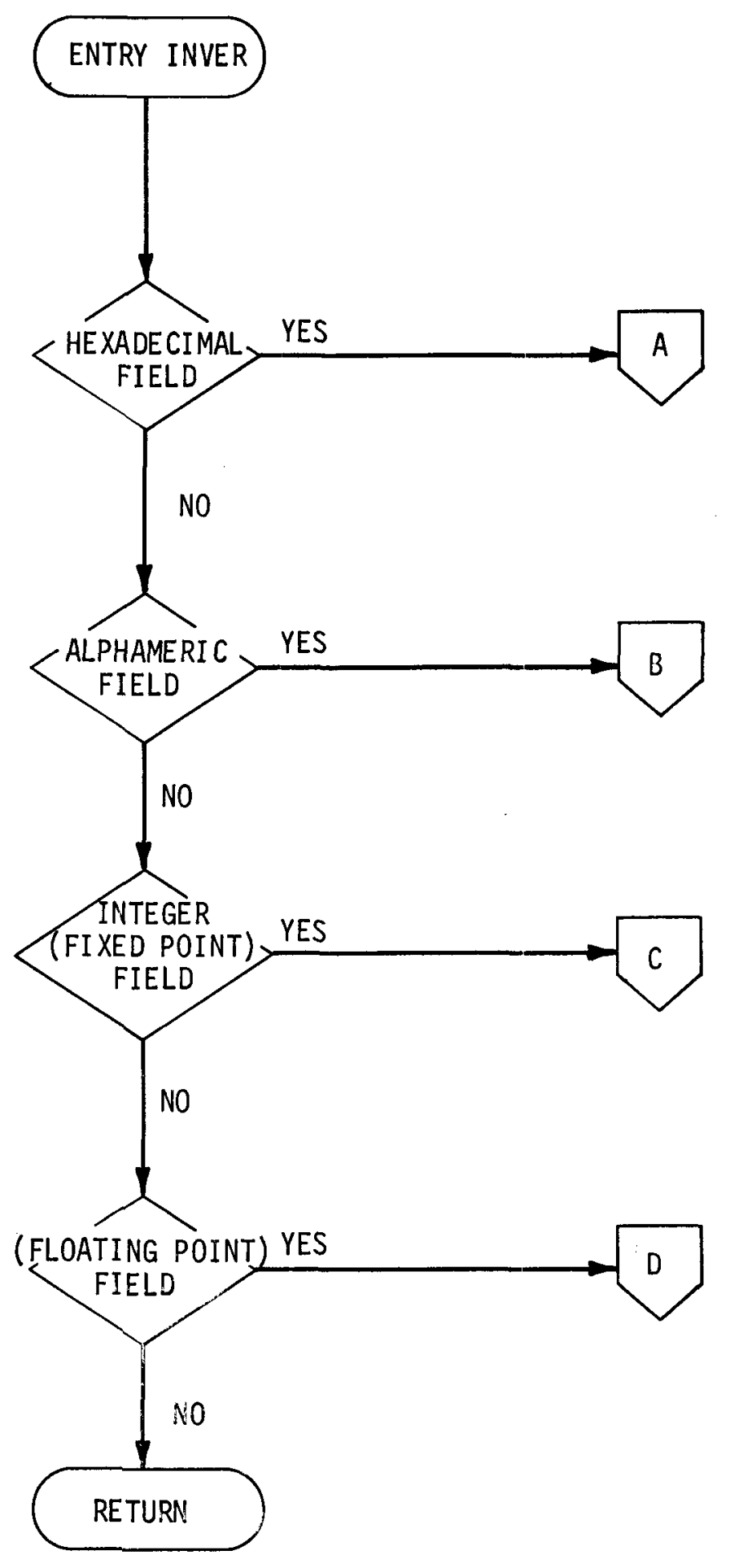




\begin{tabular}{|c|c|c|}
\hline \begin{tabular}{|l|l|} 
DPSTM -500 & Titt \\
iti
\end{tabular} & $\begin{array}{l}\text { Module: } \text { NITRPRET } \\
\text { Subrout ine: } \\
\text { TWNERER }\end{array}$ & 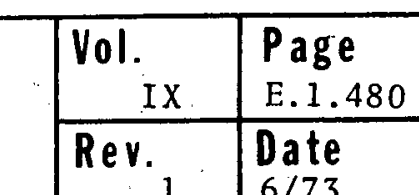 \\
\hline
\end{tabular}
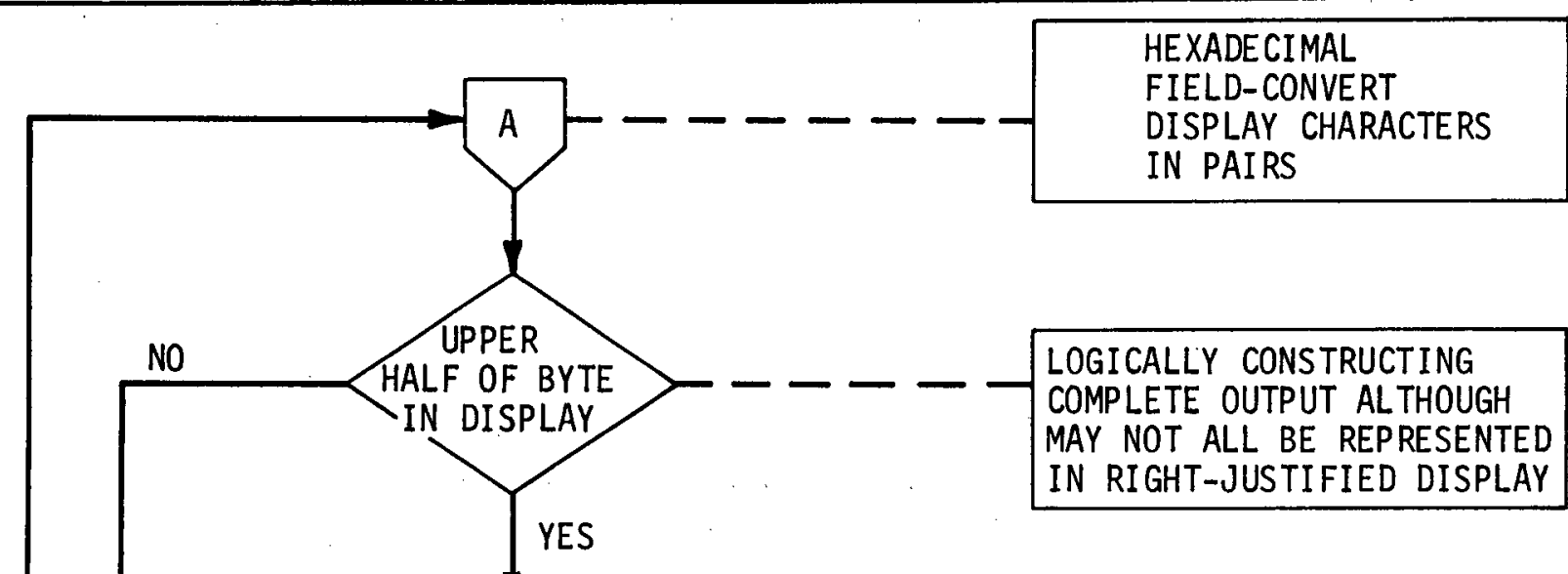

YES

HEXADECIMAL

FIELD-CONVERT

DISPLAY CHARACTERS
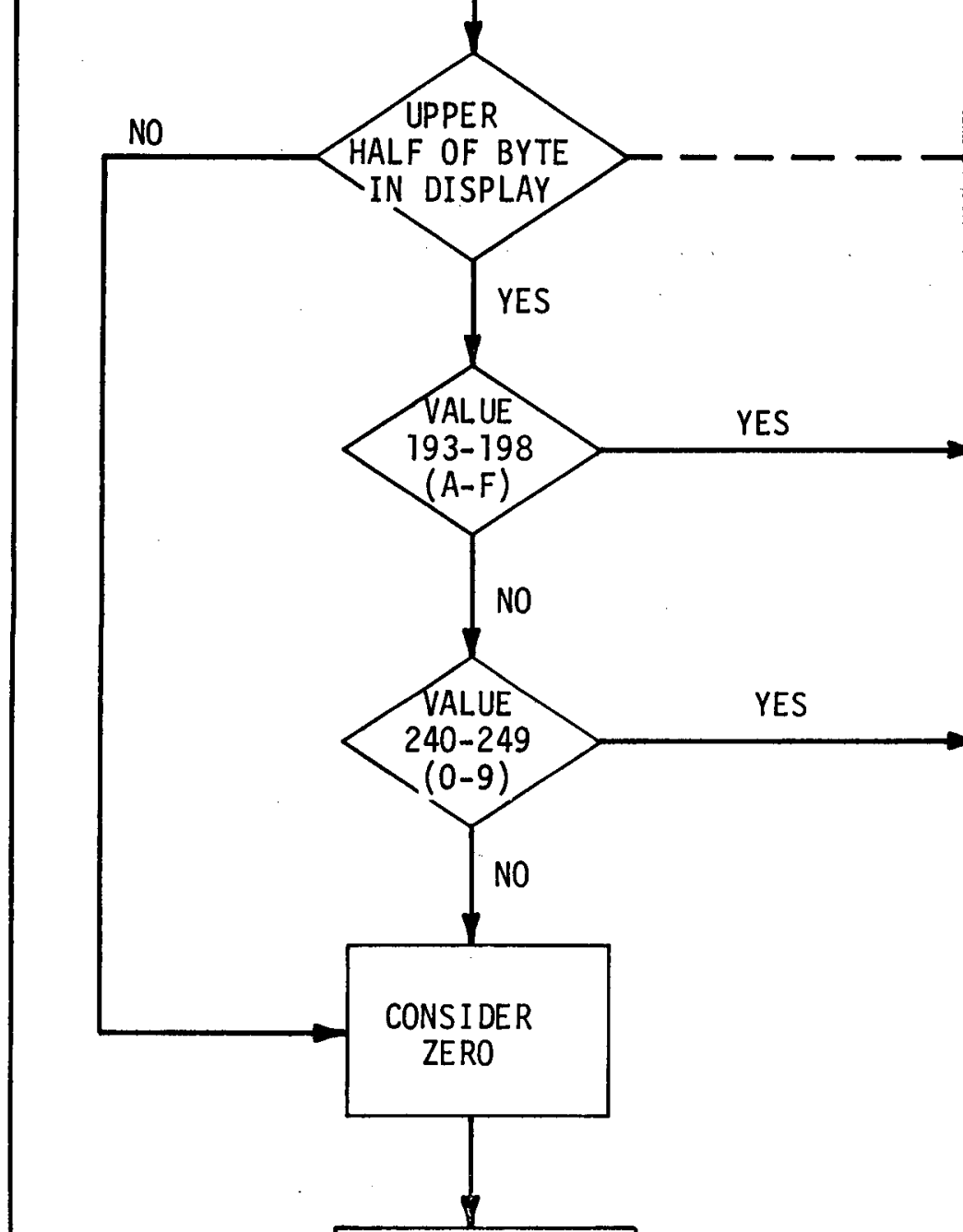

REPEAT FOR
CHARACTER REP-

RESENTING LOWER

HALF OF BYTE
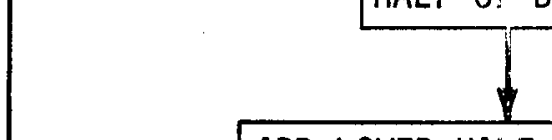

ADD LOWER HALF RESULT TO

PRODUCT OF UPPER HALF AND

SIXTEEN-PLACE IN NEXT

OUTPUT POSITION

NO

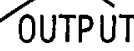

FIELD

YES
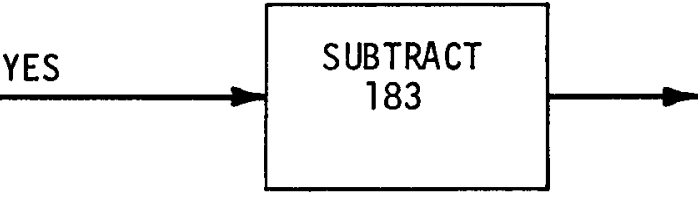

YES

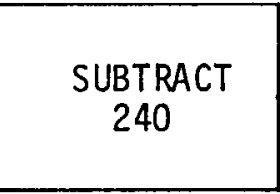

UBTRACT

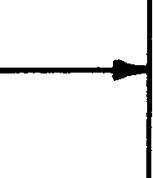




\begin{tabular}{|c|c|c|c|c|}
\hline & \multirow[t]{2}{*}{ Title } & \multirow{2}{*}{$\begin{array}{l}\text { Module: NTERPRET } \\
\text { Subrout ine: INVER }\end{array}$} & ${ }_{\text {IX }}^{\text {Vol. }}$ & \begin{tabular}{|l|} 
Page \\
E.1.481
\end{tabular} \\
\hline DPSTM. 500 & & & ${ }_{1}^{\text {Rev. }}$ & \begin{tabular}{|c|} 
Date \\
$6 / 73$
\end{tabular} \\
\hline
\end{tabular}

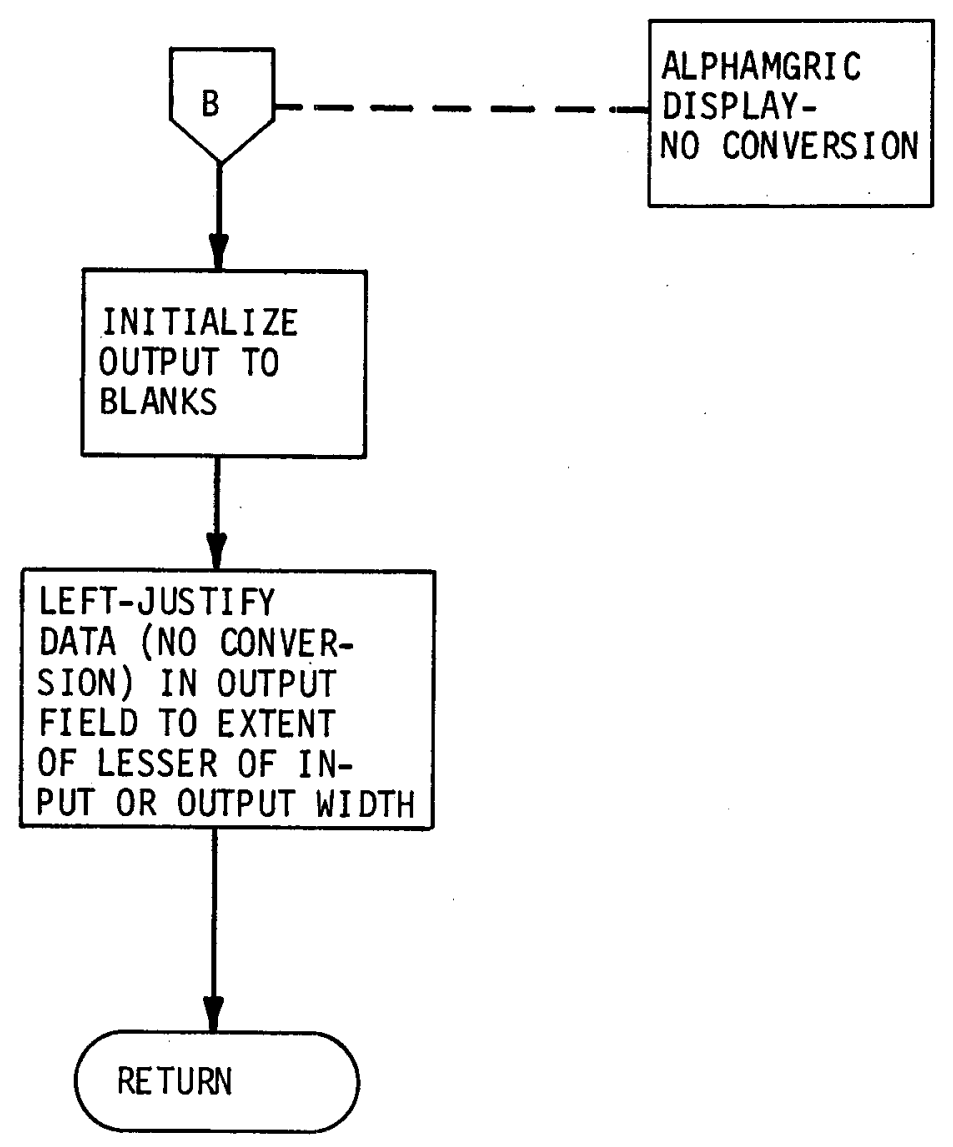




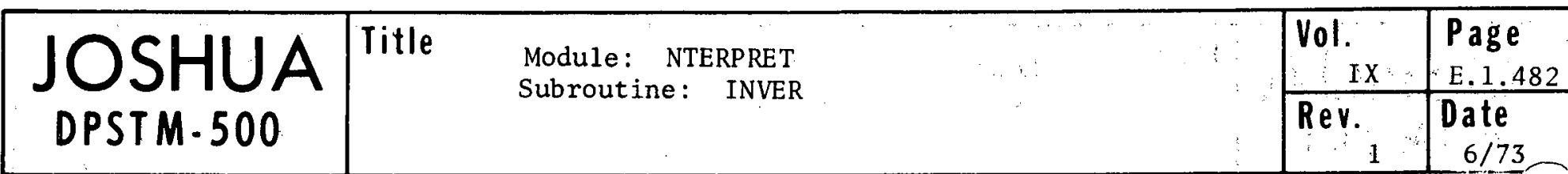

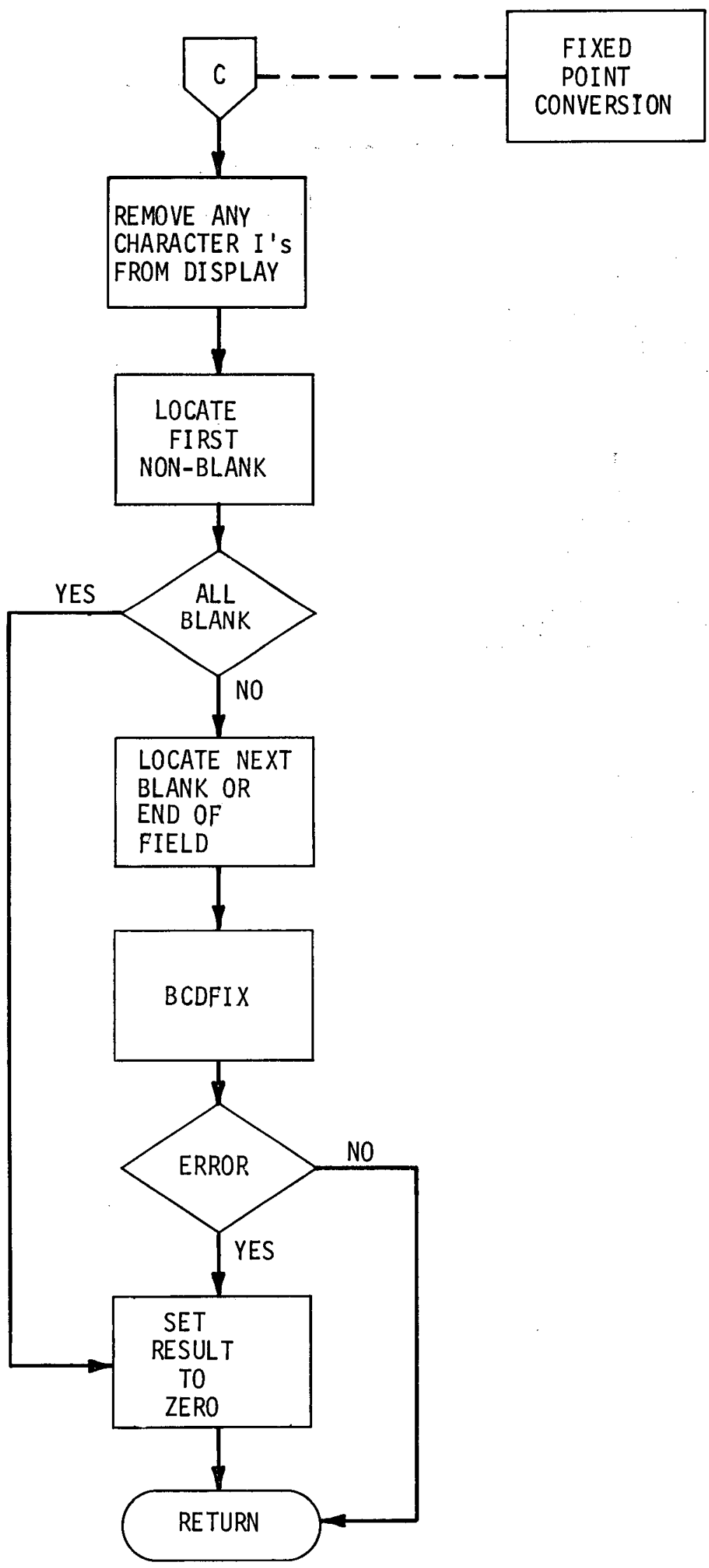




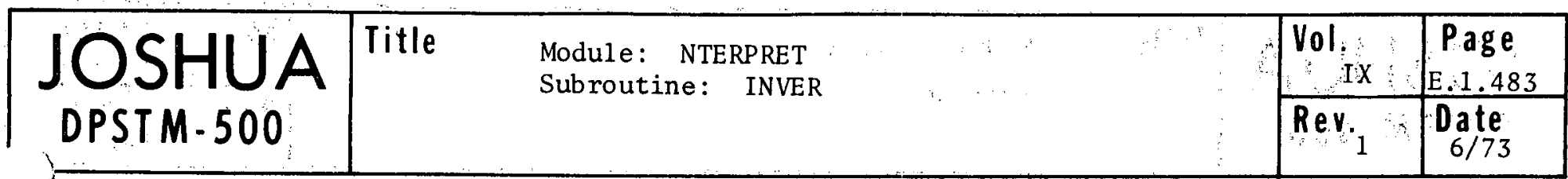

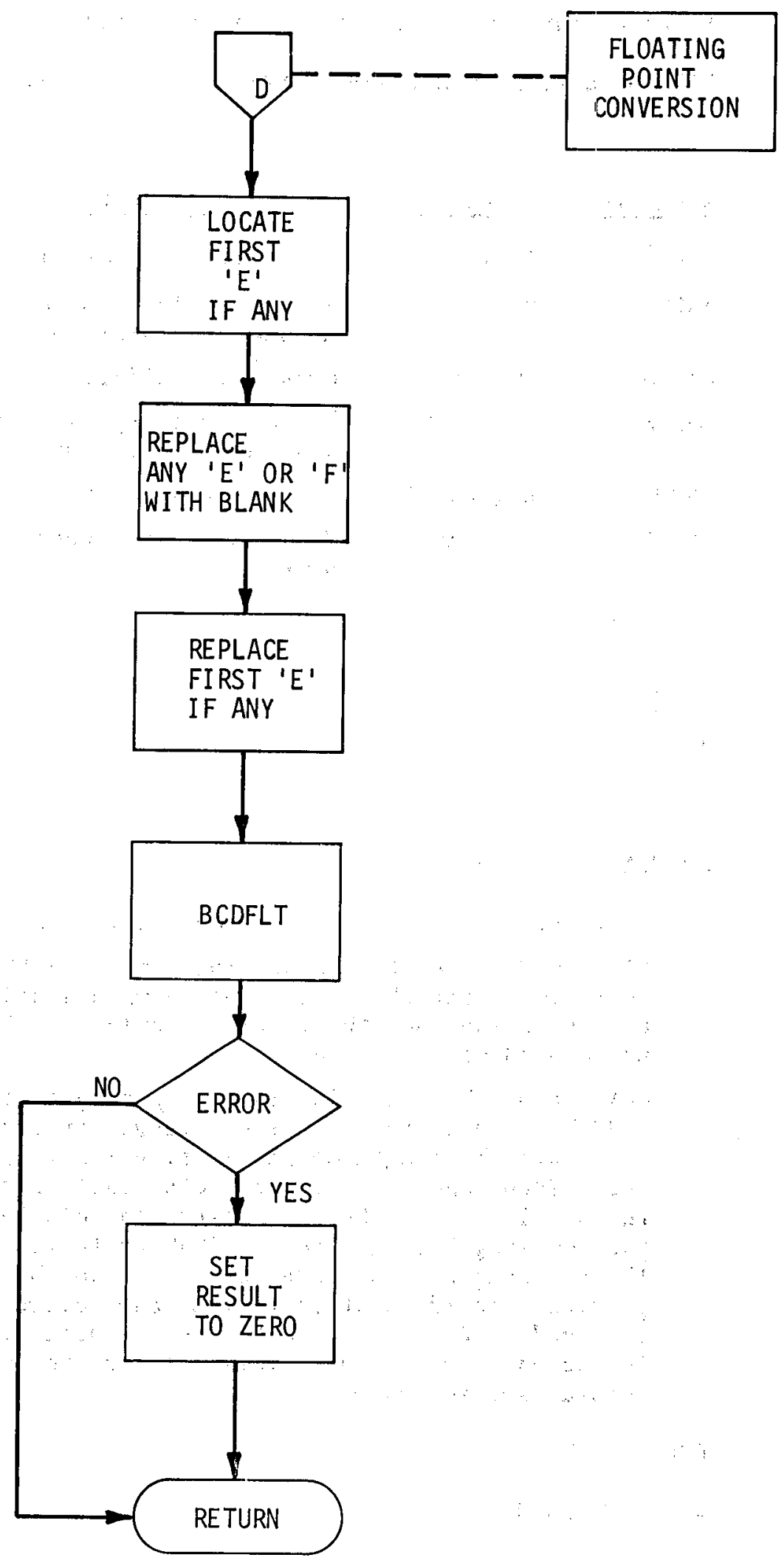




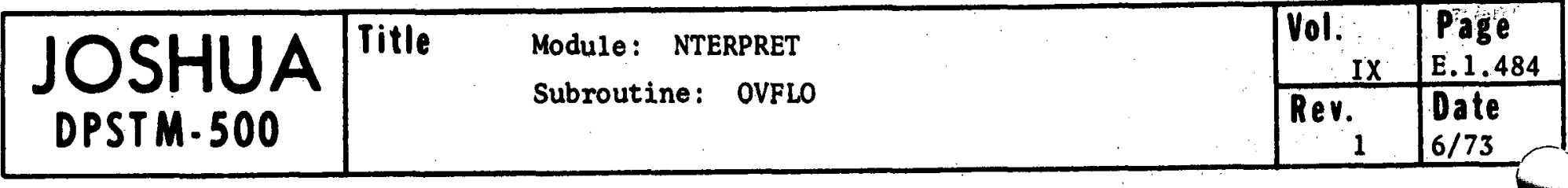

Purpose:

Usage:

Arguments:

Subprograms :

\$TERR

BNAM

JTREE
To write out new or modified named data records.

CALL OVFLO(CCB, SRCH, NAMES, MAXIN, INPUT, INSIZ)

\begin{tabular}{|c|c|c|}
\hline Mnemonic & Type & Description \\
\hline CCB & $\operatorname{Real}$ *8 & Communication Control Block. \\
\hline SRCH & $\operatorname{Rea} 1 * 8$ & $\begin{array}{l}\text { Qualifiers for the named data } \\
\text { record to be written. }\end{array}$ \\
\hline NAMES & Integer $* 4$ & Number of qualifiers in SRCH. \\
\hline MAXIN & Integer*4 & $\begin{array}{l}\text { The number of bytes to be cata- } \\
\text { loged for the output record. }\end{array}$ \\
\hline INPUT & Logica1*1 & Data to be written. \\
\hline INSIZ & Integer 4 & $\begin{array}{l}\text { Physical record length of the } \\
\text { data file. }\end{array}$ \\
\hline
\end{tabular}

\section{Data Sets:}

Program Logic:

Language:

Author:
JOSHUA data file

The subroutine is entered under two distinct conditions:

MAXIN $=0$ - When this condition exists, a BNAM write is issued using the record length maintained locally by the subroutine, the local variables reinitialized, and a BNAM close issued.

MAXIN $\neq 0$ - When the initial or opening call is indicated, a BNAM write is issued using a length of zero in order to obtain the length of an existing record if there be one. Then, and for all succeeding calls until MAXIN $=0$, the new length is checked against the old length. When the new length is greater, a BNAM write is issued using the new length. The data is written to the appropriate physical record relative to the base record number returned by BNAM. When a BNAM call indicates a change in the base number, any previously written physical records are relocated.

FORTRAN IV

R. C. Haywood 


\begin{tabular}{|c|c|c|c|}
\hline 10 & \multirow{2}{*}{\begin{tabular}{|ll} 
Title & Module: NTERPRET \\
& Subroutine: OVFLO
\end{tabular}} & $\begin{array}{l}\text { Vol. } \\
\text { IX }\end{array}$ & \begin{tabular}{|l|} 
Page \\
E.1.485
\end{tabular} \\
\hline DPSTM- 500 & & Rev. & \begin{tabular}{|l} 
Date \\
$6 / 73$
\end{tabular} \\
\hline
\end{tabular}

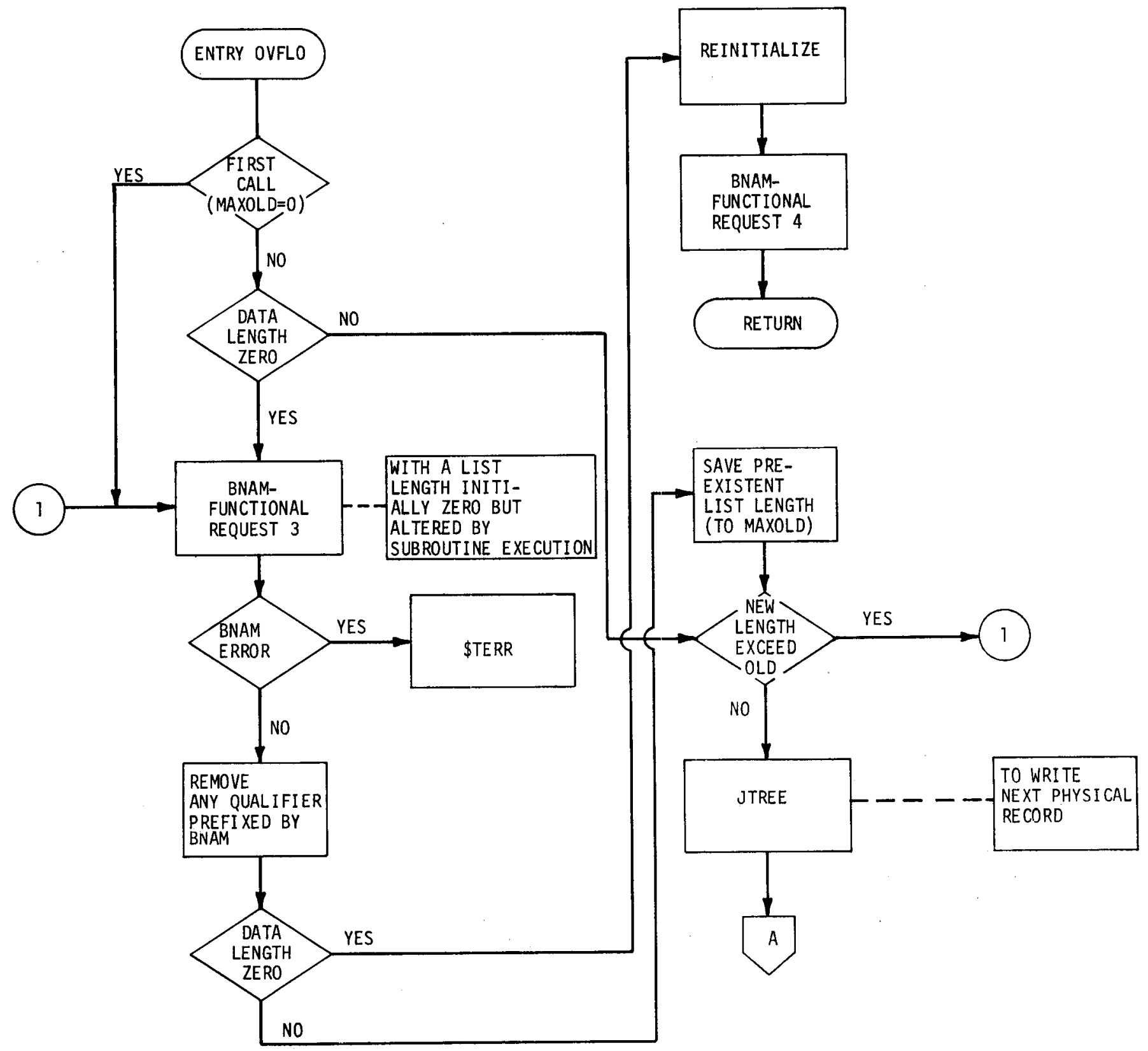




\begin{tabular}{|c|c|c|c|c|}
\hline$J$ & \multirow[t]{2}{*}{ Title } & \multirow{2}{*}{$\begin{array}{l}\text { Module: NTERPRET } \\
\text { Subroutine: } \quad \text { OVFLO }\end{array}$} & $\begin{array}{l}\text { Vol. } \\
\text { IX }\end{array}$ & $\begin{array}{l}\text { Page } \\
\text { E.1.486 }\end{array}$ \\
\hline DPSTM. 500 & & & Rev. $_{1}$ & $\begin{array}{l}\text { Date } \\
6 / 73\end{array}$ \\
\hline
\end{tabular}

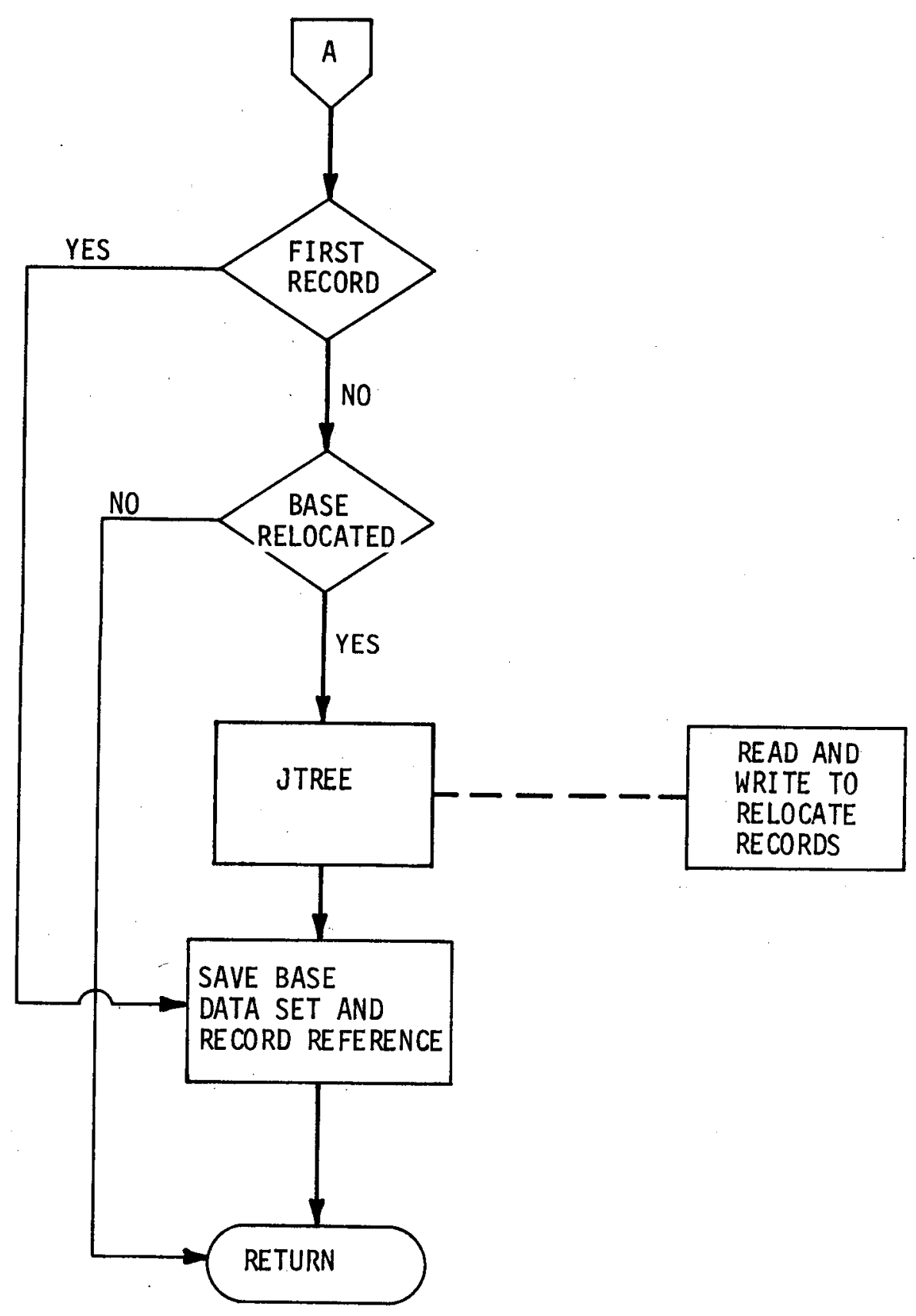




\begin{tabular}{|c|c|c|c|c|}
\hline \multirow{2}{*}{$\begin{array}{l}\text { JOSUU } \\
\text { DPSTM-500 }\end{array}$} & \multirow[t]{2}{*}{ Title } & & Vol. & $\begin{array}{l}\text { Page } \\
\text { E.1.487 }\end{array}$ \\
\hline & & e: PEELPG & Rev. & $\begin{array}{l}\text { Date } \\
6 / 73\end{array}$ \\
\hline
\end{tabular}

Purpose:

To locate the start position of the next variable on a page-type and convert the data to the designated internal format.

Usage:

CALL PEELPG(TM, TMPTR, PAG, PAGPTR, DATA, TYPE, PAGSIZ)

Arguments :

Subprogram:

Program Logic:

Language:

Mnemonic

Type Description

TM Logical*1 Page-type template segment.

TMPTR Integer*2 Index for TM.

PAG Logical*1 Formatted page.

PAGPTR Integer*2 Index to PAG.

DATA Logical*1 Receives the converted data.

TYPE Logica1*1 A two-byte field defining the type (first byte) and length (second byte) of the converted data.

PAGSIZ Integer*2 Defines the limit of PAG.

INVER

TM is examined until a data field location in PAG is determined or PAG is exhausted. The first data field encountered is converted; the next data field or index field or the end of the page results in a return to the calling routine.

FORTRAN IV

Author:

J. E. Suich 


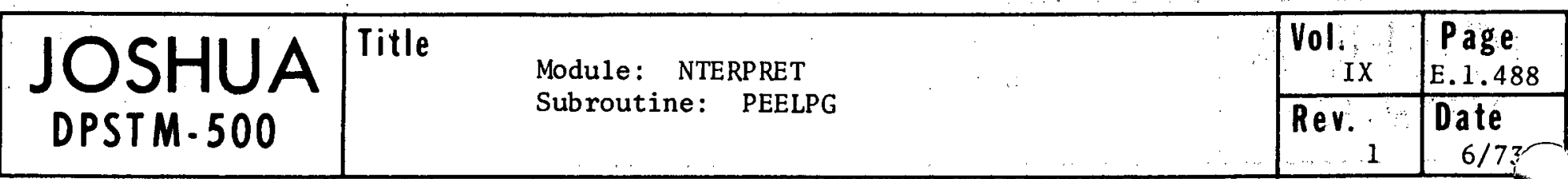

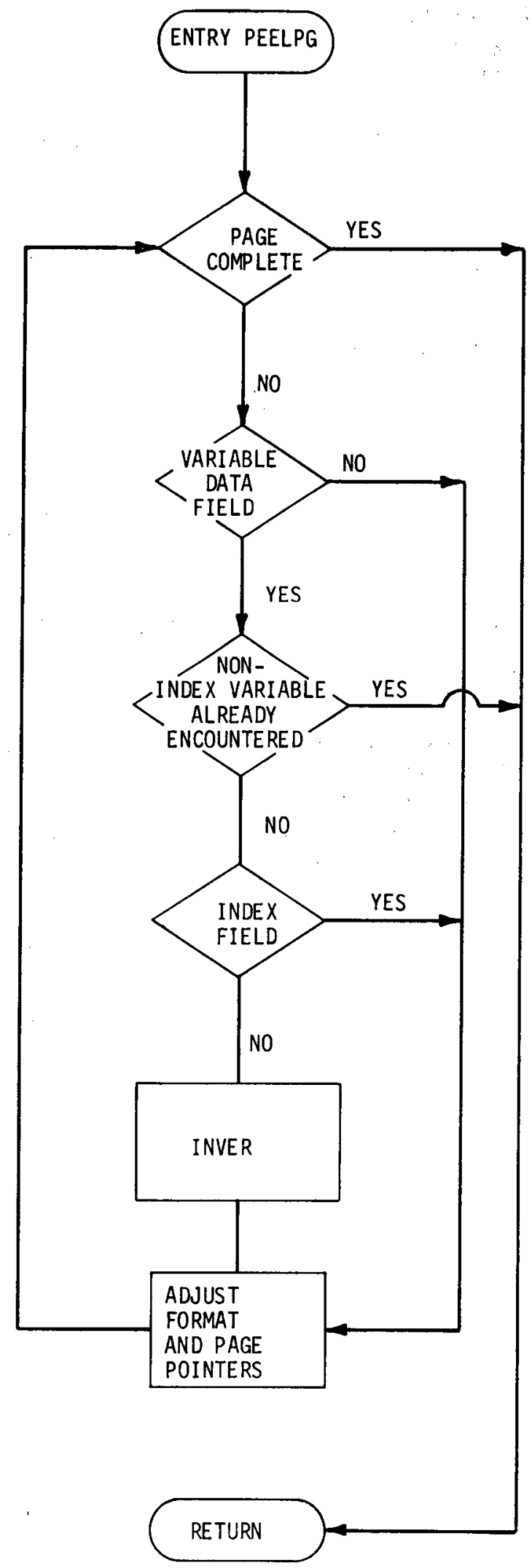




\begin{tabular}{|c|c|c|c|c|}
\hline \multirow{2}{*}{$\begin{array}{l}\text { JOSHUA } \\
\text { DPSTM.500 }\end{array}$} & \multirow{2}{*}{\multicolumn{2}{|c|}{ Title Module: PRECOP }} & Vol. & $\begin{array}{l}\text { Page } \\
\text { E.1.489 }\end{array}$ \\
\hline & & & $\operatorname{Rev} ._{1}$ & Dagte \\
\hline
\end{tabular}

Purpose: $\quad$ In the batch, to serve as an interface between a module requesting the copying of JOSHUA records and the system module COPY.

Attribute: Nonreusable

Entry: $\quad$ PRECOP

Arguments: $\quad$ General purpose register one should point to the following list of addresses.

1. Either the true CCB or the user's local CCB ( $\$ J C B)$.

2. A fullword containing the number of qualifiers in the input namestring.

3. A set of contiguous doublewords each containing a qualifier for the input namestring.

4. A fullword containing the number of qualifiers in the output namestring.

5. A set of contiguous doublewords each containing a qualifier for the output namestring.

Program Logic:

- The parameter address list to COPY is constructed.

- The designated number of doublewords of input and output record name qualifiers are transferred to WCBARG1 and WCBARG2, respectively. No more than fifteen qualifiers will be placed in either array; if more are specified, a four is placed in register 15 and execution terminated. The doublewords in WCBARG1 and WCBARG2 following the last qualifier in each is filled with hexadecimal $55^{\prime} \mathrm{s}$.

- The number of qualifiers in the input namestring is placed in WXTNTGR.

- IBCOM initialization is performed.

- A link to LIST is effected.

- Execution is terminated without clearing register 15.

Language: $\quad 0 / \mathrm{S} 360$ Assembler

Author:

R. C. Haywood

Remarks :

The following members are copied from JOS.COPYLIB:

SAVER
MCB
MCB \$CB
MCBWCB
WCBWXT




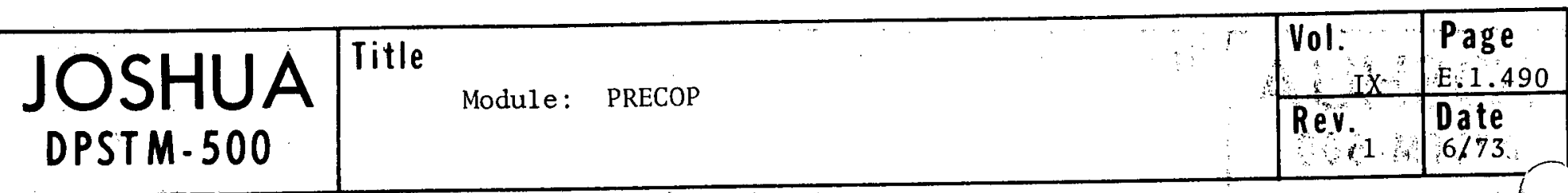

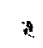

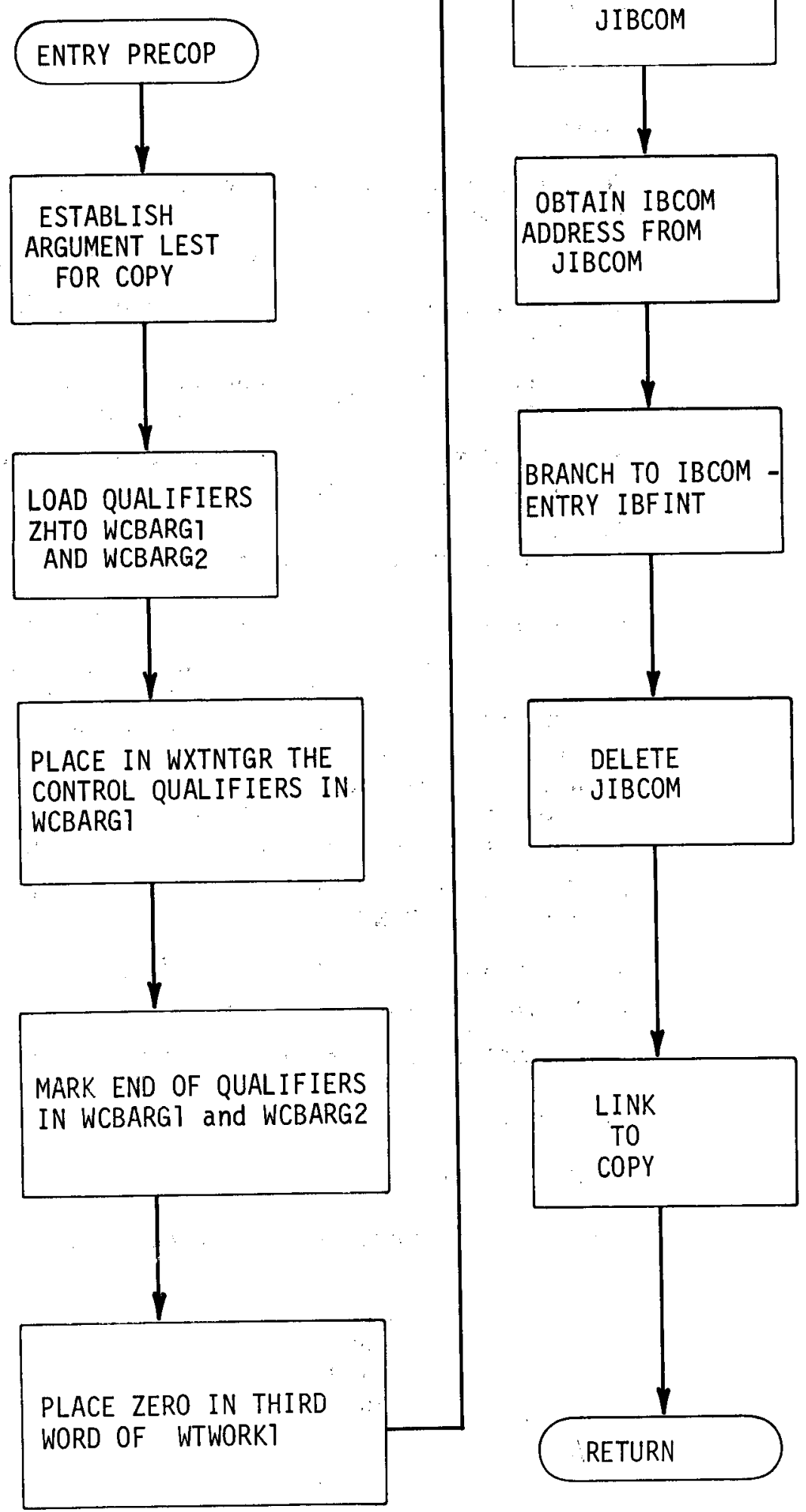




\begin{tabular}{|c|c|c|c|c|}
\hline & Title & Module: PROC & Vol. & $\begin{array}{l}\text { Page } \\
\text { E.1.491 }\end{array}$ \\
\hline DPSTM. 500 & & & $\begin{array}{r}\text { Rev. } \\
\end{array}$ & $\begin{array}{r}\text { Date } \\
6 / 73 \\
\end{array}$ \\
\hline
\end{tabular}

Purpose:

Attribute :

JOS Main Program:

Arguments :

Subprograms:
In the EP function, to control the sequence of operations as define in a procedure record.

Nonreusable

MAIN

\begin{tabular}{lll} 
Mnemonic & \multicolumn{1}{c}{ Type } & \multicolumn{1}{c}{ Description } \\
CCB & Real*8 & $\begin{array}{l}\text { CCB. } \\
\text { NAME1 }\end{array}$ \\
Real*8 & $\begin{array}{l}\text { WCBARGS1 - The data for the first } \\
\text { name line of the function frame } \\
\text { is returned. } \\
\text { NCBARGS2 - The data for the second } \\
\text { name line of the function frame } \\
\text { is returned. }\end{array}$ \\
PROCNM & Real*8 & $\begin{array}{l}\text { WXTPNAME - defines the variable } \\
\text { qualifiers for the procedure } \\
\text { record SYSTEM.PROC.? }\end{array}$ \\
FUNCTN & Real*8 & $\begin{array}{l}\text { WCBFNM - the function to be } \\
\text { executed, as defined by the pro- } \\
\text { cedure record, is returned. }\end{array}$ \\
FLAG & Integer*4 & $\begin{array}{l}\text { WXTPFLAG - a zero return indicates } \\
\text { procedure has been completed; a } \\
\text { two indicates it is incomplete. }\end{array}$ \\
PSTPNO & Integer*4 & $\begin{array}{l}\text { WXTPSTEP - Initially zero, it is } \\
\text { set to indicate the latest pro- } \\
\text { cedure step. }\end{array}$
\end{tabular}

Entry Points

\$TERR

IPUT, JPUT

JSREAD

BNAM, JTREE

MOVEIT

SHIFTB

SHIFTN

XLOC

ZCOMP

Data Sets:

JOSHUA date file specified for procedure record

JOSHUA standard data file 'SAVEDATA' for the record SAVEDATA. \$BADGE 


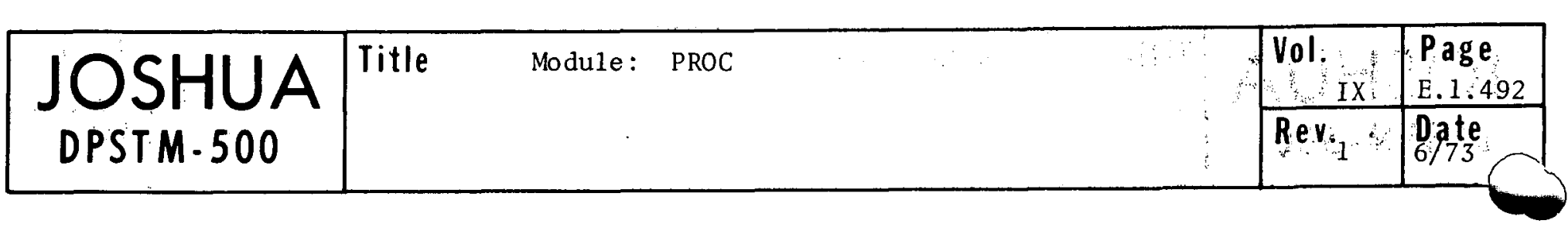

Program Logic:

- The procedure record is read. If any control values are out of range, \$TERR is called.

- '? \$JOB' is established as a variable name in addition to any defined by the procedure record.

- On the first step, the actual job name is placed as an additional value to be used for each of the nine possible iterations of a loop.

- On all but the first step, a set of saved control values is read.

- If the data indicates all steps have been executed, FLAG is set to zero, the values for the function frame initialized, and execution terminated.

- If the step to be executed is the first step of a loop, a record defined in some procedure step is read to acquire the repeat factor which will be compared to the iteration count before commencing with any iteration of the loop. The repeat factor may not exceed nine.

o. When in a loop and the previous step was a two name function and this step is not a repeat of step one, any variable values from NAMEl are used to update the list of established variable values.

- Values to replace the variable qualifiers in the current name, which is initially set up as NAME2, are obtained from the specified record. A the same time, NAMEl is being established with fixed qualifiers the same as NAME2, but with the variable values coming from the list of already established values. The blanks are packed out of NAMEI and NAME2 and the vectors padded with periods. When the function to be executed is a one-name function NAME1 is replaced by NAME2 and NAME2 filied with periods.

- FUNCTN is set as defined and an indicator set to indicate for next time whether the function is a one- or two-name function. If the FUNCTN is SK execution continues immediately with the next step.

- The set of control variables necessary for the succeeding execution is written.

- FLAG is set to two and execution terminated.

Terminating Conditions:

1. BNAM errors.

2. Any conditions which would cause an overflow of an array.

Language:

FORTRAN IV

Author:

J. C. Jensen 


\begin{tabular}{|c|l|l|l|l|}
\hline J OSHUA & Title Module: PROC & Vol. & Page \\
IX & E.1.493 \\
\cline { 3 - 5 } & & Rev. & $\begin{array}{c}\text { Date } \\
6 / 73\end{array}$ \\
\hline
\end{tabular}

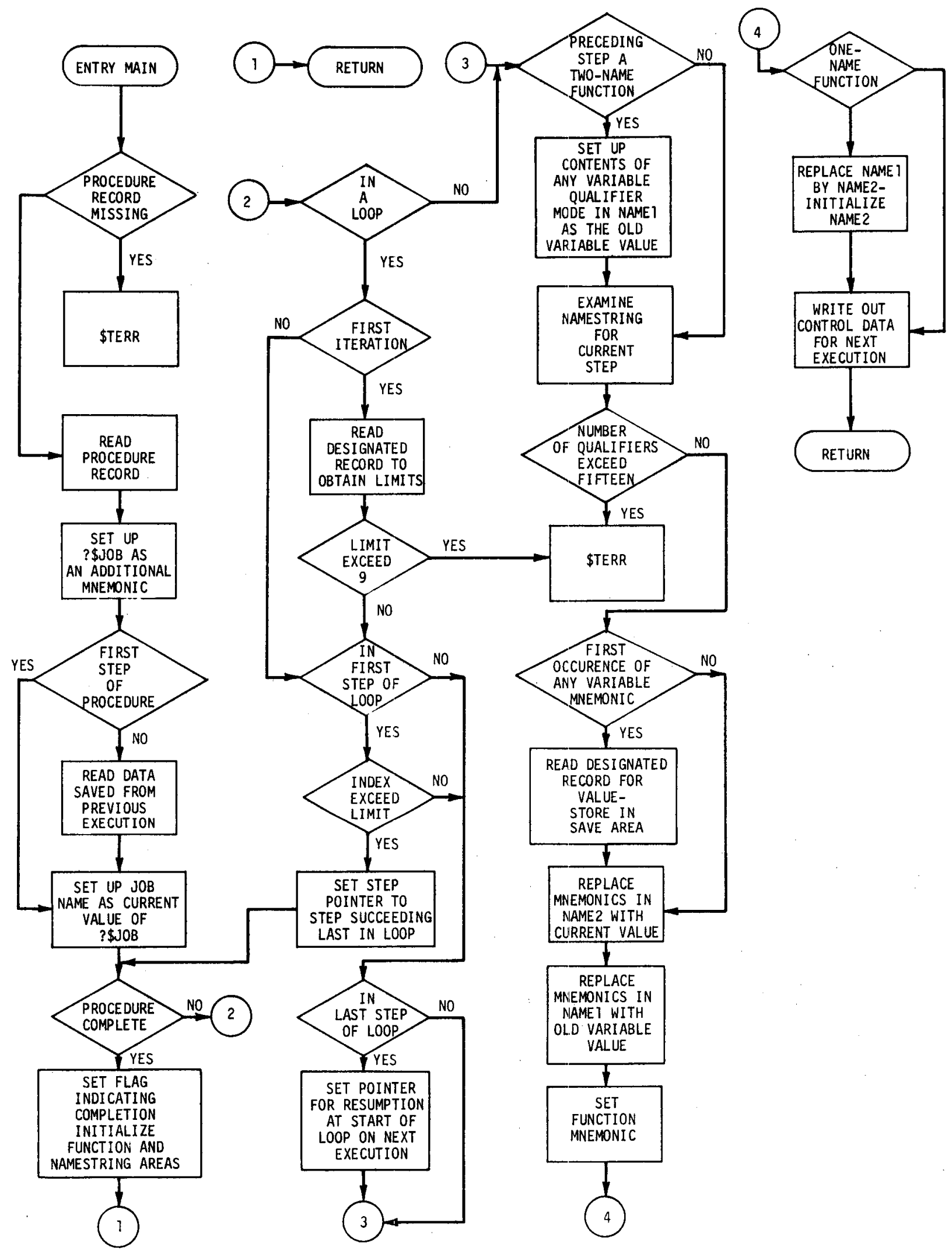




\begin{tabular}{|c|c|c|c|}
\hline & Title Madule: PROC & Vol. & $\begin{array}{l}\text { Page } \\
\text { E.1.494 }\end{array}$ \\
\hline DPSTM. 500 & & Rev. & $\begin{array}{l}\text { Date } \\
6 / 73\end{array}$ \\
\hline
\end{tabular}

(Blank) 


\begin{tabular}{|c|l|l|l|l|}
\hline JOSHUA & Title Module: RENAME & Vol. & Page \\
IX & E.1.495 \\
& & $\begin{array}{l}\text { Rev. } \\
1\end{array}$ & $\begin{array}{c}\text { Date } \\
6 / 73\end{array}$ \\
\hline
\end{tabular}

Purpose: $\quad$ To change a qualifier in a namestring.

Attribute: $\quad$ Nonreusable

JOS Main Program: MAIN

Arguments:

\begin{tabular}{lll} 
Mnemonic & \multicolumn{1}{c}{ Type } & \multicolumn{1}{c}{ Description } \\
CCB & $\begin{array}{l}\text { Real*8 } \\
\text { Real*8 }\end{array}$ & $\begin{array}{l}\text { CCB. } \\
\text { WCBARG1 - the fully or partially } \\
\text { qualified name the last qualifier } \\
\text { of which is to be replaced. }\end{array}$ \\
SX & $\begin{array}{l}\text { Real*8 } \\
\text { NSENARG2 - the new qualifier. }\end{array}$ & $\begin{array}{l}\text { WXTNTGR - the number of qualifiers } \\
\text { in S. }\end{array}$
\end{tabular}

Subprograms:

$\begin{array}{ll}\text { Control Section } & \text { Entry Point } \\ \begin{array}{l}\text { \$TERR } \\ \text { LINK }\end{array} & \text { BNERR } \\ \text { BNAM }\end{array}$

Program Logic:

- The namestring $S$ is examined for the presence of the qualifier $\langle\langle\mathrm{D}\rangle|$ any of which are replaced by the 'deleted' indicator, hexadecimal 55's.

- The qualifier in SX is added to the end of $S$.

- A rename (functional request 10) is issued to BNAM using the modified S.

- A close (functional request 4) is issued to BNAM.

Terminating Conditions:

Language:

Absence of at least one qualifier each in either $S$ or SX or the occurrence of a BNAM error results in a call to \$TERR.

Author:

FORTRAN IV

J. C. Jensen 


\begin{tabular}{|c|c|c|c|c|}
\hline UA & Title & Module: RENAME & \begin{tabular}{|l|} 
Vol. \\
IX
\end{tabular} & $\begin{array}{l}\text { Page } \\
\text { E.1.496. }\end{array}$ \\
\hline & & & $n$ & 6,73 \\
\hline
\end{tabular}

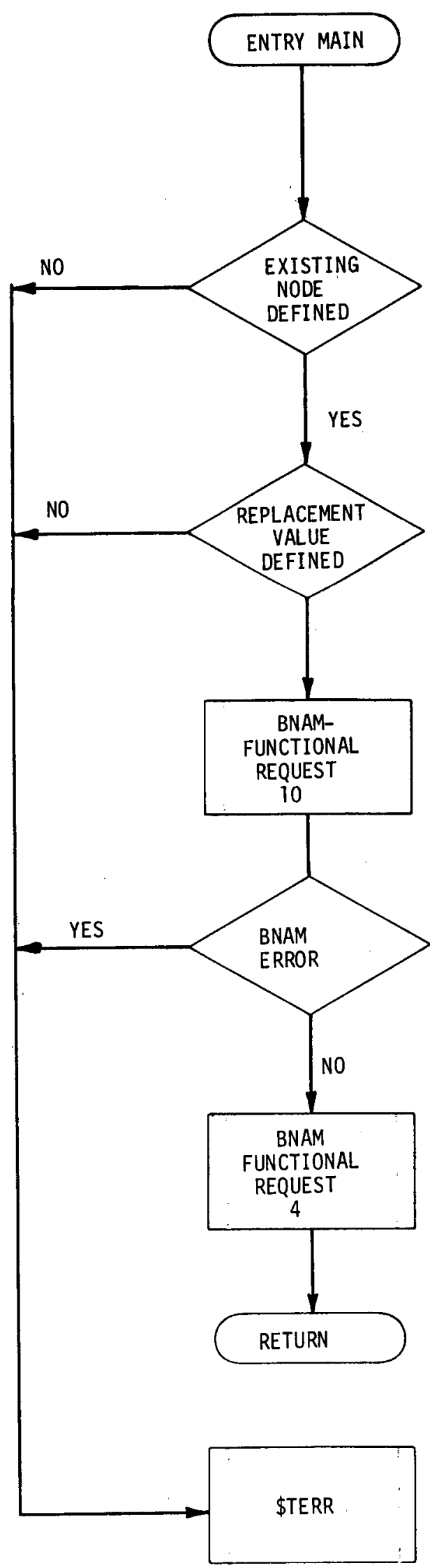




\begin{tabular}{|c|c|c|c|c|}
\hline & \multirow{2}{*}{\multicolumn{2}{|c|}{ Title Module: RMEND }} & Vol. & $\begin{array}{l}\text { Page } \\
\text { E.1.497 }\end{array}$ \\
\hline DPSTM-500 & & & Rev. & $\begin{array}{l}\text { Date } \\
6 / 73\end{array}$ \\
\hline
\end{tabular}

Purpose:

Attribute:

JOS Main Program:

Arguments:
To write the record REACTOR.?,?GEOMETRY.HEX.MESH.? with data as specified by the facemap.

Nonreusable

MAIN
Mnemonic

$\mathrm{A} 1$

A2

A4 Logical*1

A13

Integer*2
CCB.

Starting a WCBARG1, the contiguous area defined by WCBARG1 and WCBARG 2 . It is used for the communication of data as described in module RMSTART.

The area addressed by MCBBUFFG - the display buffer.
A13 is equated with the start of WXTWORK3. The actual area used is the contiguous block starting twenty-eight bytes before WXTWORK3 in WXTWORK2 and including all of WXTWORK3 and WXTWORK4. It is used to communicate the coded assembly symbols.

A15 Integer*4 MCBCFCT

Subprograms:

\begin{tabular}{ll} 
Control Section & Entry Point \\
\cline { 3 - 3 } \$TERR & \$TERR \\
FMPACK & FMPACK \\
FMUNPK & FMUNPK \\
IPUT & IPUT, JPUT \\
LCDINT & \$CDINT \\
LINK & BNAM, JTREE \\
MOVEIT & MOVEIT \\
XLOC & XLOC \\
XYHEX & XYHEX
\end{tabular}

Program Logic:

The list of assembly symbols is scanned to determine all assembly symbols 1isted. Each symbol listed is given an index corresponding to its position in the menu. All symbols not listed in the menu are given an index of zero.

From the reactor type, the number of patches and the radius of the tank are determined. 


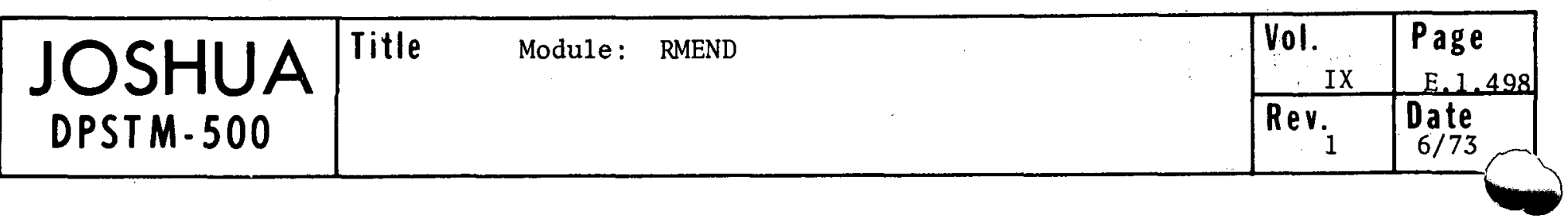

A sweep is made, patch by patch, over all hexes in the reactor. The X-Y coordinates of the hex are obtained and checks are made to determine if the hex is inside the reactor boundary. Hexes inside the reactor are given the appropriate packed assembly symbol. Hexes outside the reactor are given either the symbol of the moderator or the symbol of the reflector, depending on whether or not they are inside or outside the reactor tank.

If, during the sweep, a hex is found with the symbol "?" or with a symbol not in the menu, the CRT buffer is set up for another display to correct the error. The window portion is set to display the patch containing the error, other options (END and symmetry) are reset to their initial value, thirty-two subtracted from A15, and a return issued.

If no errors are found the geometry record is written. A call to BNAM locates a position in the user data set for the record. The reactor type, the symmetry option, and the number of points are transferred to the buffer. Then a sweep is made, in GAUGE patch/hex order, over all the hexes in the reactor. For each point the $X$ and $Y$ coordinates are determined. If the point does not fall within the sectors specified by the symmetry option, it is ignored. Otherwise, the assembly symbol is unpacked to its 2-byte form and 'MO' and 'RE' are supplied for moderator and reflector types. Then the X-coordinate, Y-coordinate, and assembly type are transferred to the buffer. The number of entries in the assembly symbol list and the menu itself are then transferred to the buffer. Whenever the buffer is full, the buffering routine writes it on the disk through JTREE. A final call to IPUT assures transfer of any partially filled buffer. A BNAM close is issued to update the tree pages.

Language:

FORTRAN IV

Author:

J. E. Suich 


\begin{tabular}{|l|l|l|l|l|}
\hline JOSHUA & Title Module: RMEND & Vol. IX & $\begin{array}{c}\text { Page } \\
\text { E. . }\end{array}$ \\
\cline { 3 - 4 } & & Rev. & $\begin{array}{c}\text { Date } \\
6 / 73\end{array}$ \\
\hline
\end{tabular}

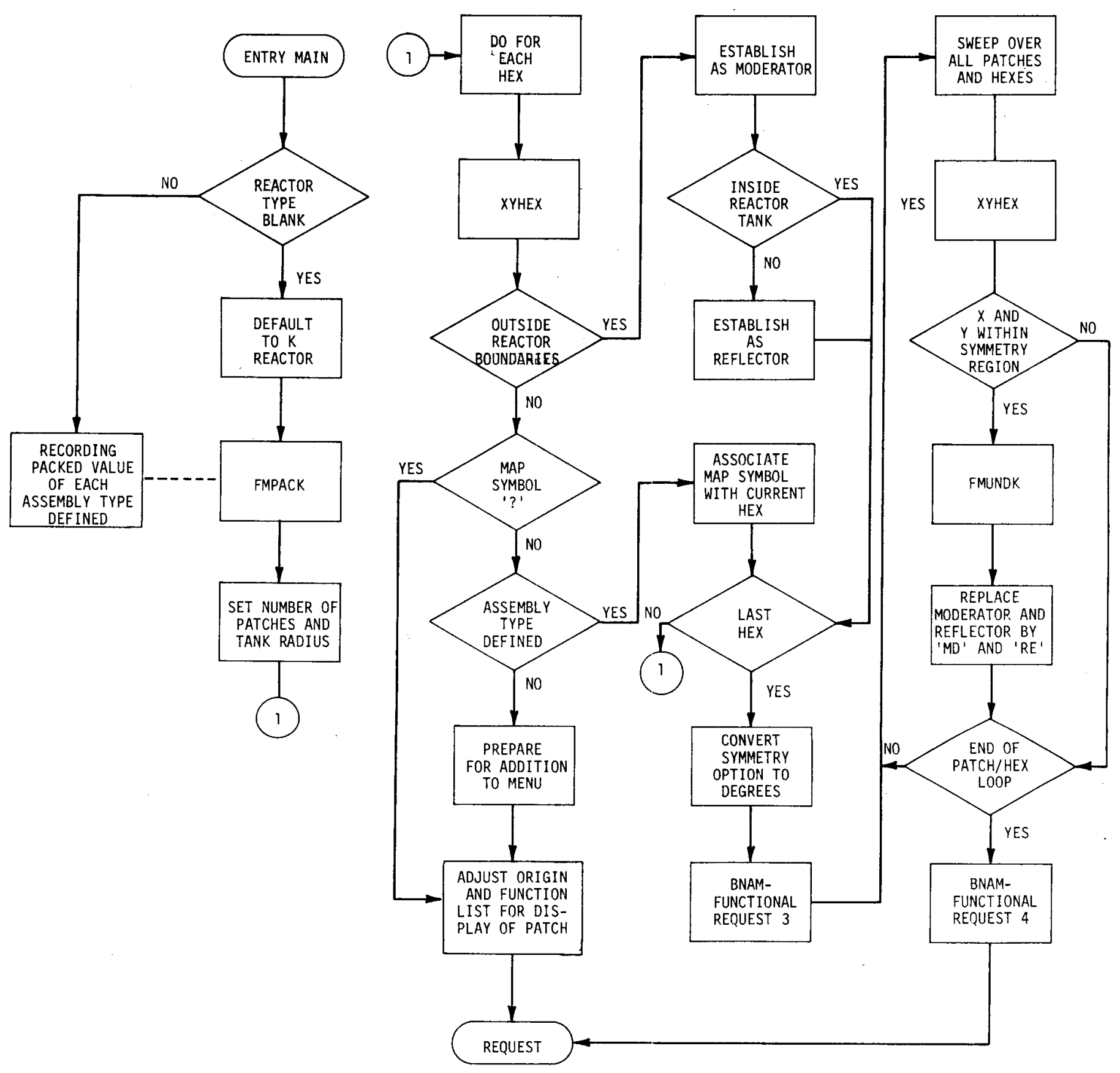




\begin{tabular}{|c|c|c|c|}
\hline 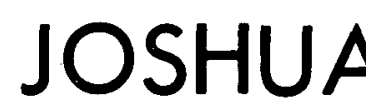 & Title Module: RMEND & $\begin{array}{l}\text { Vol. } \\
\text { IX }\end{array}$ & $\begin{array}{l}\text { Page } \\
\text { E.1.500 }\end{array}$ \\
\hline DPSTM. 500 & & Rev. & $\begin{array}{l}\text { Date } \\
6 / 73\end{array}$ \\
\hline
\end{tabular}

(Blank) 


\begin{tabular}{|c|c|c|c|c|}
\hline & \multirow{2}{*}{\multicolumn{2}{|c|}{ Title $\quad$ Module: RMSTART }} & Vol. & $\begin{array}{l}\text { Page } \\
\text { E.1.501 }\end{array}$ \\
\hline DPSTM -500 & & & $\operatorname{Rev}_{1}$ & Date \\
\hline
\end{tabular}

Purpose:

Attribute:

JOS Main Program:

Arguments:
In the RM function, to initialize the data arrays.

Nonreusable

MAIN

\begin{tabular}{lll} 
Mnemonic & \multicolumn{1}{c}{ Type } & \multicolumn{1}{c}{ Description } \\
Al & Real*8 & $\begin{array}{l}\text { CCB } \\
\text { A2 }\end{array}$ \\
Real*8 & $\begin{array}{l}\text { WCBARG1 - contains on input the } \\
\text { name of the input geometry record. }\end{array}$ \\
A3 & Rea1*8 & $\begin{array}{l}\text { WCBARG2 - may contain the name of } \\
\text { the output geometry record. }\end{array}$
\end{tabular}

A2 is also considered as the total contiguous area defined by WCBARG 1 and WCBARG 2 and is used for communication between subfunctions of the following data:

Byte Data

1-8 First variable qualifier of the output record name.

9-16 Second variable qualifier of the output record name.

17-18 Reactor type.

19-20 X-coordinate of origin.

21-22 Y-coordinate of origin.

23-24 Window type.

25-26 Symmetry type.

27-28 Character to be replaced.

29-30 Substitute character.

31-32 Number of defined assembly symbols.

33-272 Area for up to forty assembly symbols divided into six halfword nodes each composed of a twobyte assembly symbol and a four-byte description.

273-280 Not used

281-288 Third variable qualifier of the output record name. 


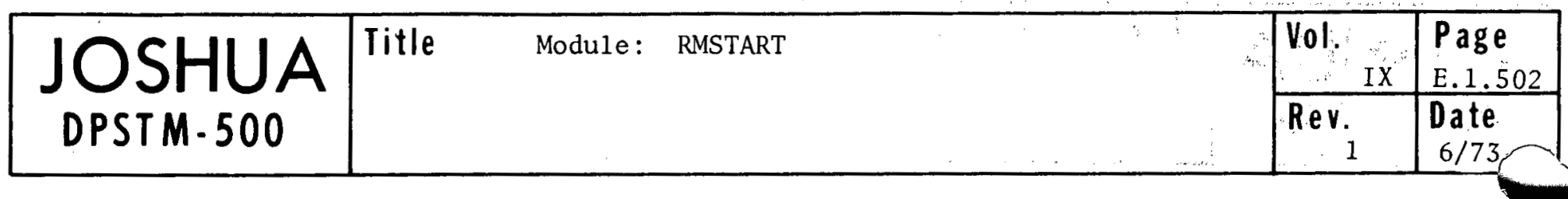

Subprograms:

$\begin{array}{ll}\text { Control Section } & \text { Entry Point } \\ \text { \$TERR } & \text { \$TERR } \\ \text { FMINIT } & \text { FMINIT } \\ \text { FMPACK } & \text { FMPACK } \\ \text { RMREAD* } & \text { RMREAD } \\ \text { HEXXY } & \text { HEXXY } \\ \text { LINK } & \text { BNAM, JTREE } \\ \text { MOVEIT } & \text { MOVEIT } \\ \text { XYHEX } & \text { XYHEX }\end{array}$

Program Logic:

- The input record is assured of being of the form REACTOR.?.?.GEOMETRY.HEX.MESH.? with or without a preceding data set designation.

- When an output record is specified, it is checked for proper form; when it is not, the name of the input record is assumed for output also. The variable qualifiers of the output record name are saved in the designated locations in A2.

- The default specifications for the display are established in $\mathrm{A} 2$ and $\mathrm{A} 13$; $\mathrm{A} 4$ is blanked.

- A BNAM read is issued to attempt to locate the input record. When successful, RMREAD is called to replace the default specifications in accordance with the data in the input record. When the record does not exist and a specific data set was designated as the source of the record, \$TERR is called.

Terminating Conditions:

- Invalid record name.

- Failure to locate a record in an explicitly designated data set.

Language: $\quad$ FORTRAN IV

Author:

R. C. Haywood - J. E. Suich 


\begin{tabular}{|c|c|c|c|}
\hline & \multirow[t]{2}{*}{ Title Yodule: RMSTART } & ${ }^{\text {Vol. }}$ & $\begin{array}{l}\text { Page } \\
\text { E.1.503 }\end{array}$ \\
\hline DPSTM. 500 & & $\begin{array}{r}\text { Rer. } \\
1\end{array}$ & $\begin{array}{r}\text { Date } \\
6 /-3 \\
\end{array}$ \\
\hline
\end{tabular}

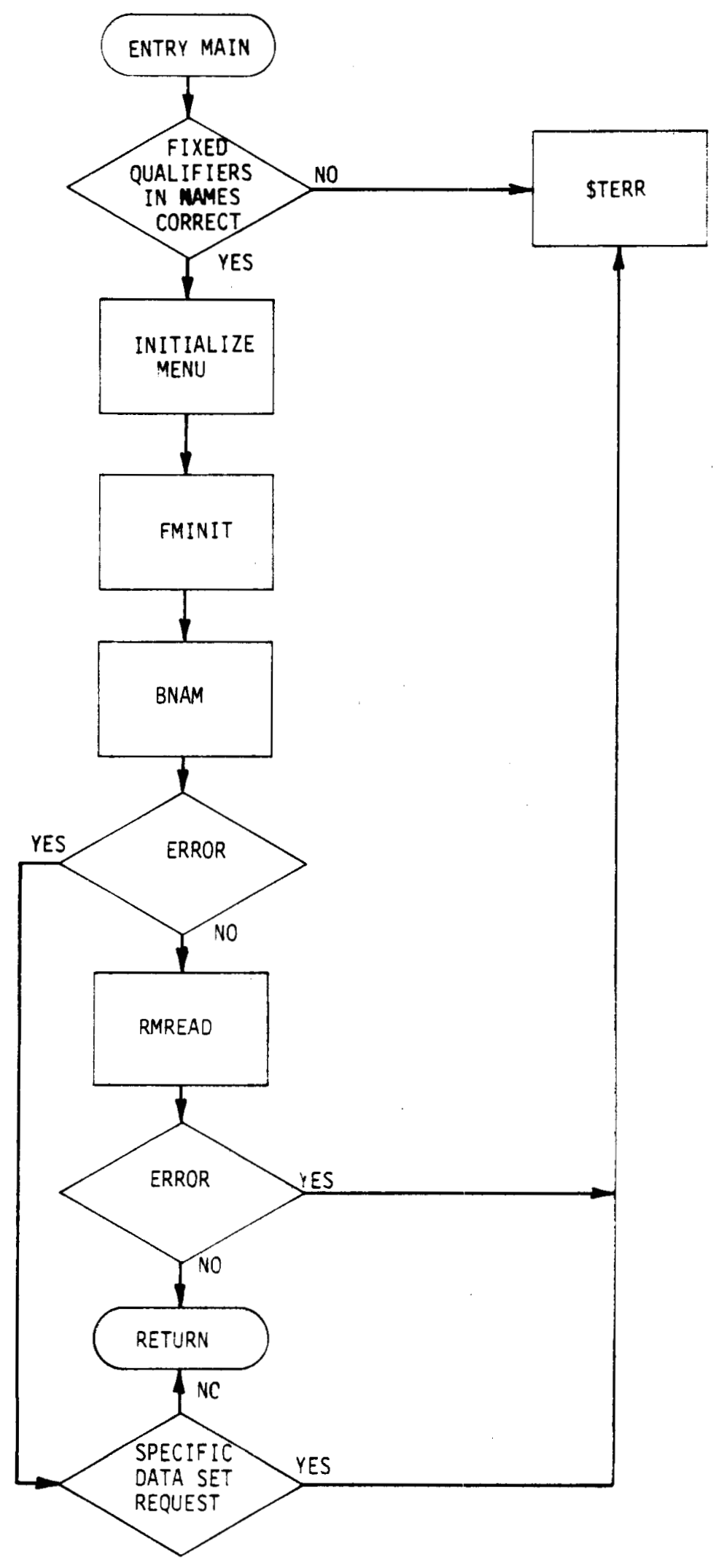




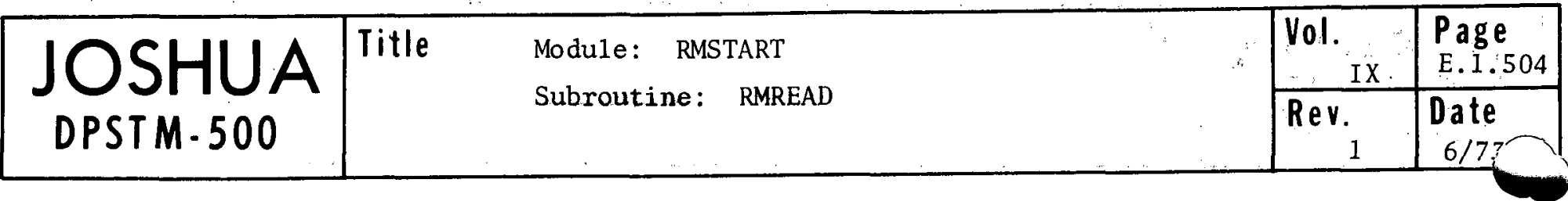

Purpose:

Usage:

Arguments:

Subprograms:

\begin{tabular}{|c|c|c|}
\hline Mnemonic & Type & Description \\
\hline JDS & Integer*4 & $\begin{array}{l}\text { The reference number (FT number) } \\
\text { of the data set on which the } \\
\text { specified geometry record resides. }\end{array}$ \\
\hline JREC & Integer*4 & $\begin{array}{l}\text { The relative record number on the } \\
\text { data set at which the specified } \\
\text { geometry record begins. }\end{array}$ \\
\hline TYPE & Integer $* 2$ & Returns the reactor type. \\
\hline MAP & $\operatorname{Logica} 1 * 1$ & $\begin{array}{l}\text { Array of twenty-eight rows and } \\
\text { thirty-one columns to be loaded } \\
\text { with coded assembly symbols. }\end{array}$ \\
\hline MENU & Integer $* 2$ & $\begin{array}{l}\text { Array to be loaded with up to } \\
\text { forty six-byte nodes each con- } \\
\text { sisting of a two-byte assembly } \\
\text { symbol and a four-byte mnemonic. }\end{array}$ \\
\hline NMEN & Integer $* 2$ & $\begin{array}{l}\text { The number of defined nodes in } \\
\text { MENU. }\end{array}$ \\
\hline
\end{tabular}

To read the geometry record and establish the facemap $(X, Y)$ coordinates.

CALL RMEAD (JDS, JREC, TYPE, MAP, MENU, NMEN) 


\begin{tabular}{|c|c|c|c|}
\hline & \multirow{2}{*}{$\begin{array}{ll}\text { Title } & \text { Module: RMSTART } \\
& \text { Subrount ine: RMREAD }\end{array}$} & Vol. IX & $\begin{array}{l}\text { Page } \\
\text { E.1.505 }\end{array}$ \\
\hline DPSTM. 500 & & $\operatorname{Rer}_{1}$ & Dates \\
\hline
\end{tabular}

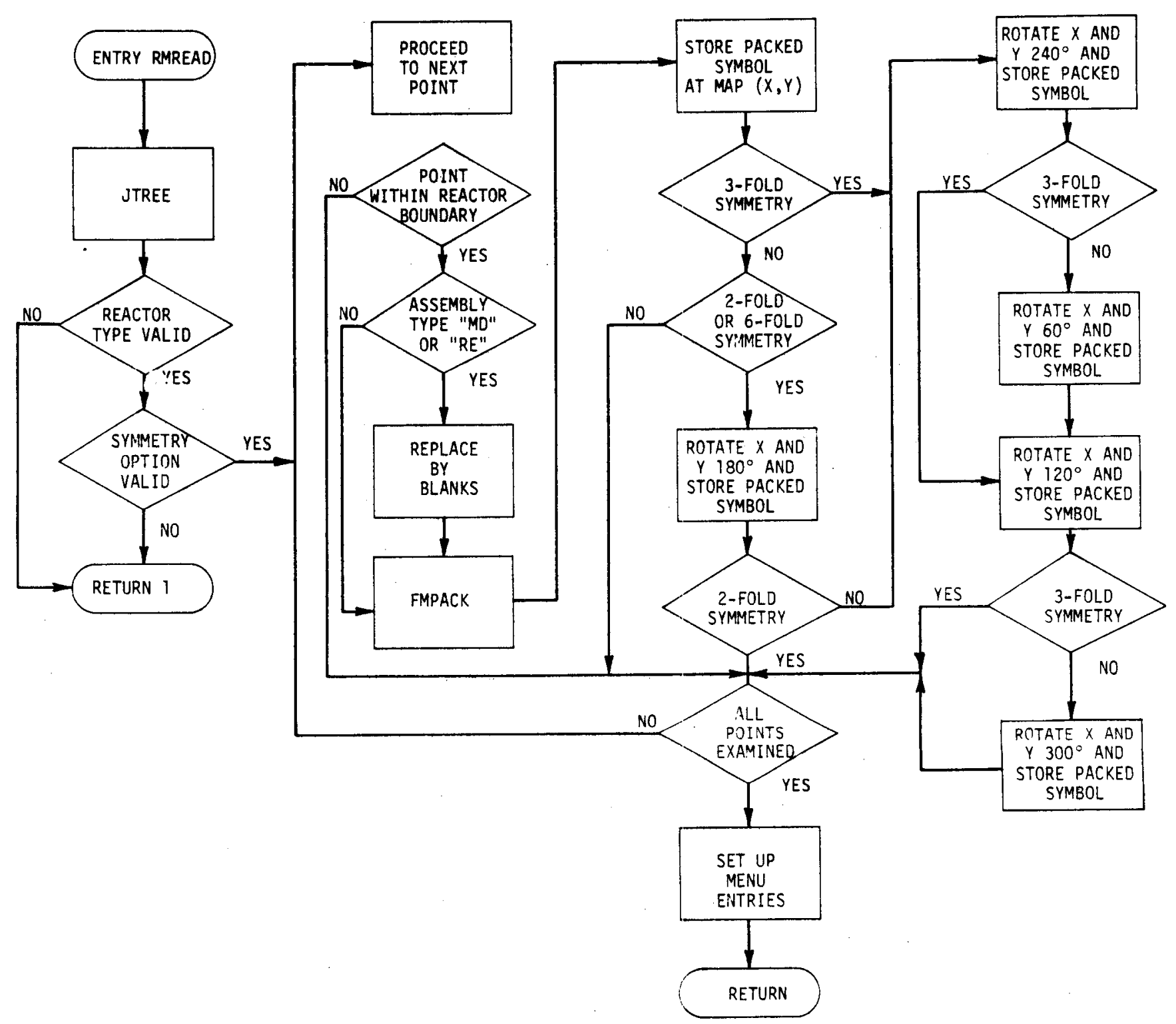




\begin{tabular}{|c|cc|c|c|}
\hline JOSHUA & Title & Vol. & Page \\
DPSTM-500 & $\begin{array}{l}\text { Module: RMSTART } \\
\text { Subroutine: RMREAD }\end{array}$ & IX.1.506 \\
\cline { 3 - 5 } & & Rev. & Date \\
\hline
\end{tabular}

(Blank) 


\begin{tabular}{|c|c|c|c|c|}
\hline & \multirow{2}{*}{\multicolumn{2}{|c|}{ Title Module: SETJOB }} & $\begin{array}{l}\text { Vol. } \\
\text { IX }\end{array}$ & \begin{tabular}{|l|} 
Page \\
I:.1.507 \\
\end{tabular} \\
\hline DPSTM.500 & & & $\begin{array}{r}\text { Rev. } \\
1\end{array}$ & $\begin{array}{l}\text { Date } \\
6 / 73\end{array}$ \\
\hline
\end{tabular}

Purpose:

Attribute:

JOS Main Program:

Arguments:

Subprograms:

\begin{tabular}{lll} 
Mnemonic & Type & \multicolumn{1}{c}{ Description } \\
CCB & Real*8 & $\begin{array}{l}\text { Communication Control Block. } \\
\text { S }\end{array}$ \\
Real*8 & $\begin{array}{l}\text { WCBARG1 - The first doubleword } \\
\text { specifies the requested job name. }\end{array}$ \\
TBUF & Real*8 & $\begin{array}{l}\text { Area pointed to by MCBBUFFG - results } \\
\text { of a successful execution returned } \\
\text { here. }\end{array}$
\end{tabular}

To set a requested jobname, if properly formed, into the CCB thus establishing the active job, and, if the job data set already exits, to assure the proper catalog is in corc.

Nonreusab le

SETJOB

\begin{tabular}{ll} 
Control Section & Entry Point \\
\hline \$TERR & \$TERR \\
LINK & BNAM, WPAGE \\
MOVEIT & MOVEIT
\end{tabular}

Data Sets:

Communication data set (CDS) - thru WPAGE.

Program Logic:

- The jobname is checked for valid form (i.e. AXXXNNNN where $A$ is an alphabetic character, $X$ an alphabetic or numeric character, and $\mathrm{N}$ a numeric character) and $\$$ TERR called to terminate the function if the test is failed.

- The jobname is placed in CCB.

- Functional request seven is made to BNAM using A2.

- A message reflecting the status of the job data set is placed in TBUF. In the batch, WPAGE is called to write TBUF to the CDS.

Terminating Conditions: Invalid job name.

Language :

FORTRAN IV

Author:

R. C. Haywood 


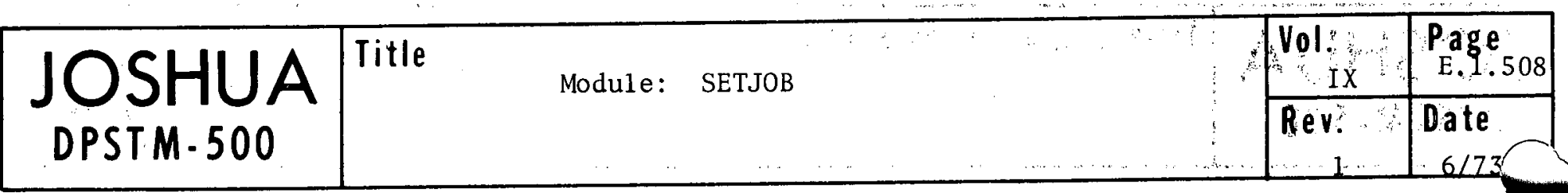

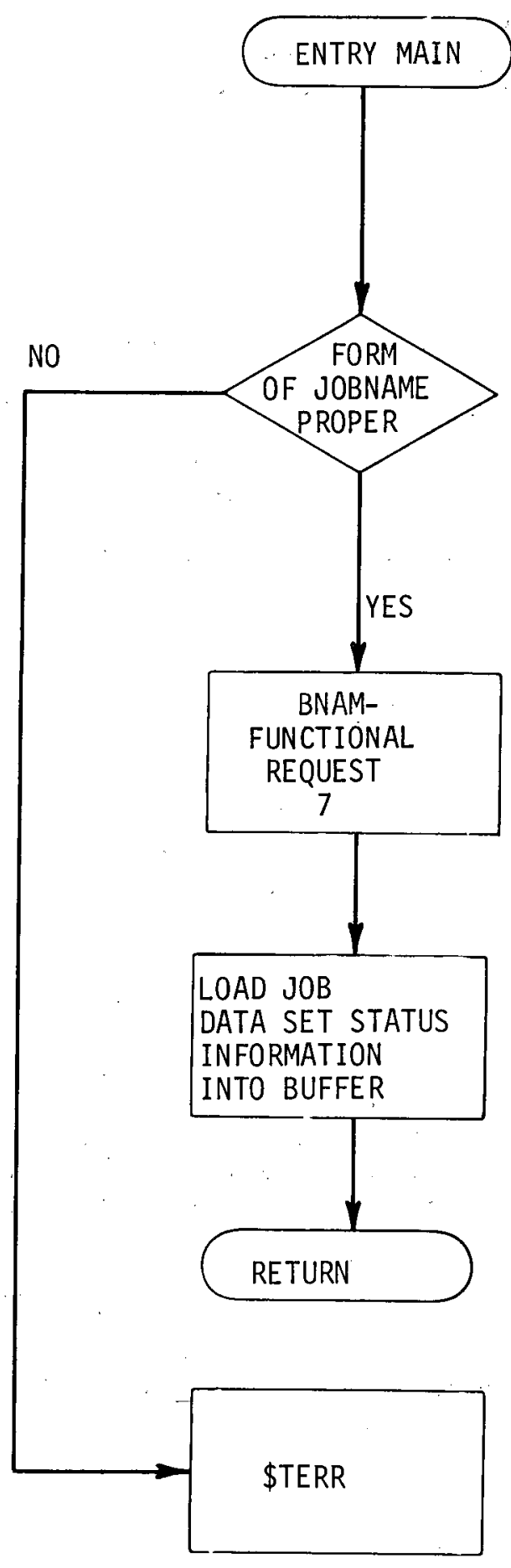




\begin{tabular}{|l|l|l|l|l|}
\hline JOSHUA & Title Module: SUPSCRTH & $\begin{array}{l}\text { Vol. } \\
\text { Ix }\end{array}$ & $\begin{array}{l}\text { Page } \\
\text { E. } 1.509\end{array}$ \\
& & $\begin{aligned} \text { Rev. } \\
\text { Date } \\
6 / 73\end{aligned}$ \\
\hline
\end{tabular}

Purpose:

To scratch all scratch data sets not in use.

Attribute:

Nonreusable

JOS Main Program Name: SUPSCRTH

Arguments:

Parameter

CC:B

External References:

Data Sets:

Program Logic:

EQN Name:

Referenced By:

Language:

Author:

\section{$\underline{\text { Type }}$}

D
Description Communication Control Block

OPEN, READ, CHECK, CLOSE, ENQ, DEQ, LINK, SCRATCH

Catalog Data Set

The address of the CCB is received via the argument 1 ist. The JOSHUA data set name catalog is opened via the OPEN macro. Each record is read by issuing a READ macro and each name (98 names per record) in each record is checked to see if it is a scratch data set name (indicated by $* *$ as first two characters of name).. On encountering a scratch data set name an ENQ is issued to see if it is in use. If the ENQ is successful, the name is deqed on and a LINK to SCRATCH is issued to scratch the particular name. If the ENQ was unsuccessfu1, the next name is checked. After going through all records a CLOSE is issued on the data set and a return is issued.

JOSYSTEM (Scratch data set name)

JTSNOPEN

Assembler

W. H. Brotherton, Jr. 


\begin{tabular}{|c|c|c|}
\hline$\left.\right|_{\text {DPSTM }-500} ^{\text {JOSHA }}$ & Module: SUPSCRTH & 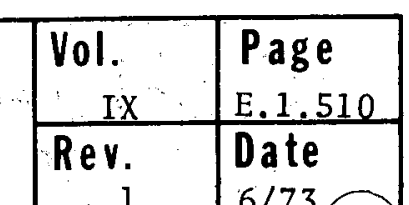 \\
\hline
\end{tabular}

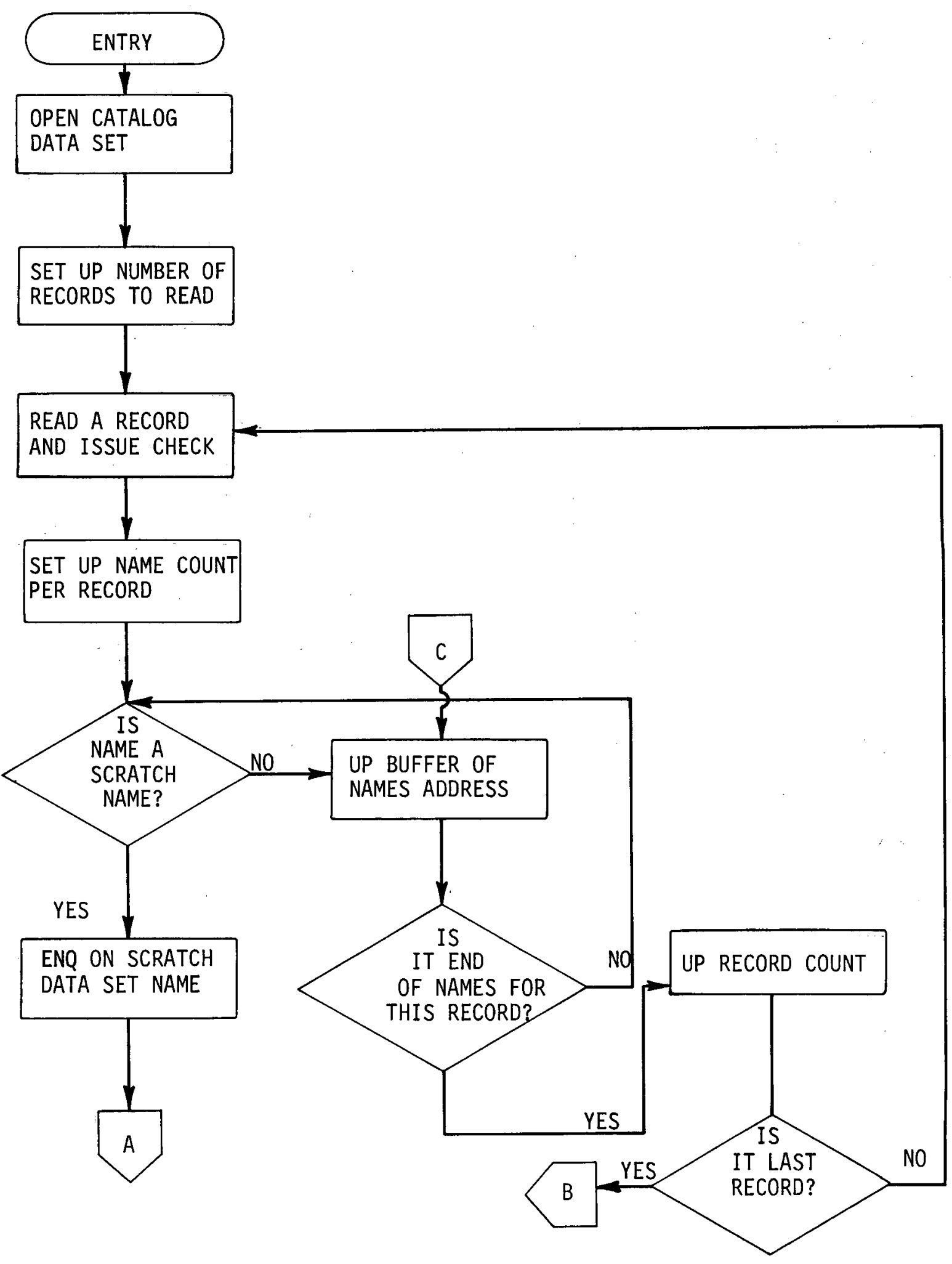




\begin{tabular}{|c|c|c|c|c|}
\hline & \multirow{2}{*}{\multicolumn{2}{|c|}{ Title Module: SUPSCRTH }} & ${ }_{\text {IX }}^{\text {Vol. }}$ & $\begin{array}{l}\text { Page } \\
\text { E.1.511 }\end{array}$ \\
\hline DPSTM. 500 & & & $\begin{array}{r}\text { Rev. } \\
1\end{array}$ & $\begin{array}{l}\text { Date } \\
6 / 73\end{array}$ \\
\hline
\end{tabular}

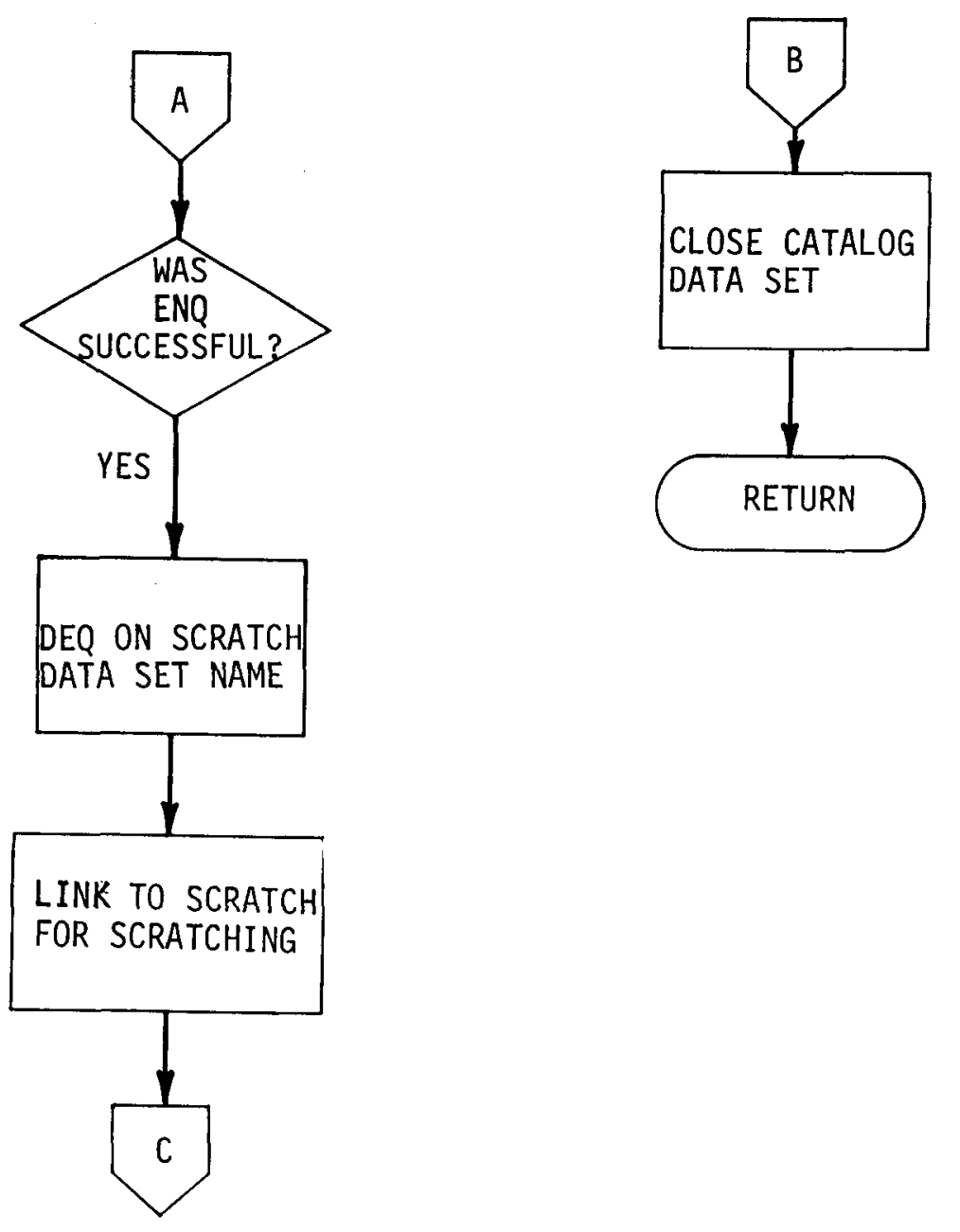




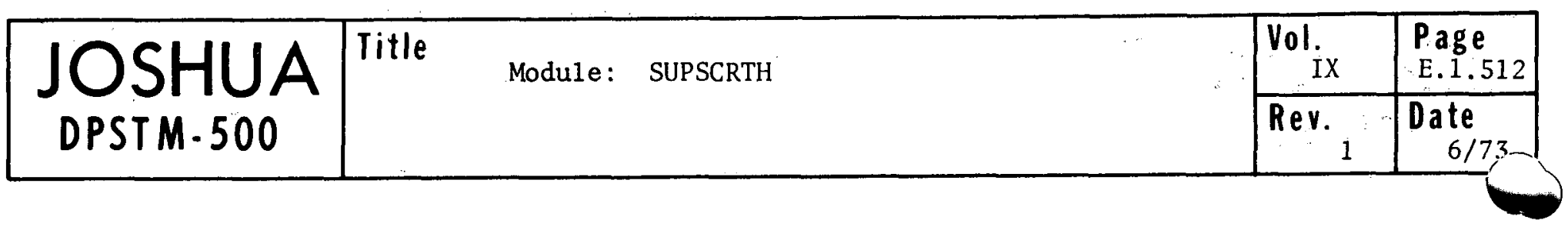

(B1ank) 


\begin{tabular}{|c|c|c|c|c|}
\hline & \multirow{2}{*}{\multicolumn{2}{|c|}{ Title $\quad$ Module: SYSMSG }} & Vol. & \begin{tabular}{|l} 
Page \\
E.1.513
\end{tabular} \\
\hline DPSTM. 500 & & & Rev. 1 & Date \\
\hline
\end{tabular}

Purpose: $\quad$ To format the record 'SYSTEM'.'USER'. 'MESSAGE' in the terminal buffer.

Attribute: Nonreusable

JOS Main Program: $\quad$ MAIN

Arguments:

\begin{tabular}{|c|c|c|}
\hline Mnemonic & Type & Description \\
\hline $\mathrm{CCB}$ & Real*8 & СCB. \\
\hline TBUF & Real * 8 & $\begin{array}{l}\text { Area addressed by MCBBUFFG - the } \\
\text { terminal buffer. }\end{array}$ \\
\hline
\end{tabular}

Subprograms:

\begin{tabular}{ll} 
Control Section & Entry Point \\
\hline LINK & BNAM, JTREE \\
MOVEIT & MOVEIT
\end{tabular}

Data Sets:

JOSHUA standard data set 'SYSTEM'

Program Logic:

Language:

- A read (functional request 2) is issued to BNAM to retrieve the record 'SYSTEM'. 'USER'. 'MESSAGE' from the data set 'SYSTEM'.

- When the record is located, two physical records are read using JTREE and the first six hundred forty bytes loaded into lines two thru eleven of A4.

Author:

FORTRAN IV

J. C. Jensen 


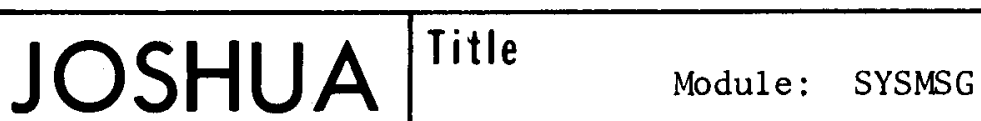

Vol.

IX

Rev.

1
TO LOCATE

SYSTEM. USER. MESSAGE

(FROM STANDARD)

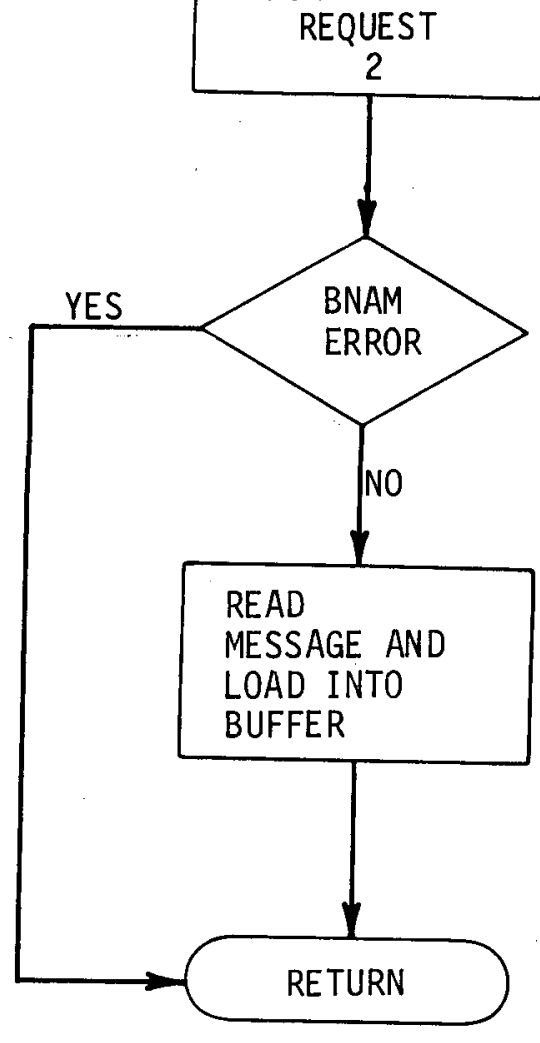




\begin{tabular}{|c|c|c|c|c|}
\hline $\mathrm{JO}$ & \multirow{2}{*}{\multicolumn{2}{|c|}{ Title Module: TDISPLAY }} & $\begin{array}{l}\text { Vol. } \\
\text { IX }\end{array}$ & $\begin{array}{l}\text { Page } \\
\text { E.1.515 }\end{array}$ \\
\hline DPSTM & & & Rev. & $\begin{array}{l}\text { Date } \\
6 / 73\end{array}$ \\
\hline
\end{tabular}

Purpose:

Attribute :

JOS Main Program:

Arguments :
To create a display of a template record.

Nonreusab1e

MAIN

\begin{tabular}{|c|c|c|}
\hline Mnemonic & Type & Description \\
\hline $\mathrm{A} 1$ & Rea $1 * 8$ & CCB. \\
\hline A2 & $\operatorname{Rea} 1 * 8$ & $\begin{array}{l}\text { WCBARG1 - specifies the template } \\
\text { record for which a display is } \\
\text { desired. }\end{array}$ \\
\hline A3 & Rea 1 * 8 & $\begin{array}{l}\text { WCBARG } 2 \text { - specifies an output } \\
\text { record name. When no qualifiers } \\
\text { are present on input, the qualifiers } \\
\text { in the input record, following } \\
\text { the qualifier 'TEMPLATE' are loaded } \\
\text { into this area. }\end{array}$ \\
\hline A4 & $\operatorname{Rea} 1 * 8$ & $\begin{array}{l}\text { Area pointed to by MCBBUFFG. Used } \\
\text { as CDS buffer as well as the terminal } \\
\text { buffer. }\end{array}$ \\
\hline A5 & Integer*2 & WCBFNM - specifies current function. \\
\hline A7 & Integer*4 & $\begin{array}{l}\text { WXTDSRF6 - provides the factor for } \\
\text { determining a starting record on } \\
\text { FT77FOO1. }\end{array}$ \\
\hline A8 & Integer*4 & $\begin{array}{l}\text { WXTNTGR - number of qualifiers in } \\
\text { A2. }\end{array}$ \\
\hline A13 & Integer $* 2$ & $\begin{array}{l}\text { WXTWORK3. Al3(136) returns the } \\
\text { calculated starting record number } \\
\text { for FT77F001. When in the 'MT' } \\
\text { function, the following initializa- } \\
\text { tions are made: }\end{array}$ \\
\hline
\end{tabular}

$$
\begin{aligned}
& \operatorname{Al} 3(134)=0 \\
& \operatorname{A13}(125)=64 \\
& \operatorname{Al}(126)=10
\end{aligned}
$$

Subprograms:
Entry Points

\$TERR

CRPAGE

CTYPE

FLDP IX

\$CDINT

BNAM, JTREE, WPAGE

MOVEIT

CHAR, RHAR

SHIFTB

XLIST

ZCOMP 


\begin{tabular}{|c|c|c|c|c|}
\hline & \multirow{2}{*}{\multicolumn{2}{|c|}{ Title Module: TDISPLAY }} & $V_{\text {IX }}$ & $\begin{array}{l}\text { Page } \\
\text { E.1.516 }\end{array}$ \\
\hline DPSTM -500 & & & Rev. & $\begin{array}{l}\text { Date } \\
6 / 73\end{array}$ \\
\hline
\end{tabular}

Data Sets:

JOSHUA Data File

Communication Data Set (CDS)

FT77FOO1

Program Logic:

- The contents of A2 are copied to a local area where the qualifier 'TEMPLATE' is prefixed to the value before issuing a BNAM read (functional request 2).

- If A3 does not specify an output record name, the name of the record read, less the qualifiers thru the first occurrence of 'TEMPLATE', are loaded into A3.

- Each nest is associated with a page type. For each page type, the total portion of the template associated with the page type is read into core and the format data passed to CRPAGE for creation of a displayable image. Each page is written to FT77F001.

- Except when in a $C D$ function, the list page is recreated first by passing the I/O list from the template to XLIST to be analyzed and then, as each page type is developed, the variable typings for each page type are passed to CTYPE where those mnemonics whose typings do not match FORTRAN default typing are singled out and loaded into A4 along with their explicit type information. When complete, the list page is written to the CDS.

- The records on FT77FOO1 are copied to the CDS.

- In the MT function, in addition to certain initializations, the list display is left in the buffer with cursor placement at the bottom of the page.

Terminating Conditions:

Comments:

Language:

Author:
- Failure to locate the template record results in termination through \$TERR.

- Various checks are made of known template limits in order to recognize invalid template records. Failure to meet these tests results in termination through \$TERR.

- Insufficient space to contain all that portion of a template pertaining to any nest - through \$TERR.

In the case of a CD function, the standard practice of establishing the root qualifier of $A 2$ as a data set override when the initial BNAM call fails is suspended. In such a case, termination will result though a call to \$TERR.

FORTRAN IV

R. C. Haywood - J. E. Suich 


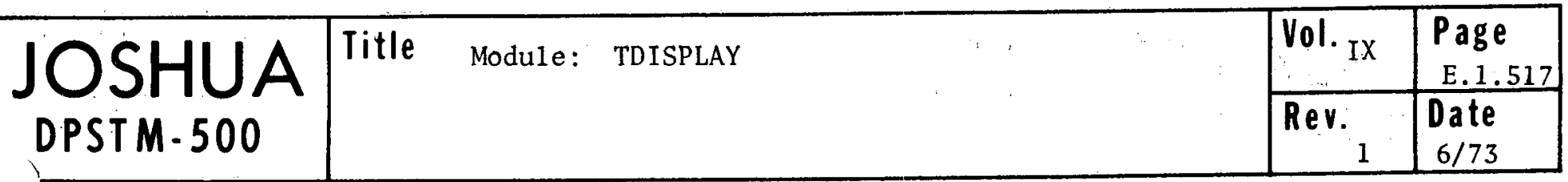

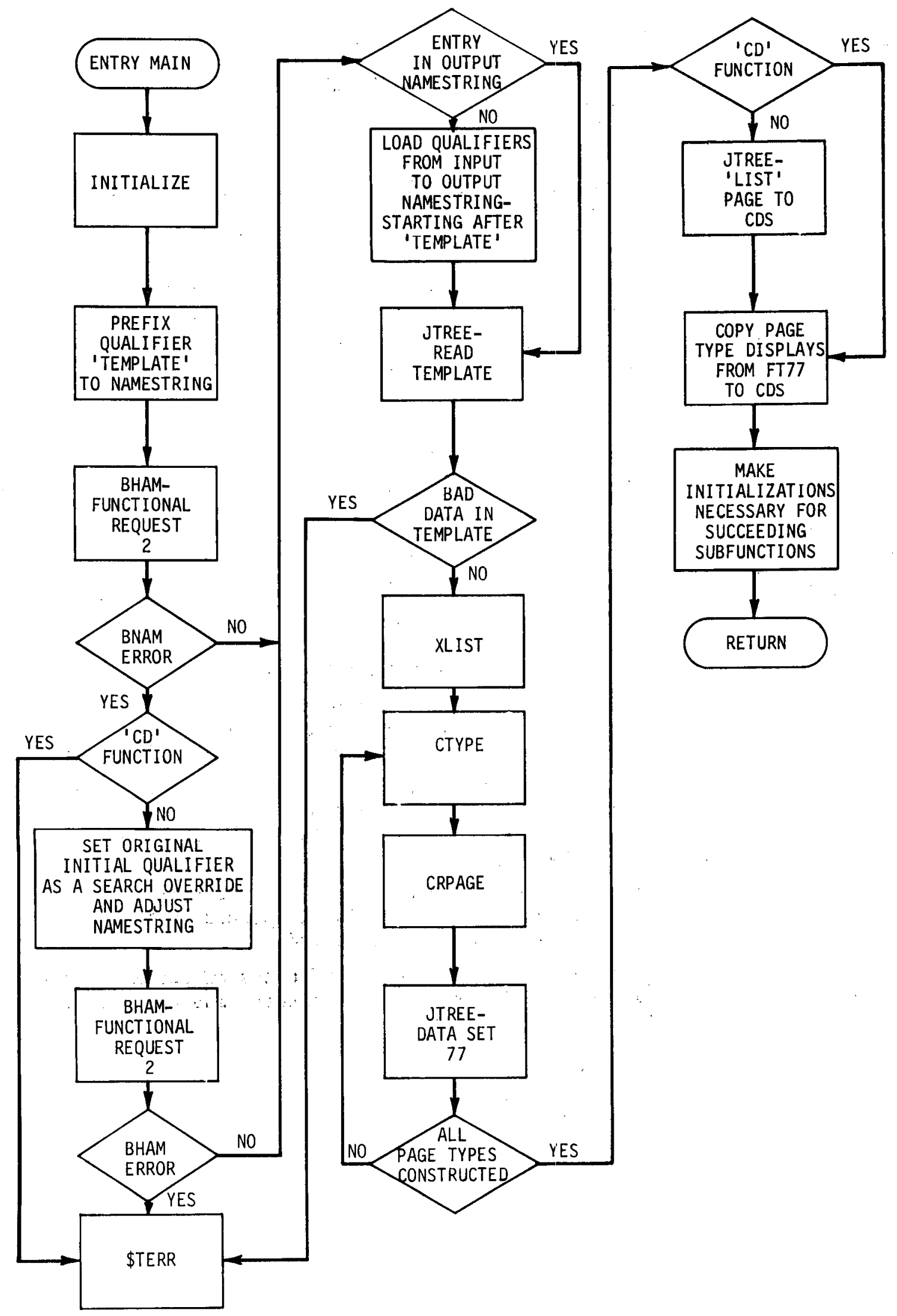




\begin{tabular}{|c|c|c|c|c|}
\hline & \multirow[t]{2}{*}{ Title } & \multirow{2}{*}{$\begin{array}{l}\text { Module: TDISPLAY } \\
\text { Subroutine: CRPAGE }\end{array}$} & \multirow{2}{*}{\begin{tabular}{|l} 
Vol. \\
Rev. \\
\end{tabular}} & $\begin{array}{l}\text { Page } \\
\text { E. } 1.518 \\
\end{array}$ \\
\hline DPSTM-500 & & & & $\begin{array}{l}\text { Date } \\
6 / 73\end{array}$ \\
\hline
\end{tabular}

Purpose:

Usage:

Arguments:
To recreate a template page type for display.

CALL CRPAGE (IN, INPTR,OUT, OUTPTR,OUTSIZ)

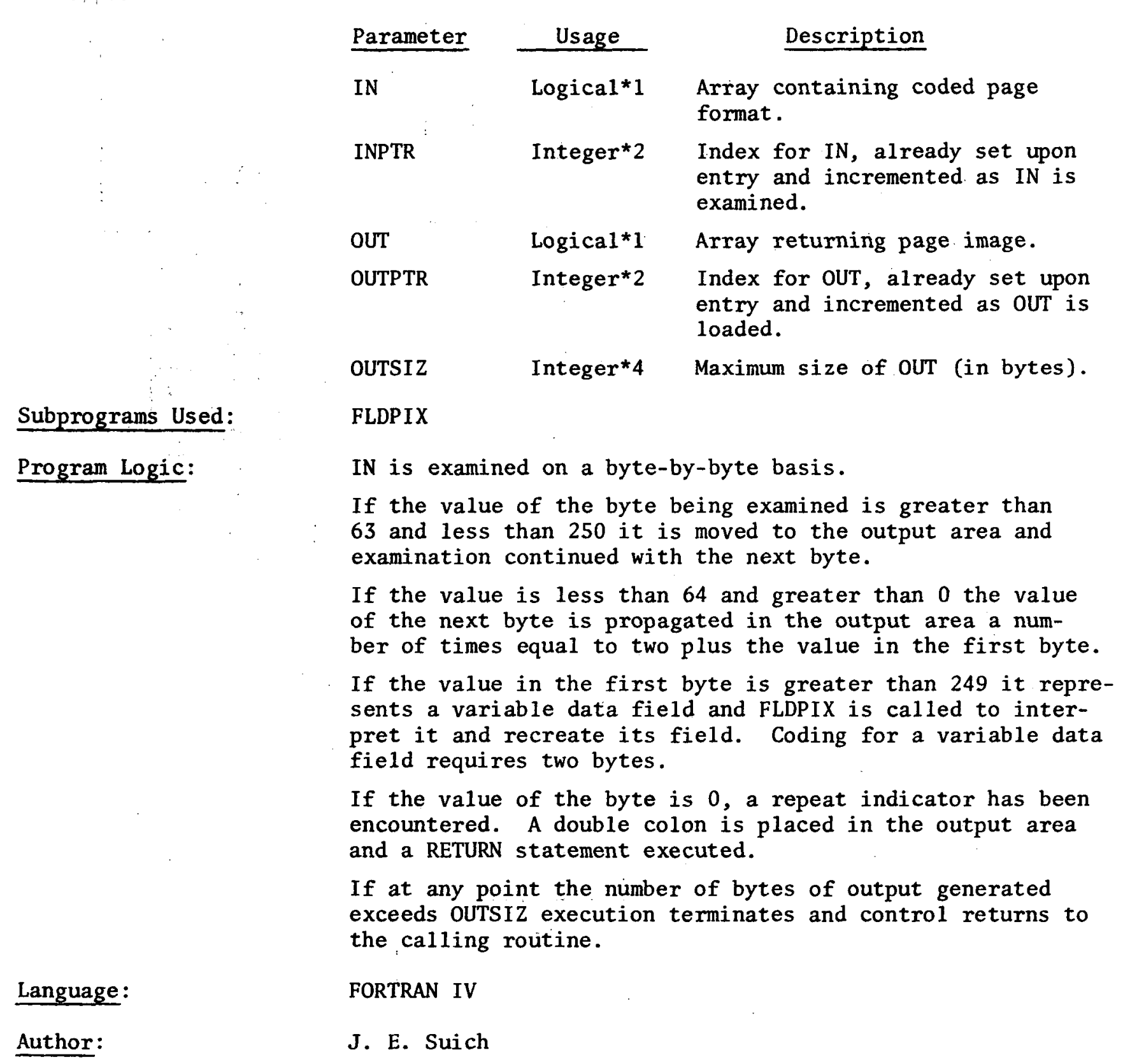




\begin{tabular}{|c|c|c|c|}
\hline 8 & Module: TDISPLAY & Vol. & \begin{tabular}{|l} 
Page \\
E.1.519
\end{tabular} \\
\hline DPSTM.500 & Subroutine: CRPAGE & $\begin{array}{r}\text { Rev. } \\
1\end{array}$ & \begin{tabular}{|c|} 
Date \\
$6 / 73$ \\
\end{tabular} \\
\hline
\end{tabular}

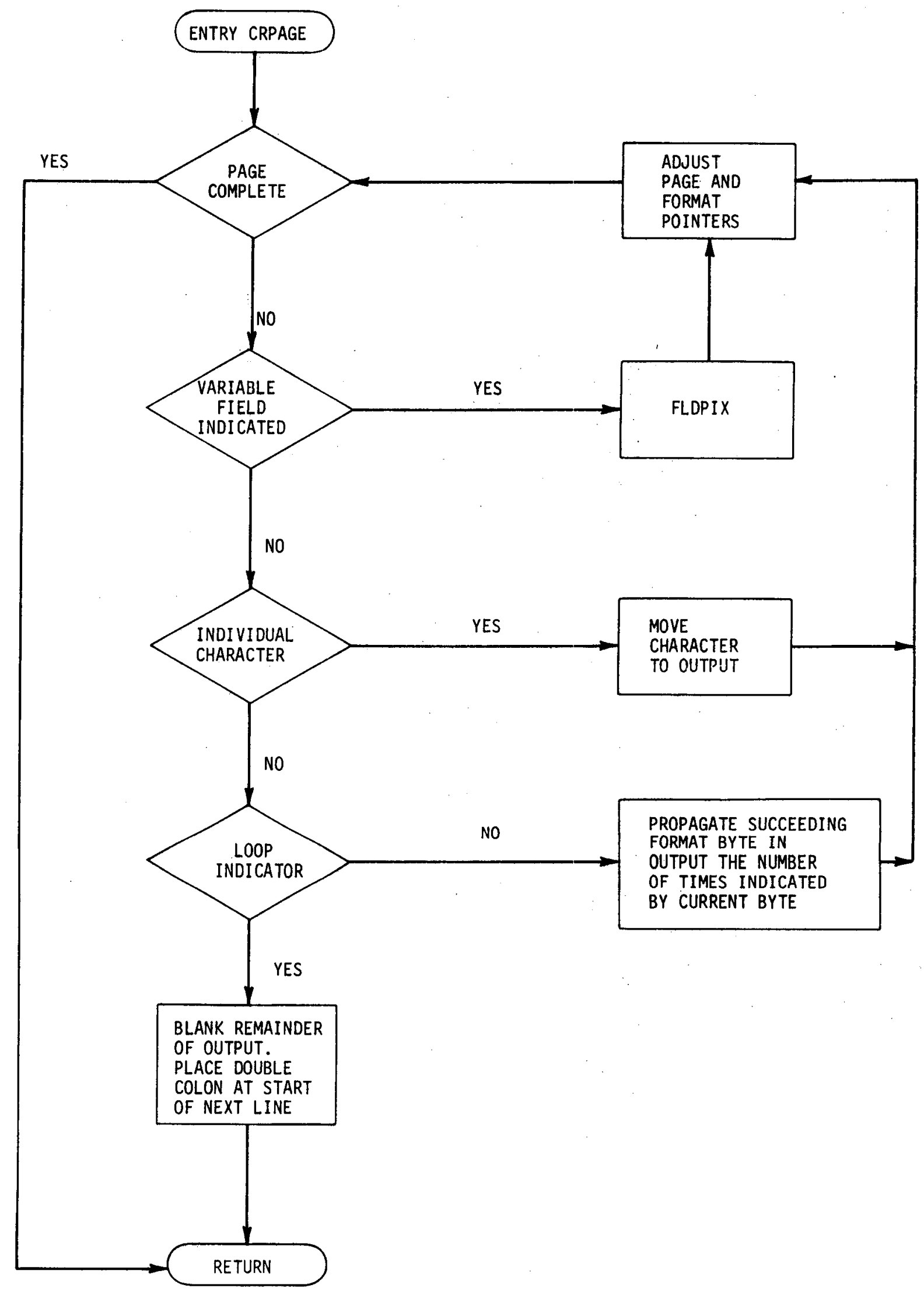




\begin{tabular}{|c|c|c|c|c|}
\hline & \multirow[t]{2}{*}{ Title } & \multirow{2}{*}{$\begin{array}{l}\text { Module: TDISPLAY } \\
\text { Subroutine: CTYPE }\end{array}$} & $\begin{array}{r}V_{0} \\
\text { IX } \\
\end{array}$ & $\begin{array}{l}\text { Page } \\
\text { E. } 1.520\end{array}$ \\
\hline DPST M- 500 & & & Rev. & Date \\
\hline
\end{tabular}

Purpose:

Usage:

Arguments :
To list variable typings as defined in a template record.

CALL CTYPE (START, END, LIST, BUFFER, BUFPOS, NTMPLT)

\begin{tabular}{|c|c|c|}
\hline Parameter & Type & Description \\
\hline START & Integer*2 & $\begin{array}{l}\text { Byte location in LIST of the start } \\
\text { of the variable's mnemonic. }\end{array}$ \\
\hline END & Integer ${ }^{\star} 2$ & $\begin{array}{l}\text { Byte location in LIST of the end } \\
\text { of the variable's mnemonic. }\end{array}$ \\
\hline LIST & Logical *1 & $\begin{array}{l}\text { Contains mnemonic of variable } \\
\text { whose typing is being investigated. }\end{array}$ \\
\hline BUFFER & $\log i c a 1 * 1$ & $\begin{array}{l}\text { Returns variable type, length and } \\
\text { mnemonic if other than FORTRAN } \\
\text { predefined specification. }\end{array}$ \\
\hline BUFPOS & Integer*2 & Index to BUFFER. \\
\hline NTMPLT & Integer*2 & $\begin{array}{l}\text { Specifies variable type and length } \\
\text { in template form (e.g. Real*4= } \\
\left.X^{\prime} D 904^{\prime}\right) \text {. }\end{array}$ \\
\hline
\end{tabular}

Subprograms Used: $\quad$ ' $\quad \$$ CDINT

Program Logic:

Language:

Author:
The variable's predefine specification type is compared to the template typing. If they do not match NTMPLT is decoded by placing the high-order byte in BUFFER followed by an $1 * 1$, the EBCDIC conversion of the low-order byte of NTMPLT, and the variable's mnemonic from LIST.

FORTRAN IV

R. C. Haywood 
Module: TDISPLAY

Subroutine: CTYPE

Vol.

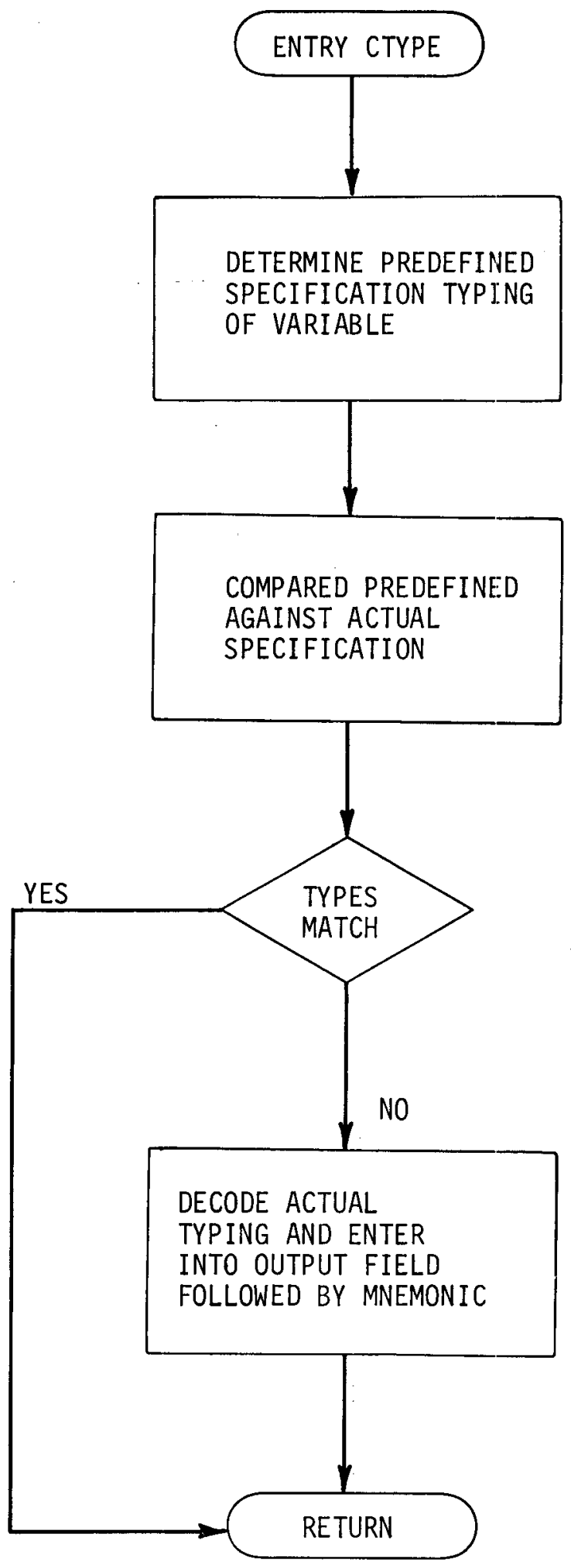


Purpose:

Usage:

Arguments:

Objective:

Program Logic:

Language:

Author:
To recreate a template variable field format for display.

CALL FLDPIX(FMT,OUT)

$\begin{array}{lcc}\text { Parameter } & \text { Type } & \text { Description } \\ \text { FMT } & \text { Logical*1 } & \begin{array}{l}\text { Two byte field containing a } \\ \text { coded variable type field. }\end{array} \\ \text { OUT } & \text { Logical*1 } & \begin{array}{l}\text { Array returns the decoded and } \\ \text { recreated variable data field. }\end{array}\end{array}$

To decide a template variable type field and recreate it in an output field.

The variable type is in the first byte of FMT and contains a fixed point value from 250 through 255 to represent an index field and FORTRAN format types $Z, A, I, E$, and $F$, respectively. The second byte of FMT describes the field. In $Z, A$, and I types it represents the field width. In other types, the field width is represented by the low-order four bits only; the binary value of the high-order four bits represents the index level or the number of decimal positions.

The actual number of bytes used in OUT is one greater than width due to the prefixing of a colon. Thus a format code X'FF37' is recreated as ':FFF.FFF'.

FORTRAN IV

J. E. Suich 


\begin{tabular}{|c|c|c|c|}
\hline & \multirow{2}{*}{ Subroutine: } & Vol. & $\begin{array}{l}\text { Page } \\
\text { E. } 1.523\end{array}$ \\
\hline DPSTM. 500 & & Rev. & $\begin{array}{l}\text { Date } \\
6 / 73\end{array}$ \\
\hline
\end{tabular}

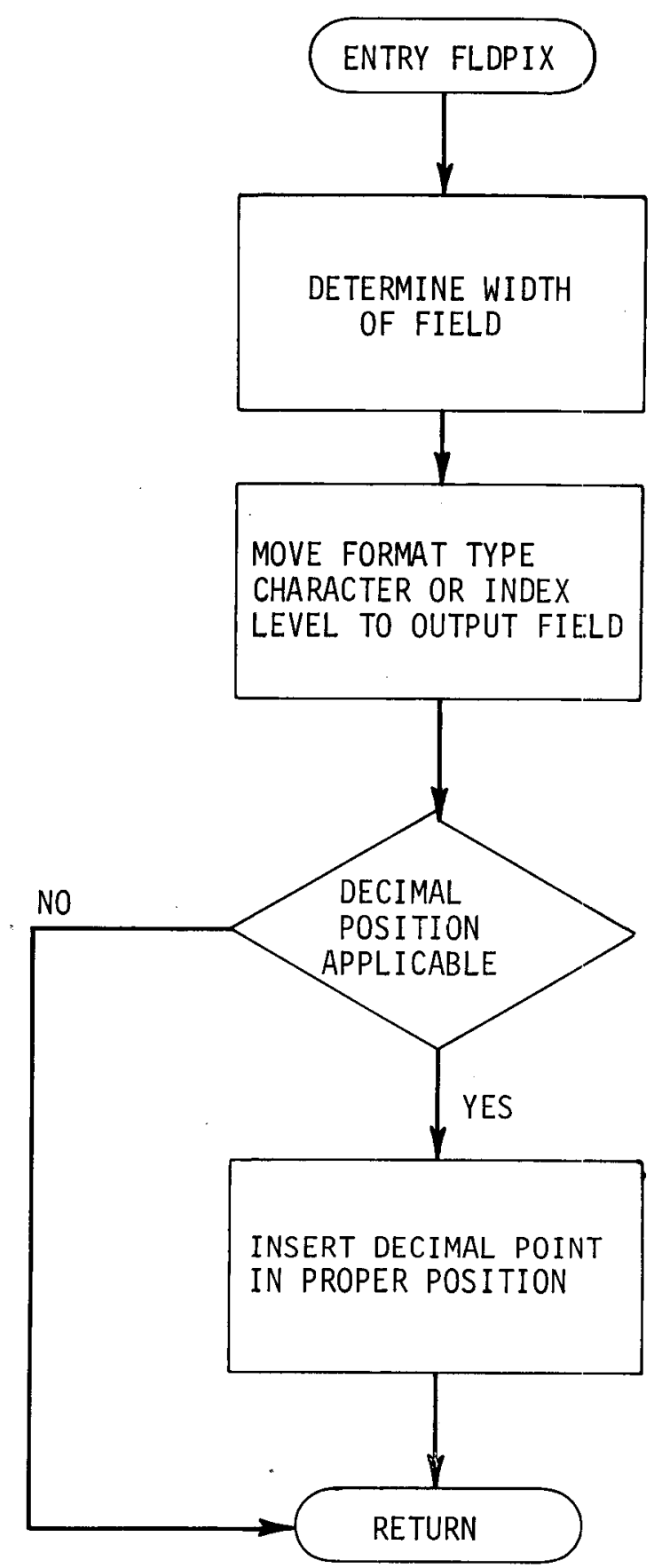




\begin{tabular}{|c|c|c|c|}
\hline 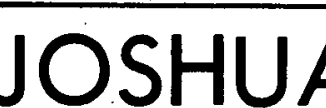 & \multirow{2}{*}{$\begin{array}{l}\text { Title } \\
\text { Module: TDISPLAY } \\
\text { Subroutine: FLDPIX }\end{array}$} & Vol. $_{\text {IX }}$ & \begin{tabular}{|l} 
Page \\
E.1.524
\end{tabular} \\
\hline DPSTM. 500 & & Rev. & \begin{tabular}{|c|} 
Date \\
$6 / 73$
\end{tabular} \\
\hline
\end{tabular}




\begin{tabular}{|c|c|c|c|c|}
\hline & \multirow{2}{*}{\multicolumn{2}{|c|}{ Title Module: TEMPEXIT }} & $\begin{array}{l}\text { Vol. } \\
\text { IX }\end{array}$ & $\begin{array}{l}\text { Page } \\
\text { E.1.525 }\end{array}$ \\
\hline DPSTM-500 & & & $\begin{array}{r}\text { Rev. } \\
\quad 1 \\
\end{array}$ & $\begin{array}{l}\text { Date } \\
6 / 73 \\
\end{array}$ \\
\hline
\end{tabular}

Purpose:

In the CT and MT functions, to assemble and write out a template record.

Attribute:

Nonreusable

JOS Main Program:

MAIN

Arguments:

Mnemonic

A1

A3

A13

Type
Real $* 8$
Real*8

Integer*2

\section{Description}

CCB.

WCBARG2 - the name of the template record being created.

WXTWORK3 - referenced as follows: A13 (1)-A13(124) - template I/O list. A13 (127) - number of halfwords of coded page types.

A13(129) - number of nests (and therefore page types).

Al3 (130) - number of loops.

A13(135) - number of records on FT77FOO1 containing a coded page types, starting with the base record plus one.

A13(136) - the base record on FT77F001.

A13 (139)-A13(152) - for each loop in the I/O list, a node here defines the byte at which that loop begins, including a pseudo-loop-start marking the end of the list. Thus A13 $(A 13(139)+A 13(130))$ defines the number of bytes in the list.

Subprograms :

\section{Entry Point}

\$TERR

BNAM, JTREE

Data Sets:

1. JOSHUA data file

2. FT77FOO1 


\section{JOSHUA Trithe

\begin{tabular}{|l|l|}
\hline Vol. & $\begin{array}{l}\text { Page } \\
\text { E.1.526 }\end{array}$ \\
\hline Rev. & $\begin{array}{c}\text { Date } \\
6 / 73\end{array}$ \\
\hline
\end{tabular}

Program Logic:

- A write (functional request 3) is issued to BNAM with the name of the template record and its calculated length in order to assure space and establish a starting record. Before the name, as defined in $\mathrm{A} 3$, can be submitted, it must have the first qualifier removed if that qualifier is the name of the 'write' data set, and it must be prefixed by the qualifier 'TEMPLATE'. A BNAM error results in a call to \$TERR.

- The template record is assembled from the portions contained in A13 and on FT77FOO1 and written to the JOSHUA data file.

- A close (functional request 4 ) is issued to BNAM.

Language:

Author:

\section{FORTRAN IV}

R. C. Haywood - J. E. Suich 


\begin{tabular}{|l|l|l|l|}
\hline JOSHUA & Title Module: TEMPEXit & Vol.IX & $\begin{array}{c}\text { Page } \\
\text { E.1.527 }\end{array}$ \\
\cline { 2 - 2 } & Rev. & $\begin{array}{c}\text { Date } \\
6 / 73\end{array}$ \\
\hline
\end{tabular}

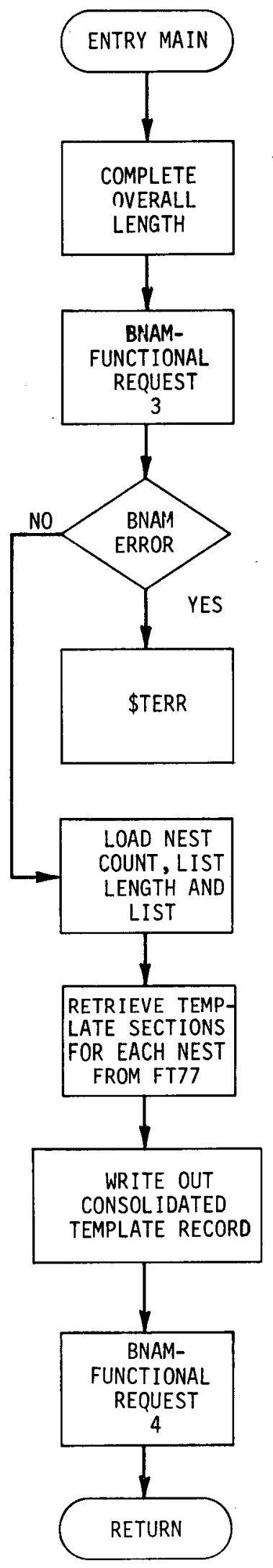




\begin{tabular}{|c|c|c|c|c|}
\hline & \multirow{2}{*}{\multicolumn{2}{|c|}{ Title Module: TEMPEXIT }} & ${ }_{\text {IX }}^{\text {Vol. }}$ & $\begin{array}{l}\text { Page } \\
\text { E. } 1.528\end{array}$ \\
\hline DPSTM-500 & & & $\operatorname{Rev.}$ & $\begin{array}{l}\text { Date } \\
6 / 73\end{array}$ \\
\hline
\end{tabular}




\begin{tabular}{|c|l|l|l|l|}
\hline JOSHUA & Title Module: tempinit & Vol. & $\begin{array}{l}\text { Page } \\
\text { E. } \\
\text { DPSTM.500 }\end{array}$ \\
\cline { 3 - 5 } & & $\begin{array}{c}\text { Rev. } \\
\text { Date } \\
6 / 73\end{array}$ \\
\hline
\end{tabular}

Purpose:

In the CT function, to perform required initializations and provide a display for entry of the I/O list.

Attribute: $\quad$ Nonreusable

JOS Main Program: MAIN

Arguments:

Subprograms :

Mnemonic Type

Al Real*8 CCB.

A2 Rea1*8 WCBARG1 - defines the record type for which a template is to be created.

A3 Rea1*8 WCBARG2 - the contents of A2 are copied here.

A4 Integer*4 Area addressed by MCBBUFFG - the terminal buffer.

A7 Integer*4 WXTDSRF6 - used in the algorithm for establishing a base record in FT77FOO1.

A8

Integer*4 WXTNTGR - the number of qualifiers in $\mathrm{A} 2$.

A13 Integer*2 WXTWORK3 - portions of this area are initialized.

Control Section Entry Point

\$TERR \$TERR

LINK BNAM

MOVEIT MOVEIT

SHIFTB SHIFTB

Program Logic:

- A write (functional request 3 ) is issued to BNAM using the contents of A2, prefixed by the qualifier 'TEMPLATE' and with a record length of zero, in order to assure that the record name is valid. \$TERR is called if an error is encountered.

- The contents of A2 are transferred to A3 and the end of the name in A3 marked with the system namestring delimiter.

- A4 is formatted to facilitate entry of the list and variable typing data. The area for entry of information by the user is defined with question marks and instructions are loaded into the remaining area. SHIFTB loads the record name into the start of $\mathrm{A} 4$.

- Portions of A13 are initialized. This includes: 


\begin{tabular}{|c|c|c|c|c|}
\hline \multirow{2}{*}{$\begin{array}{l}\text { JOSHUA } \\
\text { DPSTM-500 }\end{array}$} & \multirow{2}{*}{\multicolumn{2}{|c|}{ Title Module: TEMPINIT }} & $\begin{array}{|ll|}\text { Vol. } & \\
& \text { IX } \\
\end{array}$ & \begin{tabular}{|l|} 
Page \\
E. 1.530 \\
\end{tabular} \\
\hline & & & $\begin{aligned} \text { Rev: } & \\
& \end{aligned}$ & $\begin{array}{l}\text { Date } \\
6 / 73\end{array}$ \\
\hline
\end{tabular}

$$
\begin{aligned}
& A 13(125)-64 \\
& \text { A13(126) }-10 \\
& \text { A13(134) }-0 \\
& \text { A13(136) - A7*10 }
\end{aligned}
$$

Language:

FORTRAN IV

Author:

R. C. Haywood - J. E. Suich 


\begin{tabular}{|c|c|c|c|}
\hline , & \multirow[t]{2}{*}{ Title Module: TEMPINIT } & ${ }_{\text {Vol. }}$ & $\begin{array}{l}\text { Page } \\
\text { E.1.531 }\end{array}$ \\
\hline DPSTM. 500 & & Rev. & $\begin{array}{l}\text { Date } \\
6 / 73\end{array}$ \\
\hline
\end{tabular}

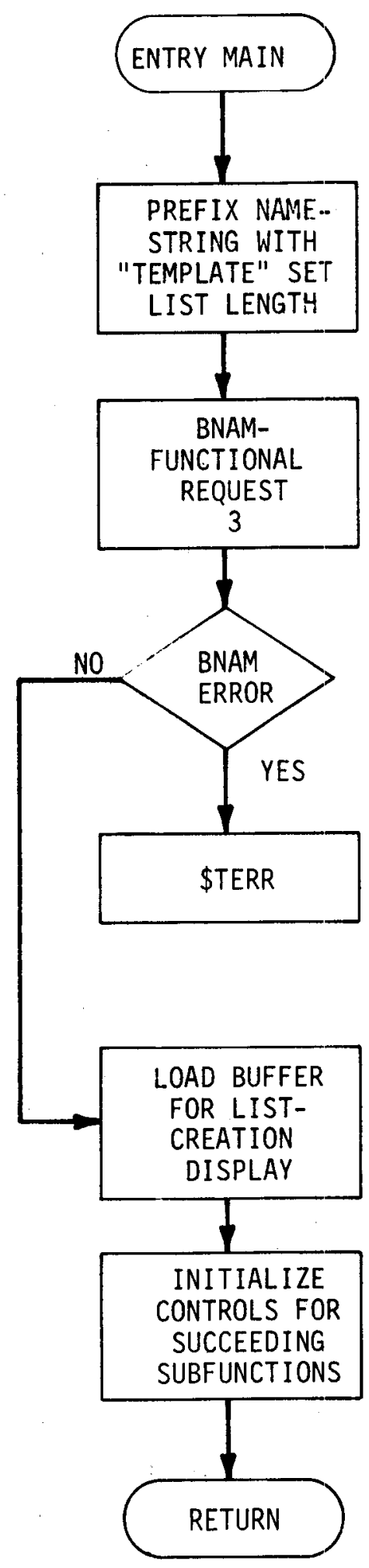




\begin{tabular}{|c|c|c|c|c|}
\hline & Title Module: TEMPINIT & $\theta$ & ${ }_{\text {IX }}^{\text {Vol. }}$ & $\begin{array}{l}\text { Page } \\
\text { E.1.532 }\end{array}$ \\
\hline DPSTM-500 & & & Rev: $_{1}$ & $\begin{array}{l}\text { Date } \\
6 / 73\end{array}$ \\
\hline
\end{tabular}

(B1ank) 


\begin{tabular}{|l|l|l|l|l|}
\hline JOSHUA & Title Module: TEMPLIST & Vol. & \multicolumn{1}{l|}{ Page } \\
DPSTM.500 & & E. 1.533 \\
\cline { 3 - 5 } & & Rev. & $\begin{array}{c}\text { Date } \\
6 / 73\end{array}$ \\
\hline
\end{tabular}

Purpose:

To analyze a template $I / O$ list into sets of nested DO-loops, determining the number of nests, the number of loops in each nest, the number and type of the variables in each loop, and the limits to each loop.

Attribute:

Nonreusable

JoS Main Program:

MAIN

Arguments:

\begin{tabular}{|c|c|c|}
\hline Mnemonic & Type & Description \\
\hline $\mathrm{A} 1$ & Real * 8 & CCB. \\
\hline $\mathrm{A} 4$ & Rea $1 * 8$ & $\begin{array}{l}\text { Area pointed to by MCBBUFFG. } \\
\text { Contains the I/O list and any } \\
\text { explicit variable typings. }\end{array}$ \\
\hline A10 & Integer $* 2$ & $\begin{array}{l}\text { WXTWORK1 and WXTWORK2 used as } \\
\text { follows: } \\
\text { A10(1)-AlO(72) divided into sets } \\
\text { of six halfwords each to contain } \\
\text { the following information for } \\
\text { each loop: } \\
\text { 1. number of variables; } \\
\text { 2. loop lower limit; } \\
\text { 3. loop upper limit; } \\
\text { 4-6. for later use. } \\
\text { Al0(73)-Al0(92) - the type and } \\
\text { length specification for each } \\
\text { variable in the list. }\end{array}$ \\
\hline A13 & Integer $* 2$ & $\begin{array}{l}\text { WXTWORK } 3 \text { used as follows: } \\
\text { A13(1)-A13(124) - saves the } 1 / 0 \\
\text { list. } \\
\text { Al3(125) - considering A4 to be } \\
\text { series of } 80 \text {-byte lines the } \\
\text { number of characters to be con- } \\
\text { sidered in each line. } \\
\text { Al3(129) - the number of nests. } \\
\text { A13(130) - the number of loops. } \\
\text { A13(131) - the number of variables. } \\
\text { A13(134) - set to zero. } \\
\text { A13(136) - base record number on } \\
\text { FT77F001. } \\
\text { A13(139)-A13(151) - loop start } \\
\text { positions. } \\
\text { A13(152)-A13(156) - number of loops } \\
\text { in each nest. } \\
\text { A13(161) - set to zero. }\end{array}$ \\
\hline A 15 & Integer*4 & \\
\hline
\end{tabular}




\section{Entry Point}

\begin{tabular}{ll} 
Control Section & Entry Point \\
\hline MOVEIT & MOVEIT \\
STRIP* & STRIP \\
XLIMIT* & XLIMIT \\
XLIST & XLIST \\
ZCOMP & ZCOMP
\end{tabular}

Program Logic:

- The I/O list with blanks and question marks packed out, is passed to XLIST to be analyzed into nests, loops, and variables.

- The I/O list as returned from XLIST is loaded into Al3.

- The loop limits are analyzed by XLIMIT.

- Typing instructions are packed and passed along with the list to XLIST where all variables in the list are typed. Standard FORTRAN default typing is assigned any variable for which no explicit typing is given.

- Required initializations for subsequent subfunctions is performed.

- If a syntax error is encountered, a diagnostic message is set in the last 80 positions of A4 and the display returned for correction.

Language:

FORTRAN IV

Author:

R. C. Haywood - J. E. Suich 


\begin{tabular}{|c|l|l|l|l|}
\hline JOSHUA & Title Module: TEMPLIST & Vol. & $\begin{array}{l}\text { Page } \\
\text { I. }\end{array}$ \\
& & Rev. & $\begin{array}{l}\text { Date } \\
6 / 73\end{array}$ \\
\hline
\end{tabular}

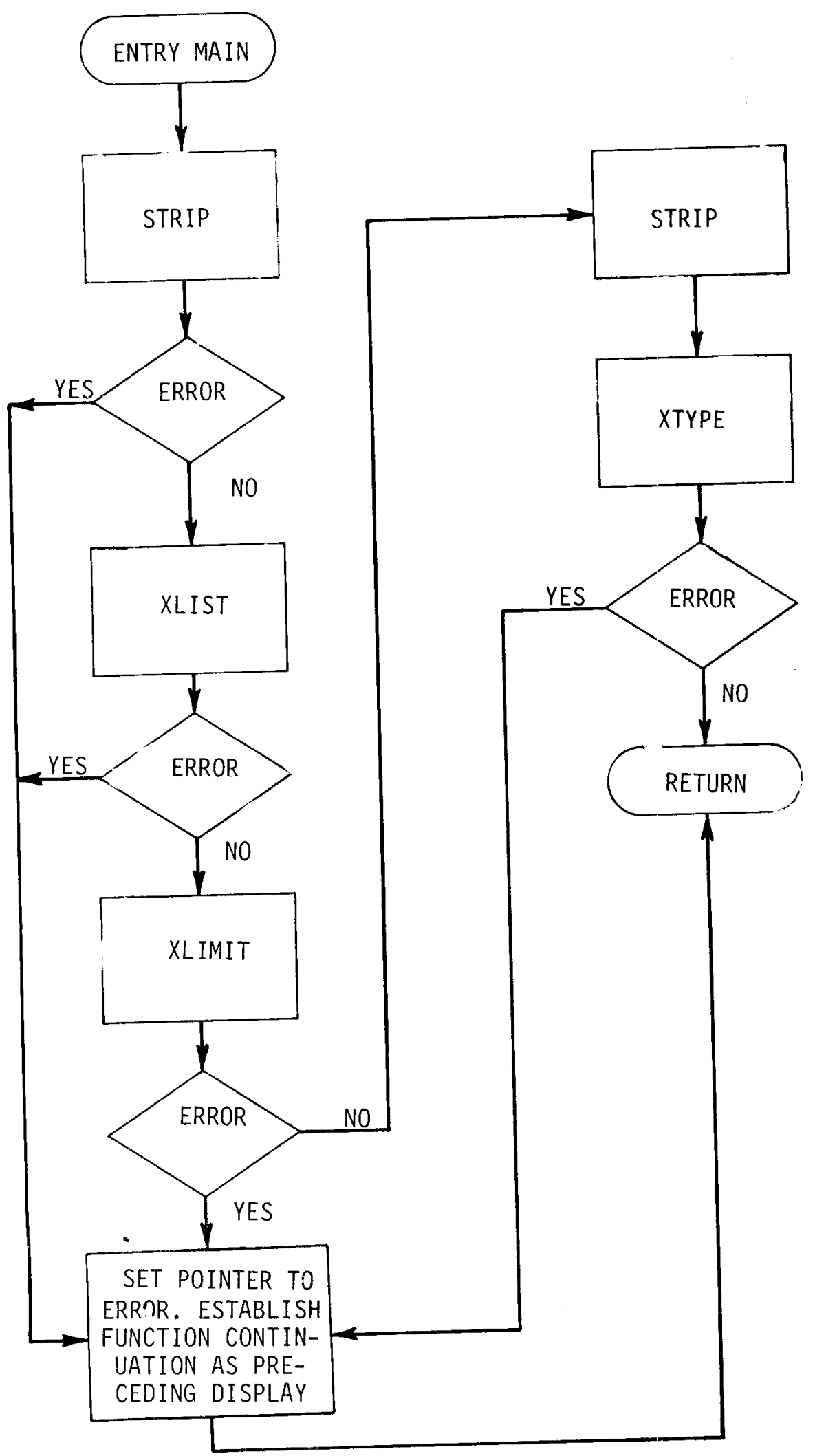




\begin{tabular}{|c|c|c|c|c|}
\hline 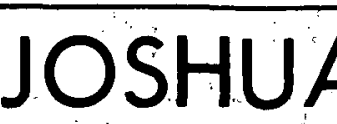 & \multirow[t]{2}{*}{ Title } & \multirow[t]{2}{*}{$\begin{array}{l}\text { Module: TEMPLIST } \\
\text { Subroutine: STRIP }\end{array}$} & \begin{tabular}{|l} 
Vol. \\
IX
\end{tabular} & $\begin{array}{l}\text { Page } \\
\text { E. } 1.536\end{array}$ \\
\hline DPSTM -500 & & & Rev. & $\begin{array}{c}\text { Date } \\
6 / 73\end{array}$ \\
\hline
\end{tabular}

Purpose:

Usage:

Arguments:
To pack a data string by eliminating blanks and question marks.

CALL STRIP (CD, NCMAX, MAXCAR)

\begin{tabular}{lll} 
Mnemonic & Type & \multicolumn{1}{c}{ Description } \\
LD & Integl*1 & $\begin{array}{l}\text { The data string from which the } \\
\text { blanks and question marks are to } \\
\text { be packed out. }\end{array}$ \\
NCMAX & $\begin{array}{l}\text { The number of characters in each } \\
\text { line to be considered when han- } \\
\text { dling CD as a series of } 80 \text { byte } \\
\text { lines. }\end{array}$ \\
MAXCAR & Integer*4 & $\begin{array}{l}\text { The overa11 length of CD on input; } \\
\text { the length of the packed string } \\
\text { on return. }\end{array}$
\end{tabular}

Program Logic:

- Each character in the string is examined and any character not a blank or a question mark is shifted so as to complete a contiguous string of characters none of which is a blank or a question mark. The length of that string is loaded into MAXCAR.

Language:

FORTRAN IV

Author:

R. C. Haywood 


\begin{tabular}{|c|c|c|c|c|}
\hline \multirow{2}{*}{$\begin{array}{l}\text { JSHUA } \\
\text { DPSTM.500 }\end{array}$} & \multirow{2}{*}{\multicolumn{2}{|c|}{$\begin{array}{ll}\text { Title } & \text { Module: } \\
& \text { SEMPLIST } \\
& \text { Subroutine: }\end{array}$}} & Vol. $_{\text {IX }}$ & $\begin{array}{l}\text { Page } \\
\text { E.1.537 }\end{array}$ \\
\hline & & & Rev. & $\begin{array}{l}\text { Date } \\
6 / 73\end{array}$ \\
\hline
\end{tabular}

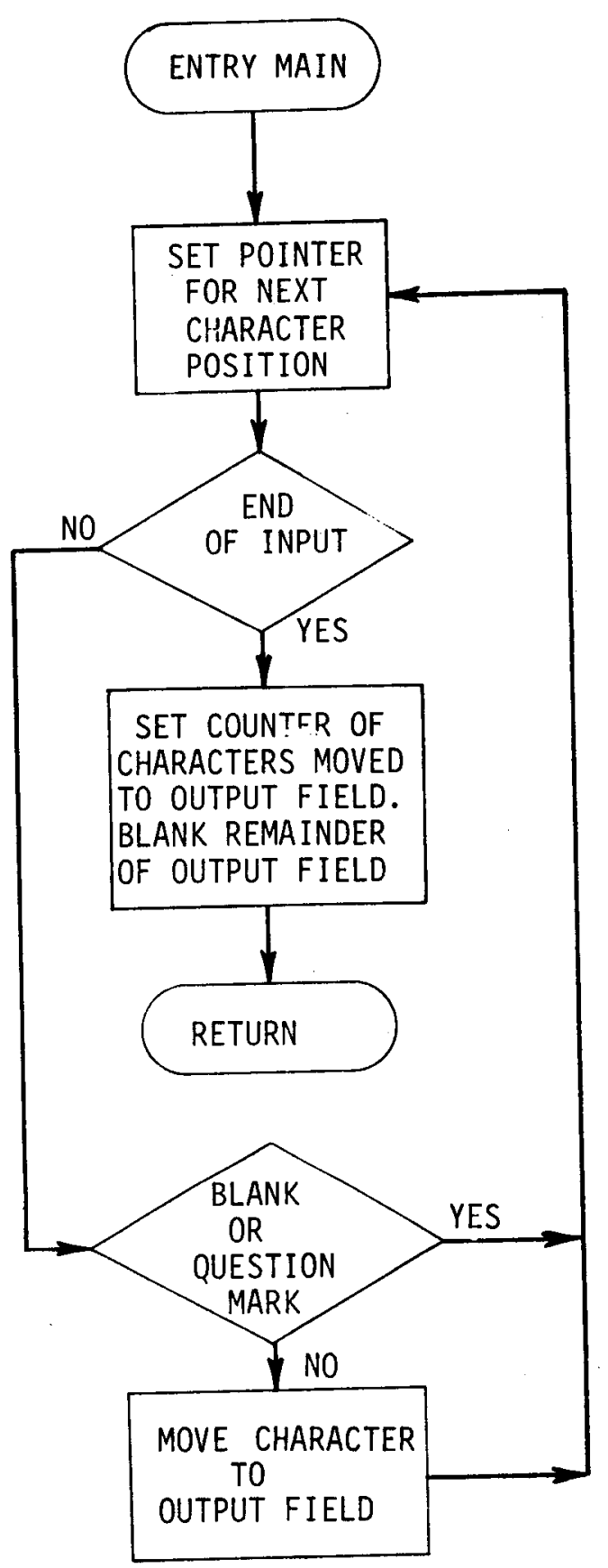




\begin{tabular}{|c|c|c|c|c|}
\hline & \multirow[t]{2}{*}{ Title } & \multirow{2}{*}{$\begin{array}{l}\text { Module: TEMPLIST } \\
\text { Subroutine: XLIMIT }\end{array}$} & $\begin{array}{|ll|}\text { Vol. } & \vdots \\
& \text { IX } \\
\end{array}$ & $\begin{array}{l}\text { Page } \\
\text { E. } 1.538 \\
\end{array}$ \\
\hline$T M-500$ & & & Rev. & $\begin{array}{l}\text { Date } \\
6 / 73\end{array}$ \\
\hline
\end{tabular}

Purpose:

Usage:

Arguments:
To define for a template the limits of loops in the $1 / 0$ list.

CALL XLIMIT (LIMIT, EOL, NLOC, NLOX, MAXCAR, NESTS, NVMAX, NERR, LOOPS, FLAG, CD)

\begin{tabular}{|c|c|c|}
\hline Mnemonic & Type & Description \\
\hline LIMIT & Integer $* 2$ & $\begin{array}{l}\text { Six contiguous nodes per loop. } \\
\text { The second and third node in each } \\
\text { set return the lower and upper } \\
\text { limits, respectively, of the } \\
\text { associated loop as defined for a } \\
\text { template. }\end{array}$ \\
\hline EOL & Integer ${ }^{*}$ & $\begin{array}{l}\text { The location in } C D \text { of the end of } \\
\text { each loop. }\end{array}$ \\
\hline NLOC & Integer *2 & $\begin{array}{l}\text { The starting location in } \mathrm{CD} \text { of } \\
\text { each variable. }\end{array}$ \\
\hline NLOX & Integer $* 2$ & $\begin{array}{l}\text { The ending location in } C D \text { of each } \\
\text { variable. }\end{array}$ \\
\hline MAXCAR & Integer ${ }^{\star} 2$ & The length of the $I / 0$ list. \\
\hline NESTS & Integer*2 & The number of nests. \\
\hline NVMAX & Integer*2 & The number of variables. \\
\hline NERR & Integer $* 2$ & $\begin{array}{l}\text { Location in the list of a syntax } \\
\text { error. }\end{array}$ \\
\hline LOOPS & Integer $* 2$ & The number of loops in each nest. \\
\hline FLAG & Integer*2 & Indicates an error when FLAG $=1$. \\
\hline $\mathrm{CD}$ & $\operatorname{Logical}{ }^{*} 1$ & The I/O list. \\
\hline
\end{tabular}

Program Logic:

- Loops to which there is not explicit indexing (do not end on an equal sign) have their limits set to one.

- In loops with explicit indexing, the lower limit is recognized as being bounded by an equal sign and a comma; the upper limit by a comma and a right parenthesis.

- Explicit limits are examined to determine if they are constant, a previously defined variable, or an index in an outer loop of the same nest. Being any of these, LIMIT is loaded with the appropriate code.

- Invalid syntax results in FLAG and NERR being set as indicated above.

Language :

FORTRAN IV

Author:

J. E. Suich 


\begin{tabular}{|c|c|c|c|}
\hline & Title Module: TEMPLIST & Vol.IX & $\begin{array}{l}\text { Page } \\
\text { E.1.539 }\end{array}$ \\
\hline DPSTM.500 & Subroutine: XLIMIT & Rev. $_{1}$ & Date \\
\hline
\end{tabular}

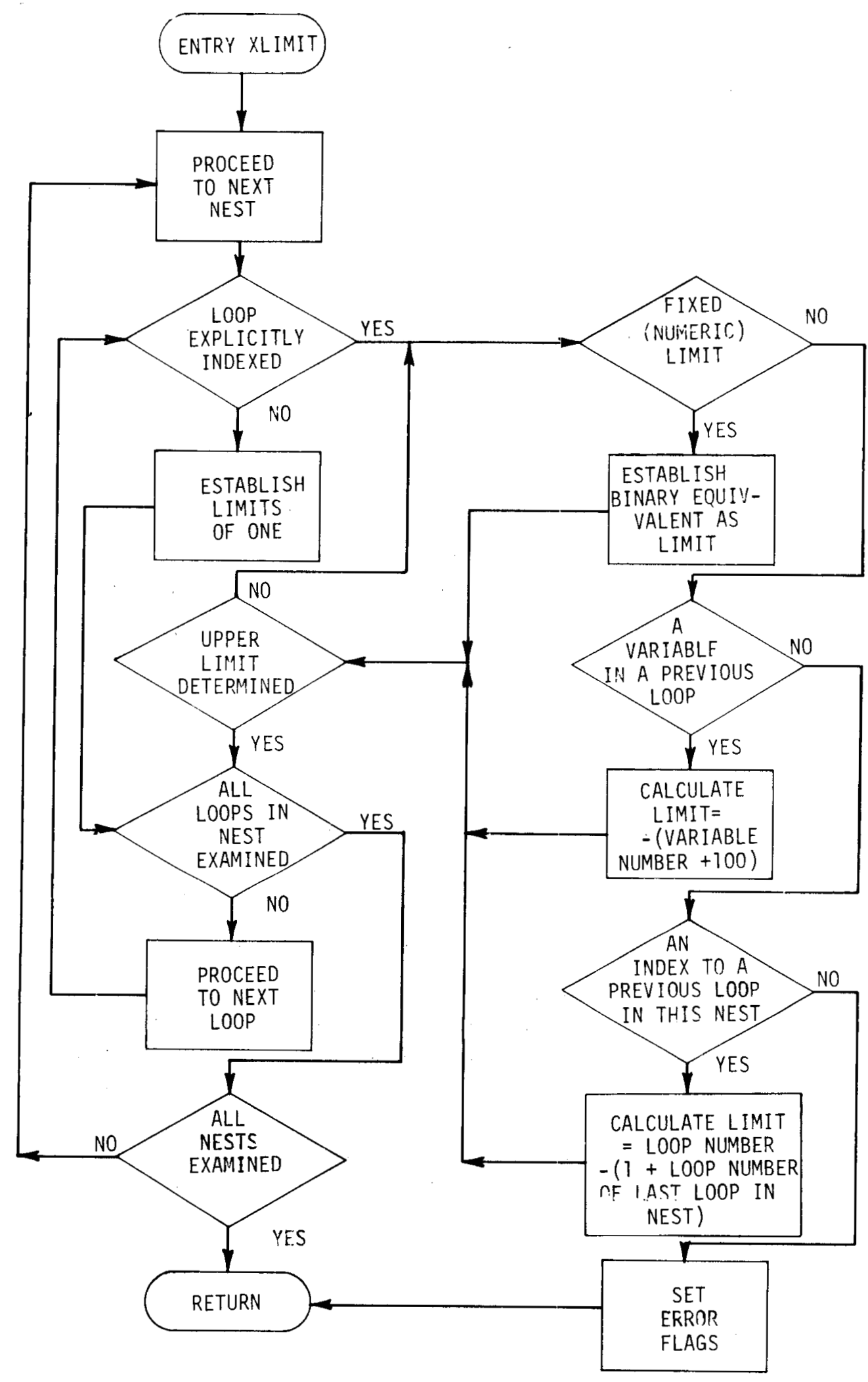




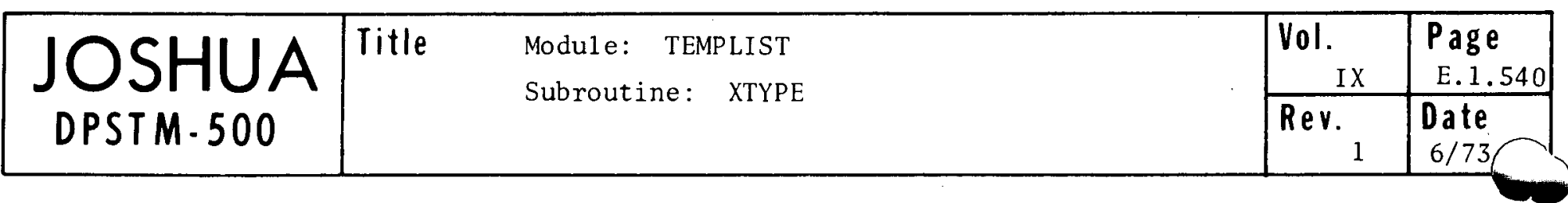

Purpose:

Usage:

Arguments:
To define the type and length of template variables.

CALL XTYPE(NLOC, NLOX, TYPE, LIST, MAXCAR, NVMAX, NERR, FLAG, CD)

\begin{tabular}{|c|c|c|}
\hline Mnemonic & Type & Description \\
\hline NLOC & Integer $* 2$ & $\begin{array}{l}\text { The starting location in LIST of } \\
\text { each variable. }\end{array}$ \\
\hline NLOX & Integer*2 & $\begin{array}{l}\text { The ending location in LIST of } \\
\text { each variable. }\end{array}$ \\
\hline TYPE & Integer $* 2$ & $\begin{array}{l}\text { Returns the type and length code } \\
\text { for each variable. }\end{array}$ \\
\hline LIST & Logical*1 & I/O list. \\
\hline MAXCAR & Integer*2 & Length of LIST. \\
\hline NVMAX & Integer*2 & Number of variables in the list. \\
\hline NERR & Integer*2 & Location of an error. \\
\hline FLAG & Integer*2 & Indicates an error when FLAG $=1$ \\
\hline $\mathrm{CD}$ & $\operatorname{Logica} 1 * 1$ & Explicit variable typings. \\
\hline
\end{tabular}

Subprograms:

ZCOMP

Program Logic:

- Each variable is typed according to the standard FORTRAN IV predefined length and type specifications.

- $C D$ is examined and any explicit typing overrides the predefined value already established in TYPE for the variables indicated. Valid types are:

$I * 2$ and $I * 4$ for integer values;

$R * 4$ and $R * 8$ for real values;

$C^{*} N$, where $0<N<64$ for variable length strings.

- Invalid syntax or explicit typing of a variable not in the list results in an error condition.

Language:

FORTRAN IV

Author:

R. C. Haywood - J. E. Suich 


\begin{tabular}{|l|l|l|l|l|}
\hline JOSHUA & Mitle & Module: TEMPLIST & Vol. ix & $\begin{array}{c}\text { Page } \\
\text { E.1.541 }\end{array}$ \\
${ } }$ & Subroutine: yTYPE & Rev. & $\begin{array}{c}\text { Date } \\
6 / 73\end{array}$ \\
\hline
\end{tabular}

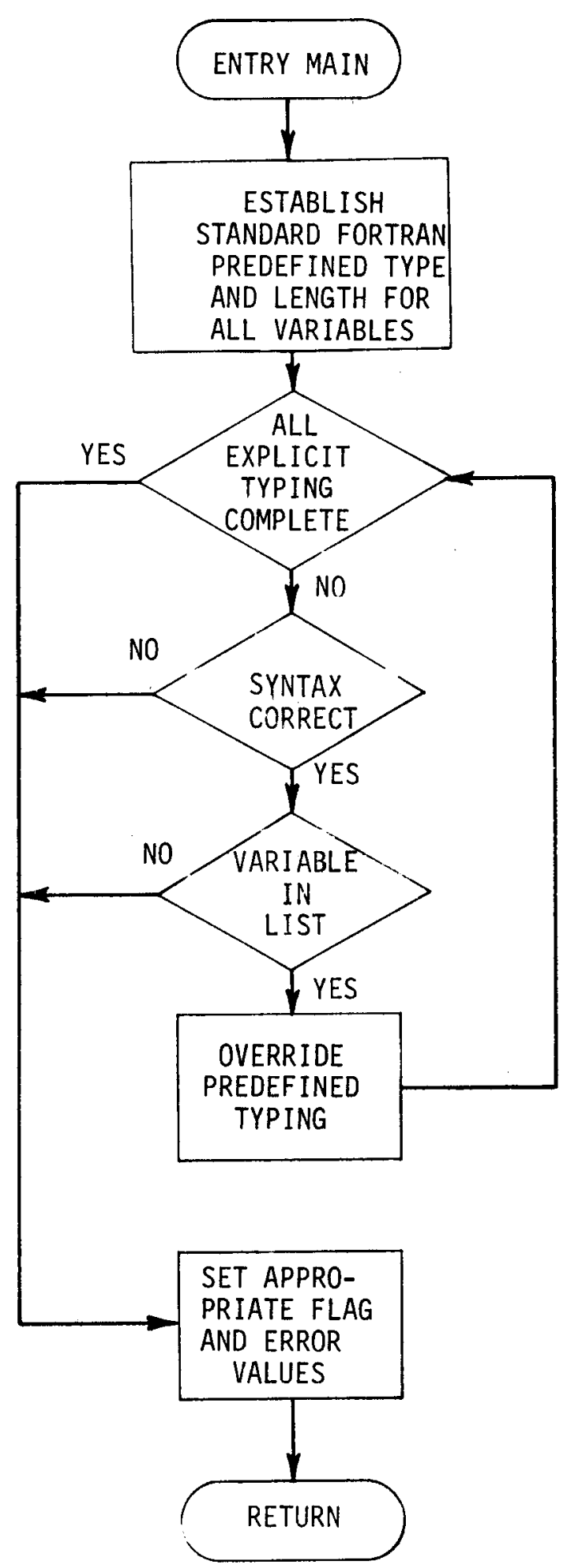




\begin{tabular}{|c|c|c|c|}
\hline & \multirow{2}{*}{ 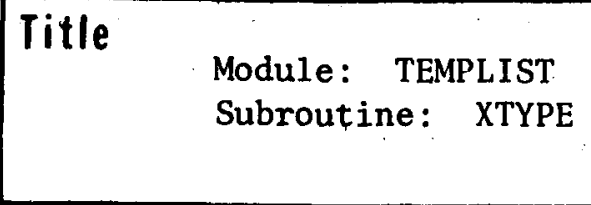 } & Vol. & \begin{tabular}{|l} 
Page \\
E.1.542
\end{tabular} \\
\hline DPSTM. 500 & & Rev. & $\begin{array}{c}\text { Date } \\
6 / 73\end{array}$ \\
\hline
\end{tabular}

(Blank) 


\begin{tabular}{|c|c|c|c|c|}
\hline \multirow{2}{*}{$\begin{array}{l}\text { JOSHUA } \\
\text { DPSTM.500 }\end{array}$} & \multirow[t]{2}{*}{ Title } & \multirow[t]{2}{*}{ Module: TEMPNEST } & Vol. & $\begin{array}{l}\text { Page } \\
\text { E.1.543 }\end{array}$ \\
\hline & & & Rev.: & $\begin{array}{l}\text { Date } \\
6 / 73\end{array}$ \\
\hline
\end{tabular}

Purpose:

To provide format instructions and display area guides for preparation of a template page type.

Attribute:

Nonreusable

JOS Main Program:

MAIN

Arguments:

$\begin{array}{lll}\text { Mnemonic } & \text { Type } \\ \text { Al } & \text { Rea1*8 } & \text { CCB. } \\ \text { A4 } & \text { Rea1*8 } & \text { Ar }\end{array}$

A13 Integer*2 WXTWORK2 - portions referenced by this module:

Al3(1)-Al3(124) - template I/O list.

Al3(134) - number of the nest for which a page type is to be created. $A 13(139)-A 13(151)$ - array of loop start positions in the $1 / 0$ list. A13(152)-A13(156) - array of loop counts for each nest.

Al5 Integer*4 MCBCFCT.

Subprograms:

$\frac{\text { Control Section }}{\text { XNSTID }} \quad \frac{\text { Entry Point }}{\text { XNSTID }}$

Program Logic:

- A4 is considered in terms of twelve eighty character lines. The first sixty-four positions of lines two thru eleven are loaded with question marks. The remaining sixteen positions of these lines are loaded with formatting instructions. Line twelve is loaded with that portion of the template $I / 0$ list relating to the page type to be defined.

- Al5 is incremented by sixteen in order to skip a position in the function list.

Language:

FORTRAN IV

Author:

J. E. Suich 


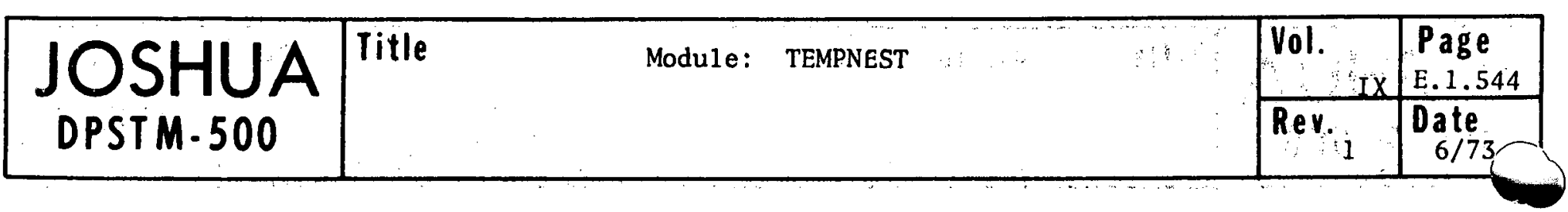

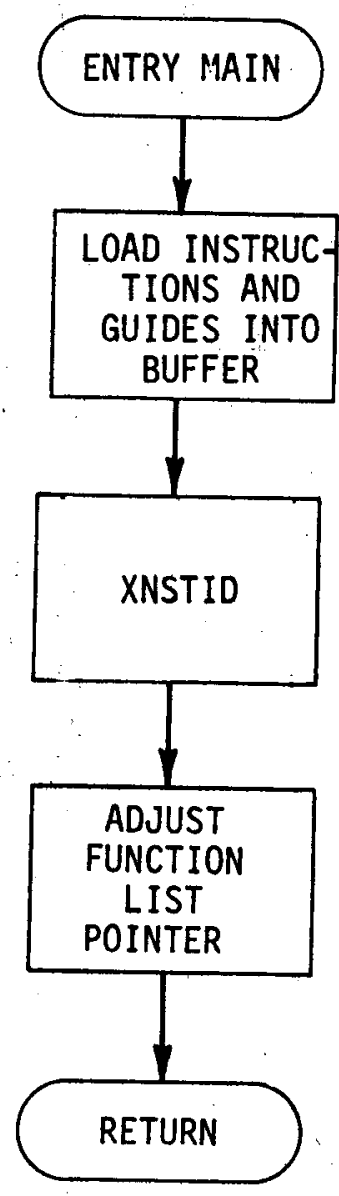




\begin{tabular}{|c|c|c|c|c|}
\hline 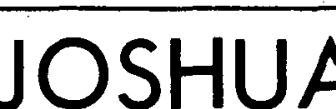 & \multirow{2}{*}{\multicolumn{2}{|c|}{ Title $\quad$ Module: TEMPPAGE }} & $\begin{array}{r}\text { Vol. } \\
\text { IX }\end{array}$ & $\begin{array}{l}\text { Page } \\
\text { E. } 1.545\end{array}$ \\
\hline DPSTM. 500 & & & $\begin{array}{r}\text { Rev. } \\
1\end{array}$ & $\begin{array}{l}\text { Date } \\
6 / 73 \\
\end{array}$ \\
\hline
\end{tabular}

Purpose:

Attribute:

Main Program:

Arguments:

Mnemonic

A1

A4

A5

A10

A13

A1 5

To scan a template page-type display, convert it to a template format, and assemble a page-type segment.

Nonresuable

MAIN
Type
Real *8
Logical *1
Integer *2
Integer $* 2$

Integer *2

Integer *4

\section{Description}

$\mathrm{CCB}$

Area pointed to by MCBBUFFG - the display buffer.

WCBFNM

WXTWORK1 and WXTWORK2 referenced as follows:

Alo(1)-Al0(72) sets of six nodes for each loop containing?

1. number of variables,

2. lower loop limit;

3. upper loop limit;

4. format start location;

5. page start location;

6. page type (always one).

A10(73)-A10(92) - variable type and

length specifications.

WXTWORK3 - referenced as follows:

Al3(125) - Considering A4 to be a

series of 80-byte lines, the number of bytes to be scanned in each line.

A13(126) - Number of contiguous lines to be scanned.

A13(127) - Total length of coded pagetypes - in halfwords.

A13(129) - Total number of nests.

A13(130) - Total number of loops.

A13 (131) - Total number of variables.

A13 (132) - Cumulative number of bytes

of coded format.

A13(134) - Nest counter

A13(135) - Counters of records written

to FT77ROO1 starting at $\mathrm{Al3}(136)+1$.

A13(1.36) - Starting relative record on FT77F001.

A13 (152)-A13(156) - The number of loops in each of the two possible nests. MCBCFCT. 


\begin{tabular}{|c|c|c|c|c|}
\hline & \multirow{2}{*}{\multicolumn{2}{|c|}{ Title Module: TEMPPAGE }} & \begin{tabular}{|l} 
Vol. \\
IX
\end{tabular} & $\begin{array}{l}\text { Page } \\
\text { E. } 1.546 \\
\end{array}$ \\
\hline DPSTM. 500 & & & $\begin{array}{r}\text { Rer. } \\
1\end{array}$ & $\begin{array}{c}\text { Date } \\
6 / 73\end{array}$ \\
\hline
\end{tabular}

Subprograms Used:

Data Sets:

\begin{tabular}{l} 
Control Section \\
\hline LINK \\
MOVEIT \\
SKIP* \\
XPAGE* $^{*}$ \\
XPTRS * $^{*}$ \\
XTMPLT $^{*}$
\end{tabular}

\begin{tabular}{l} 
Entry Point \\
\hline JTREE \\
MOVEIT \\
SKIP \\
XPAGE \\
XPTRS \\
XTMPLT
\end{tabular}

FT77F001

Program Logic:

- XPAGE is called to code the display

o XPTRS is called to set the page and format loop start positions.

0 . XTMPLT is called to assemble the format and controls into a page-type segment.

o The page-type segment is written to FT77001.

o When finishing the last page-type the total number of halfwords in all the page-type segments is calculated to be passed to the succeeding subfunction.

- A15 is adjusted for proper continuation.

o When an error is indicated by XPAGE, XPTRS, or XTMPLT, a diagnostic is placed in the buffer and continuation set for the preceding display.

Language:

FORTRAN IV

Author:

R. C. Haywood - J. E. Suich 


\begin{tabular}{|c|c|c|c|c|}
\hline & \multirow{2}{*}{\multicolumn{2}{|c|}{ Title Module: TEMPPAGE }} & Vol. IX & $\begin{array}{l}\text { Page } \\
\text { E.1.547 }\end{array}$ \\
\hline DPST M. 500 & & & $\begin{array}{r}\text { Rev. } \\
1 \\
\end{array}$ & \begin{tabular}{|c} 
Date \\
$6 / 73$ \\
\end{tabular} \\
\hline
\end{tabular}

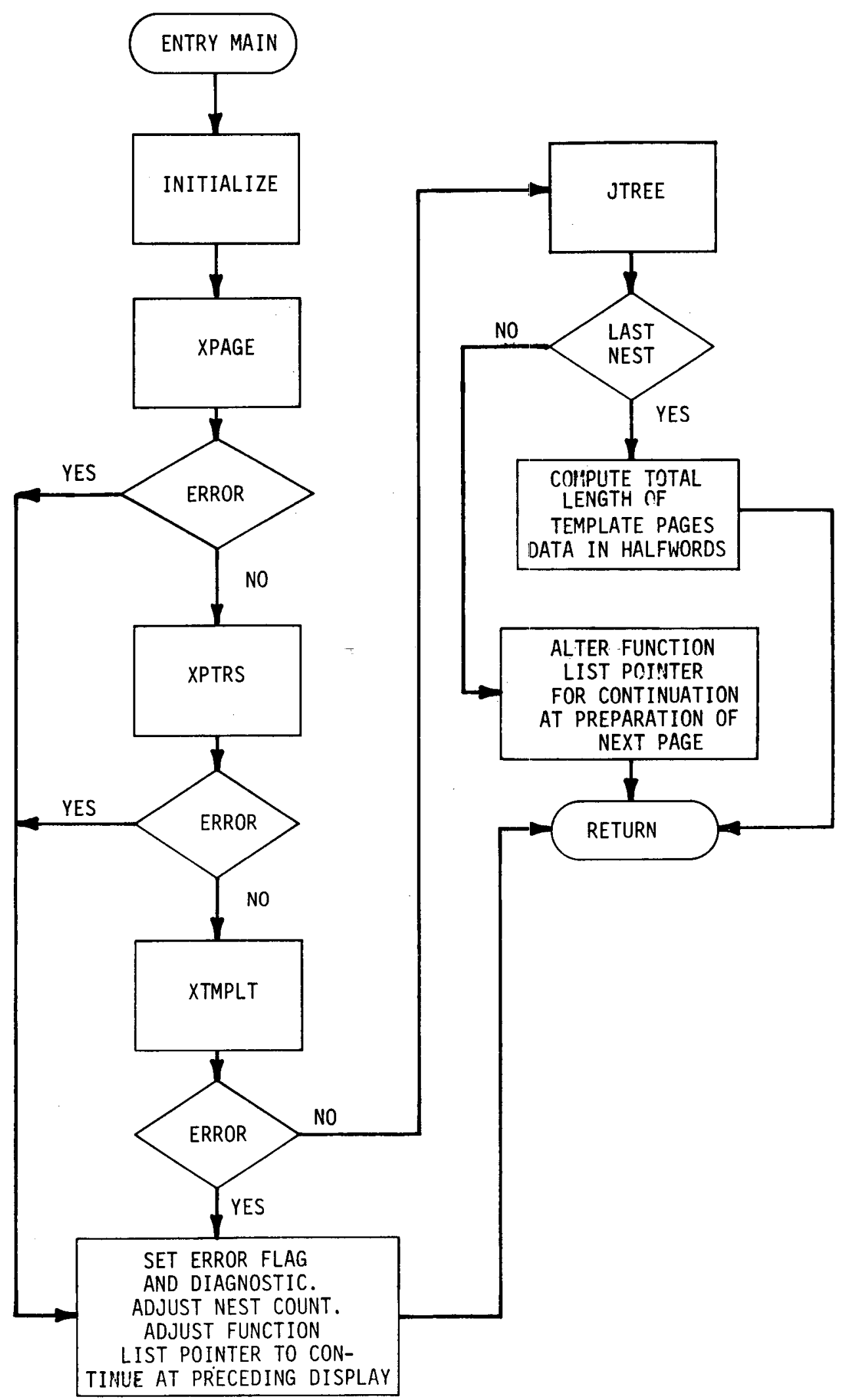




\begin{tabular}{|c|c|c|c|c|}
\hline & \multirow[t]{2}{*}{ Title } & Module: TEMPPAGE & Vol. IX & $\begin{array}{l}\text { Page } \\
\text { E.1.548 }\end{array}$ \\
\hline DPSTM-500 & & Subroutine: SKIP & $\operatorname{Rev}_{1}$ & $\begin{array}{l}\text { Date } \\
6 / 73\end{array}$ \\
\hline
\end{tabular}

Purpose:

Usage:

Arguments:

Parameter

FMT

I

$\mathrm{N}$

B

Program Logic:

Language:

Author:

Restrictions:
To record in a two-byte field the number of successive occurrences of a one-byte variable.

Cal1 SKIP (FMT, I , N, B)
Type

Logical*1

Integer*2

Integer*2

Logical*1

\author{
Description \\ Returns a one- or two-byte coded form of \\ input. \\ Incrememented by number of bytes used to \\ code input. \\ The number of occurrences of $B$. \\ Variable whose occurrences are to be \\ recorded.
}

If the value of $\mathrm{N}$ is $0-2$, the value in $\mathrm{B}$ is placed in $\mathrm{N}$ number of bytes of FMT.

If $\mathrm{N}$ is greater than two the value in $\mathrm{B}$ is moved to the second byte of FMT and the value $\mathrm{N}-2$ placed in the first byte.

I" is incremented by the number of bytes utilized.

\section{Fortran IV}

J. E. Suich

To allow proper decoding the value of $\mathrm{N}$ should be in the range of $0-65$ inclusive. 


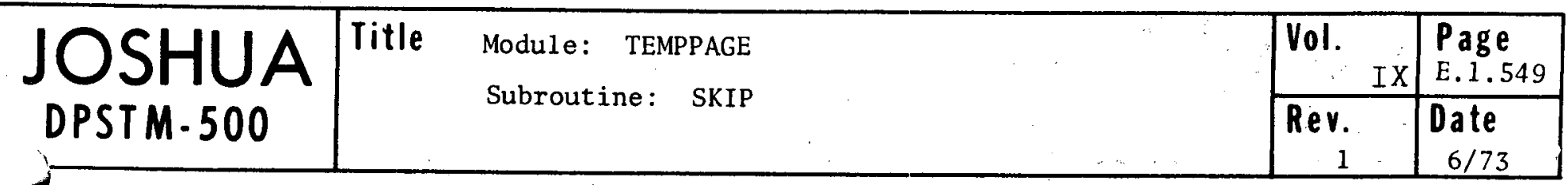

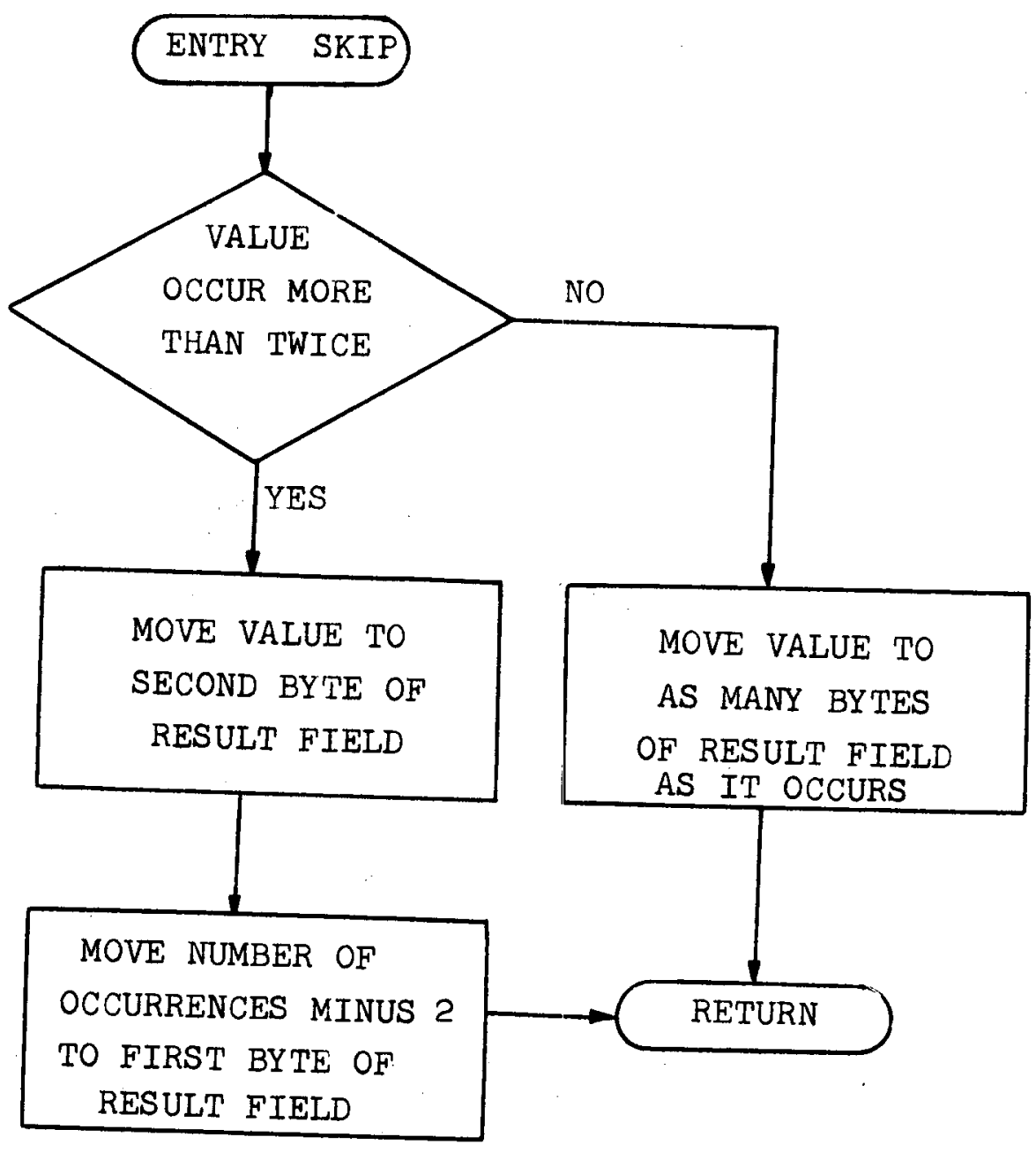


Module: TEMPPAGE

Subroutine: XPAGE

Purpose:

Usage :

Arguments:
To scan a template page-type display and convert it to a template format.

Call XPAGE (NCMAX, NLMAX, NSTAR, NERR, FMTL, CD, NDFS)

\begin{tabular}{lll} 
Mnemonic & \multicolumn{1}{c}{ Type } & \multicolumn{1}{c}{ Description } \\
NCMAX & Integer *2 & $\begin{array}{l}\text { Only the first NCMAX positions of } \\
\text { each set of eighty positions of CD } \\
\text { are of interest. }\end{array}$ \\
NLMAX & Integer *2 & $\begin{array}{l}\text { Number of eighty-byte fields (or } \\
\text { lines) in CD. }\end{array}$ \\
NSTAR & Integer *2 & $\begin{array}{l}\text { Index to FMTL. } \\
\text { NERR }\end{array}$ \\
Integer *2 & $\begin{array}{l}\text { Returns the position in CD of any } \\
\text { illegal syntax; otherwise set to } \\
\text { zero. }\end{array}$ \\
FMTL & Logical $* 1$ & $\begin{array}{l}\text { Returns the template format } \\
\text { Page-type display. } \\
\text { CD }\end{array}$ \\
LDFS & Logical $* 1$ & $\begin{array}{l}\text { Returns the number of variable } \\
\text { data fields. }\end{array}$
\end{tabular}

Subprograms:

Program Logic:
SKIP

- Test data is coded and stored in FMTL. All byte configurations are considered text except for colons and any characters following a colon which constitute a data field definition.

- A colon may indicate a page roll-off, a format repeat, an index data field, or a variable data field.

1. A colon at some NCMAX indicates a roll-off request; the colon is stored as text.

2. A double colon represents a format repeat with the repeat starting at the beginning of the previous line. A double colon ending a line is adjusted to the start of the next line. Scanning of the page terminates when a format repeat indication is encountered.

3. A colon followed by a numeric character 1-7 indicates an index data field. The width of the field is limited to fifteen positions (excluding the colon). Field definitions may not span Iines; any continuation is interpreted as tEx:.

4. A colon followed by a series of one of the characters in the set $A, E, F, I$, or $Z$ indicates a variable data field. 


\begin{tabular}{|c|c|c|c|l|}
\hline JOSHUA & Title Module: tEMPPAGE & Vol: Ix & $\begin{array}{l}\text { Page } \\
\text { E.1.551 }\end{array}$ \\
DPSTM-500 & Subroutine: xPAGE & Rev. & $\begin{array}{l}\text { Date } \\
6 / 73\end{array}$ \\
\hline
\end{tabular}

Error Conditions: 1. Page starts with a repeat indicator.

2. Illegal use of colon.

3. Floating-point field does not have a decimal point.

4. Width of an index or floating-point field exceeds fifteen positions.

5. Fewer than four decimal positions specified for an E field.

Language:

FORTRAN IV

Author:

R. C. Haywood - J. E. Suich

Remarks:

See Template Interpretation and Structure for explanation of actual template coding. 


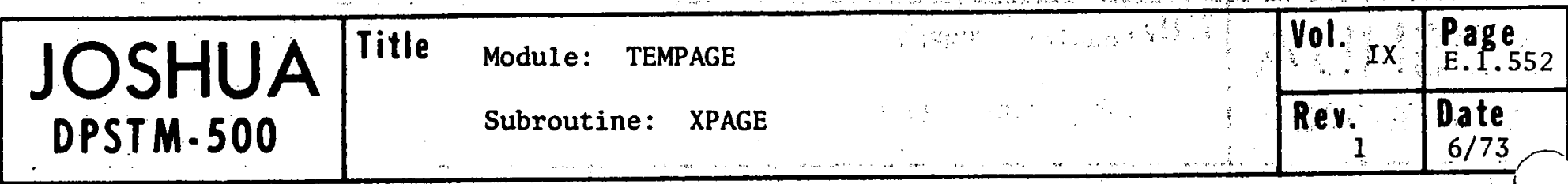

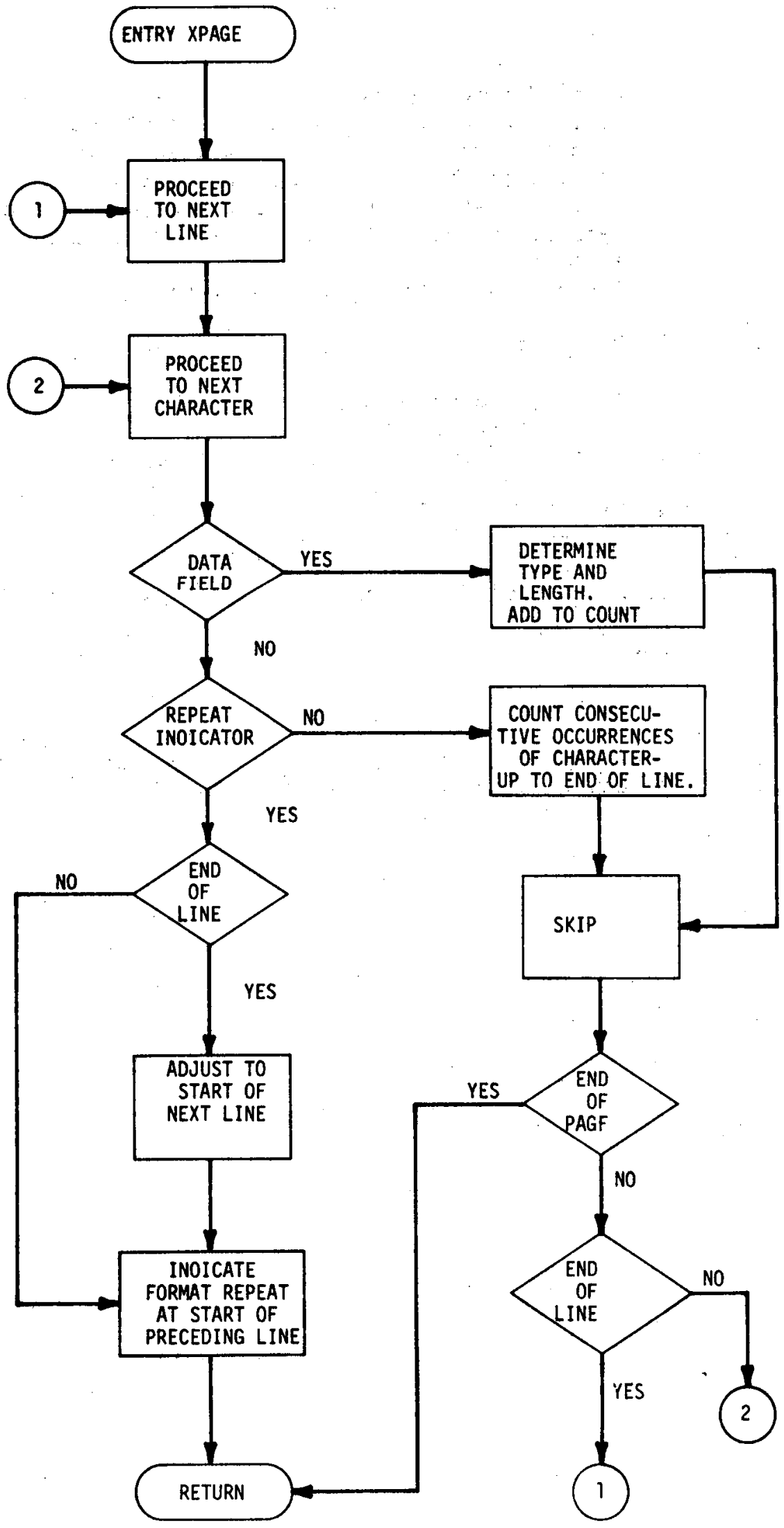




\begin{tabular}{|c|c|c|c|}
\hline 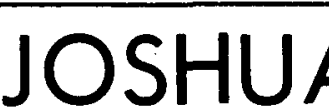 & \multirow{2}{*}{$\begin{array}{ll}\text { Title } & \text { Module: TEMPPAGE } \\
& \text { Subroutine: } \quad \text { XPTRS }\end{array}$} & Vol. IX & \begin{tabular}{|l|} 
Page \\
E.1.553
\end{tabular} \\
\hline DPSTM & & Rev. & $\begin{array}{l}\text { Date } \\
6 / 73\end{array}$ \\
\hline
\end{tabular}

Purpose:

Usage:

Arguments:
For a template page-type, to determine the loop starting locations both in the format and on the page and to set the loop page type.

Cal1 XPTRS (LIMIT, NSTAR, LOOPS, FLAG, FMTL, PGESIZ)

Mnemonic Type Description

LIMIT Integer *2 For each loop, a set of six nodes defined as follows:

1. Number of variables in the loop.

2. Loop lower limit.

3. Loop uper limit.

4. Loop format start location.

5. Loop page start location.

6. Page-type (always one).

NSTAR Integer $* 2$ Pointer to end of FMTL.

LOOPS Integer *2 Indicates the number of loops on the page.

FLAG Integer *2 Returns a completion code: zero for successful completion. One when an error is encountered.

FMTL Logical ${ }^{*} 1$ Coded page format.

PGESIZ Integer *2 Size of page-in bytes.

Program Logic:

- The page type for all loops is one.

- A loop start is considered to have been encountered when an index or variable data field is encountered after having passed over sufficient variable data fields to accomodate the preceding loops. The format and page start for the first loop is set to one.

- When a roll-off is indicated the format start is set for the next position and the page start to one. A11 succeeding page starts are based on the resetting unless a another roll-off is encountered.

Terminating Conditions: Page or format limits exceeded:

Language:

FORTRAIN IV

Author:

R. C. Haywood - J. E. Suich 


\begin{tabular}{|c|c|c|c|}
\hline & Title Module: TEMPAGE & Vol. IX & $\begin{array}{l}\text { Page } \\
\text { E.1.554 }\end{array}$ \\
\hline DPSTM.500 & Subroutine: XPTRS & Rev. & $\begin{array}{l}\text { Date } \\
0 ;-5\end{array}$ \\
\hline
\end{tabular}

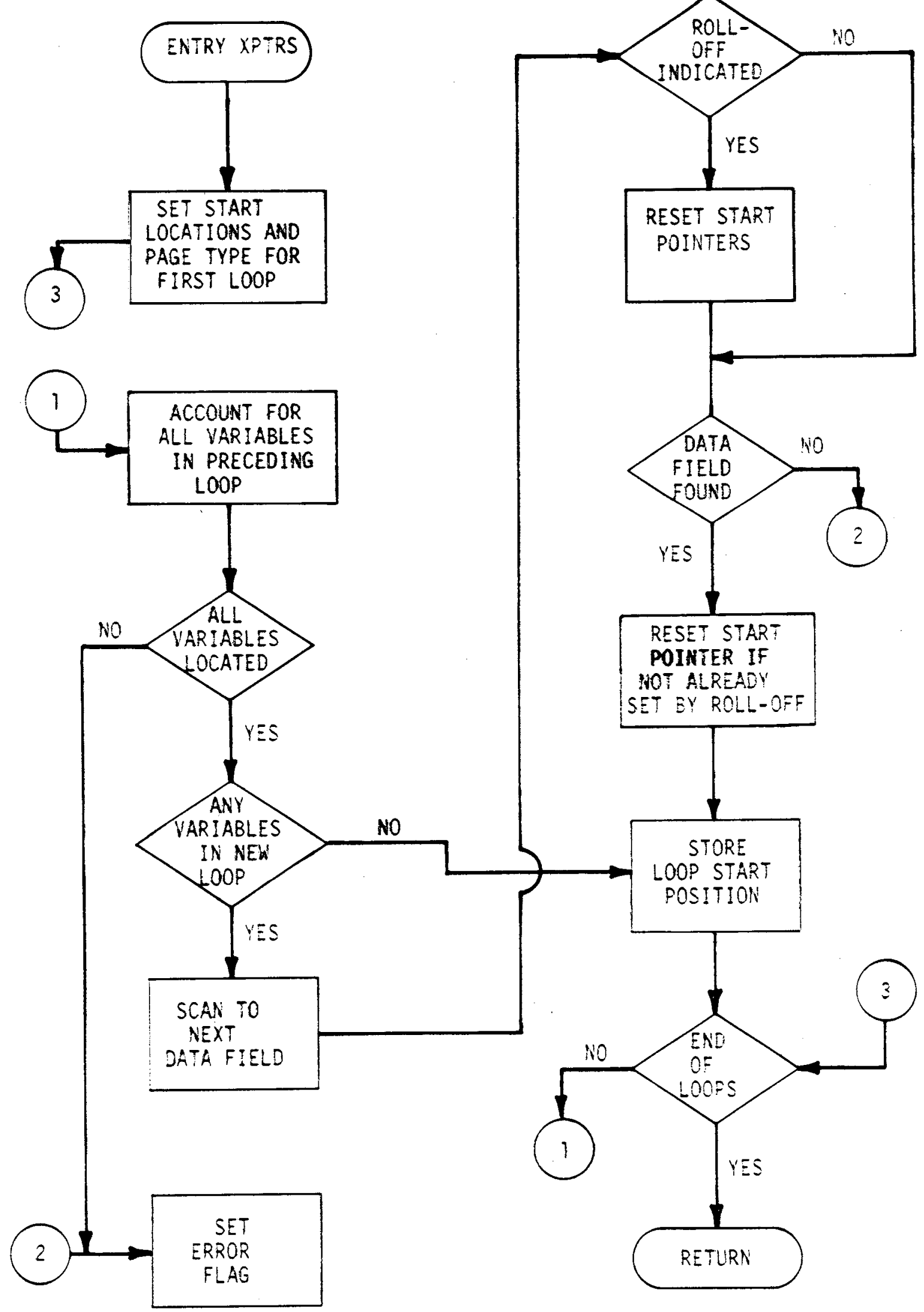




\begin{tabular}{|c|l|l|l|l|}
\hline \multirow{2}{\text{JOSHUA}}{$\begin{array}{c}\text { Title } \\
\text { DPSTM-500 }\end{array}$} & $\begin{array}{l}\text { Module: TEMPPAGE } \\
\text { Subroutine: XTMPLT }\end{array}$ & $\begin{array}{l}\text { Pol. Ix } \\
\text { E.1.555 }\end{array}$ \\
\cline { 3 - 5 } & & Rev. & $\begin{array}{l}\text { Date } \\
6 / 73\end{array}$ \\
\hline
\end{tabular}

Purpose:

Usage:

Arguments:
To consolidate the data for a template nest segment.

Cal 1 XTMPLT (LIMIT, LOOPS, NSTAR, TSIZE, NTMPLT, FMTL, TYPE, FLAG)

Mnemonic

Type

Description

LIMIT Integer *2 For each loop, a set of six nodes defined as follows:

1. Number of variables.

2. Lower limit.

3. Upper limit.

4. Format start position.

5. Page start position.

6. Page type.

LOOPS Integer *2 Number of loops.

NSTAR Integer *2 Pointer to the end of FMTL.

TSIZE Integer *2 Maximum number of halfword allowed for a nest segment.

NTMPLT Integer *2 Area into which the segment is consolidated.

FMTL Logical $*_{1} \quad$ Coded format.

TYPE Integer *2 For each variable in the nest, a mode supplies the length and type.

FLAG Integer *2 Completion code - one of an error is encountered, zero.
Program Logic:

Error Condition:

Language:

Author:
The data is consolidated to form a segment as described in Template Interpretation and Structure.

Space required exceeds space allowed.

FORTRAN IV

R. C. Haywood - J. E. Suich 


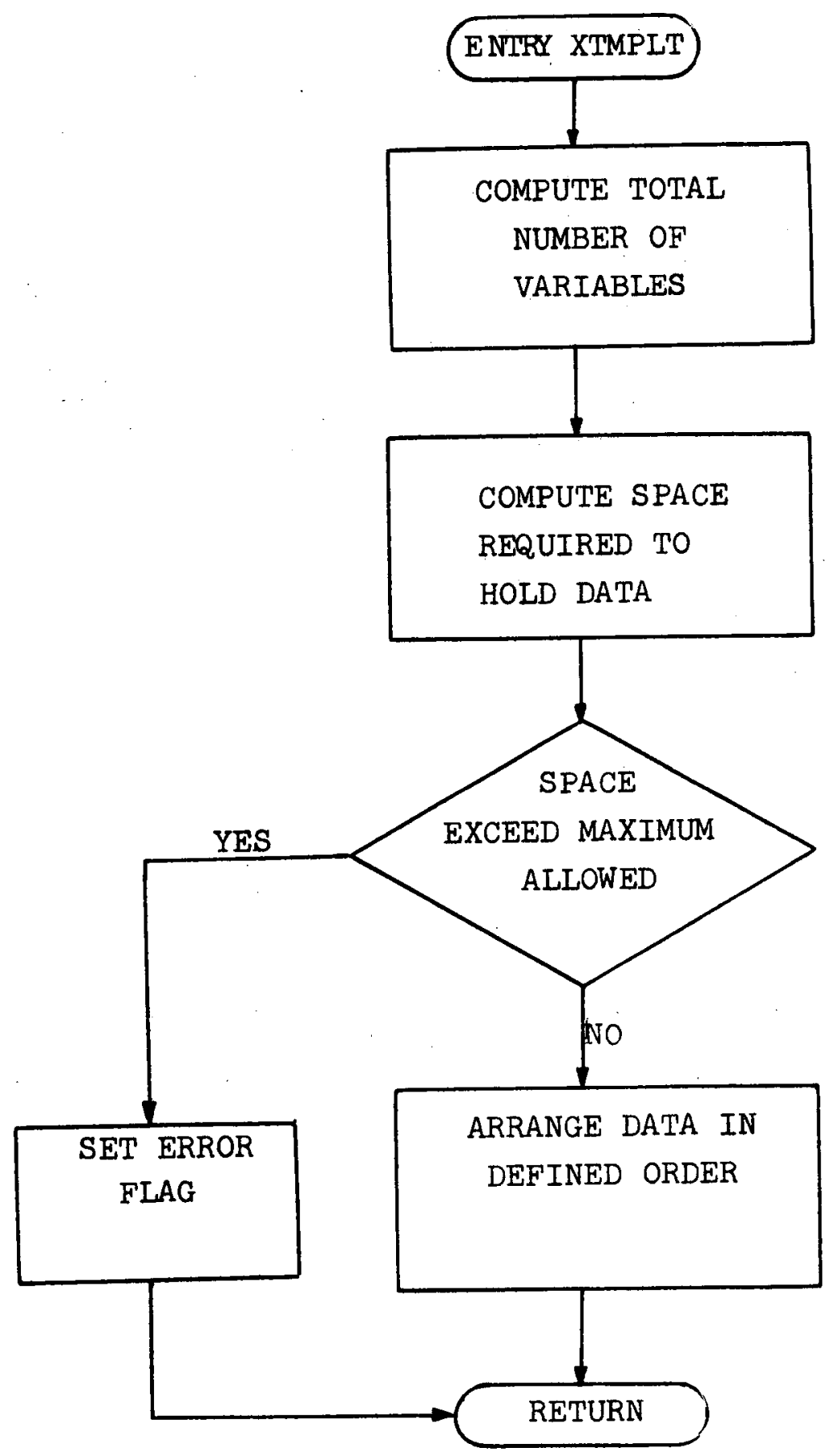




\begin{tabular}{|l|l|l|l|l|}
\hline JOSHUA & Title Module: VERIFY & Vol. & Page \\
DPSTM-500 & & Ix & E.1.557 \\
\cline { 3 - 5 } & & $\begin{array}{l}\text { Rev. } \\
\text { Date } \\
6 / 73\end{array}$ \\
\hline
\end{tabular}

Purpose

To determine whether a given user may have access to a data set.

Attribute: $\quad$ Nonreusable

JOS Main Program: MAIN

Arguments:

\begin{tabular}{lll} 
Mnemonic & \multicolumn{1}{c}{ Type } & \multicolumn{1}{c}{ Description } \\
\$MCB & Rea1*8 & CCB. \\
DSN & Rea1*8 & $\begin{array}{l}\text { WCBARG1 - specifies the JOSHUA } \\
\text { data set for which access is to } \\
\text { be verified. }\end{array}$
\end{tabular}

Subprograms:

\begin{tabular}{ll} 
Control Section & Entry Point \\
\hline \$TERR & \$TERR \\
MOVEIT & MOVEIT \\
TRNSLT & TRNSLT
\end{tabular}

Program Logic:

- The access record is sought. The search is restricted to the subject data set and standard or, for standard data sets, to standard only. When no record is located, access is allowed any user.

- The access record is read and checked to see if it contains the USER number. When it is, a functional request 7 is made to BNAM to assure the correct copy of the JDSCB is in core. Otherwise, \$TERR is called to indicate unsucessful completion.

Terminating Conditions:

- USER number not included in an existing access record.

Language:

FORTRAN IV

Author:

R. C. Haywood - J. C. Jensen 


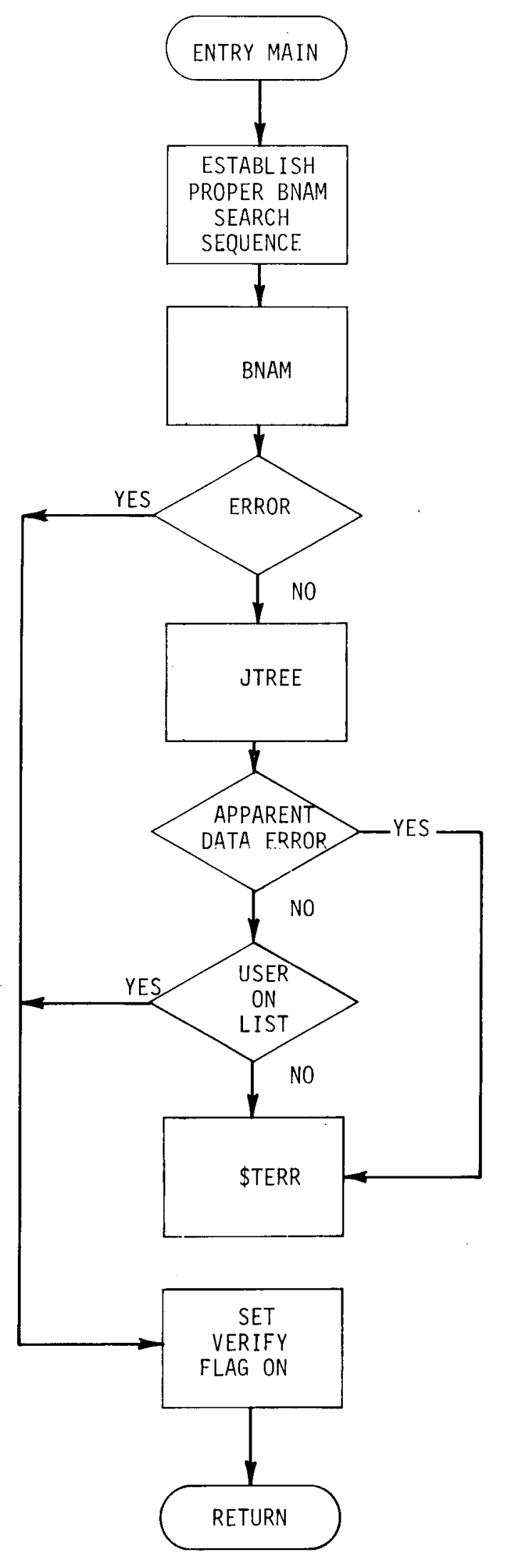

Rev. 


\begin{tabular}{|l|l|l|l|l|}
\hline \multirow{2}{*}{ DPSTM-500 } & Title Module: zonK1 & Vol. Ix & $\begin{array}{l}\text { Page } \\
\text { E.1.559 }\end{array}$ \\
\cline { 3 - 5 } & & Rev. & $\begin{array}{l}\text { Date } \\
6 / 73\end{array}$ \\
\hline
\end{tabular}

Purpose:

Attribute:

JOS Main Program Name:

Arguments:

Párameter

Job name

Badge Number

Externa1 References:

Data Sets:

Objective:

Program Logic:

Referenced by:

Language:

Author:
To provide a display of job accounting information based upon the current days completed jobs.

Nonreusable

ZONK1

Type

Description

D

1 to 8 byte character string defining search argument

F $\quad 4$ alpha numeric digits defining search argument.

EXCP, WPAGE, WAIT

SYSI. ACCTNGI

The program builds displayable screen images VIA module WPAGE of job accounting information based on one of two arguments

(a) Full or partial job name

(b) User Badge number

The address of search argument and a screen buffer is received VIA Register 1. The code searches the nucleus for the Data Control Block and Data Extent Block that define the SYS1. ACCTNG1 data set and builds an Input Output Control Block to allow retrevial of accounting records. The current data is established and a cylinder search using a full track read in initiated. Once the current data is located the search continues until a record containing 8:00 A.M. is located. The code then searches on either job name or user badge number for matching records. On a match, accounting information including job statistics are formated for display to the requesting user. The search continues until either an end of file or 4:00 P.M. is encountered.

JTMON

Assembler

Leo F. Zimmerman 


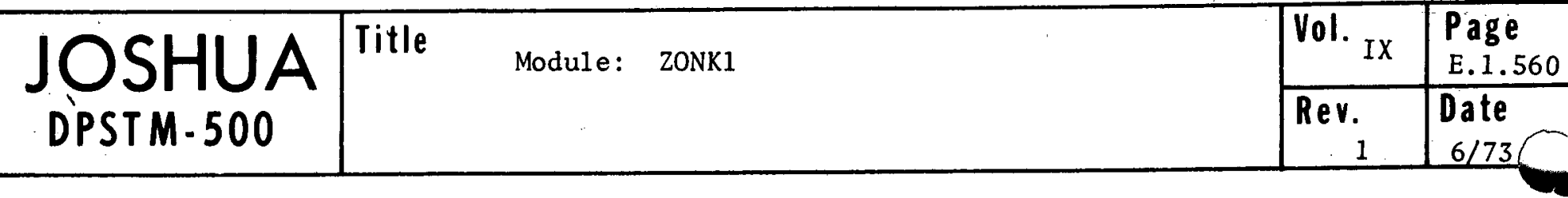
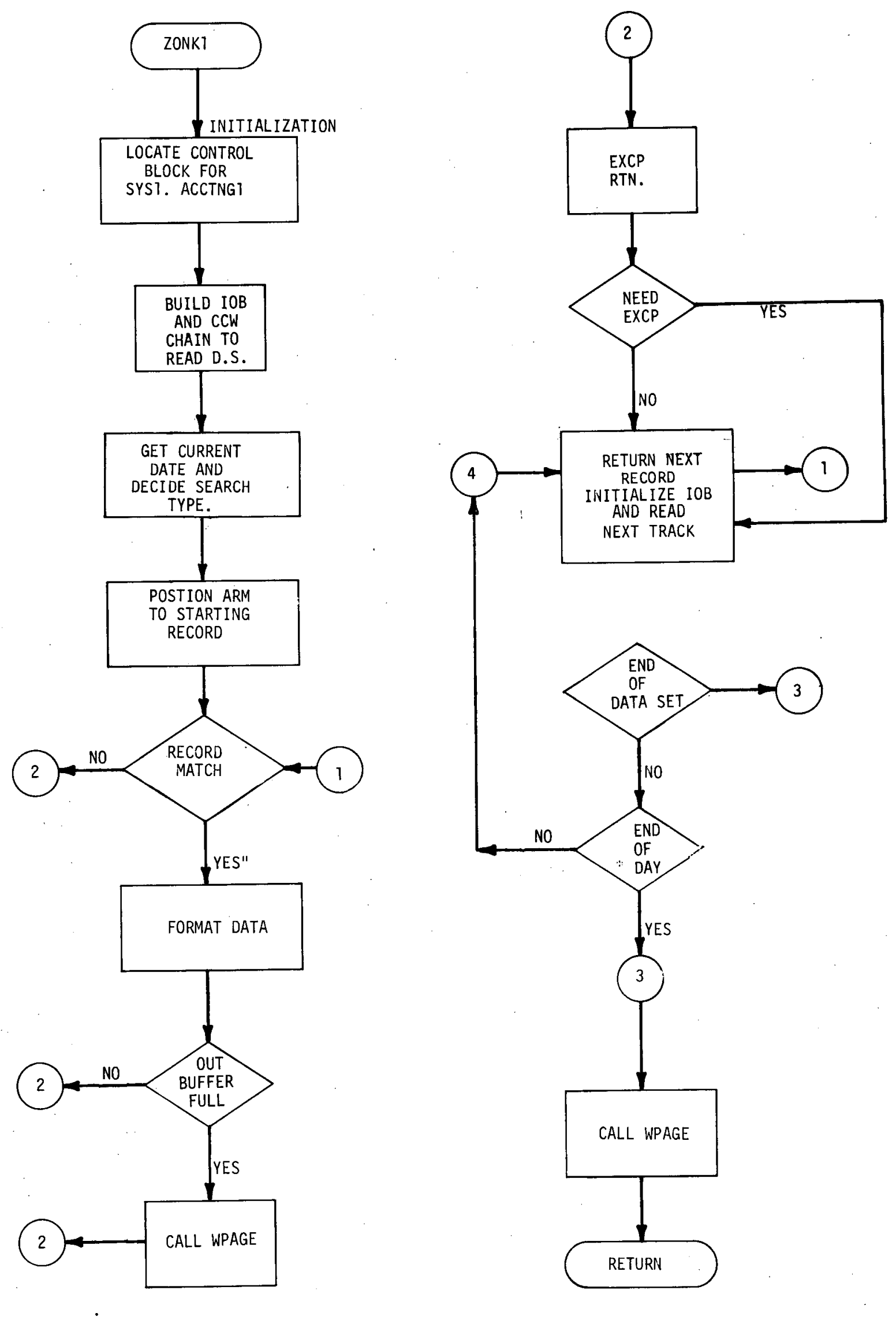


\begin{tabular}{|c|c|c|c|}
\hline$J$ & Title Subprograms & $\begin{array}{r}\text { Vol. } \\
\text { IX }\end{array}$ & $\begin{array}{l}\text { Page } \\
\text { E.2.1 }\end{array}$ \\
\hline DPSTM-500 & & $\begin{array}{l}\text { Rev. } \\
1\end{array}$ & $\begin{array}{l}\text { Date } \\
6 / 73\end{array}$ \\
\hline
\end{tabular}

Work Done By

R. L. Boyce, Jr.

W. H. Brotherton, Jr.

R. C. Haywood

J. C. Jensen

R. S. Wood
Report Written By

R. L. Boyce, Jr.

W. H. Brotherton, Jr.

R. C. Haywood

R. S. Wood

\section{Contents}

1. Introduction

2. Subprograms

$2.1 \$ \$ D P$

$2.2 \quad \$ \$ F I$

$2.3 \$ \$ I P$

$2.4 \$ \$ I U$

$2.5 \$ \$ \mathrm{PI}$

$2.6 \$ \$$ SC

2.7 \$\$L

$2.8 \$ \$$ UI

2.9 \$AER

2.10 \$BDG

2.11 \$BERR

2.12 \$BOX

2.13 \$CC\$

2.14 \$CF\$

$2.15 \$$ CFO

$2.16 \$$ CLC

2.17 \$CLI

2.18 \$DIR

2.19 \$EXC

$2.20 \$$ FLG16

2.21 \$JCOMA

2.22 \$MVC

2.23 \$PKF

2.24 \$RDR

$2.25 \$ S F \$$

2.26 \$TERR

2.27 \$UNT

2.28 \$WTR

2.29 BCDFIX

2.30 BCDFLT

2.31 DEFINE

2.32 FLEXIT

2.33 FMINIT

2. 34 FMPACK

2.35 FMUNPK

2.36 HEXXY

2.37 IBMDATE

2.38 IBMJUL

2.39 IPUT

2.40 JOSDEQ

2.41 DOSENQ

2.42 JSREAD $\underline{\text { Page }}$

E. 2.3

E.2.5

E. 2.5

E. 2.7

E.2.9

E. 2.11

E. 2.13

E. 2.15

E. 2.19

E. 2.21

E. 2.23

E. 2.25

E. 2.27

E. 2.29

E. 2.31

E. 2.33

E. 2.35

E. 2.37

E. 2.39

E. 2.41

E. 2.45

E. 2.47

E. 2.49

E. 2.51

E. 2.53

E. 2.55

E. 2.61

E. 2.63

E. 2.65

E. 2.67

E. 2.73

E. 2.77

E. 2.79

E. 2.81

E. 2.83

E. 2.85

E. 2.87

E. 2.89

E. 2.97

E. 2.99

E. 2.101

E. 2.105

E. 2.107

E. 2.109 


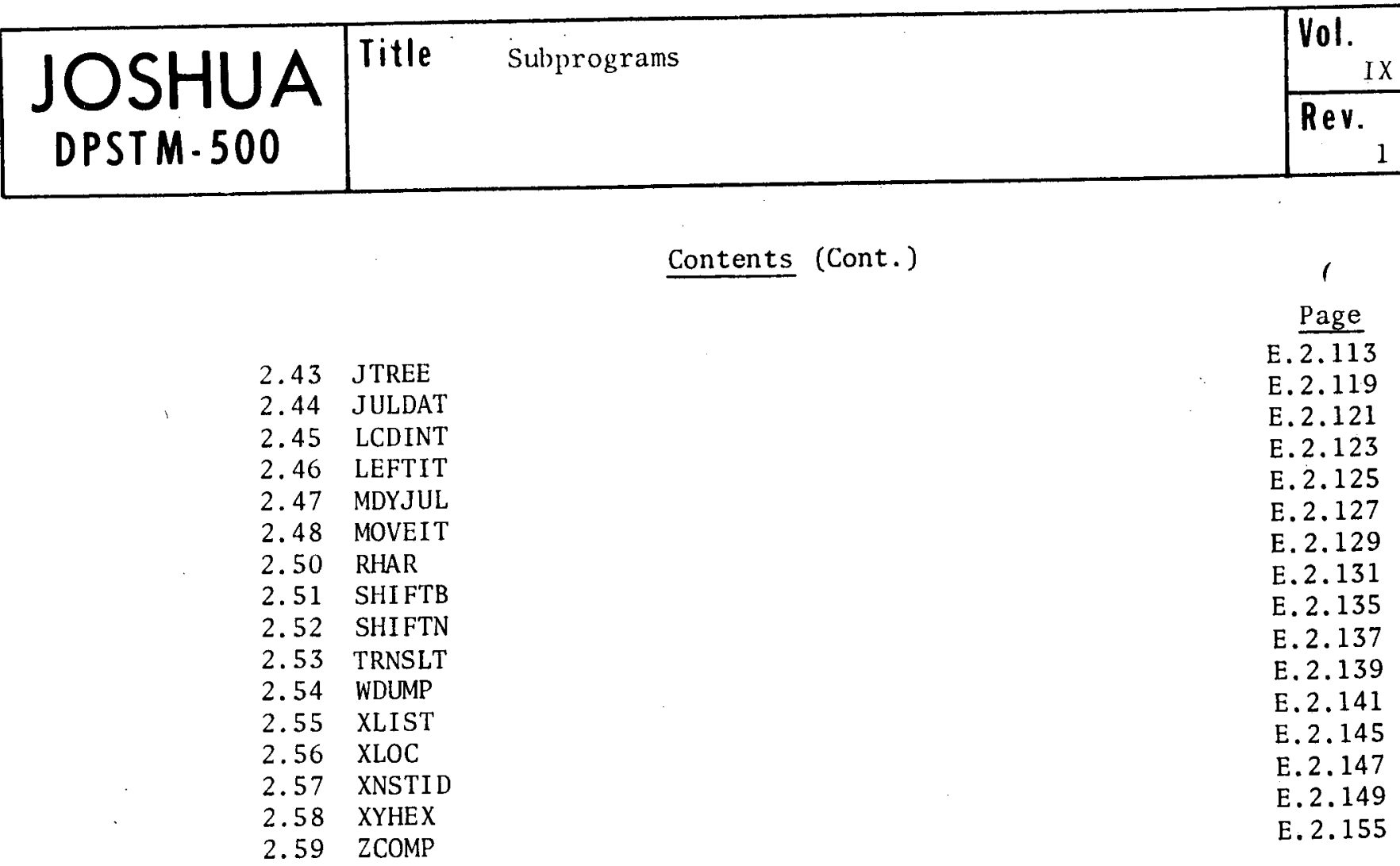




\begin{tabular}{|l|l|l|l|l|}
\hline \multirow{2}{*}{$\begin{array}{l}\text { JOSHUA } \\
\text { DPSTM-500 }\end{array}$} & Title Subprograms & $\begin{array}{l}\text { Vol. } \\
\text { Ix }\end{array}$ & $\begin{array}{c}\text { Page } \\
\text { E.2.3 }\end{array}$ \\
\cline { 3 - 5 } & & Rev. & Date \\
& & & $6 / 73$ \\
\hline
\end{tabular}

1. Introduction

This section will describe the subroutines and functions which compose the JOSHUA Operating System. The subroutine description is followed by a flow chart. If a particular subroutine cannot be found in this section, its description may be found within the module that used it (exclusively uses it) in the Module Section. 


\begin{tabular}{|c|c|c|c|}
\hline & \multirow[t]{2}{*}{ Title Subprograms } & ${ }_{\text {Vol. }}$ & $\begin{array}{l}\text { Page } \\
\text { L:.2.4 }\end{array}$ \\
\hline DPSTM. 500 & & Rev. & Date \\
\hline
\end{tabular}




\begin{tabular}{|c|c|c|c|c|}
\hline & \multirow{2}{*}{\multicolumn{2}{|c|}{ Title $\quad$ Subroutine: $\$ \$ D P$}} & Vol. $_{\text {IX }}$ & $\begin{array}{l}\text { Page } \\
\text { E.2.5 }\end{array}$ \\
\hline DPST M. 500 & & & $\operatorname{Rev.~}_{1}$ & $\begin{array}{l}\text { Date } \\
6 / 73\end{array}$ \\
\hline
\end{tabular}

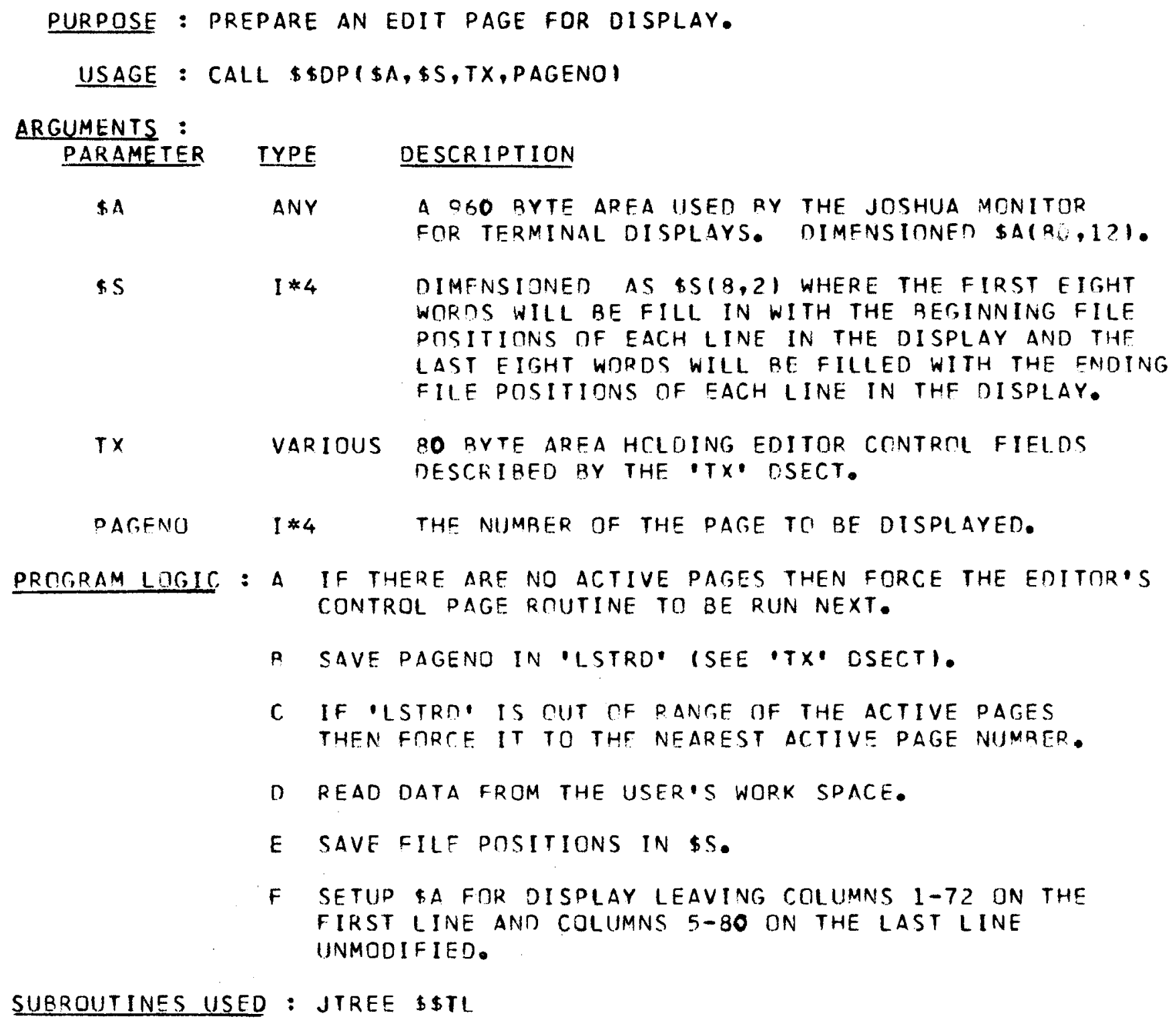




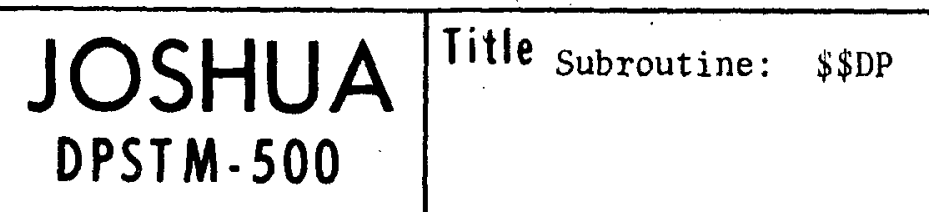

Vol.

Page

\begin{tabular}{|c|c|}
\hline Rev. & Date \\
& $6 / 73$
\end{tabular}




\begin{tabular}{|l|l|l|l|l|}
\hline$\underset{\text { DPSTM.500 }}{\text { J Sitle Subroutine: \$\$FI }}$ & Vol. & $\begin{array}{l}\text { Page } \\
\text { IX.2.7 }\end{array}$ \\
\cline { 3 - 5 } & & Rev. & $\begin{array}{c}\text { Date } \\
6 / 73\end{array}$ \\
\hline
\end{tabular}

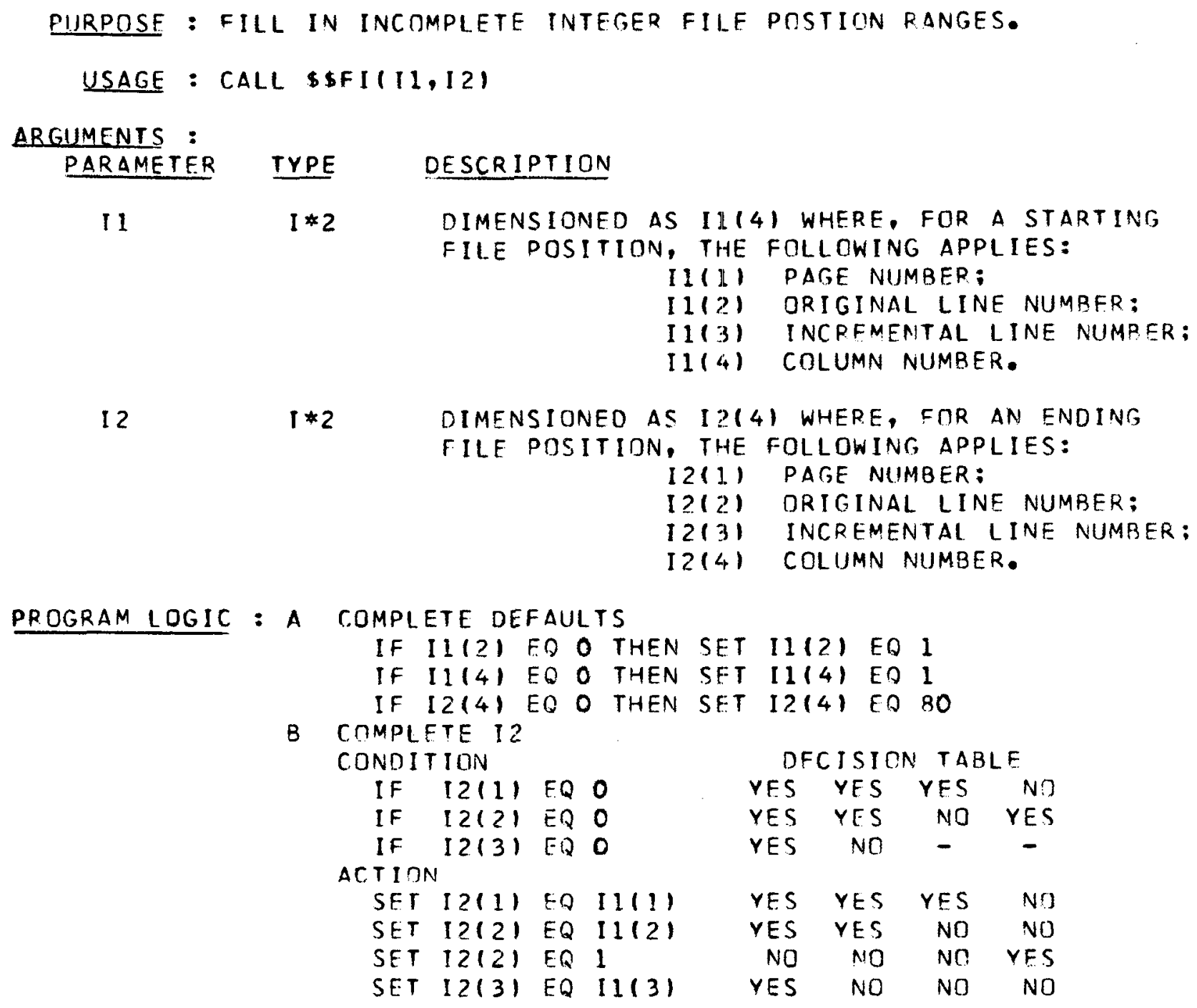

SUBRDUTINES USED : NONE

LANGUACE : ASSEMBLER

AUTHOR : R S WOOD 


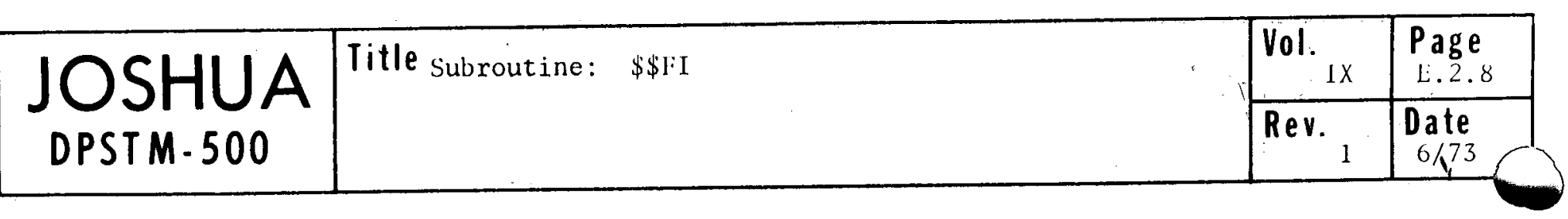




\begin{tabular}{|c|c|c|c|c|}
\hline \multirow{2}{*}{$\begin{array}{l}\text { JOSHUA } \\
\text { DPSTM } 500\end{array}$} & \multirow{2}{*}{\multicolumn{2}{|c|}{ Title Subroutine: $\$ \$$ IP }} & $\begin{array}{l}\text { Vol. } \\
\text { IX }\end{array}$ & \begin{tabular}{|l} 
Page \\
E.2.9 \\
\end{tabular} \\
\hline & & & $\operatorname{Rev.~}_{1}$ & $\begin{array}{l}\text { Date } \\
6 / 73\end{array}$ \\
\hline
\end{tabular}

PURPOSE : CONVERT INTEGER FILE POSITIONS TO PACKEO FILF POSITIONS. USAGE : CALL \$\$IP(II,PK)

\section{ARGUMENTS :}

PARAMETER

I1

PK

$L * 1$

IYPE

$I * 2$

L*1

\section{DESCR I PTION}

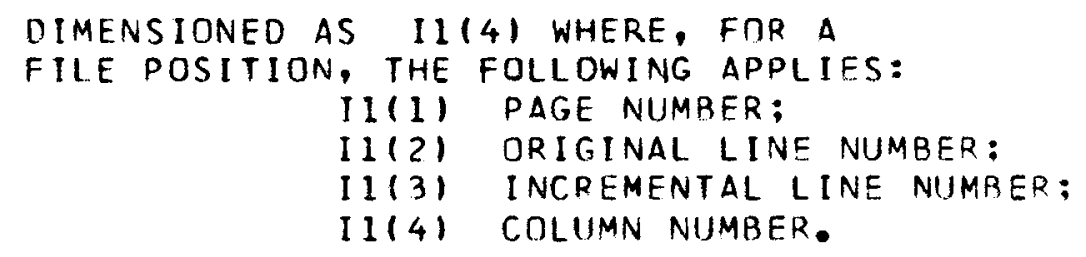

\section{SUBROUTINES USED : NONE}

\section{LANGUAGE : $A S S E M B L E R$}

AUTHOR : $R S$ WOOD 


\begin{tabular}{|l|ll|l|l|}
\hline JOSHUA & Title Subroutine: \$\$IU & Vol. & Page \\
& DPSTM.500 & & IX.2.11 \\
\cline { 3 - 5 } & & Rev. & $\begin{array}{c}\text { Date } \\
6 / 73\end{array}$ \\
\hline
\end{tabular}

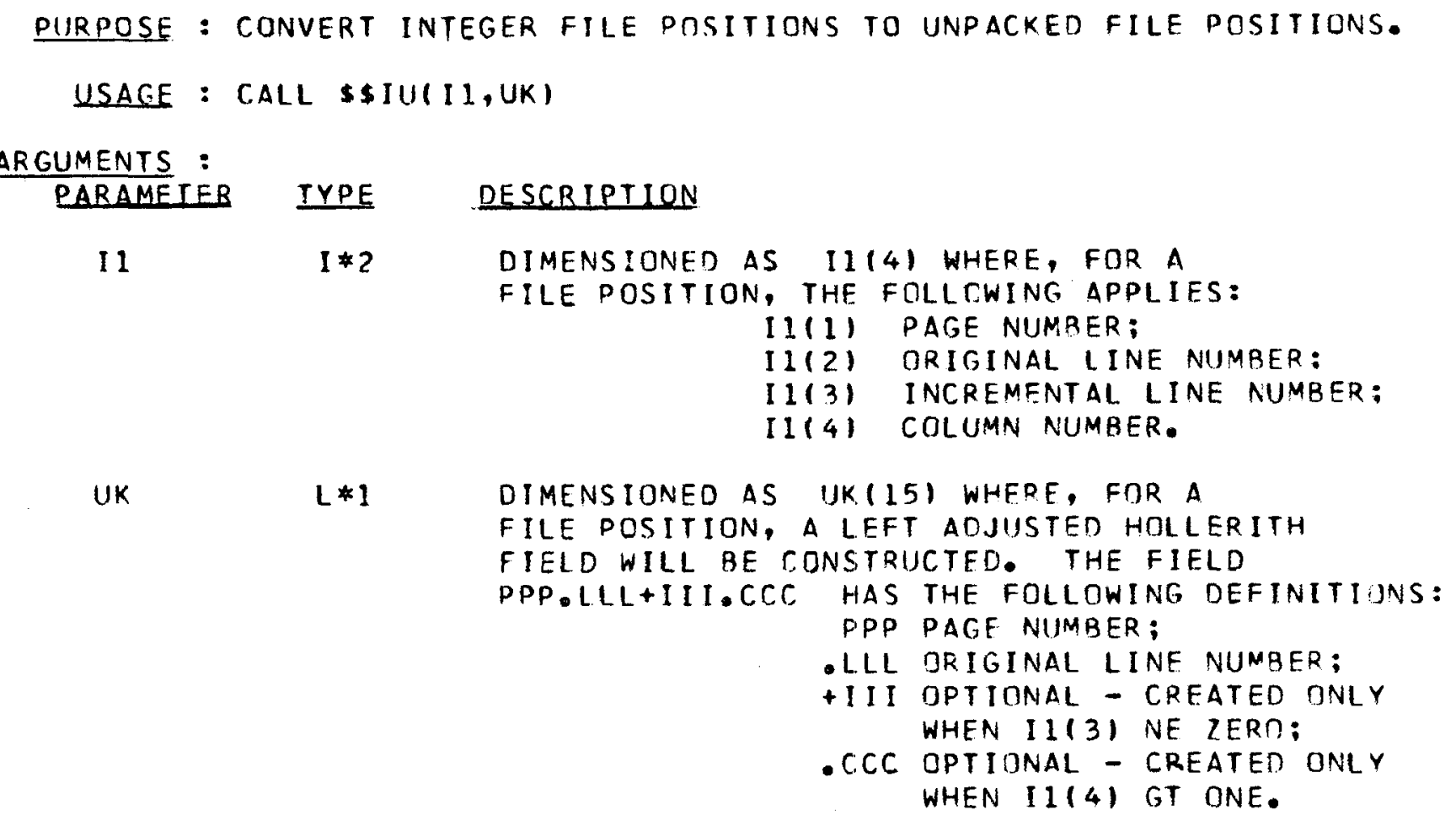

SURRDUTINES USED : NONE

LANGUAGE : ASSEMBLER

AUTHOR : F 5 WOND 


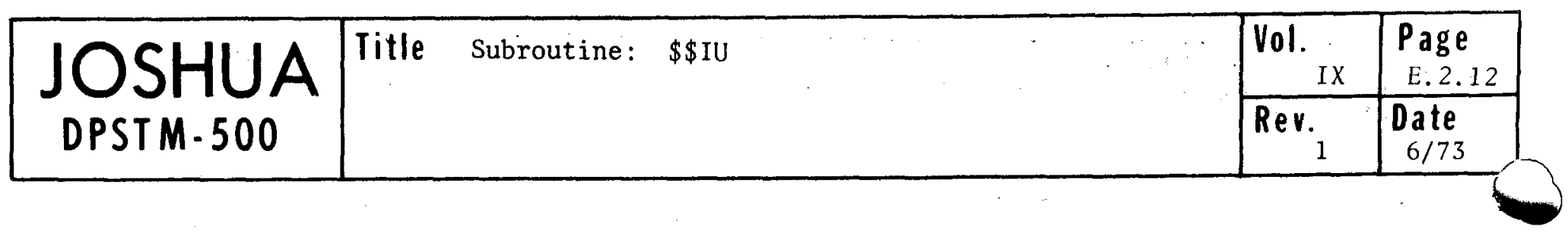

(Blank) 


\begin{tabular}{|l|l|l|l|l|}
\hline JOSHUA & Title Subroutine: \$\$PI & Vol. & $\begin{array}{c}\text { Page } \\
\text { IX.2.13 }\end{array}$ \\
\cline { 3 - 5 } & & Rev. & $\begin{array}{c}\text { Date } \\
6 / 73\end{array}$ \\
\hline
\end{tabular}

PURPOSE : CONVERT PACKEO FILE POSITIONS TO INTEGER FILE POSITIONS. USAGE : CALL \$\$PIIPK, III

\section{ARGUMENTS :}

PARAMETER TYPE DESCRIPTION

PK

L*1

DIMENSIONED AS PK(4) WHERE, FOR A

FILE POSITION, THE FOLLCWING APPLIES:

PK(I) PASE NUMBER;

PK(2) ORIGINAL LINE NUMBER:

PK (3) INCREMENTAL LINE NUMBER;

PK(4) COLUMN NUMBER.

11

I*?

DIMFNSIONED AS II(4) WHERE, FOR A

FILE POSITIDN, THE FOLLOWING APPLIES:

I111) PAGE NUMBER:

I1(2) ORIGINAL LINE NUMBER;

I1 13 ) INCREMENTAL LINE NUMBER;

I $1(4)$ COLUMN NUMBER.

SUBROUTINES USED : NONE

LANGUAGE : $\triangle S$ SEMRLER

AUTHOR : R S WUOD 


\begin{tabular}{|c|c|c|c|}
\hline & \multirow[t]{2}{*}{ Title subroutine: $\$ \$ P I$} & Vol. & $\begin{array}{l}\text { Page } \\
\text { E.2.14 }\end{array}$ \\
\hline DPSTM. 500 & & $\operatorname{Rev.~}_{1}$ & $\begin{array}{l}\text { Date } \\
6 / 73\end{array}$ \\
\hline
\end{tabular}

(B1ank) 


\begin{tabular}{|c|c|c|c|c|}
\hline & \multirow{2}{*}{\multicolumn{2}{|c|}{ Title $\quad$ Function: $\$ \$ S C$}} & Vol. $_{\text {IX }}$ & $\begin{array}{l}\text { Page } \\
\text { E.2.15 }\end{array}$ \\
\hline DPSTM. 500 & & & $\begin{array}{r}\text { Rev. } \\
1\end{array}$ & $\begin{array}{l}\text { Date } \\
6 / 73\end{array}$ \\
\hline
\end{tabular}

PURPOSE : ANALYZE THE EOITOR COMMAND RETURNED ON A TERMINAL DISPLAY. USAGE : $N=\$ \$ S C\{I N$, OUT

\title{
ARGUMENTS :
}

PARAMETER

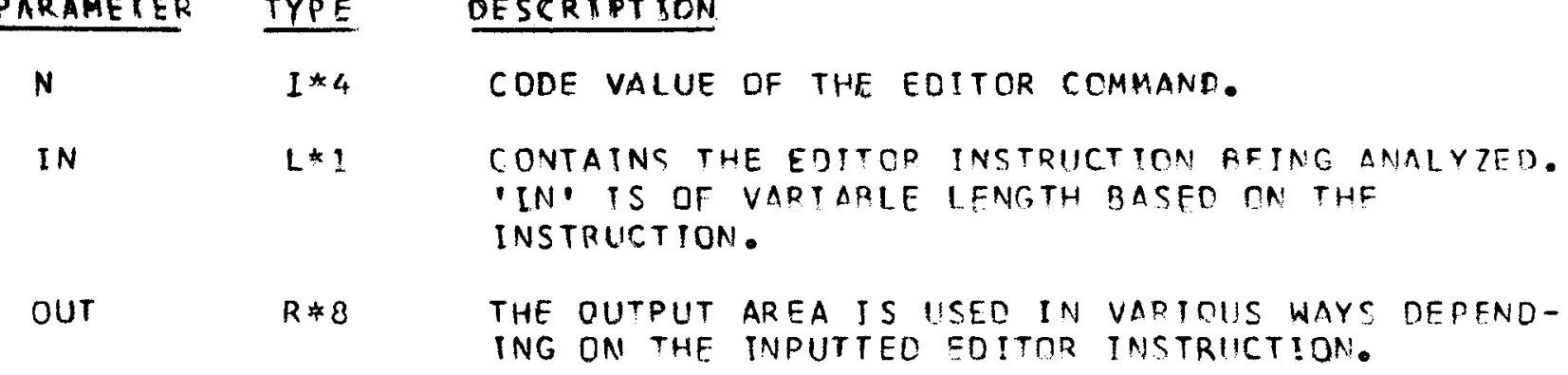

\section{EQU IVAL ENCES WITH OUT 111 USEC:}

\author{
PARAMETER TYDE DESCRTPTTIA: \\ FP(4,I) I*2 WILL CONTAIN FILE POSITIONS WHEN AFPRCPIATE.
}

COYMANDS ANALYZED: THE FOLLOWING FDITOR COMMANO SYNTAX IS HANOLED:

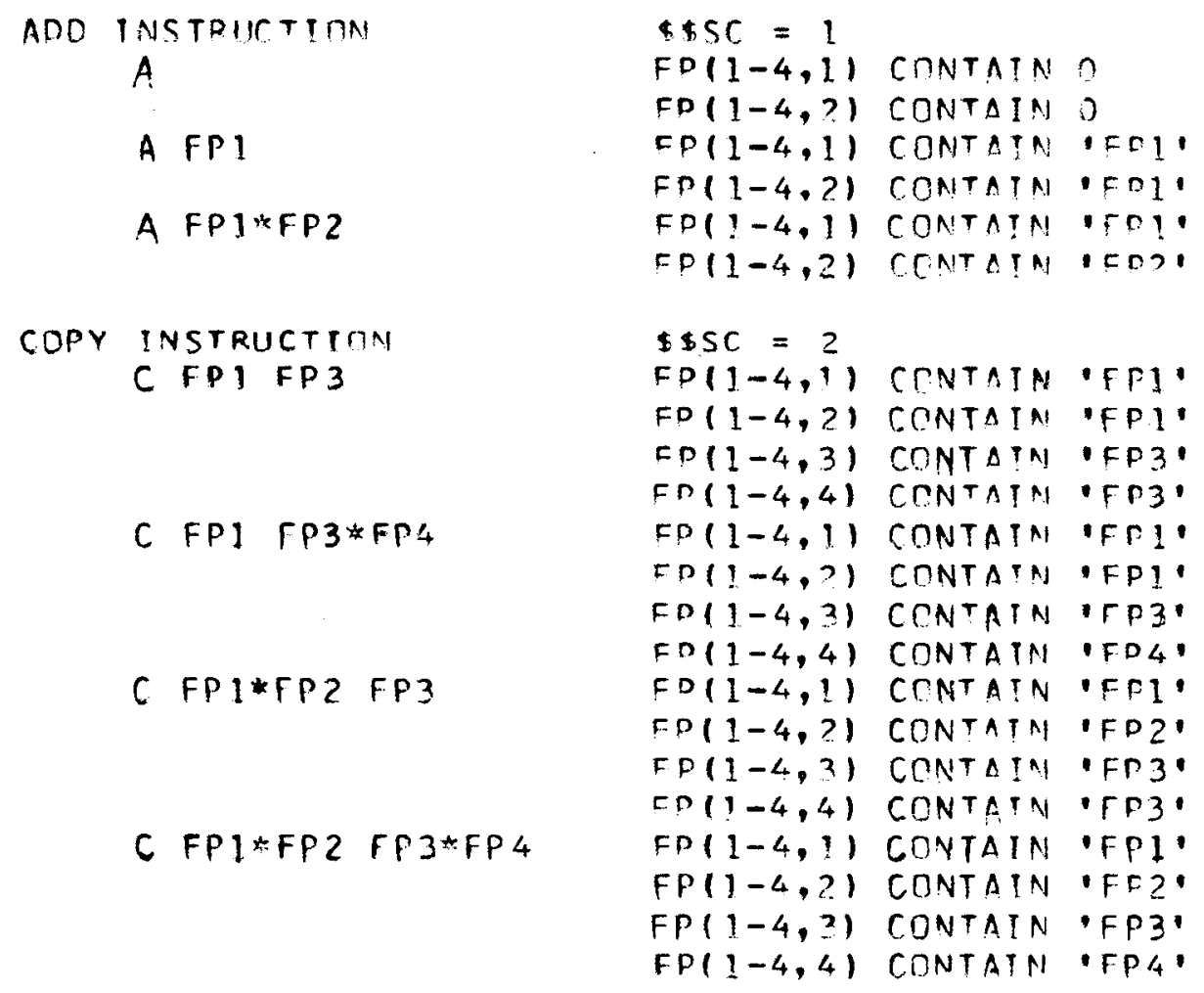




\begin{tabular}{|c|c|c|c|c|}
\hline JOSHUA & Title Function: \$\$SC & Vol. & Page \\
DPSTM.500 & & Ix & E.2.16 \\
\cline { 3 - 4 } & & $\begin{array}{c}\text { Rev. } \\
\text { Date } \\
6 / 73\end{array}$ \\
\hline
\end{tabular}

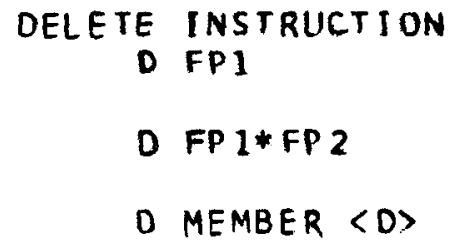

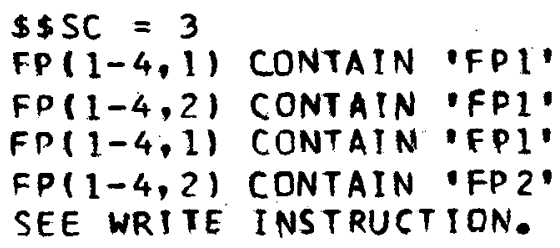

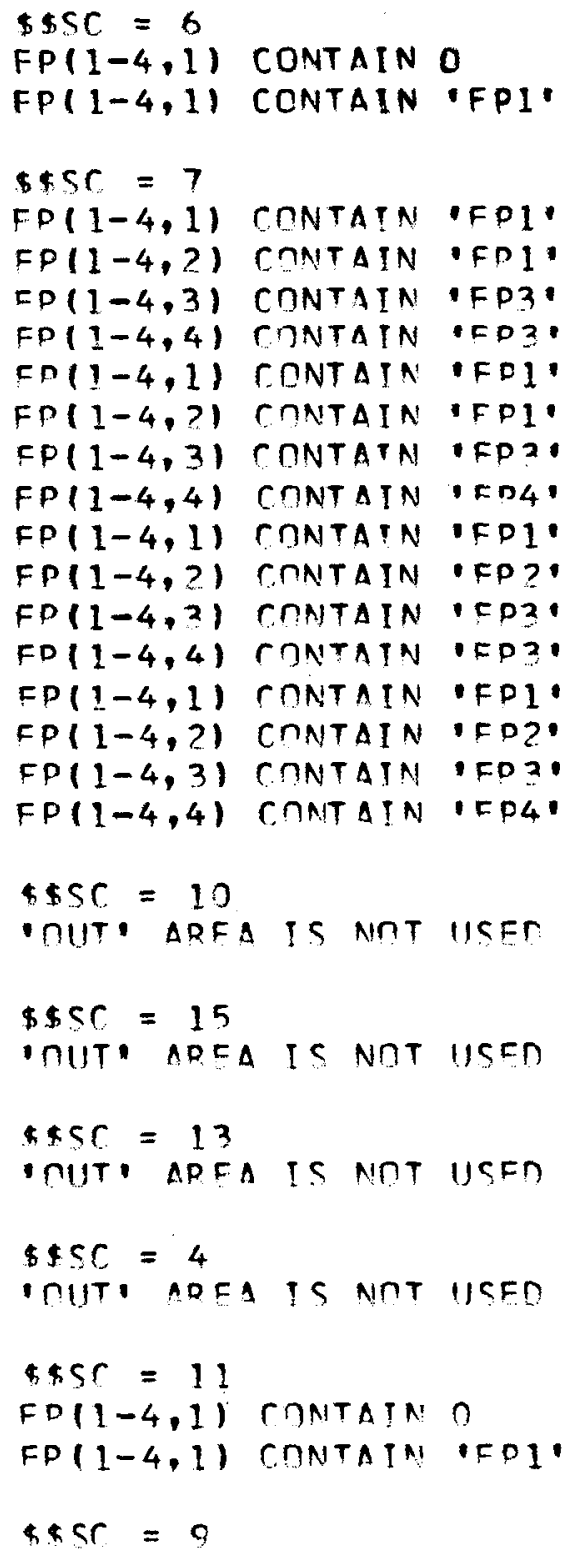




\begin{tabular}{|c|l|l|l|l|}
\hline \multirow{2}{\text{JPSTM}-500}{} & Title & Function: $\$ \$ S C$ & Vol. & Page \\
Ix & $E .2 .17$ \\
\cline { 3 - 5 } & & $\begin{array}{c}\text { Rev. } \\
\text { Date } \\
6 / 73\end{array}$ \\
\hline
\end{tabular}

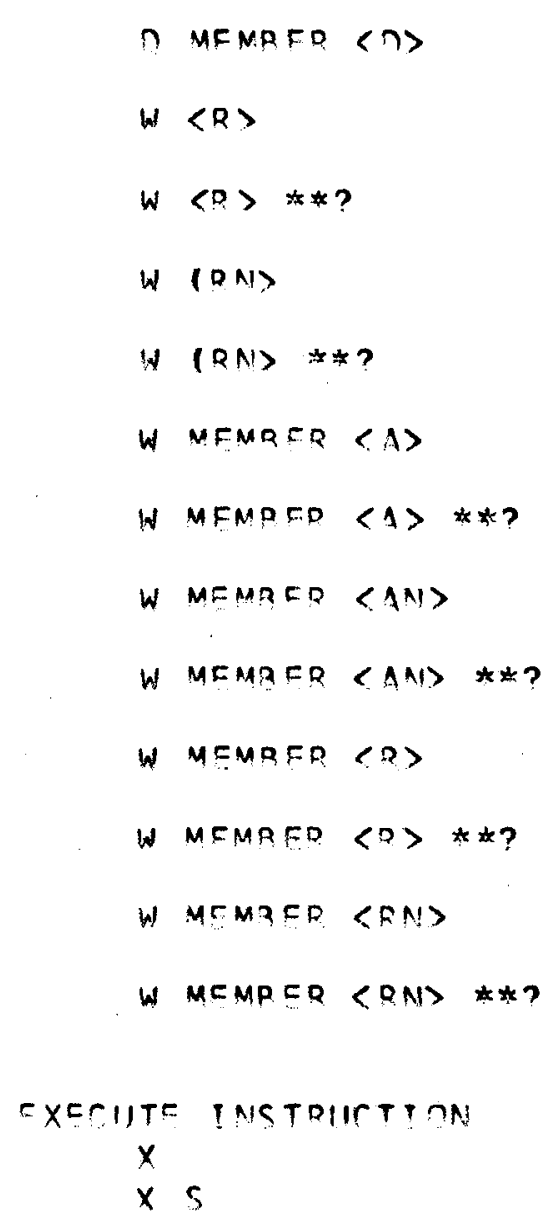

COMORESS WTFKEOARF

$Y$

$Y R$

$Y$ A

NATASET UTIITTES

7.

26

7 is

2 is

7.96

75

72

775
FO (?-4.1) RONTATN O IN ALL CASFS

EP $(1,1)$ CONTAINS On

DUT(?) CONTATNS NEMPED.

EP $(1.1)$ CONTAINS OPS

חUTID) CONTAINS OPI $\triangle N K S$

FD(1,1) CONTAINS IDS

חIT (?) CONTAINS PLANKS.

FD $(1,1)$ CONTAINS PA

OITI DI CONTAINS PLANKS

FD $(1,1)$ CONTAINS IPA!

OUT(?) CONTATNS BLANKS

FD(1,1) CONTAINS -AS:

DUT (2) CONTATNS NNFMFR.

FO (1.1) CONTATNS IAS.

NITI?) CONTAINS MEMRFD.

FP(1,1) CONTAINS AN.

NUT(?) CONTATNS MEMPFP.

FP(1.1) CONTAINS 'AN!

RUT(?) CONTATNS MFMRFR.

FD (1,1) CONTAINS ODS.

NUT(2) CRNTAINS MEMPER.

FP(1, 1$)$ CONTAINS IRS.

OUTI?) CONTATNS MFMRED.

FP(1.1) CONTATNS TRN

TUT(Z) COMTAINS MEMRER.

FP(1, 1$)$ CONTAINS IRN.

DUTIZI CONTAINS INFMPER.

$\$ \$ C=12$

inute apFa is nnt usen

inute apta is nint ilgen

$\$ \$ r=R$

inItT. AREA tS NOT lisEn

- nut adea is net hesen

inilT, ADFA IS NÎTT liCED

\begin{tabular}{|c|c|c|c|c|}
\hline $\begin{array}{l}\$ \$ 5 \% \\
\text { CIIT. }\end{array}$ & $\begin{array}{c}14 \\
\Delta R=n\end{array}$ & IS & $A \cap T$ & UeEn \\
\hline חIJT: & $\triangle Q F \triangle$ & TS & NOT & HSC? \\
\hline nIfT. & $\triangle D F A$ & 15 & NחT & lISFR \\
\hline י & $A P \subset \Lambda$ & 15 & NחT & usen \\
\hline ' nut' & $A O=\triangle$ & IS & $\Lambda \cap T$ & listen \\
\hline InUt & $A D=A$ & ic & AnT & usen \\
\hline - OIIT" & $A R=A$ & IS & NกT & $115=\pi$ \\
\hline nut & $A D \subseteq A$ & $T S$ & $\mathrm{AOT}$ & 11550 \\
\hline
\end{tabular}

$\$ 5 r=14$

- cilt. area is not ueEn

- mitt apea ts not usen

- mijte $\triangle D E A$ IS NOT lisfon

- rujt apea is nit lisen

- nut aDe is nOt liser

- nitt. area is nOt licer.

inUt. apea tS AOT HSEO

SUBROUIINES USED : $\$ 4 E, \$ 411 !$

\section{LANGUAGE : ASCEMAIER}

AUTHQR : P \& WOOD 


\begin{tabular}{|c|c|c|c|c|}
\hline 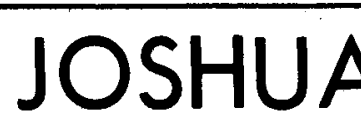 & \multirow{2}{*}{\multicolumn{2}{|c|}{ Title Subroutine: $\quad \$ \$ T L$}} & \begin{tabular}{|l|} 
Vol. \\
IX
\end{tabular} & $\begin{array}{l}\text { Page } \\
\text { E.2.19 }\end{array}$ \\
\hline DPSTM. 500 & & & Rev. & \begin{tabular}{|l} 
Date \\
$6 / 73$ \\
\end{tabular} \\
\hline
\end{tabular}

\section{PURPOSE : CONVERT UP TO EIGHT PACKED FILE POSITIONS TO A HOLLERITH STRING.}

USAGE : CALL \$\$TL (LI,\$S)

ARGUMENTS :

PARAMETER TYPE DESCRIPTION

LI

$L * 1$

DIMENSIONEO AS L1(64) WHERE UP TO EIGHT UNPACKED FILE POSITIONS, PRECEEDED BY A LFADING ", WILl re CREATED. If THE PAge CHANGES then a "WILl pRECEed that UNPACKEd fILe position also. EACH OF THE UNPACKED FILE POSITIONS WILL BE SEPARATED FROM THE NEXT BY TWD BLANKS. IN GENERAL PPP.LLL+III.CCC IS THE FORM WHERE:

PPP PAGE NUMBER;

- Lll original LINE NUMBer;

+ II I INCREMENTAL LINE NUMBER;

- CCC COLUMN NUMBER.

INCREMENTAL LINE NUMBERS OF ZERD AND COLUMN NUMBERS EQUAL TO ONE WILL NOT BE USED FOR THE HOLLERITH GENERATION.

\$S I 4 DIMENSIONED AS \$S(8) WHERE UP TO EIGHT PACKED FILE POSITIIONS ARE CONTAINED. THE END OF THIS VECTOR IS SIGNALLED BY A ZERO FILE POSITION.

\section{SUBROUTINES USED : \$\$IU \$\$PI}

LANGUAGE : ASSEMBLER

AUTHOR : R S WOOD 


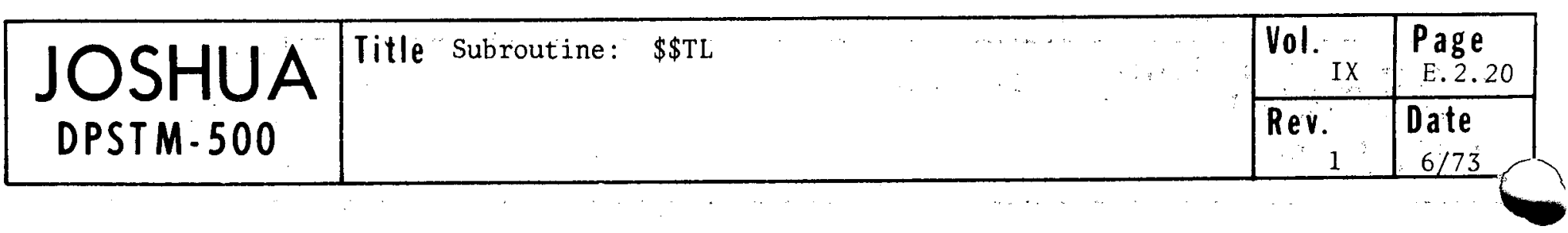

(Blank) 


\begin{tabular}{|c|c|c|c|c|}
\hline 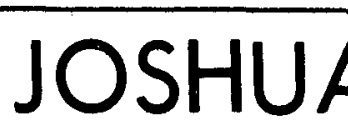 & \multirow{2}{*}{\multicolumn{2}{|c|}{ Title subroutine: $\$ \$ U I$}} & $\begin{array}{l}\text { Vol. } \\
\text { IX }\end{array}$ & $\begin{array}{l}\text { Page } \\
\text { E.2.21 } \\
\end{array}$ \\
\hline DPSTM-500 & & & $\operatorname{Rev}_{i}$ & $\begin{array}{l}\text { Date } \\
6 / 73\end{array}$ \\
\hline
\end{tabular}

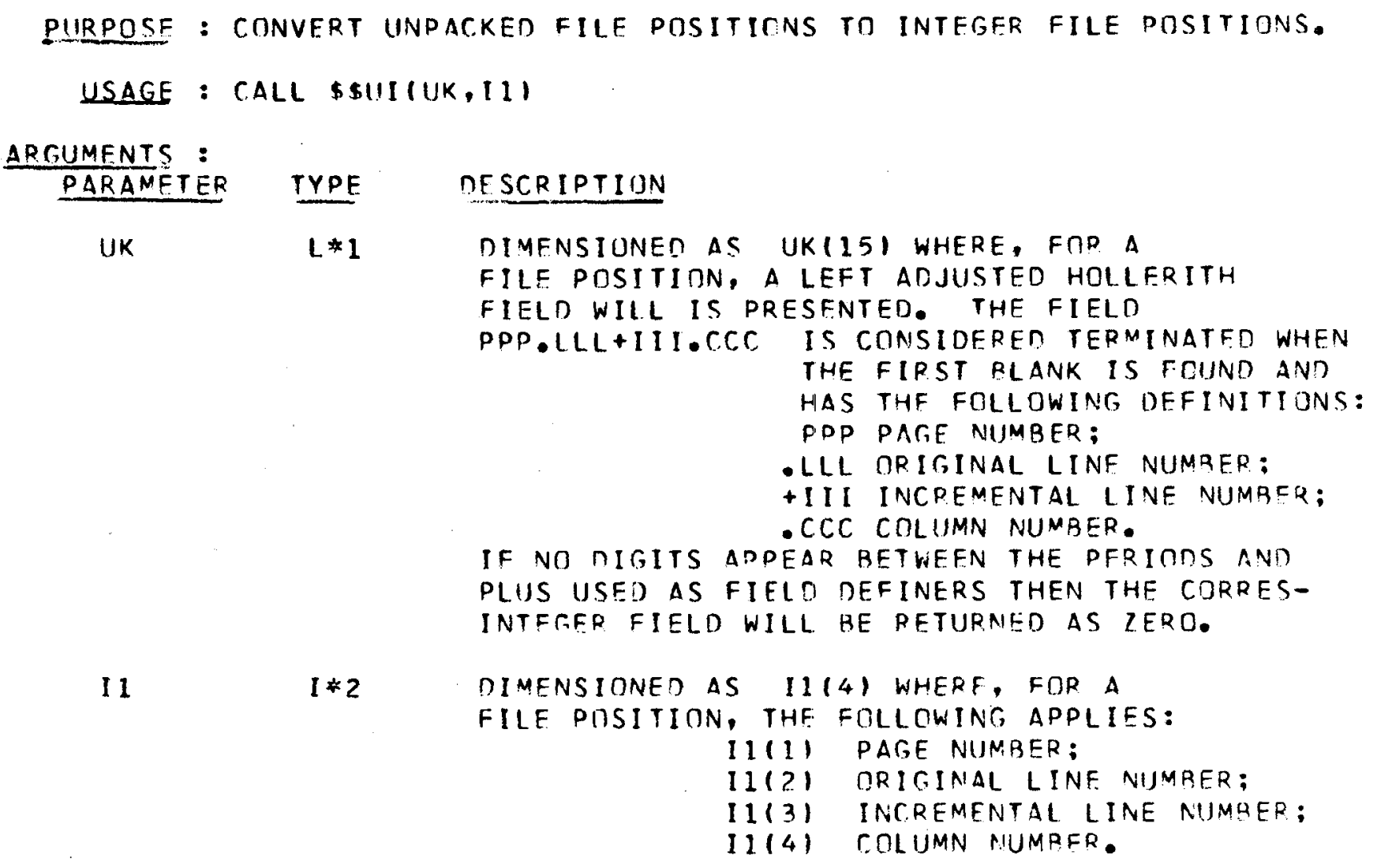

SUBRDUTINES USED : NANE

LANGUAGF: ASSEMBLFR

AUTHOR : $R$ S WחDR 


\begin{tabular}{|c|c|c|c|c|c|}
\hline \multirow{2}{*}{$\begin{array}{l}\text { OSHU } \\
\text { DPST } M-500\end{array}$} & \multirow[t]{2}{*}{ Title } & \multirow[t]{2}{*}{ Subroutine: $\quad \$ \$ U I$} & & $\begin{array}{ll}\text { Vol. } \\
\end{array}$ & \begin{tabular}{|c|} 
Page \\
$E .2: 22$
\end{tabular} \\
\hline & & & & Rev. & $\begin{array}{l}\text { Date } \\
6 / 73\end{array}$ \\
\hline
\end{tabular}




\begin{tabular}{|c|c|c|c|c|}
\hline 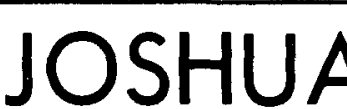 & \multirow{2}{*}{\multicolumn{2}{|c|}{ Title Subroutine: $\quad$ AEER }} & Vol. $_{\text {IX }}$ & $\begin{array}{l}\text { Page } \\
\text { E.2.23 }\end{array}$ \\
\hline DPSTM. & & & $\begin{aligned} & \text { Rev. } \\
& 1\end{aligned}$ & $\begin{array}{l}\text { Date } \\
6 / 73\end{array}$ \\
\hline
\end{tabular}

PURPOSE : CONTAINS ALL THE MESSAGES USED WHEN EITHER THE ALLOCATION OR. THE DEALLOCATION OF AN OS CATALOGED DATASET FAILS.

USAGE : CALL \$AER(\$A, \$S, *)

ARFUMENTS :

PARAMETEP TYPE NESCRIPTION

\$A ANY A 9 GO BYTE AREA USED BY THE JOSHUA SYSTEM FOR DISPLAYING PURPOSES.

\$S I*2 DIMENSIONNED AS \$S(2,32) WHERE \$S(2,3) CONTAINS ONE OF THE FRLLOWING ERROR CODES:

1 LE \$S(2,30) LE 31 ALLOCATION TERMINATING

32 LE $\$ S(2,30)$ LE 38 ALLUCATING NDNTERMINA-

TING ERROR:

49 EO $\$ S(2,30)$ OEALIOCATION TERMINA-

TING ERROR.

* RETURN 1 IS TAKEN WHEN TERMINATING THE TEXT EDITOR.

SUBROUTINES USER : \$MVC HCDINT

LANGUAGE : FORTRAN

AUTHOR : R S WOOD 


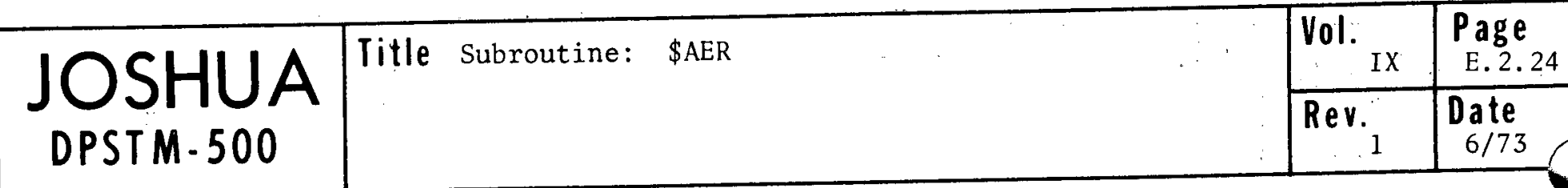




\begin{tabular}{|c|c|c|c|c|}
\hline 1 & \multirow{2}{*}{\multicolumn{2}{|c|}{ Title $\quad$ Subroutine: $\$ B D G$}} & Vol. & $\begin{array}{l}\text { Page } \\
\text { E.2.25 }\end{array}$ \\
\hline DPSTM. 500 & & & Rev. $_{1}$ & $\begin{array}{l}\text { Date } \\
6 / 73\end{array}$ \\
\hline
\end{tabular}

PURPOSE : RETURN THE HOLLFRITH USER'S BADGF NUMBER.

USAGE: $B A O G E=\$ A \cap G(C C B)$

AR GUMENTS :

PARAMETER TYPE DESCRIPTION

BADGE R*8 RFTURNING FIFLD CONTAINING THE USER'S

RADGE NUMBER AS A HOLLERITH.

CCB VARIOUS JOSHIJA CCB CONTROL BLOCK.

PRDGRAM LOGIC : USE THE CCB TO RETURN THE SCREADGE FIELD.

JOSHUA CONTROL RLOCKS IISED : CCR

SURPOUTINES USED : NONE

LANGUAGE : ASSFMRLFR

AUTHQR : R S WOOD 


\begin{tabular}{|c|c|c|c|c|}
\hline & \multirow{2}{*}{\multicolumn{2}{|c|}{ Title Subroutine: \$BDG }} & \begin{tabular}{|l} 
Vol. \\
IX
\end{tabular} & \begin{tabular}{|l|} 
Page \\
E.2.26 \\
\end{tabular} \\
\hline DPSTM -500 & & & $\begin{array}{c}\text { Rev. } \\
1\end{array}$ & \begin{tabular}{|c|} 
Date \\
$6 / 73$ \\
\end{tabular} \\
\hline
\end{tabular}

(Blank) 


\begin{tabular}{|c|c|c|c|c|c|}
\hline$\omega$ & \multirow[t]{2}{*}{ Title } & \multirow{2}{*}{\multicolumn{2}{|c|}{ Subroutine: \$BERR }} & $\begin{array}{l}\text { Vol. } \\
\text { IX }\end{array}$ & $\begin{array}{l}\text { Page } \\
\text { E. } 2.27\end{array}$ \\
\hline DPSTM-500 & & & & Rev. $_{1}$ & $\begin{array}{l}\text { Date } \\
6 / 73\end{array}$ \\
\hline
\end{tabular}

Purpose: $\quad$ To write BNAM error and statistical messages to SYSOUT data set.

Usage: $\quad$ Call $\$ B E R R(C C B, N, S)$

Arguments:

Parameter

Type

Usage

$\mathrm{CCB}$

Rea $1 * 8$

CCB communication array of 16 double words.

$\mathrm{N}$

Integer* 4

Eight occurrences - error number is in sixth occurrence; number of names in $S$ is in fourth occurrence; position in $S$ of an invalid name would occur in eighth occurrence.

$\mathrm{S}$

$\operatorname{Rea} 1 * 8$

Namestring - eighteen double words.

Subprogram Used: \$FLG16

Data Sets:

SYSOUT Data Set (FT06F001).

Program Logic: A branch is calculated on the basis of the error message number, the proper error message written to the SYSOUT data set and a STOP 17 executed. Statistical information is also written to the SYSOUT data set. A branch is issued to \$FLG16 to set error code.

Language: $\quad$ FORTRAN IV

Author: $\quad$ J. C. Jensen 


\begin{tabular}{|c|c|c|c|c|c|}
\hline & \multirow{2}{*}{\multicolumn{3}{|c|}{ Title Subroutine: $\quad$ \$BERR }} & $\begin{array}{l}\text { Vol. } \\
\text { IX }\end{array}$ & $\begin{array}{l}\text { Page } \\
\text { E. } 2.28\end{array}$ \\
\hline DPSTM & & & & $\begin{array}{r}\text { Rer. } \\
1\end{array}$ & $\begin{array}{l}\text { Date } \\
6 / 73\end{array}$ \\
\hline
\end{tabular}

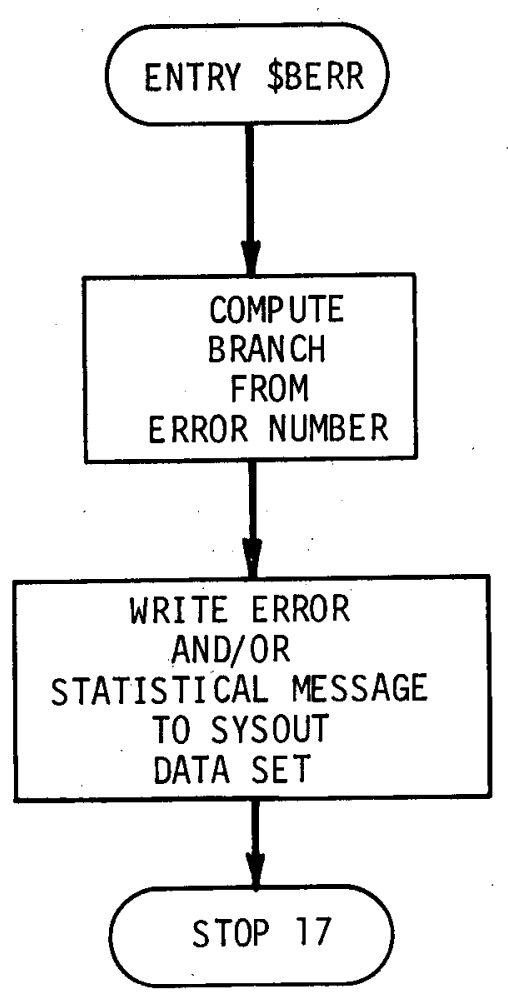




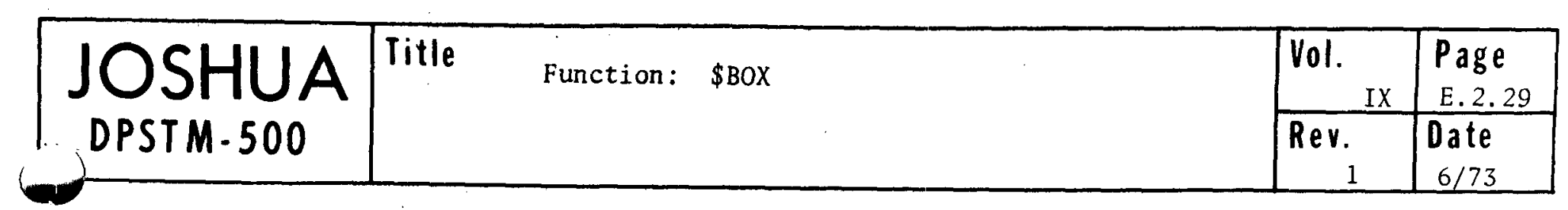

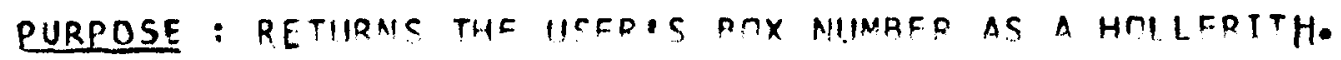

USAGE : $B O X=R D \cap X(2 \triangle \cap G E)$

ARGUMENTS:

PAFAMETER TYOE DESCRIPTION

BOX

$1 * 4$

RETIIRNING FIELD CONTAINING, THE IISER 'S COMPUTER ROOM BOX NUMRER AS A HCLLERITH.

BADCE

$\triangle N Y$

CONTAINS THE ISSER OS HOLLERITH PADRF NIMMR=D.

SUBROUTINES USED: RTNCRH

LAVIOUAGE : FORTRAN

NITHOR: R S WOOO 


\begin{tabular}{|c|c|c|c|c|}
\hline JOSHIUA & Title function: $\$ \mathrm{BOX}$ & Vol: & Page \\
DPSTM-500 & & Rev. & E.2.30 \\
\cline { 3 - 5 } & & $\begin{array}{c}\text { Rate } \\
6 / 73\end{array}$ \\
\hline
\end{tabular}




\begin{tabular}{|c|c|c|c|c|}
\hline 00111 & Title Function: $\$$ & $\$ C C \$$ & \begin{tabular}{|l|} 
Vol. \\
IX \\
\end{tabular} & \begin{tabular}{|l|} 
Page \\
E.2.31 \\
\end{tabular} \\
\hline DPSTM. 500 & & & Rev. $_{1}$ & $\begin{array}{l}\text { Date } \\
6 / 73\end{array}$ \\
\hline
\end{tabular}

PUPDOSE : RETIRN THF HOIERTTH USEO'S COST CODF.

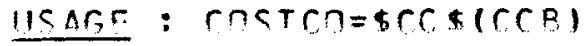

ADGIMENTS:

PARAMETER TYDE NESTRIPTITN

COSTCD R*Q RETIIPNTAG FIFLO CONTAINING THE UISEDIS COST CORE AS A HOLLERTTH.

CCR VARTIIS JNSHUA CCB CONTROL BLOCK.

PRDGRAM LOGIC : ISE THE CCB TD RETURN THF SCBCC FIELD.

JOSHUA CONTROL BLOCKS USED : TRA

SUREOUTTNFS ISTO : NTAF

LAVGUAGE : ASCEMALER

AUTHCO : R S WOOD 


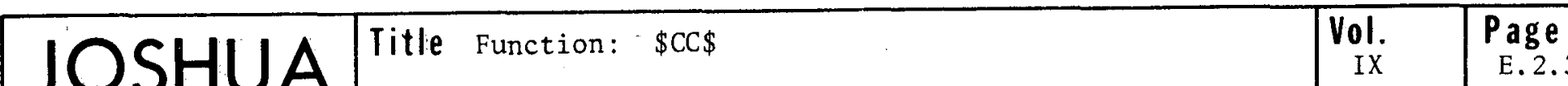

Rev.

Date

1

6.73

(Blank) 


\begin{tabular}{|l|l|l|l|}
\hline \multirow{2}{\text{JPSTM-500}}{} & Title Function: \$CF\$ & $\begin{array}{l}\text { Vol. } \\
\text { Ix }\end{array}$ & $\begin{array}{c}\text { Page } \\
E .33\end{array}$ \\
\cline { 3 - 5 } & & $\begin{array}{c}\text { Rev. } \\
i\end{array}$ & $\begin{array}{c}\text { Date } \\
6 / 73\end{array}$ \\
\hline
\end{tabular}

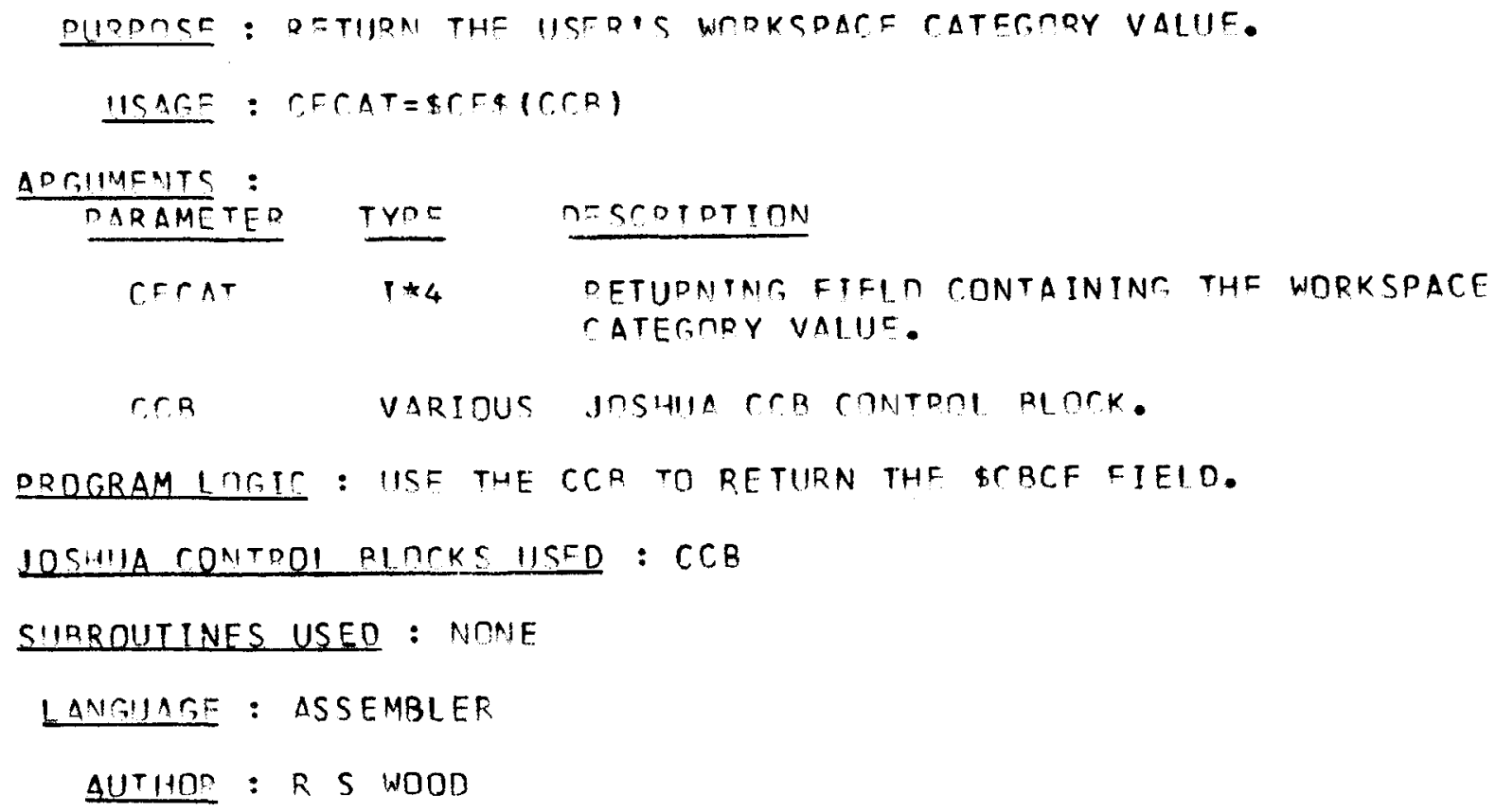




\begin{tabular}{|c|l|l|c|c|}
\hline JOSHUA & Title Function: \$CF\$ & $\begin{array}{c}\text { Vol. } \\
\text { Ix }\end{array}$ & $\begin{array}{c}\text { Page } \\
\text { E.2.34 }\end{array}$ \\
\cline { 3 - 5 } & & $\begin{array}{c}\text { Rev. } \\
1\end{array}$ & $\begin{array}{c}\text { Date } \\
6 / 73\end{array}$ \\
\hline
\end{tabular}

(Blank) 


\begin{tabular}{|l|ll|l|l|}
\hline JOSHUA & Title subroutine: \$CFO & $\begin{array}{l}\text { Vol. } \\
\text { DPSTM }-500\end{array}$ & $\begin{array}{l}\text { Page } \\
\text { E.2.35 }\end{array}$ \\
\cline { 3 - 5 } & & Rev. & $\begin{array}{c}\text { Date } \\
6 / 73\end{array}$ \\
\hline
\end{tabular}

DIIROASE : SET THF USFR'S WORKSPACE CATEGRPY VALUE.

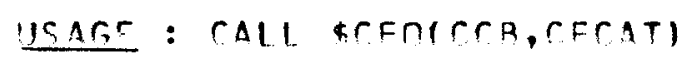

AORIJMENTS:

DAR $\triangle M F T F P$

TYPE DESCRTPTION

reCAT THA TUDENT VALUE OF THE USER'S WIORKSPACE
rATERORY.

ECR VARTEIS JOSHIIA CCA CONTPRL BLOCK.

PROCPAM LOEIC : SET THE SCBCF FICLD IN THF CCB TO CFCAT.

IOSHIIA CONTROL RLOCKS USED: CCB

SUROOUTINFC USED : MINNF

LANCIIACE : ASSEMRLED

A!ITHOB : $0<$ WOOD 


\begin{tabular}{|c|l|l|l|l|}
\hline JOSHUA & Title Subroutine: \$CFO & $\begin{array}{l}\text { Vol. } \\
\text { IX }\end{array}$ & $\begin{array}{l}\text { Page } \\
\text { E.2.36 }\end{array}$ \\
& & $\begin{array}{c}\text { Rev. } \\
1\end{array}$ & $\begin{array}{l}\text { Date } \\
6 / 73\end{array}$ \\
\hline
\end{tabular}

(Blank) 


\begin{tabular}{|l|l|l|l|l|}
\hline JOSHUA & Title & Vol. & Page \\
DPSTM.50utine: \$CLC & E.2.37 \\
\cline { 3 - 5 } & & $\begin{array}{l}\text { Rev. } \\
\text { Date } \\
\end{array}$ \\
\hline
\end{tabular}

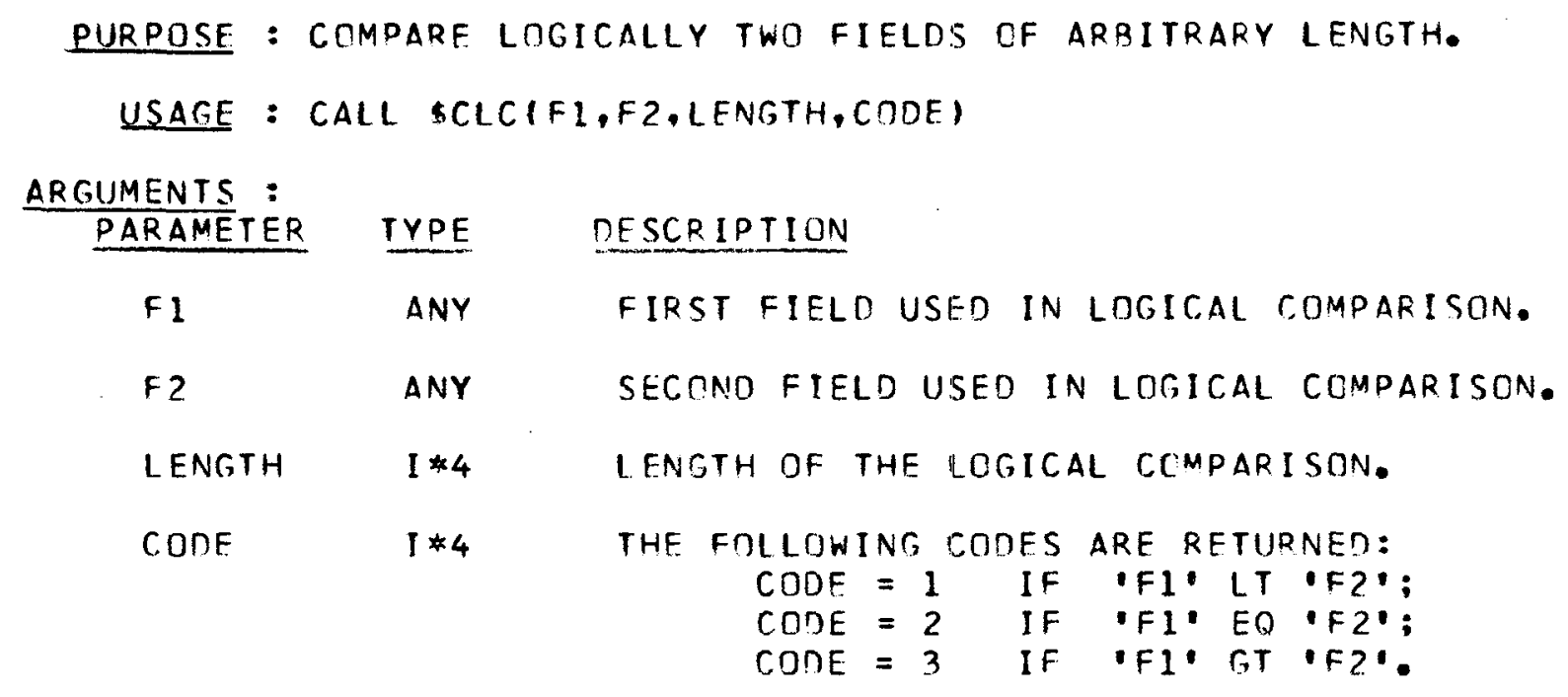

SURROUTINES USED : NANE

LANGUAGE : $\triangle S$ SEMBLFR

AUTHDR : $R S$ WNOD 


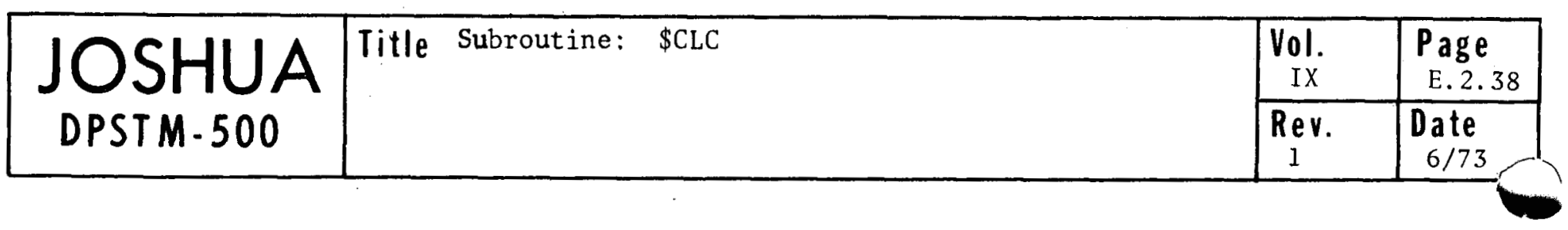




\begin{tabular}{|c|r|r|r|r|}
\hline JOSHUA & $\begin{array}{r}\text { Title Subroutine: \$CLI } \\
\text { EPSTM-500 }\end{array}$ & Entry: \$RLI & Vol. & $\begin{array}{l}\text { Page } \\
\text { IX } \\
\text { E.2.39 }\end{array}$ \\
\cline { 3 - 5 } & & Rev. & $\begin{array}{c}\text { Date } \\
6 / 73\end{array}$ \\
\hline
\end{tabular}

PURPOSE : COMPARE LOGICALLY A SINGLE BYTE WITH A BYTE STRING. FOR \$CLI RETURN I IF AN EQUAL COMPARISON WAS MADE. FOR \$RLI RETURN I IF AN EQUAL COMPARISON WAS NOT MADE.

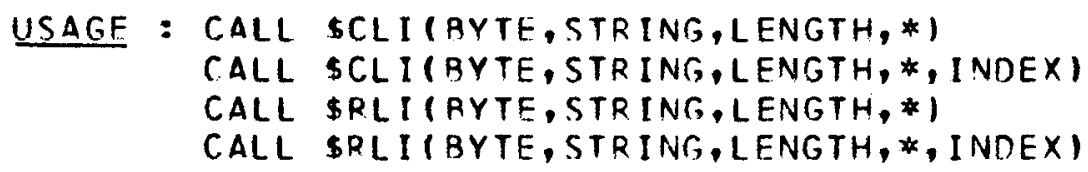

ARGUMENTS :

PARAMETER

BYTE

TYPE

DESCRIPTION

STRING

$L * 1$

SINGLE BYTF FOR WHICH A SEARCH IS BEING MAOE.

DIMENSIONED STRING(LENGTH). THE STRING OF BYTES IN WHICH A SEARCH FOR AN EQUAL COMPARISON WITH 'RYTE' IS BEING CONCUCTEC.

LENGTH I $* 4$

LENGTH OF THE STRING USED IN COMPARISON.

INDEX

I *4

DPTIONAL ARGUMENT. ON RETURN IT WILL CONTAIN THF INDFX WITHIN 'STRING' OF WHERE AN EQUAL COMPARISON WAS FCUND. UNCETERMINED IF NO EOUAL COMPARISON WAS FDUND.

SUBROUTINES USED : NONF

LANGUAGE : ASSEMBLER

AUTHCR : R S WOOD 


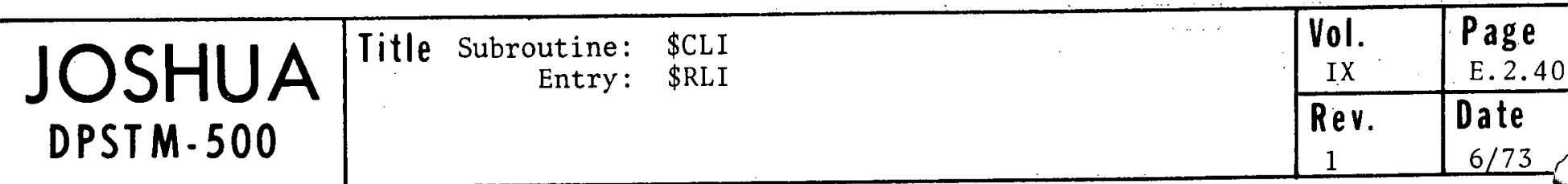




\begin{tabular}{|c|c|c|c|c|}
\hline 1 & \multirow{2}{*}{\multicolumn{2}{|c|}{ Title Subroutine: \$DIR }} & Vol. $_{\text {IX }}$ & Page \\
\hline DPSTM. & & & Rev. & $\begin{array}{l}\text { Date } \\
6 / 73\end{array}$ \\
\hline
\end{tabular}

Purpose:

Usage:

DCBADR

LOC

LNTH

ERRNO

Arguments:
To read the directory of a partitioned data set.

To open the data set:

CALL \$DIRO (USERBASE, DCBADR, ERRNO)

To retrieve the next directory entry:

CALL \$DIRR (LOC, LNTH, ERRNO)

To close the data set:

CALL \$DIRC
Mnemonic

USERBASE
Type

Logical*1

Integer* 4

Integer *4

Integer $* 4$

Integer $* 4$

\section{Description}

A directory entry will be retrieved by specifiying its location as being at some displacement from the start of this pseudo-array.

The address of a ninety-six byte area located on a fullword boundary which will be overlaid during \$DIRO, except for the DDNAME field, by a local DCB and which is then used as the DCB for the data set in question.

The displacement, relative one, in USERBASE of the location in the buffer of the current directory entry.

The length in bytes of the current directory entry.

An optional error number field.

Error numbers for \$DIRO are:

Number

0

1 Not used.

2 No DD statement.

3 Data set not located.

4 Data set not a PDS. 


\begin{tabular}{|c|c|c|c|c|}
\hline & \multirow{2}{*}{\multicolumn{2}{|c|}{ Title $\quad$ Subroutine: $\quad$ DIR }} & $\begin{array}{l}\text { Vol. } \\
\text { IX }_{\text {IX }}\end{array}$ & $\begin{array}{l}\text { Page } \\
\text { E.2.4.2 }\end{array}$ \\
\hline DPSTM. 500 & & & Rev. & $\begin{array}{r}\text { Date } \\
6 / 73 \\
\end{array}$ \\
\hline
\end{tabular}

Error numbers for $\$ D I R R$ are:

Number

0

1

The error number is also multiplied by four and loaded into register fifteen as a return code.

External References: The following system macro instructions are used:

CHECK
CLOSE
DCB
DCBD
LOCATE
OBTAIN
OPEN
READ (BSAM)
READJFCB
REGDEF

Program Logic:

- \$DIRO

- The location of USERBASE is stored locally.

- The external DCB is established by overlaying the area with a local DCB except for the DCBDDNAM field of the external area which is left unchanged. All DCB references will now relate to the external area.

- The data set organization is checked by

1. Issuing a READJFCB to obtain the DSNAME prior to

2. Issuing a LOCATE to check the device class and obtain the volume number and

3. Issuing an OBTAIN to assure that the data set is a partitioned data set. 


\begin{tabular}{|l|l|l|l|}
\hline$\underset{\text { DPSTM.500 }}{\text { OSH Sitle Subroutine: \$DIR }}$ & Vol. Ix & $\begin{array}{l}\text { Page } \\
\text { E.2.43 }\end{array}$ \\
\cline { 3 - 5 } & & Rev. & $\begin{array}{c}\text { Date } \\
6 / 73\end{array}$ \\
\hline
\end{tabular}

- The DCBDSORG field is set accordingly.

- An OPEN is issued.

- $\$$ DIRR

- If no entries remain in the current block, the next block is read and the number of bytes defined as being used checked for reasonability.

- The member name in the next directory entry is checked for the highest collating value in the system (i.e. all bits on) as this signifies that all entries have been passed.

- The location of the next valid directory entry is determined as a displacement from USERBASE and returned in LOC. The length of the entry is returned in LNTH and also used in a calculation to determine for next time the number of bytes of data remaining in the block.

- \$DIRC

Language:

- A close is issued.

- DCB addressability is reestablished as being the local DCB.

- All other initializations necessary to allow reuse of the subroutine are performed.

Author:

oS/360 Assembler

R. C. Haywood 


\section{JOSHUA ${ }^{\text {Title }}$ subroutine: \$DIR

\begin{tabular}{|c|c|c|}
\hline 4 & Vol. IX & $\begin{array}{l}\text { Page } \\
\text { E. } 2.44\end{array}$ \\
\hline & Rev. & $\begin{array}{l}\text { Date } \\
6 / 73\end{array}$ \\
\hline
\end{tabular}
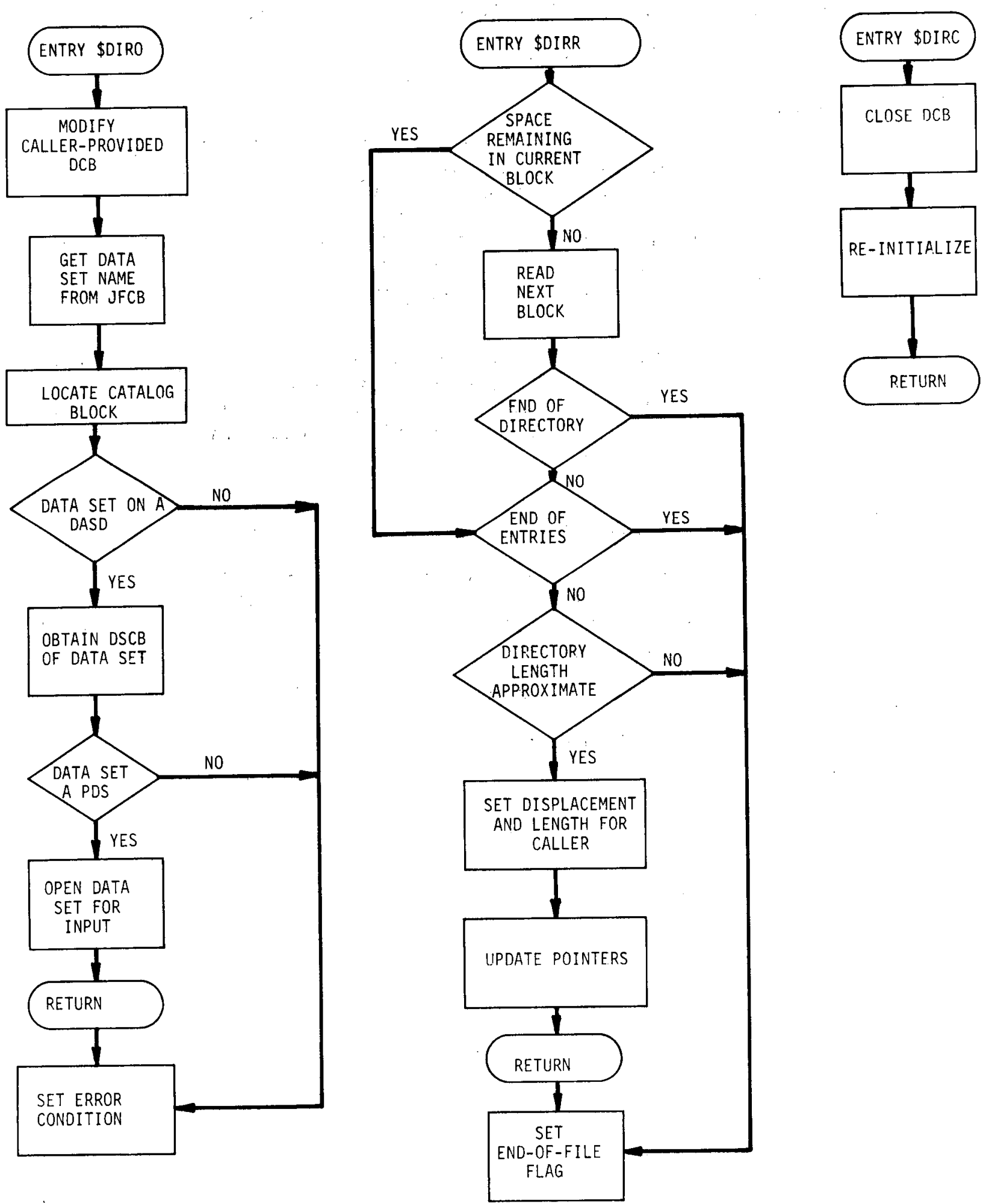


\begin{tabular}{|c|l|l|l|l|}
\hline JOSHUA & Title Function: \$EXC & Vol. & Page \\
DPSTM & E.2.45 \\
\cline { 3 - 5 } & & Rev. & $\begin{array}{l}\text { Date } \\
6 / 73\end{array}$ \\
\hline
\end{tabular}

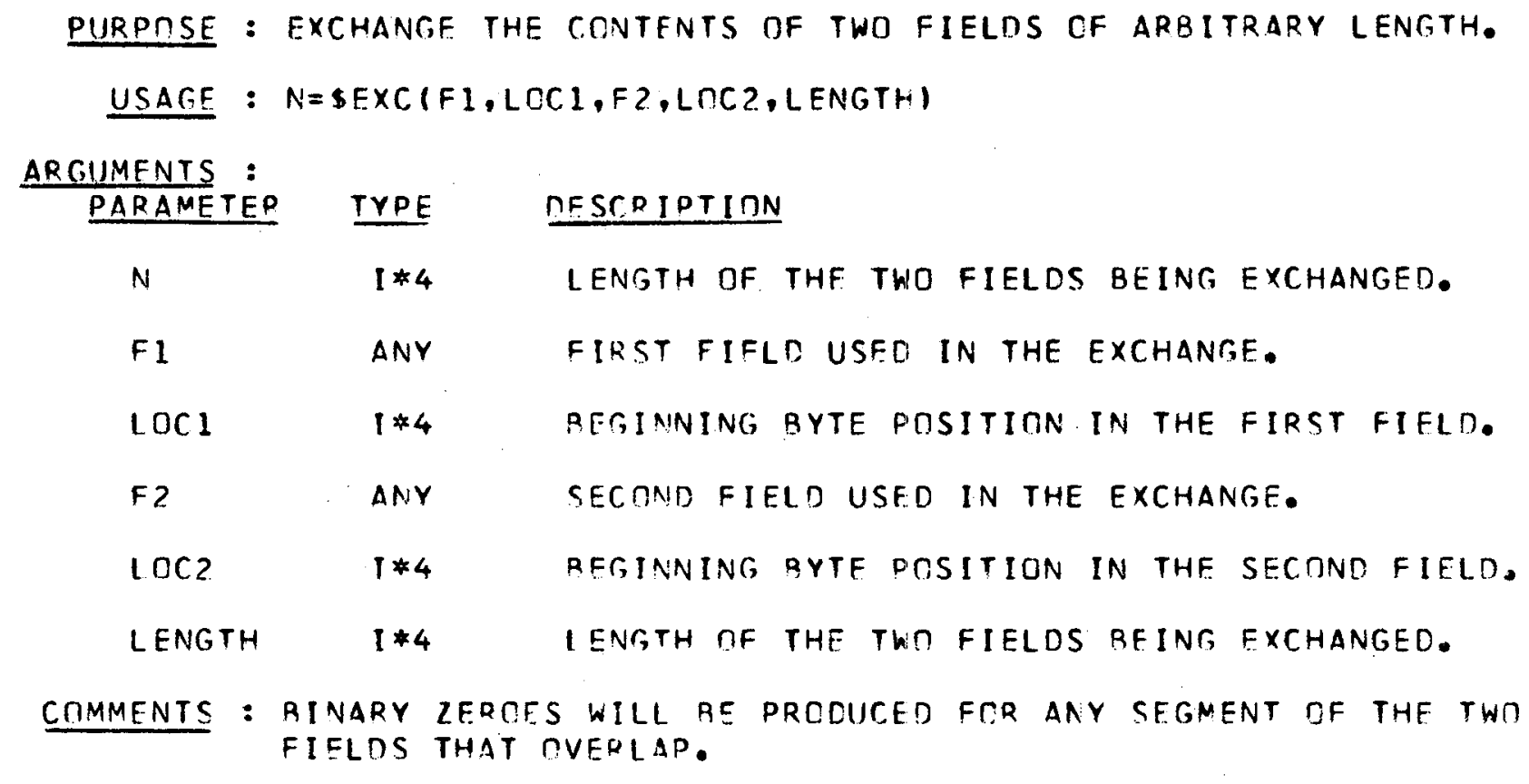

SURRDUTINES USED : NDNE

LANGUAGE : $\triangle$ SSEMRLER

AUTHOR : R $S$ WOOD 


\begin{tabular}{|c|c|c|c|c|}
\hline & \multirow{2}{*}{\multicolumn{2}{|c|}{ Title Subroutine: $\$$ FLG16 }} & $\begin{array}{l}\text { Vol. } \\
\text { IX }\end{array}$ & $\begin{array}{l}\text { Page } \\
\text { E.2.47 }\end{array}$ \\
\hline DPSTM -500 & & & $\begin{array}{c}\text { Rev. } \\
1\end{array}$ & $\begin{array}{l}\text { Date } \\
\quad 6 / 73\end{array}$ \\
\hline
\end{tabular}

Purpose: $\quad$ To set error flag in communication area.

Usage: $\quad$ CALL $\$$ FLG16 (CCB), where CCB = Communication Control Block

Program Logic: The address of the $\mathrm{CCB}$ is received via the argument 1 ist. The error code condition (fullword one) is set for both the JCB and $\mathrm{CCB}$ areas. A return is issued.

Language: $\quad$ Assembler

Author: $\quad$ R. L. Boyce, Jr. 


\begin{tabular}{|l|l|l|l|l|}
\hline JOSHUA & Title Subroutine: \$FLG16 & Vol. & Page \\
DPSTM.500 & & IX & E.2.48 \\
\cline { 3 - 5 } & & Rev. & Date \\
1 & $6 / 73$ \\
\hline
\end{tabular}

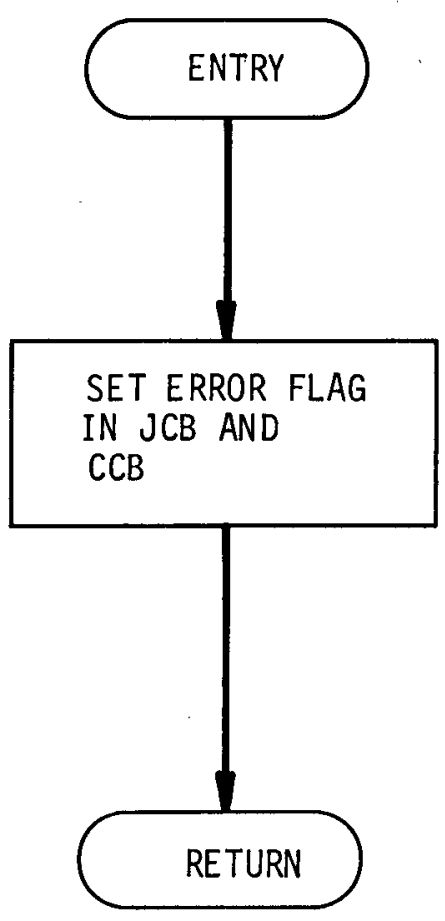




\begin{tabular}{|l|l|l|l|l|}
\hline JOSHUA & $\begin{array}{l}\text { Title } \\
\text { Common: \$JCOMA }\end{array}$ & Vol. & Page \\
Ix & E.2.49 \\
\cline { 3 - 5 } & & Rev. & Date \\
& $6 / 73$ \\
\hline
\end{tabular}

Purpose: To establish certain initializations of the named common area \$JCOMA.

External References: Named common area \$JCOMA structured as follows:

$\$ J C B$ - Sixteen doublewords

\$NAMES - Eighteen doublewords

\$BNAMI - Sixteen words

Description:

The total area is defined as zero except:

$\begin{array}{ll}\text { \$BNAMI }(9)= & 16 \\ \text { \$BNAMI }(10)= & 1 \\ \text { \$BNAMI }(11)= & 16 \\ \text { \$BNAMI }(12)= & 2 \\ \text { \$BNAMI }(13)= & 2\end{array}$

Language: $\quad$ FORTRAN IV

Author: $\quad$ R. C. Haywood 


\begin{tabular}{|c|l|l|l|l|}
\hline JOSHUA & Title Common: \$JCOMA & Vol. & $\begin{array}{c}\text { Page } \\
\text { DPSTM.500 }\end{array}$ \\
\cline { 3 - 5 } & Rev. & Date \\
& $6 / 73$ \\
\hline
\end{tabular}




\begin{tabular}{|c|c|c|c|c|c|}
\hline & \multirow{2}{*}{\multicolumn{3}{|c|}{ Title Subroutine: \$MVC }} & $\begin{array}{l}\text { Vol. } \\
\text { IX }\end{array}$ & $\begin{array}{l}\text { Page } \\
\text { E.2.51 }\end{array}$ \\
\hline DPSTM.500 & & & & $\begin{array}{c}\text { Rev. } \\
1\end{array}$ & $\begin{array}{l}\text { Date } \\
6 / 73\end{array}$ \\
\hline
\end{tabular}

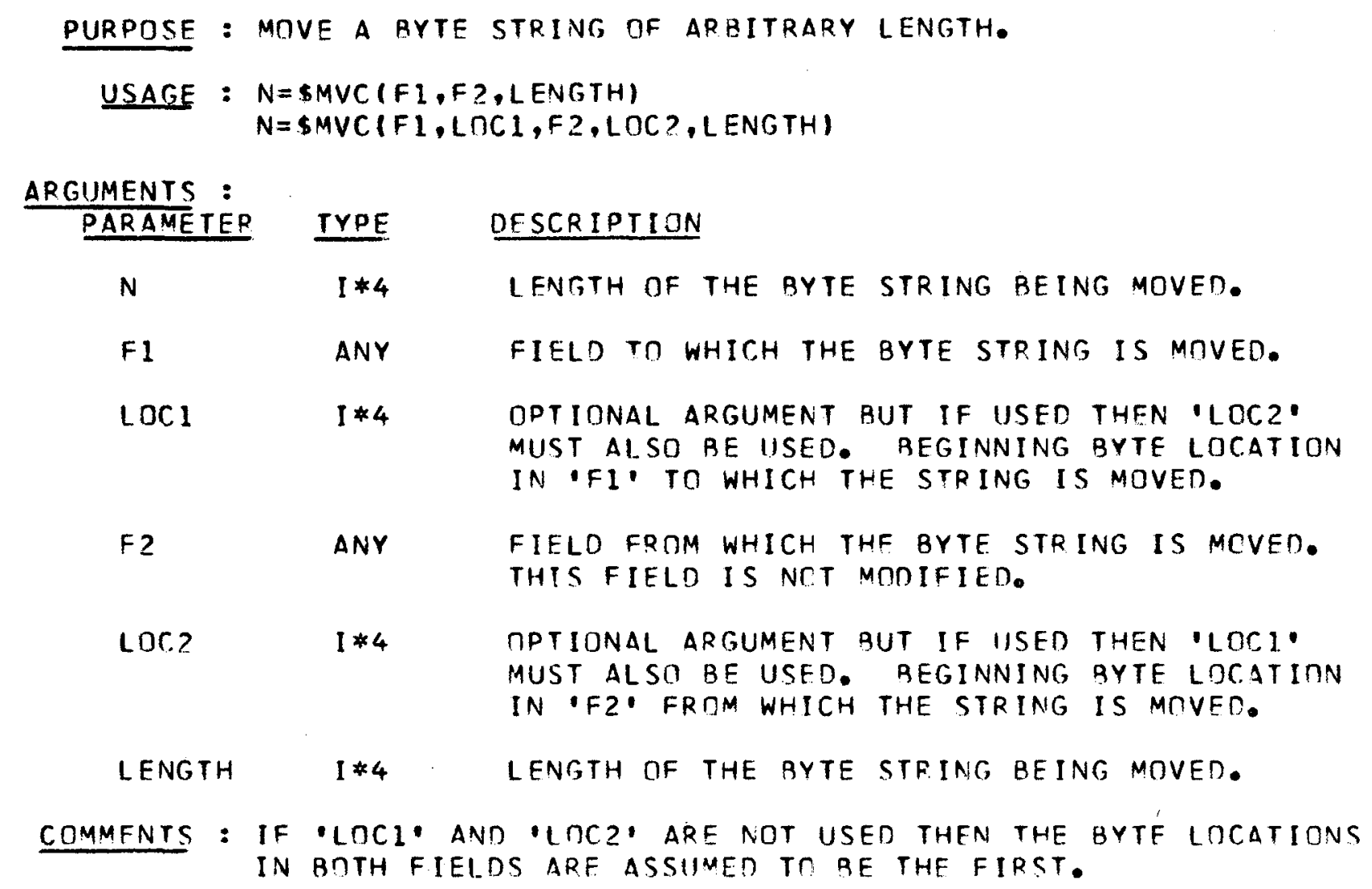

SUBROUTINES USED : NINE

LANGUAGE : $\triangle S S E M B L E R$

AUTHCR : R $S$ WCOD 


\begin{tabular}{|c|c|c|c|}
\hline JC & Title Subroutine: \$MVC & \begin{tabular}{|l} 
Vol. \\
Ix
\end{tabular} & \begin{tabular}{|l|} 
Page \\
E.2.52 \\
\end{tabular} \\
\hline DPSTM.500 & & $\begin{array}{l}\text { Rev. } \\
1\end{array}$ & \begin{tabular}{|l} 
Date \\
$6 / 73$
\end{tabular} \\
\hline
\end{tabular}




\begin{tabular}{|l|l|l|l|l|}
\hline JOSHUA & Title Subroutine: \$PKF & Vol. & $\begin{array}{l}\text { Page } \\
\text { IX }\end{array}$ \\
\cline { 3 - 4 } \\
\cline { 3 - 5 }
\end{tabular}

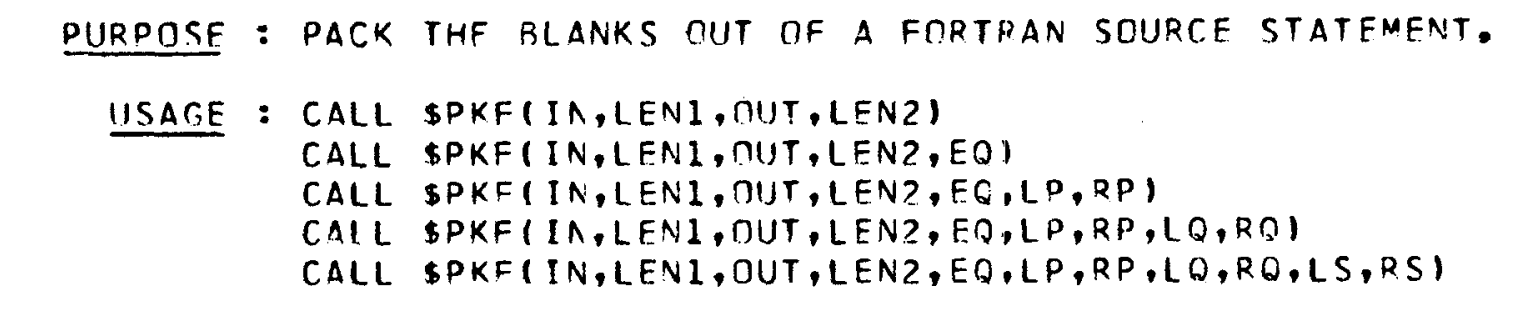

ARGUMENTS : PARAMETER

IN

LEN1

RUT

LFN2

EQ

LP

RP

10

$R Q$

LS

RS

$1 * 4$

\section{DESCRIPTION}

FIFLD CONTAINING THE INDUTTFD FORTRAN SOURCE STATEMENT.

LENGHT OF INPUTTED FORTRAN SMURCE STATEMENT. FIELD CONTAINING THE NUTPUTTED FORTRAN SMURCE STATEMFNT.

LENGHT OF DUTPUTTED FNRTRAN SOUREE STATEMENT.

OPTIONAL ARGUMENT. CONTAINS THE ENIEX IN ' DUT' DF THE LAST ' =' FOUNO.

IDTIONAL ARGUMENT. CONTAINS THE HODEX IN -OUT' OF THE FIPST LEFT PARENTHFSYS FCUNO.

DPTIONAL ARGUMENT. 'CONTAINS IHE ROEX IN I OUT' DF THE MATCHING RIGHT PAPENTHESIS, SFE 'LP' ABOVE.

OPTIONAL ARGUMENT. CONTAINS THE INMEX IN

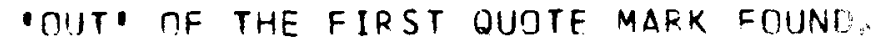

OPTIONAL ARGUMENT. CONTAINS THE INDEX IN 'OUT' DF the second QUDTE MARK.

QPTIONAL ARGUMENT. CONTAINS THE INDEX IN 'OUT' DF THE FIRST SLASH MARK FOUNO.

OPTIONAL ARGUMENT. CONTAINS THE INDEX IN 'out' of the matching slash mark, SeE 'Ls'.

COMMENTS : ALL UPTIONAL APGUMENTS DEFAULT TR. ZERO. IF USED, THEY MUST RF USED IN THE ORDER IN WHICH THEY ARE DESERIBED.

SUBRDUTINES USFD : NINE

LANGUAGE : $\triangle$ SSSEMBLFR

AUTHCR : P S WOOD W H BRITHERTON 


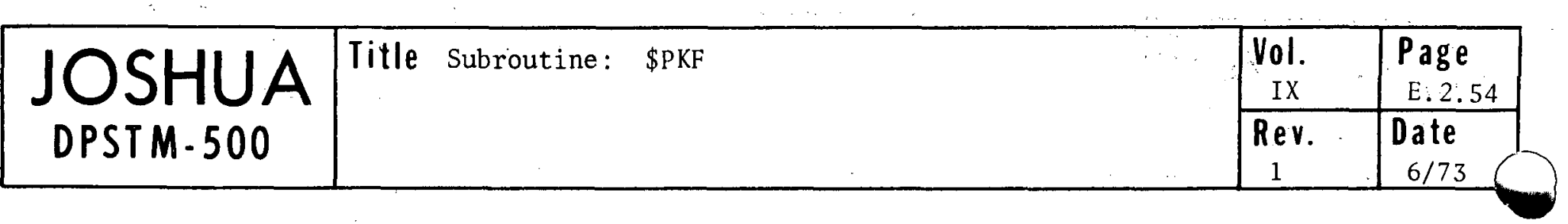

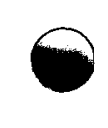




\begin{tabular}{|c|c|c|c|c|}
\hline & & \multirow[t]{2}{*}{ Subroutine: $\quad \$ R D R$} & Vol. $_{\text {IX }}$ & $\begin{array}{l}\mathrm{Page} \\
\mathrm{E} .2 .55\end{array}$ \\
\hline DPSTM & & & ${ }_{1}$ Rev. & $\begin{array}{c}\text { Date } \\
6 / 73\end{array}$ \\
\hline
\end{tabular}

Purpose:

To read a sequential data set or a member of a partitioned data set.

Usage:

To open the data set:

CALL \$RDRO (USERBASE, DCBADR, [MEMBER])

To retrieve the next logical record:

CALL \$RDRR (LOC, LNTH)

To close the data set:

CALL \$RDRC

Arguments:

Mnemonic

USERBASE

DCBADR

MEMBER

LOC

LNTH
Type

Logical*1

Integer*4

Logical*1

Integer*4

Integer* 4
Description

A relative record will be retrieved by specifying its location in the buffer as a displacement within the pseudo-array USERBASE.

The address of a ninety-six byte area originating on a fullword boundary which will be overlaid during \$RDRO, except for the DDNAME field, by a local DCB and which is then used as the $D C B$ for the data set in question.

An eight-byte field specifying the member to be selected from a partitioned data set.

The displacement, relative one, in USERBASE of the location in the buffer of the start of the current logical record.

The length in bytes of the current logical record. 


\begin{tabular}{|c|c|c|c|c|c|}
\hline 1 & \multirow[t]{2}{*}{ Title } & \multirow{2}{*}{ Subroutine: \$RDR } & \multirow{2}{*}{$\begin{array}{l} \\
\end{array}$} & $\begin{array}{|ll|}\text { Vol. } & \\
& \text { IX } \\
\end{array}$ & $\begin{array}{l}\text { Page } \\
\text { E. } 2.56\end{array}$ \\
\hline DPSTM. 500 & & & & $\begin{array}{c}\text { Rev. } \\
\vdots 1 \\
\end{array}$ & $\begin{array}{r}\text { Date } \\
6 / 73 \\
\end{array}$ \\
\hline
\end{tabular}

Return Codes: $\quad$ The following values are found in register fifteen following execution of the subroutine.

\begin{tabular}{|c|c|c|}
\hline Entry & Code & Explanation \\
\hline \multirow[t]{7}{*}{ \$RDRO } & 0 & Successful completion. \\
\hline & 4 & No DD statement. \\
\hline & 8 & Data set not located. \\
\hline & 12 & Illegal data set organization. \\
\hline & 16 & $\begin{array}{l}\text { Discrepancy exists in the member } \\
\text { specification vis-a-vis the data set } \\
\text { organization or the DD statement. }\end{array}$ \\
\hline & 20 & $\begin{array}{l}\text { Specified member does not exist in } \\
\text { the data set. }\end{array}$ \\
\hline & 24 & $\begin{array}{l}\text { Blocksize exceeds size of area } \\
\text { provided for buffer. }\end{array}$ \\
\hline \multirow[t]{2}{*}{$\$ R D R R$} & 0 & Successful read. \\
\hline & 4 & End of data set or member. \\
\hline \$RDRC & 0 & Always set to zero. \\
\hline
\end{tabular}

External References: The following system macro instructions are used:

CHECK

CLOSE

DCB

DCBD

FIND

LOCATE

OBTAIN

OPEN

READ (BPAM, BSAM)

READJFCB

REGDEF 


\begin{tabular}{|c|c|c|c|c|}
\hline \multirow{2}{*}{$\begin{array}{l}\text { JOSHUA } \\
\text { DPSTM-500 }\end{array}$} & \multirow{2}{*}{\multicolumn{2}{|c|}{ Title $\quad$ Subroutine: $\quad$ \$RDR }} & \multirow{2}{*}{\begin{tabular}{|l|} 
Vol. \\
IX \\
Rev.
\end{tabular}} & $\begin{array}{l}\text { Page } \\
\text { E.2.57 }\end{array}$ \\
\hline & & & & $\begin{array}{c}\text { Date } \\
6 / 73\end{array}$ \\
\hline
\end{tabular}

Program Logic:

- $\$$ RDRO

- The location of USERBASE. is stored locally.

- The external DCB is established by overlaying the area with a local DCB except for the DCBDDNAM field of the external area which is left unchanged. All DCB references following this operation are set to relate to the external area.

- The data set organization is determined by:

1. Issuing a READJFCB to obtain the DSNAME preparatory to

2. Issuing a LOCATE to check the device class and obtain the volume number and, if necessary,

3. Issuing an OBTAIN when the device type is direct-access.

The only valid organizations are sequential and partitioned; sequential is assumed when the device type is not directaccess.

- If the argument MEMBER is not present or is blank the data set must be sequential or the member must have been specified in the DD statement. If MEMBER is present and nonblank the data set must be partitioned and the JFCBELNM field must be either blank or the same as MEMBER.

- The DCBDSORG field is set as was indicated as a result of the OBTAIN except when, for a PDS, the member name was specified in the DD statement $i$ which case it is set as physical sequential.

- An OPEN is issued and the DCBBLKSI checked.

- For data sets opened as partitioned organization, a FIND is issued to position for the first read at the first block of the specified member.

- \$RDRR

- If no logical records remain in the current block, the next block is read and the size of the block and the number of logical records it contains are determined

- The next logical record is located. Its position is saved to be used on the next call and is then calculated as a displacement in USERBASE. This displacement and the length of the logical record are returned in LOC and LNTH, respectively. 


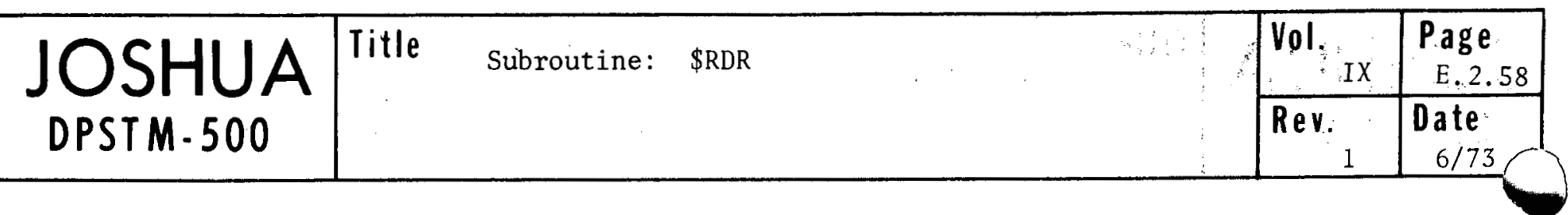

- When EODAD is indicated the operations described in $\$ R D R C$ are performed except that a return code of four is issued.

- \$RDRC

- A CLOSE is issued.

- $D C B$ addressing is reset to the local DCB.

- All other initializations necessary to allow reuse of the subroutine are performed.

Language:

0S/360 Assembler

Author:

R. C. Haywood 


\begin{tabular}{|c|c|c|c|}
\hline & \multirow[t]{2}{*}{ Title $\quad$ Subroutine: $\$$ RDR } & Vol. IX & \begin{tabular}{|l|} 
Page \\
E.2.59
\end{tabular} \\
\hline DPSTM.500 & & $\begin{array}{r}\text { Rev. } \\
1\end{array}$ & \begin{tabular}{|c|} 
Date \\
$6 / 73$
\end{tabular} \\
\hline
\end{tabular}

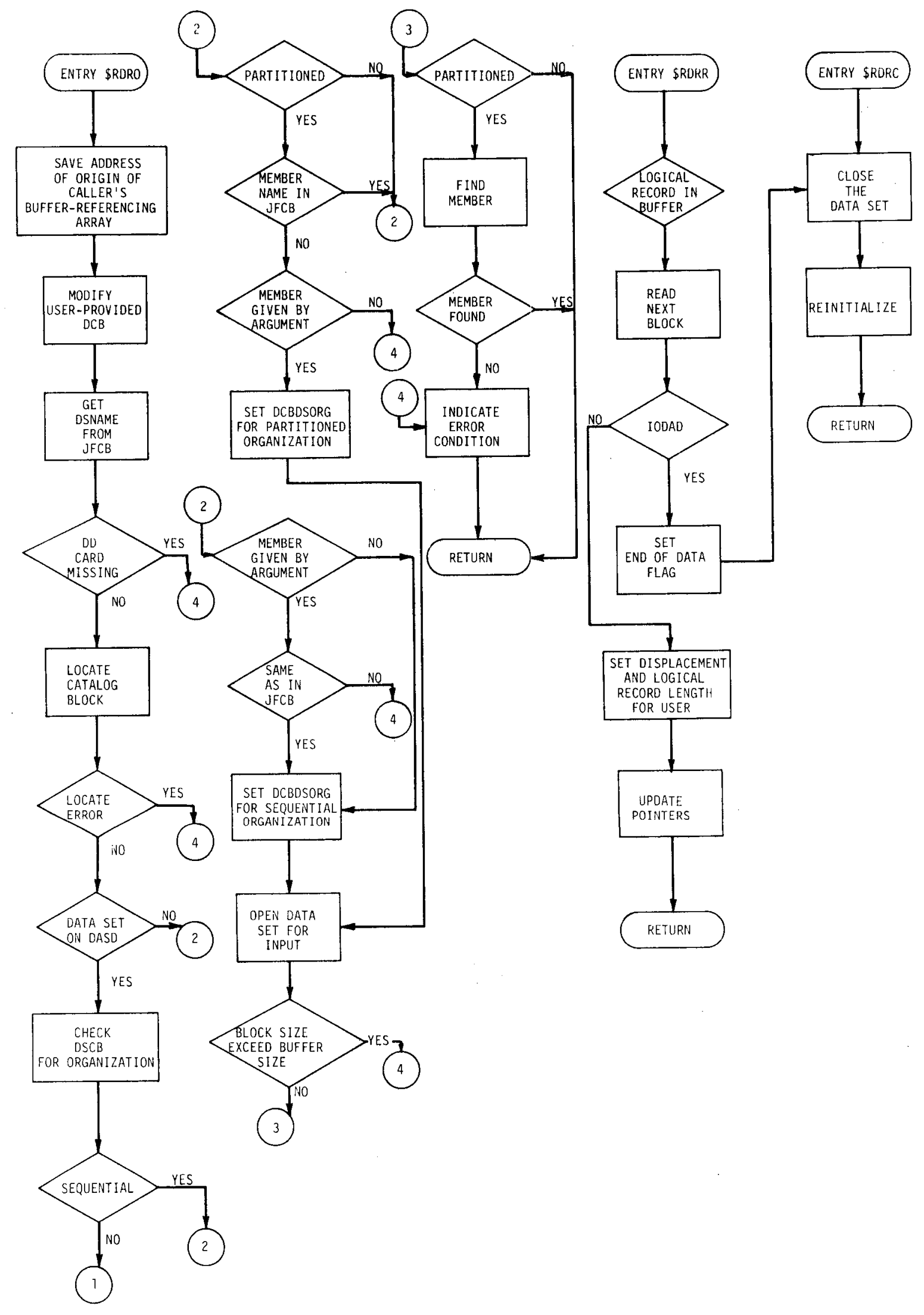




\begin{tabular}{|c|l|c|c|}
\hline JOSHUA & Title subroutine: \$RDR & Vol. & Page \\
DPSTM-500 & & IX & E.2.60 \\
\hline Rev. & Date \\
\hline
\end{tabular}




\begin{tabular}{|l|ll|l|l|}
\hline JOSHUA & Title & Function: \$SF\$ & Vol. & $\begin{array}{c}\text { Page } \\
\text { E.2.61 }\end{array}$ \\
\cline { 3 - 5 } & & Rev. & Date \\
& $6 / 73$ \\
\hline
\end{tabular}

DURPASE : RETURN THF USER'S SIGNCN CATEGORY VALUE.

IISAGF : SFCAT=\$SF\$(CCR)

AR GUMFNTS:

PARAMETFR TYPE NESTDIPTINN

RETURNING FIELD CONTAINING THF SICNCN CATEGORY VALUE.

CEB VARIMUS INSHUA CCR CONTROL BLOCK.

PROGRAM LTGIC : USE THF CER TO RETURN THE SCBSF FIELC.

JOSHIIA CONTAOL BLOCKS USEO : CCR

SURROUTTINES IISEN : NONE

LAVGUAGE: ASSEMRLER

A11THOD: 25 won 


\begin{tabular}{|c|l|l|l|}
\hline JOSHUU & Title Function: \$SF\$ & Vol. & Page \\
DPSTM-500 & & IX & E.2.62 \\
\cline { 3 - 5 } & & $\begin{array}{c}\text { Rev. } \\
1\end{array}$ & $\begin{array}{l}\text { Date } \\
6 / 73\end{array}$ \\
\hline
\end{tabular}

(Blank) 


\begin{tabular}{|c|c|c|c|c|}
\hline & \multirow{2}{*}{\multicolumn{2}{|c|}{ Title Subroutine: $\quad$ \$TERR }} & Vol. ${ }_{\text {IX }}$ & \begin{tabular}{|l|} 
Page \\
E.2.63
\end{tabular} \\
\hline DPSTM. 500 & & & $\begin{array}{l}\text { Rev. } \\
\\
1\end{array}$ & $\begin{array}{l}\text { Date } \\
6 / 73\end{array}$ \\
\hline
\end{tabular}

Purpose: $\quad$ To handle module abends.

Usage:

CALL \$TERR (CCB, PGNM) Or

CALL \$TERR (CCB, FWAR, NMI) where

$\begin{array}{lll}\text { Parameter } & \text { Type } & \text { Description } \\ \text { CCB } & \text { D } & \text { Communication Control Block } \\ \text { PGNM } & \text { H } & \text { Program abend number } \\ \text { FWAR } & \text { F } & \text { Twenty Full-word Array (optiona1) } \\ \text { NM1 } & \text { D } & \text { Name 1 Arguments (optiona1) }\end{array}$

External References: LOAD, JIBCOM, SVC 13

Program Logic: The addresses of the CCB and the program number are received on a two argunent call or the addresses of the $\mathrm{CCB}$, twenty full-word array, and name one argument area are received on a three argument call. If it is a two argument call, the program number and error number are set up in the $C C B$, and the abending subfunction is checked to see if IBCOM is used. If IBCOM is used, a LOAD is issued on JIBCOM and a link is made to the 'STOP' routine for IBCOM; otherwise, only an abend service is issued (SVC 13). If the call was with three arguments, the name one string is moved to the full-word array and the BNAM program number is set up before checking for IBCOM usage (as indicated in a two argument call).

Referenced by: Calling routines.

Language: $\quad$ Assembler

Author:

W. H. Brotherton, Jr., R. L. Boyce, Jr. 


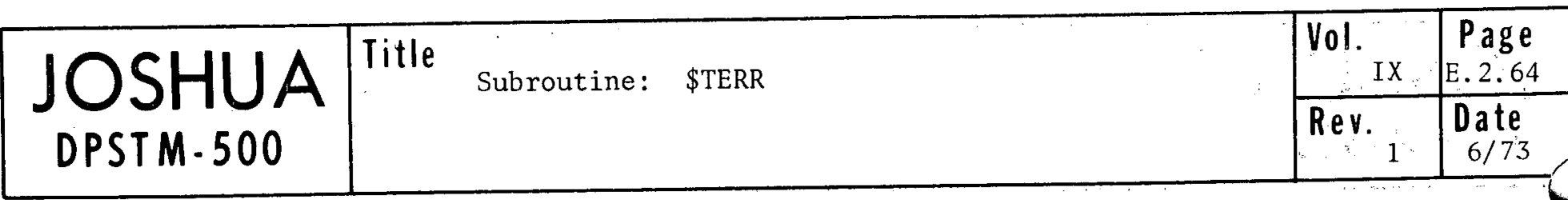

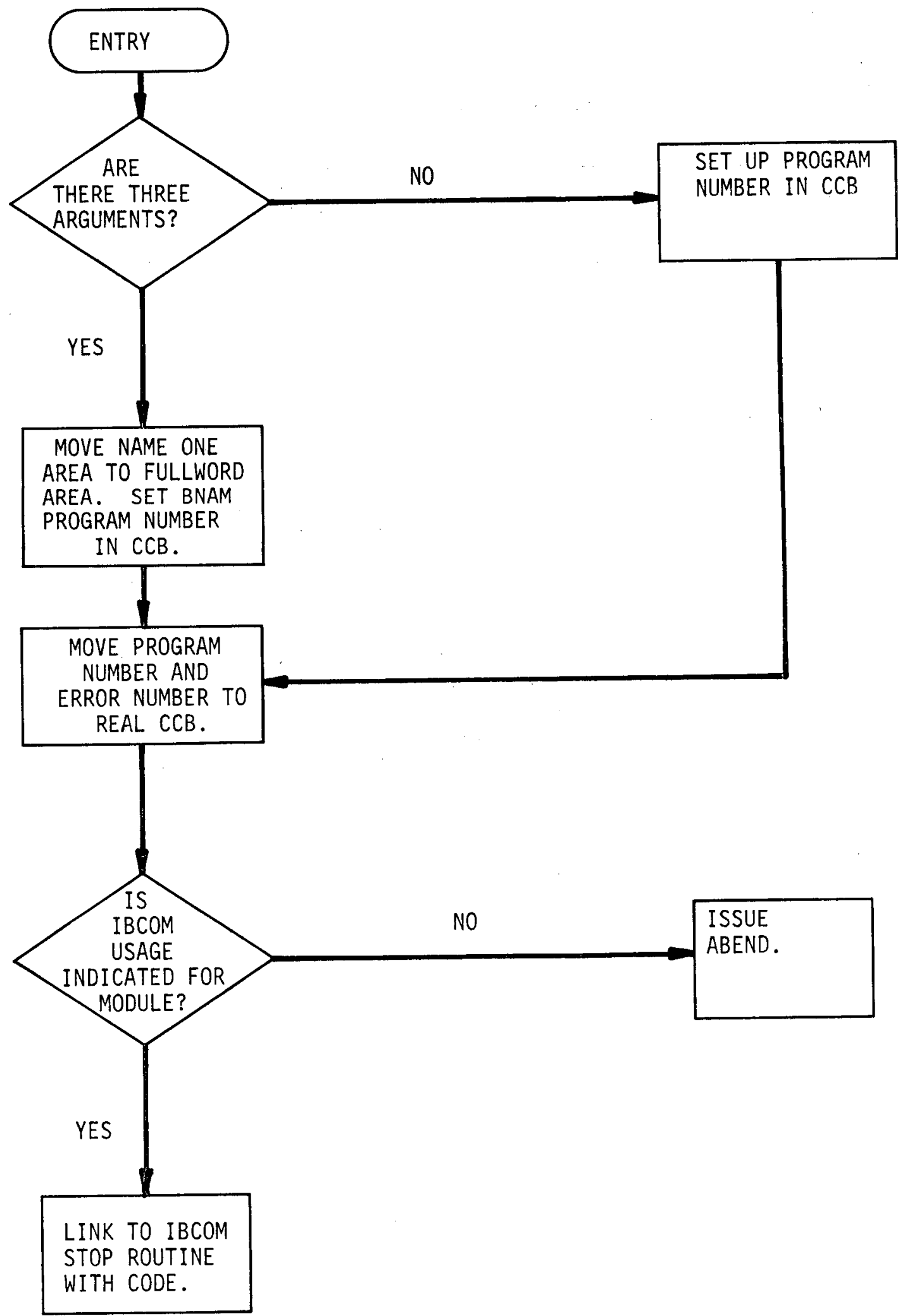




\begin{tabular}{|c|c|c|c|c|}
\hline & \multirow{2}{*}{\multicolumn{2}{|c|}{ Title $\quad$ Function: $\quad$ \$UNT }} & \begin{tabular}{|ll} 
Vol & \\
$\vdots \quad I X$ \\
\end{tabular} & \begin{tabular}{|l|} 
Page \\
E.2.65 \\
\end{tabular} \\
\hline DPSTM. 500 & & & Rev. 1 & $\begin{array}{l}\text { Date } \\
6 / 73\end{array}$ \\
\hline
\end{tabular}

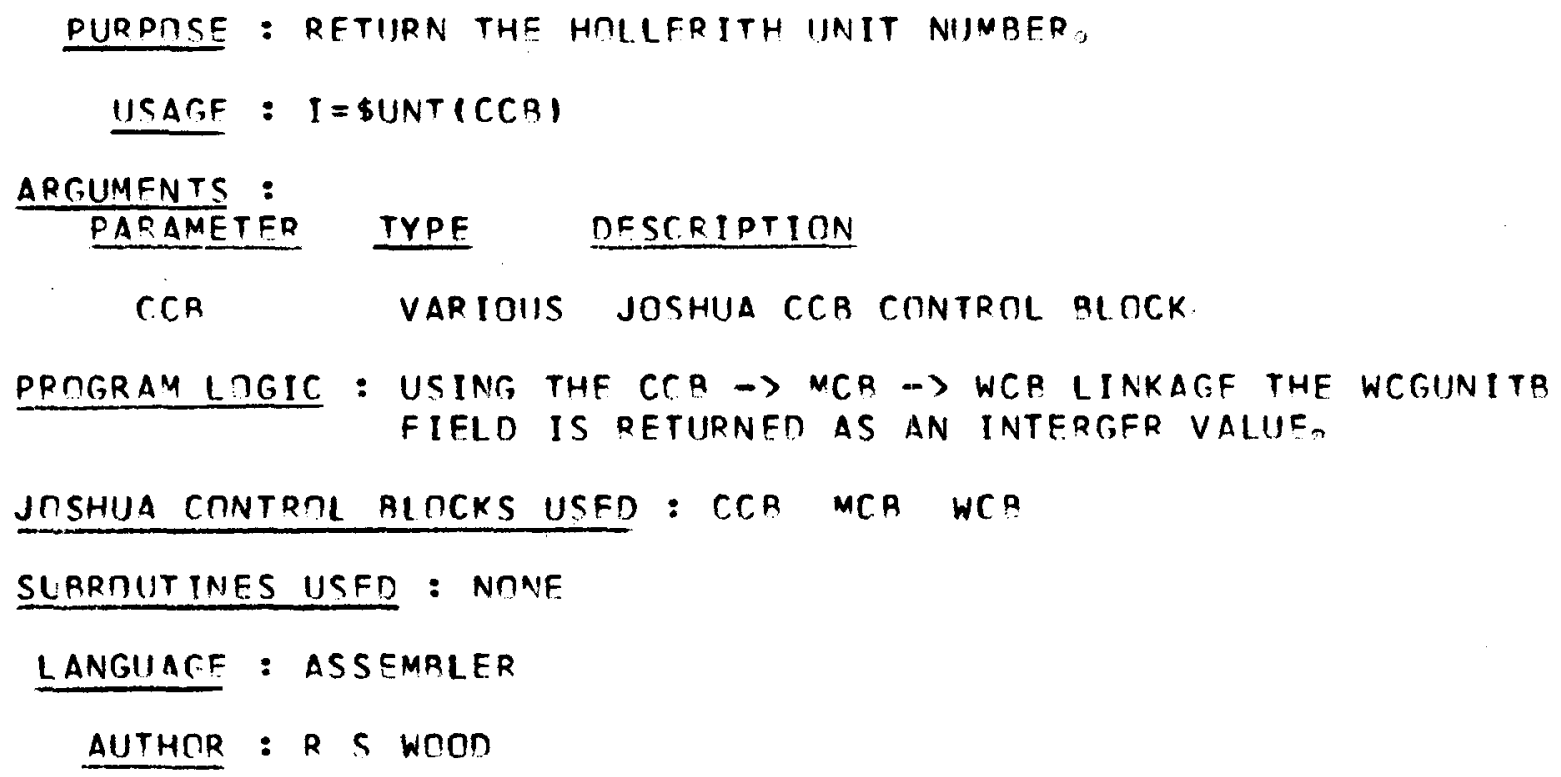




\begin{tabular}{|c|c|c|c|}
\hline JOSHUA & Title Function: \$UNT & $\begin{array}{c}\text { Vol. } \\
\text { IX }\end{array}$ & $\begin{array}{c}\text { Page } \\
\text { E.2.66 }\end{array}$ \\
\cline { 3 - 4 } & & $\begin{array}{c}\text { Rev. } \\
1\end{array}$ & $\begin{array}{c}\text { Date } \\
6 / 73\end{array}$ \\
\hline
\end{tabular}




\begin{tabular}{|c|l|l|l|l|}
\hline JOSHUA & Title Subroutine: \$WTR & Vol. IX & $\begin{array}{l}\text { Page } \\
\text { DPSTM.67 }\end{array}$ \\
\cline { 3 - 5 } & & & Rev. & Date \\
& $6 / 73$ \\
\hline
\end{tabular}

Purpose:

Usage:

MEMBER

DIRACT

DATA

DATALENGTH

Return Codes:

Arguments:

Mnemonic
To write a sequential data set.

To add, replace, or delete a member in a partitioned data set.

To open the data set:

Call \$WTRO (DCBADR [,MEMBER [,DIRACT]])

To write a logical record:

CALL \$WTRW (DATA, DATALENGTH)

To close the data set:

CALL \$WTRC

Type

Integer * 4

Logical*1

Logical ${ }^{*}$

$\operatorname{Logical} 1$

Integer * 4

\section{Description}

The address of a ninety-six byte area, a DCB, located on a fullword boundary which will be overlaid during \$WTRO, except for the DDNAME field, by a local DCB and which is then used as the DCB for the data set in question.

An eight-byte field specifying the member of a partitioned data set.

Specified the desired directory action of adding (' $A$ '), deleting (' $D$ ') or replacing (' $R$ ') a member in a PDS. When this argument is not given, add is assumed.

The data to be written.

The length of DATA in bytes.

The following values are returned in general purpose register fifteen:

$\begin{array}{lll}\text { Entry } & \text { Code } & \text { Explanation } \\ \text { \$WTRO } & 00 & \text { Successful completion. } \\ 04 & \text { RDJFCB failed - No DD statement. } \\ 08 & \begin{array}{l}\text { LOCATE failed - control volume not } \\ \text { mounted. }\end{array}\end{array}$




\begin{tabular}{|l|l|}
\hline Vol. II & $\begin{array}{l}\text { Page } \\
\text { E.2.68 }\end{array}$ \\
\hline Rev. & Date \\
& $6 / 73$ \\
\hline
\end{tabular}

\begin{tabular}{|c|c|c|}
\hline Entry & Code & Explanation \\
\hline & OC & $\begin{array}{l}\text { Illegal organization - only physical } \\
\text { sequential and partitioned organizations } \\
\text { are supported. }\end{array}$ \\
\hline & 10 & $\begin{array}{l}\text { A discrepancy exists in the member } \\
\text { specification vis-a-vis the data set } \\
\text { organization or the DD statement; or } \\
\text { the specified directory action is } \\
\text { invalid. }\end{array}$ \\
\hline & 14 & OPEN failed. \\
\hline & 18 & Blocksize exceeds buffer size. \\
\hline & $1 C$ & $\begin{array}{l}\text { Blocksize for data set was not pre- } \\
\text { viously established. }\end{array}$ \\
\hline & 20 & $\begin{array}{l}\text { Directory update (a deletion) was } \\
\text { successful. }\end{array}$ \\
\hline & 24 & Not used. \\
\hline & 28 & Member to be deleted could not be found. \\
\hline & $2 \mathrm{C}$ & Not used. \\
\hline & 30 & $\begin{array}{l}\text { A permanent } 1 / 0 \text { error was detected when } \\
\text { attempting to update the directory. }\end{array}$ \\
\hline \$WTRW & 00 & Successful execution. \\
\hline & 04 & Data set not open. \\
\hline & 08 & $\begin{array}{l}\text { Data length specified exceeds maximum } \\
\text { logical record size - no transfer made. }\end{array}$ \\
\hline & OC & $\begin{array}{l}\text { DASD primary allocation exhausted - } \\
\text { no secondary allocation requested. }\end{array}$ \\
\hline$\$ W T R C$ & 00 & Successful operation. \\
\hline & 04 & $\begin{array}{l}\text { Attempt to add a member - directory } \\
\text { already contained specified member. }\end{array}$ \\
\hline & 08 & $\begin{array}{l}\text { Attempt to replace a member - specified } \\
\text { member could not be found; member added. }\end{array}$ \\
\hline & $\mathrm{OC}$ & No directory space. \\
\hline & 10 & $\begin{array}{l}\text { A permanent } 1 / 0 \text { error was detected when } \\
\text { attempting to update the directory. }\end{array}$ \\
\hline & 14 & Data set was not open. \\
\hline
\end{tabular}




\begin{tabular}{|c|c|c|c|c|}
\hline & \multirow{2}{*}{\multicolumn{2}{|c|}{ Title Subroutine: $\quad$ \$WTR }} & Vol. & $\begin{array}{l}\text { Page } \\
\text { E.2.69 }\end{array}$ \\
\hline DPSTM. 500 & & & $\begin{aligned} \text { Rev. } \\
\end{aligned}$ & $\begin{array}{c}\text { Date } \\
6 / 73\end{array}$ \\
\hline
\end{tabular}

External References: The following system macro instructions are used:

CHECK

CLOSE

DCB

DCBD

LOCATE

OBTAIN

RDJFCB

REGDEF

WRITE (BPAM, BSAM)

The following SVC is issued:

21 (STOW)

Program Logic:

- \$WTRO

- The external DCB is established by overlaying the area with a local DCB, except for the DCBDDNAM field of the external area which is left unchanged. Following this operation, all DCB references are applicable to the external area.

- The data set organization is determined by:

1. Issuing a READJFCB to obtain the DSNAME preparatory to;

2. Issuing a LOCATE to check the device class and obtain the volume number, and if necessary;

3. Issuing an OBTAIN when the data set is located on a direct-access device.

The only valid organizations are physical sequential and partitioned; sequential is assumed when the data set is not on a direct-access device.

- If the argument MEMBER is not provided or is blank, the data set organization must be physical sequential or the member name must have been specified in the DD statement. If MEMBER is given, and non-blank, the data set must be partitioned and the JFCBELNM field must be blank or the same as member. 


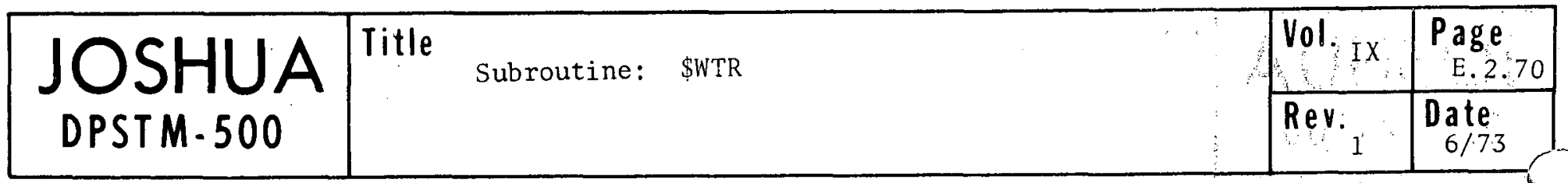

- The DCBDSORG field is set as indicated by the OBTAIN.

- When the data set organization is partitioned, DIRACT is checked. If it is not present it is assumed that an addition to the directory is to be made. When an action is specified, it must be an 'A', ' $R$ ', or ' $D$ ' indicating, respectively, add, replace, or delete.

- A type ' $\mathrm{J}$ ' OPEN is issued and a test made to assure it was successful.

- If a directory action of delete was specified for a partitioned data set, execution is concluded by issuing a STOW followed by a CLOSE.

- The DCBRECFM and DCBBLKSI fields are checked. Both the record format (fixed or undefined only) and the blocksize must have been previously defined. The maximum length of any logical record to be accepted is established as either the blocksize (for undefined) or as indicated by the DCBLRECL field (for fixed format). The number of logical records per block is established. The blocksize may not exceed the space allocated for the buffer.

- \$WTRW

- The open or closed status of the data set is ascertained.

- The length of the logical record is checked to insure it does not exceed the maximum established size.

- If space for another record exists in the buffer, DATA is transferred into it; when space does not exist, a write is issued before transferring the data. If the record format is $\mathrm{U}$ a wte is issued following each transfer of data to the buffer.

- When the data set is located on a DASD and no secondary allocation was specified, a check is made before writing a block to see if the space has been exhausted.

- \$WTRC

- If the data set is not opened, a return code is set; no further action is taken.

- If a data remairs in the buffer, the DCBBLKSI field is set to indicate how much data and a WRITE issued.

- If the data set is of partitioned organization and a WRITE was issued, a STOW is executed with the appropriate directory action (add or replace) indicated.

- Initializations necessary to allow reuse of the subroutine are made.

- A ClOSE is issued. 


\begin{tabular}{|c|c|c|c|}
\hline IOSHIJA & Title ${ }_{\text {Subroutine: }}$ \$WTR & Vol. & $\begin{array}{l}\text { Page } \\
\text { E.2.71 }\end{array}$ \\
\hline DPSTM. & & Rev. & $\begin{array}{c}\text { Date } \\
6 / 73\end{array}$ \\
\hline
\end{tabular}

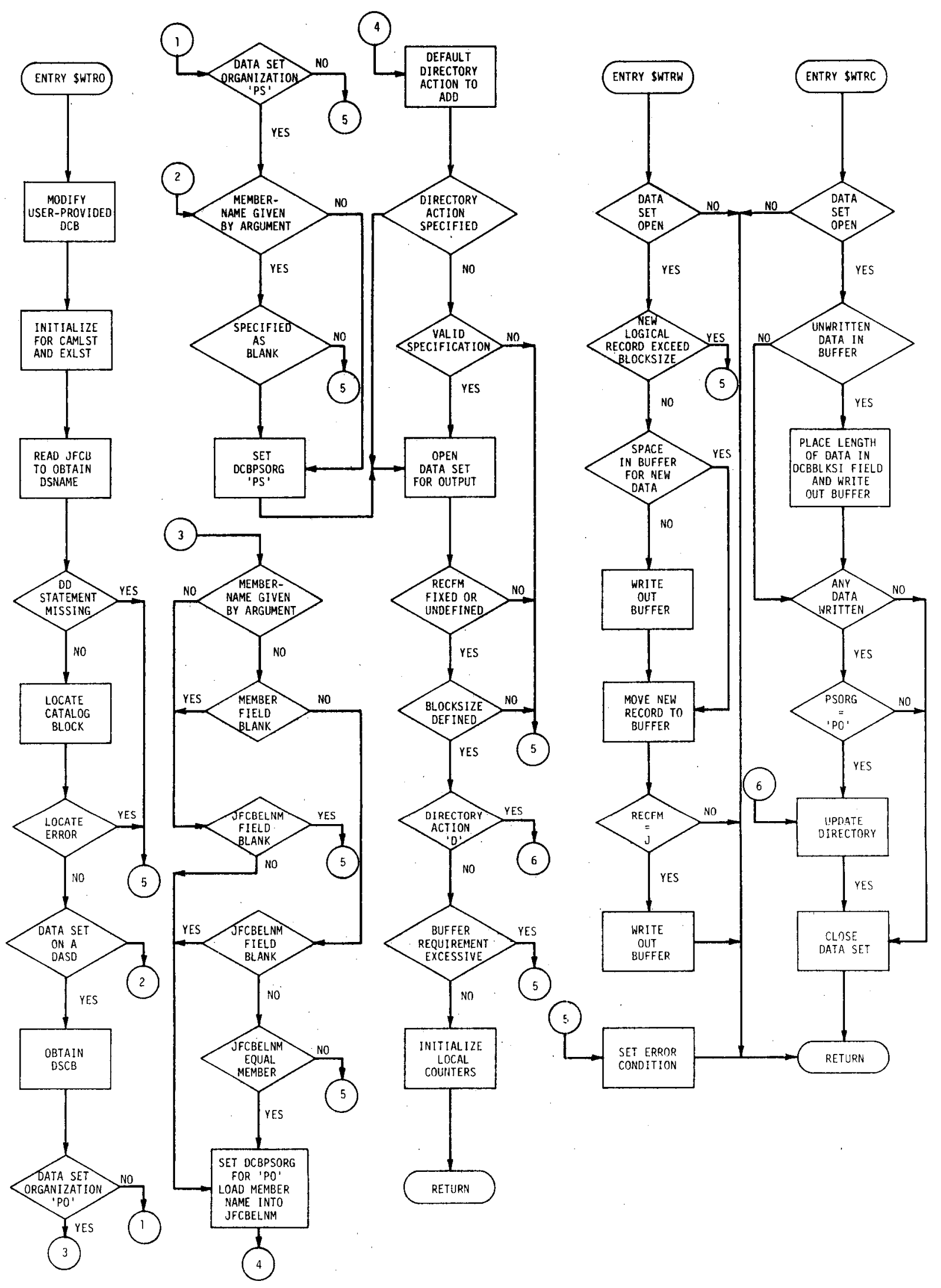




\begin{tabular}{|c|c|c|c|}
\hline \multirow{2}{*}{ DSPTM-500 } & Title Subroutine: \$WTR & Vol. & Page \\
\cline { 3 - 5 } & Rev. & Date.72 \\
\hline
\end{tabular}




\begin{tabular}{|c|c|c|c|}
\hline $1 \cap 01$ & Title Subroutine: BCDFIX & Vol. & $\begin{array}{l}\text { Page } \\
\text { E.2.73 }\end{array}$ \\
\hline DPSTM.500 & & ${ }^{R e v .}$ & $\begin{array}{l}\text { Date } \\
6 / 73\end{array}$ \\
\hline
\end{tabular}

Purpose:

To convert a zoned or edited number to a fixed point value.

Attribute:

Reusable

Usage:

The genera1 Fortran form is

$I=\operatorname{BCDFIX}(X, L,[K])$

where, $\quad I$ is the resulting fullword fixed-point number;

$X$ is the zoned or edited value string;

$L$ is a fullword specifying the length of $x$ in bytes;

$K$ is a fullword composite of one or more of the following values:

0 - ignore al1 blanks.

1 - return an error indication (by returning $K<0$.

2 - treat blanks as zeros.

4 - treat embedded or trailing blanks as an error.

Program Logic:

- Initialize to an error condition.

- Check for optional argument $K$; if present, assure proper value or return.

- Return if L is not greater than zero.

- The string $X$ must meet the following criteria -

a. It may be signed, but redundant signs are treated as an error.

b. Blanks are treated as specified. Blanks between a leading sign and the number are not considered as embedded; blanks between a trailing sign and the number are considered embedded.

c. In each byte, bits 4-7 must compose a value in the range $0-9$.

d. In each byte, except when blank, bits 0-3 must be on except for the last byte in a zoned number for which two other possible configurations are valid, representing the sign. 


\begin{tabular}{|c|c|c|c|c|}
\hline & \multirow{2}{*}{\multicolumn{2}{|c|}{ Title Subroutine: BCDFIX }} & Vol. IX & $\begin{array}{l}\text { Page } \\
\text { E.2.74 }\end{array}$ \\
\hline DPSTM -500 & & & Rev. & $\begin{array}{r}\text { Date } \\
6 / 73\end{array}$ \\
\hline
\end{tabular}

Language:

- Conversion takes place by originally setting register zero to zero and then for each byte to be converted, multiplying the register by ten and then adding in the value of the byte after masking the zoned bits.

- If processing of $X$ is completed with no numeric data encountered, the error flag is left on and control returned to the calling routine.

- When processing of $X$ is successfully completed, the error flag is turned off and the sign of the result established.

- In returning control to the calling routine when an error indication has been requested and an error encountered, an undefined negative value is placed in $K$; otherwise $K$ is not changed.

Author:

OS/360 Assembler

R. C. Haywood 


\begin{tabular}{|l|l|l|l|l|}
\hline$\underset{\text { DPSTM-500 }}{\text { Jitle Subroutine: BCDFIx }}$ & & $\begin{array}{l}\text { Vol. } \\
\text { Ix }\end{array}$ & $\begin{array}{c}\text { Page } \\
\text { E.2.75 }\end{array}$ \\
\cline { 3 - 5 } & $\begin{array}{c}\text { Revate } \\
6 / 73\end{array}$ \\
\hline
\end{tabular}

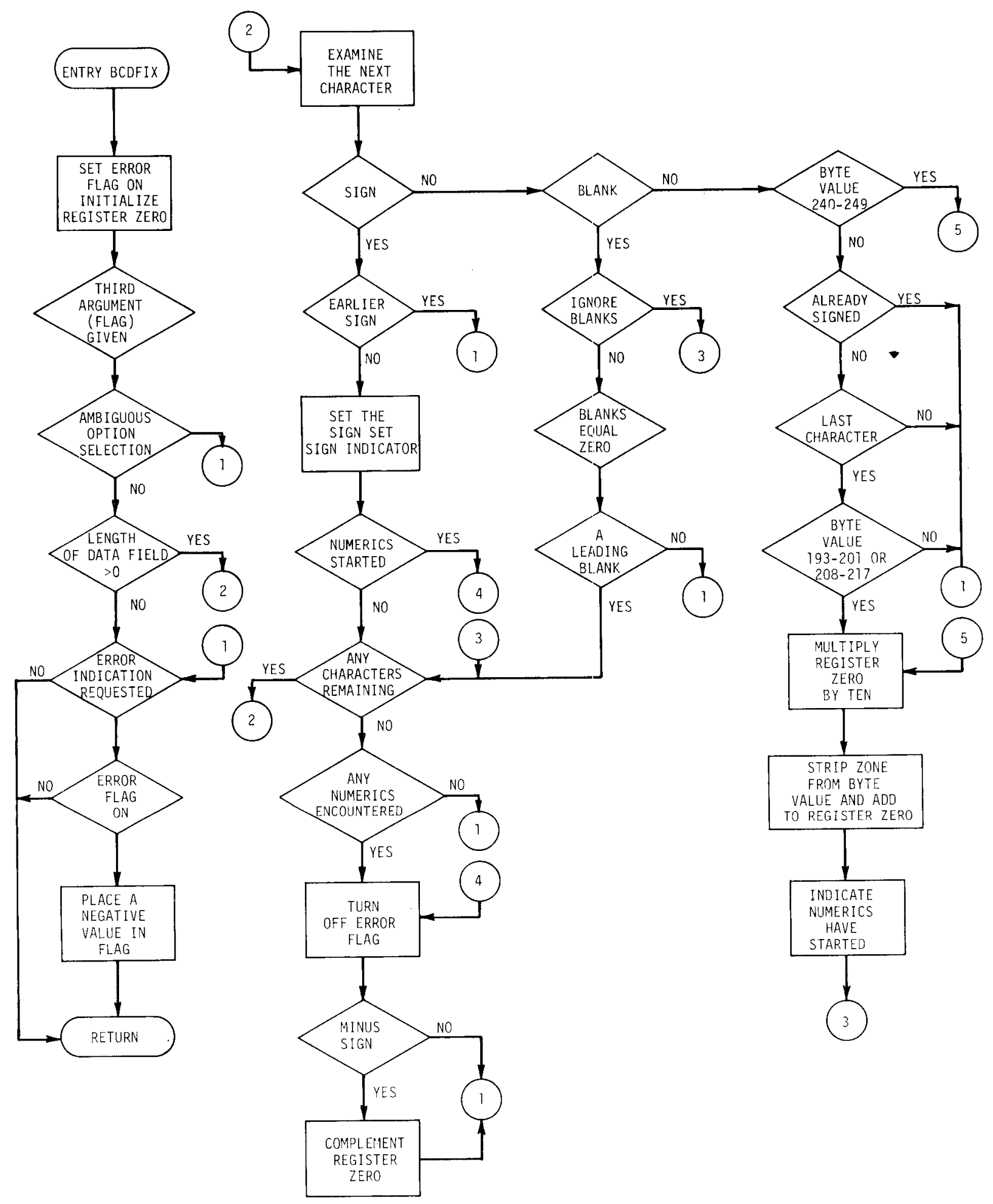




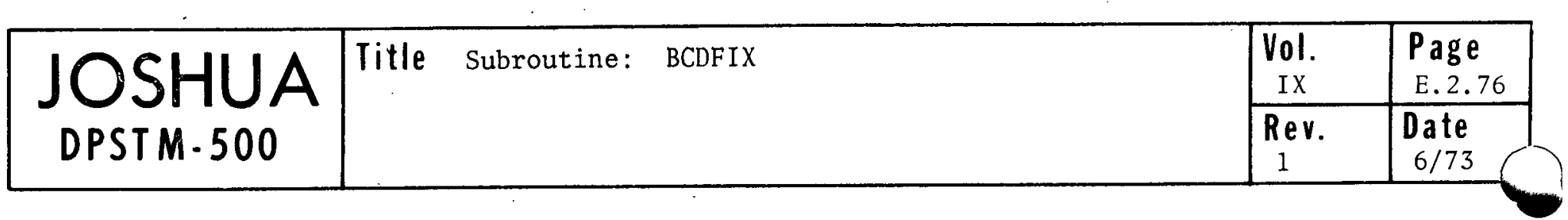




\section{JOSHUA}

\begin{tabular}{|l|l|}
\hline Vol. & Page \\
IX & E.2.77 \\
\hline Rev. & $\begin{array}{l}\text { Date } \\
6 / 73\end{array}$ \\
\hline
\end{tabular}

Purpose:

To convert to a double precision value and EBCDIC string of the form

$[[[N][\cdot[N]]][(D \mid E)[+\mid-] N]]$

Usage:

where $\mathrm{N}$ represents one or more numeric characters.

From Fortran -

as a subroutine

CALL BCDFLT (A, L, X, \& N)

as a double-precision function

$$
X=\operatorname{BCDFLT}(A, L)
$$

Arguments:

Mnemonic

A

$\mathrm{L}$

$\mathrm{X}$

Program Logic:

Language :

Author:
Type

Not restricted

Ful lword

Doubleword

General purpose register one should point to the list of addresses of the variables used as arguments.

A translate and test table is constructed. A is scanned using a TRT instruction. Between each continuation of the scan, the various function bytes are altered appropriately. Each group of numerics is converted to fixedpoint. The two values representing the whole and fractional portion of the number are converted separately to floatingpoint, the fractional floating-point value successively divided by ten until the proper value is obtained and then added to the whole number floating-point value after first normalizing the whole number. The sum is then adjusted by the appropriate power of ten as indicated by the value representing the exponent portion of the original representation. The result is left in floating point register zero as well as stored at $X$ if $X$ is defined as an argument.

0/S 360 Assembler

R. C. Haywood 


\begin{tabular}{|c|c|c|}
\hline JOSHUA & Tittle sulrout inc: Bcoplit & \begin{tabular}{|l|l|l|} 
Vol. \\
Rev.
\end{tabular} \\
\hline
\end{tabular}

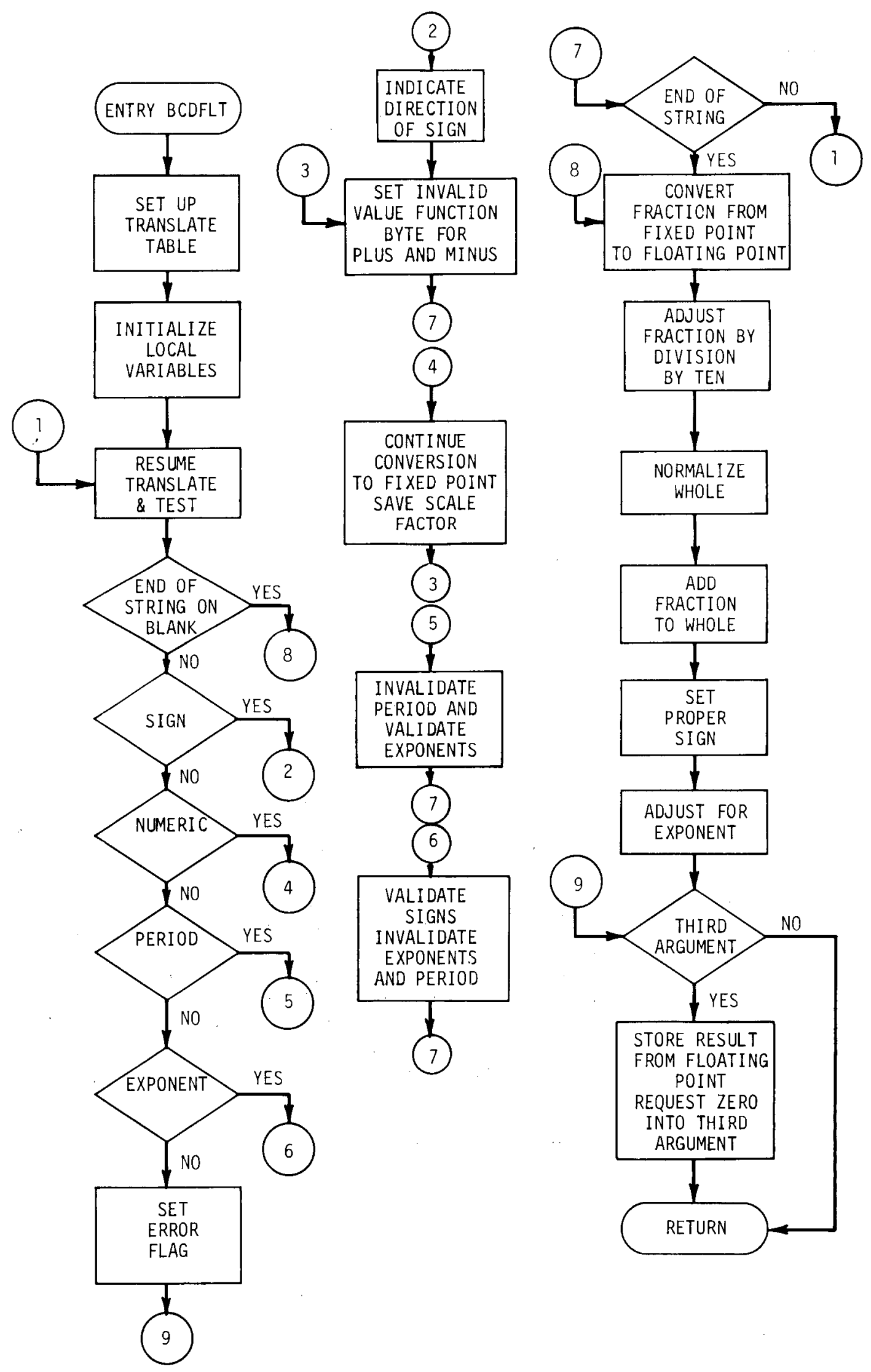




\begin{tabular}{|c|c|c|c|c|c|}
\hline 10 & Title & Subroutine: & DEFINE & \begin{tabular}{|r|} 
Vol. \\
IX
\end{tabular} & \begin{tabular}{|l|} 
Page \\
E.2.79 \\
\end{tabular} \\
\hline DPSTM.500 & & & & Rev. & Date \\
\hline
\end{tabular}

Purpose: $\quad$ To describe the characteristics of the data sets used during a JOSHUA direct-access operation.

Usage: $\quad$ CALL DEFINE

Data Sets: Direct-Access Data Sets for JOSHUA Data Record Storage

Program Logic: The program is entered via its entry name.

FORTRAN DEFINE FILE statements are then issued on the direct-access data sets for JOSHUA data record storage. Thirty-two thous and seven hundred sixty-seven 400-byte records are estabilshed for each data set. A return is then issued.

Language: $\quad$ FORTRAN IV

Author: $\quad$ J. C. Jensen 


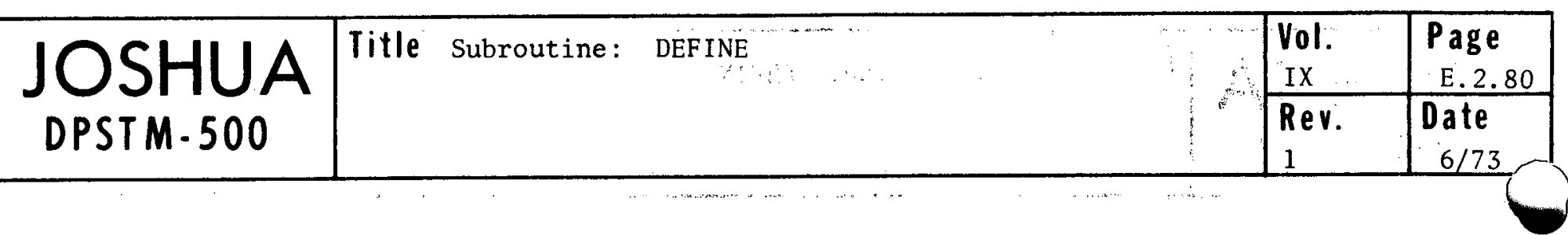




\begin{tabular}{|l|l|l|l|l|}
\hline \multirow{2}{*}{ DPSTM.500 } & Title Subroutine: FLEXIT & Vol. & $\begin{array}{c}\text { Page } \\
\text { E.2.81 }\end{array}$ \\
\cline { 3 - 5 } & & $\begin{array}{c}\text { Rev. } \\
\text { Date } \\
6 / 73\end{array}$ \\
\hline
\end{tabular}

Purpose:

To terminate the function.

Usage:

CALL FLEXIT (CCB or $\$ J C B$ )

where,

$\mathrm{CCB}=$ Communication Control Block (terminal region)

$\$ \mathrm{JCB}=$ Common MCB - (batch region)

Program Logic:

The address of the $\mathrm{CCB}$ or $\$ \mathrm{JCB}$ is received via the argument list. The next sub-function name area is located and set to a blank. A return is then issued.

Referenced by: Calling routines.

Language: Assembler

Author: R. L. Boyce, Jr. 


\begin{tabular}{|c|c|c|c|c|}
\hline & Title & Subroutine: FLEXIT & 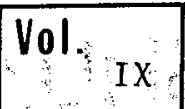 & \begin{tabular}{|l} 
Page \\
E.2.82
\end{tabular} \\
\hline DPSTM. 500 & & & Revis & $\begin{array}{l}\text { Date } \\
6 / 73\end{array}$ \\
\hline
\end{tabular}

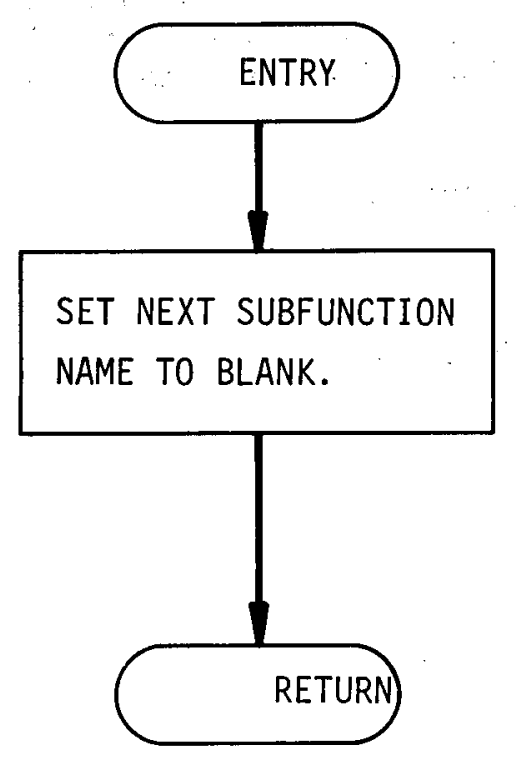




\begin{tabular}{|c|c|c|c|}
\hline 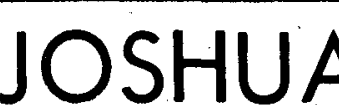 & \multirow[t]{2}{*}{ Title Subroutine: FMINIT } & Vol. $_{\text {IX }}$ & $\begin{array}{l}\text { Page } \\
\text { E. } 2.83\end{array}$ \\
\hline DPSTM -500 & & Rev. & $\begin{array}{l}\text { Date } \\
6 / 73\end{array}$ \\
\hline
\end{tabular}

Purpose:

Usage:

Arguments:

Parameter

MAP

RTYPE

Subprograms:

Program Logic:

Language:

Author:
To initialize the MAP array to its default values.

CALL FMINIT (MAP, RTYPE)

Type

Description

Logical*1 $(28,31)$ One character mnemonic of assembly types at each position of a $28 \times 31$ $(X, Y)$ grid.

Integer $* 2$

Literal denoting reactor type:

' $\mathrm{C}$ ' or not ' $\mathrm{C}$ '.

HEXXY

XYHEX

FMPACK

The reactor boundary on the $(X, Y)$ grid is contained in an array $Y_{0}=R X\left(X_{0}\right)$. Within this boundary, the mnemonic for '?' is stored unless the $X, Y$ position is either a control assembly, ' $\mathrm{C}$ ', or a sparjet, 'S', or a gasport, ' '.

Fortran IV

J. E. Suich 


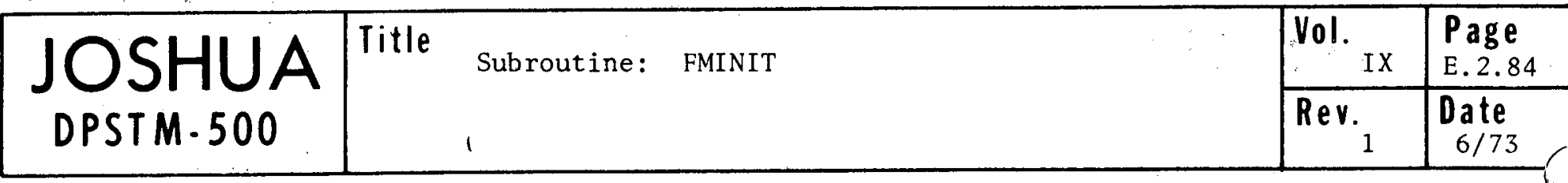

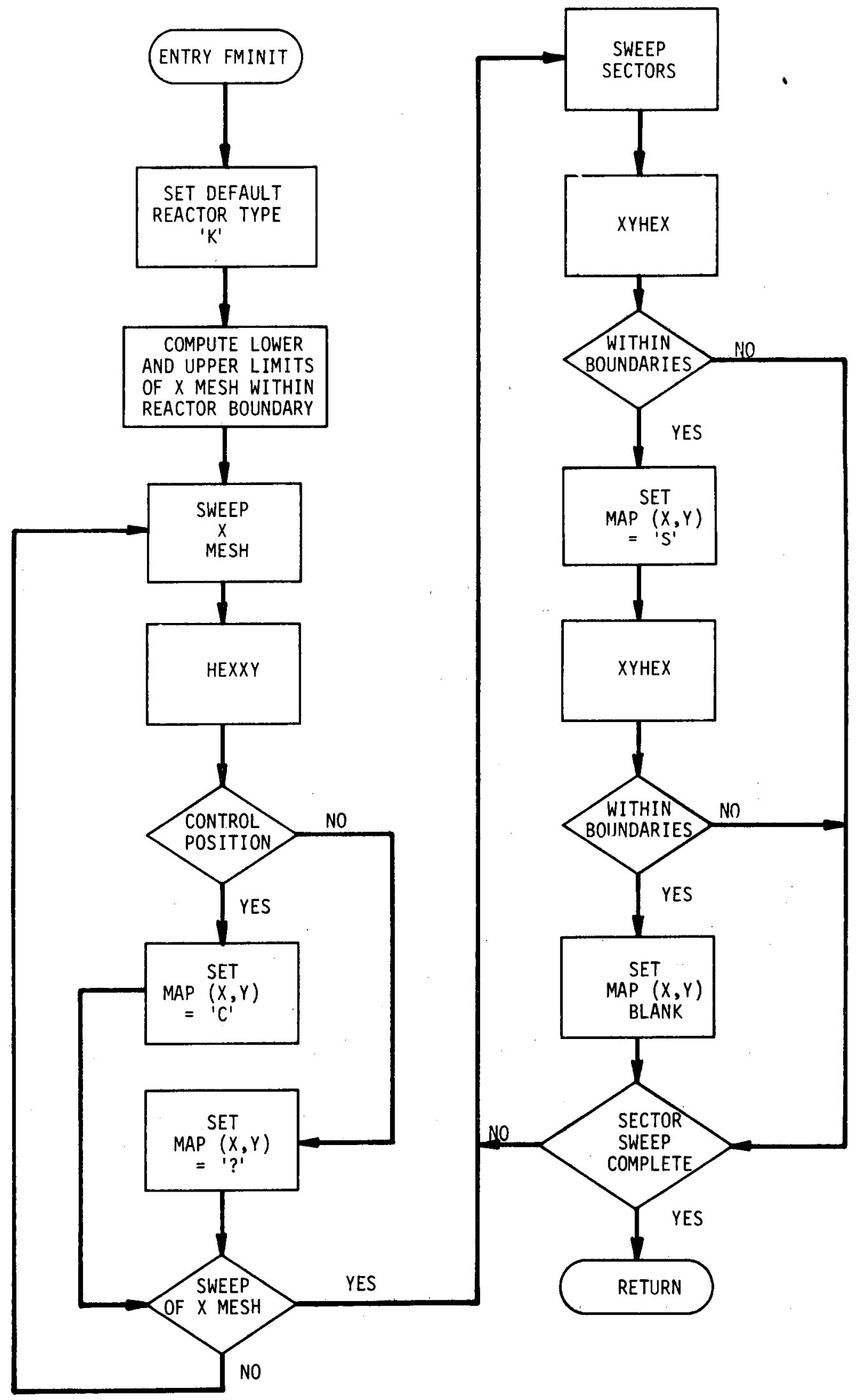




\begin{tabular}{|c|c|c|c|c|}
\hline & \multirow{2}{*}{\multicolumn{2}{|c|}{ Title Subroutine: FMPACK }} & Vol. IX & $\begin{array}{l}\text { Page } \\
\text { E.2.85 }\end{array}$ \\
\hline DPSTM -500 & & & Rev. $_{1}$ & $\begin{array}{l}\text { Date } \\
6 / 73\end{array}$ \\
\hline
\end{tabular}

Purpose:

Usage:

Arguments:

Parameter

$\mathrm{K}$

L

Program Logic:

Language:

Author:

Restrictions:
To code two-byte reactor assembly symbols into a one-byte representation.

$\operatorname{CALL} \operatorname{PACK}(K, L)$

Type

Description

Logical*1

Output code value.

Logical*1

Two-byte input symbol.

Associate with each symbol $\mathrm{L}$ (of the form ai, where a may be $A-H, J-N, P-Y$ and $i$ may be $0-9$ or blank) a coded value $n * 11+j$ where $n$ and $j$ are the sequence numbers of $a$ and $i$ over their defined possible strings. The two special symbols, blank-blank and ?blank, are coded as 255 and 254, respectively. Exceptions are treated as follows: The input characters are set to "AI", and the output value is set to 254 for "?b".

Fortran IV

J. E. Suich

Exception logic is dependent upon use of EBCDIC for the input symbols. 


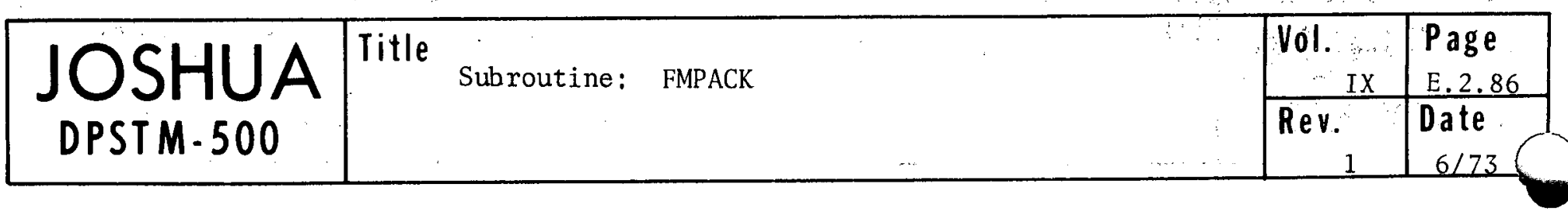

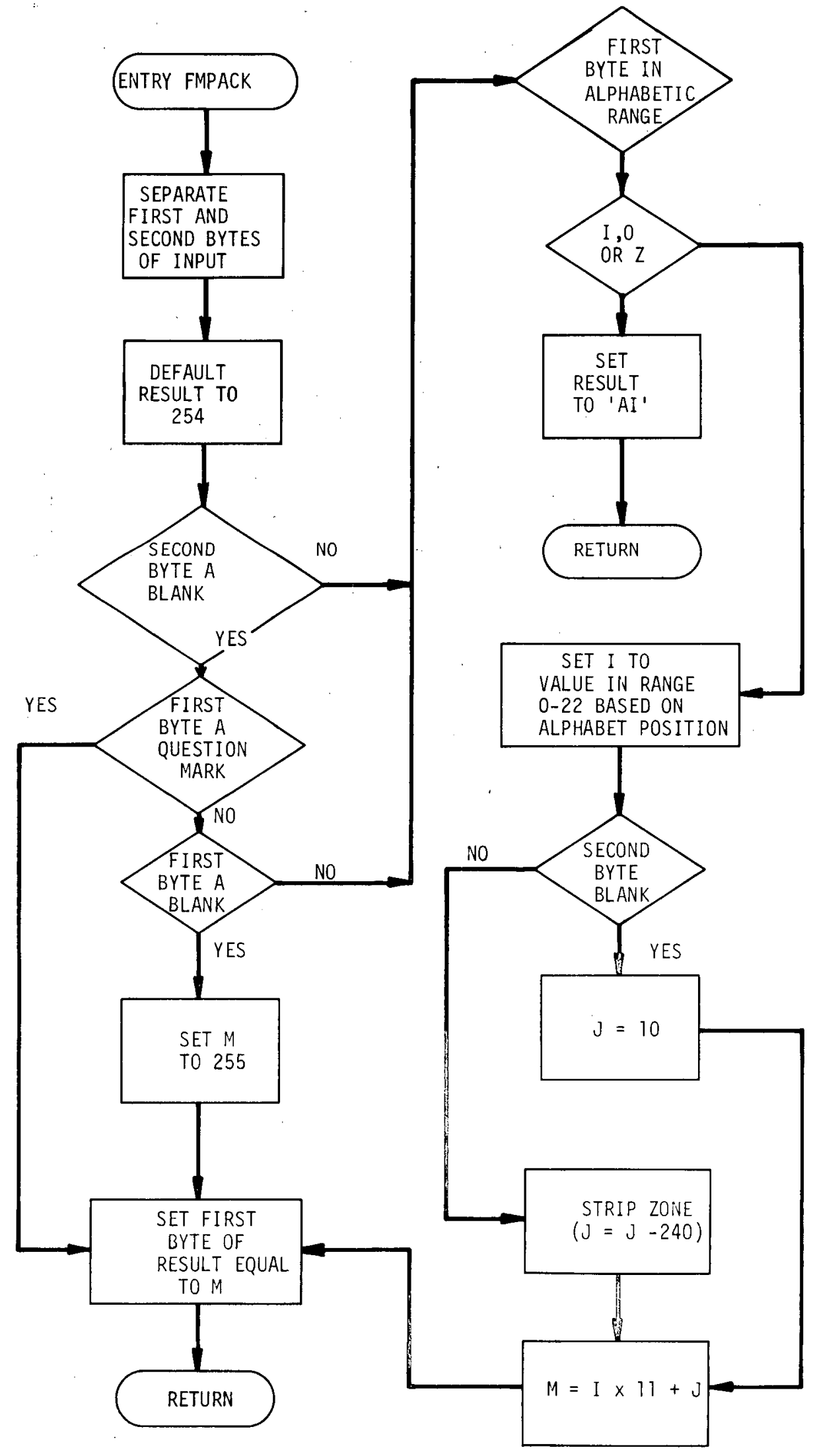




\begin{tabular}{|c|l|l|l|l|}
\hline \multirow{2}{*}{$\begin{array}{l}\text { DSPTM-500 } \\
\text { DPST Subroutine: FMUNPK }\end{array}$} & $\begin{array}{l}\text { Vol. } \\
\text { IX }\end{array}$ & $\begin{array}{l}\text { Page } \\
\text { E. } 2.87\end{array}$ \\
\cline { 3 - 5 } & & $\begin{array}{c}\text { Rev. } \\
\text { Date } \\
6 / 73\end{array}$ \\
\hline
\end{tabular}

Purpose: $\quad$ To decode the one-byte representation of reactor assembly symbols into two EBCDIC characters.

Usage:

$\operatorname{CALL} \operatorname{PACK}(K, L)$

Arguments:

Parameter

Type

\section{Description}

K

Logical*1

Input code.

$\mathrm{L}$

Logical*1

Output characters.

Program Logic:

Perform a table look-up to translate the input code into 256 output, two-byte symbols. The table is constructed of the symbols A-H,J-N,P-Y and the symbols $0-9$, blank. The first output symbol is the $[K / 11]-t h$ entry in the first table, and the second is the ( $K$ mod 11)-th entry in the second table. In addition, the two special codes, 254 and 255, respectively are translated as ?-blank and blank-blank.

Language:

Fortran IV

Author:

J. E. Suich

Restrictions:

Tables established by a data statement as EBCDIC. 


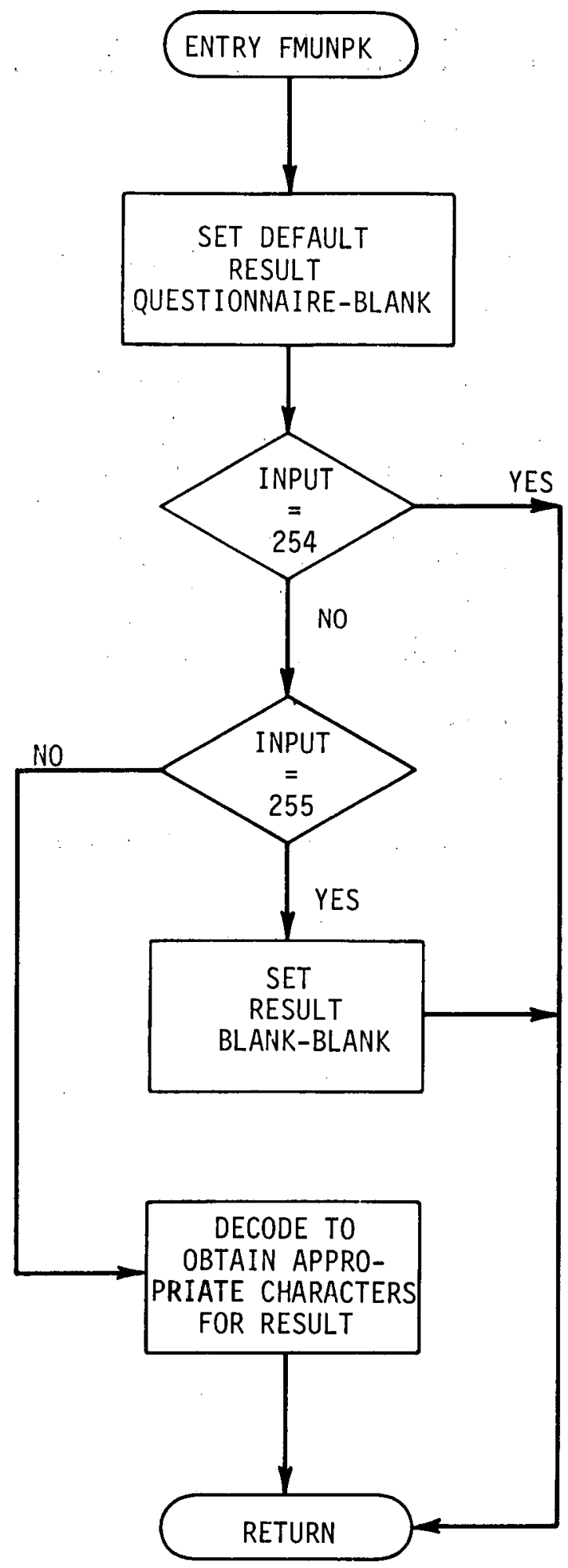




\begin{tabular}{|l|l|l|l|l|}
\hline \multirow{2}{*}{$\begin{array}{c}\text { OSPTM } \\
\text { DPS } 500\end{array}$} & Title & Vol. & Page \\
IX & E.2.89 \\
\cline { 3 - 5 } & & Rev. & Date \\
& & & $6 / 73$ \\
\hline
\end{tabular}

Purpose:

To convert from the SRP $X, Y$ coordinate representation of a hexagonal reactor lattice to the patch/point or GAUGE indexing representation.

Usage:

CALL HEXXY(IX, IY, IP, IPT, IBC, IR, IQ, IXP, IYP)

where:

IX - $X$ coordinate of the point

$I Y \quad-Y$ coordinate of the point

IP - patch number

IPT - point number in patch

IBC - boundary flag ( $=1$ if a 5 point or corner patch, $=0$ otherwise)

IR - ring number

IQ - sector number

IXP - X coordinate of patch center

IYP - Y coordinate of patch center

IX and IY are transmitted to the subroutine; all the other variables are calculated by HEXXY. All arguments are integer* 4 variables.

The $X-Y$ coordinate system is that used at SRP except that the origin has been translated to the center of the reactor.

The GAUGE indexing scheme used is that in the original code with three points per hex and a full six sectors in the geometry. The interior points of a patch are numbered 1 to 13 as in GAUGE; the boundary points are given negative indexes which will run from -1 to -5 or -8 depending on the patch. (Superpatch or one point per hex index numbers can also be obtained from HEXXY. Set $I X=Y$ coordinate, $I Y=1 / 3$ (X coordinate) and $H E X X Y$ will return with the appropriate index numbers in the supernatch structure.

Program Logic: First the sector number is determined. This is done using the set of lines which bisect each sector. These lines are perpendicular to the lines connecting the centers of the 'corner' patches. The projection of the point on each of these lines is calculated. From the sign of these three projections, the sector in which the point lies may be found. See Figure 1. 


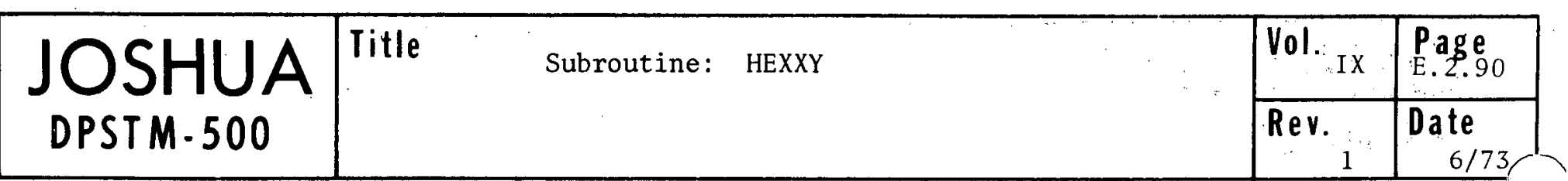

A decision table, shown below, is used to generate the sector number from the six different combinations of signs. A value, stored in the array QTST, is assigned to each line. If $Q$ is given an initial value of 2 and the appropriate QTST is added to $Q$ for each negative sign found, the resulting $Q$ will determine the sector.

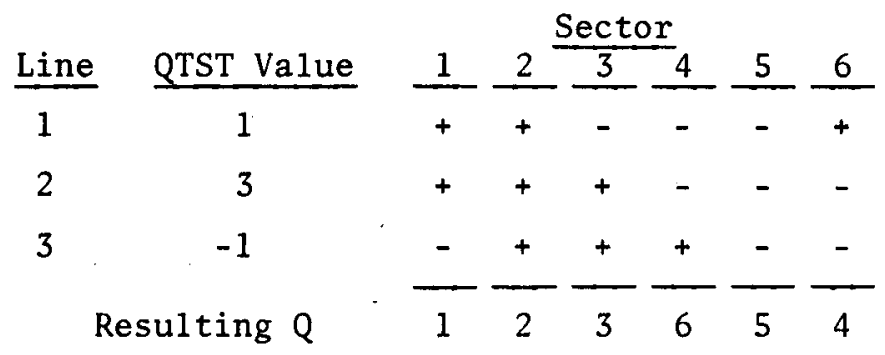

For $Q \leq 3$, the sector number is $Q$; for $Q>3$, the sector number is $10-Q$ and the sector (either 1,2 , or 3) which is opposite to this is $7-Q$.

Once the sector has been determined, we can decide where the point is in its patch using the value of the projection of the point on the line bisecting the sector. Figure 2 shows the projections for three patches which are in the same ring. You can see that similarly placed points in each patch have the same projection. Furthermore, the projections occur in evenly spaced increments. This pattern repeats in each successive ring. Taking the distance modulo 21 identifies each point irrespective of ring. A table lookup, using the array XYPTS, converts the point index in terms of distances into the GAUGE point number.

Given the point number, the coordinates of the patch center can be determined as a translation from the $X-Y$ coordinates of the point. The CORR array is used to effect this translation. To save space in the CORR array, use is made of the fact that the displacements for points in sectors $4-6$ are the negative of those in the corresponding sectors $1-3$.

The projection of the patch center along the line besecting the sector is calculated. This distance, divided by 21 , gives the ring number. The third index needed to locate the particular patch, namely the index of the patch in each row or ring of the sector, is calculated from the displacement of the patch. 


\begin{tabular}{|l|ll|l|l|}
\hline JOSHUA & Title Subroutine: HEXXY & Vol. & Page \\
DPSTM & E.2.91 \\
\cline { 3 - 5 } & & Rev. & $\begin{array}{c}\text { Date } \\
6 / 73\end{array}$ \\
\hline
\end{tabular}

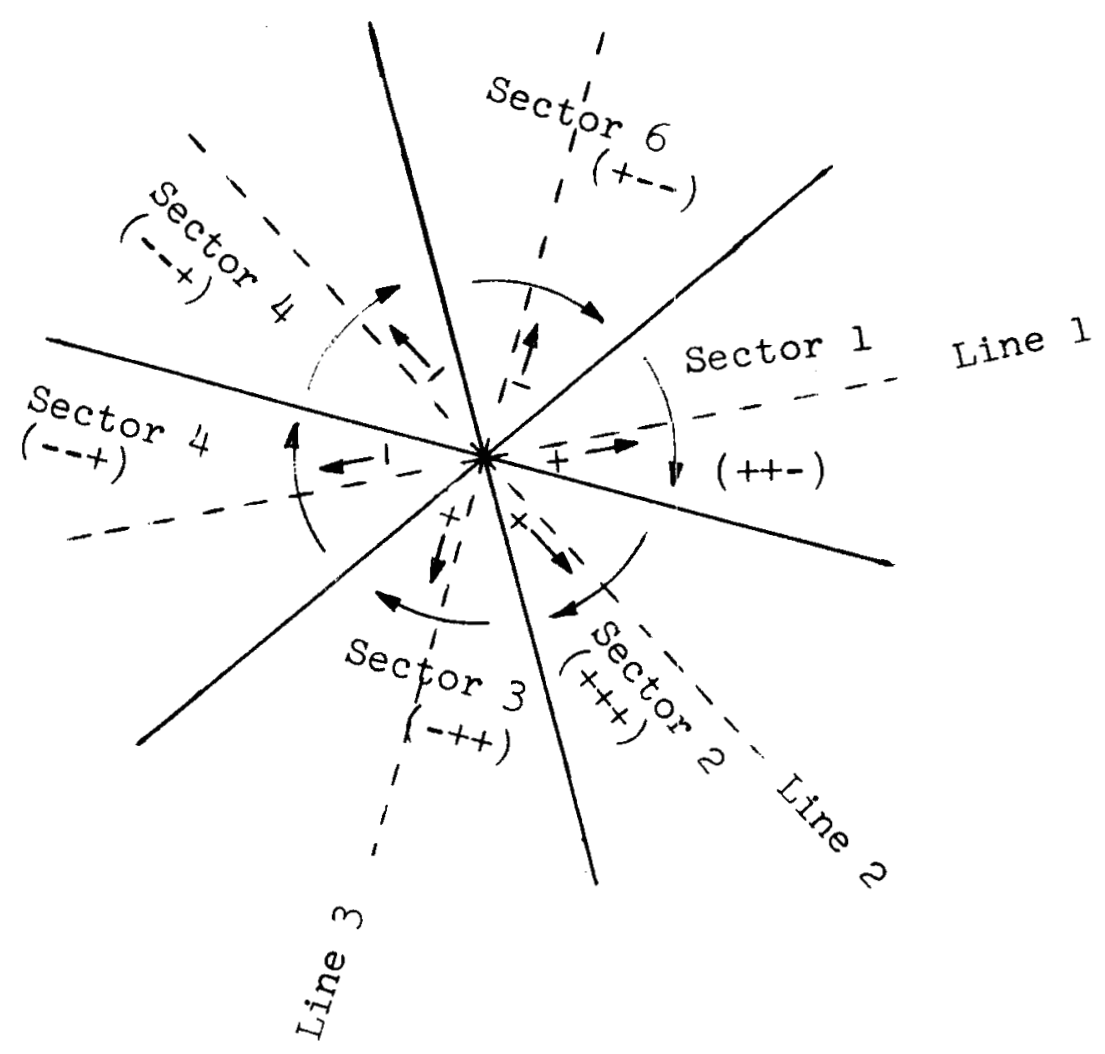

Figure 1

The solid lines are the lines connecting the centers of the 'corner' patches. The dashed lines are the lines through the middle of each sector and are perpendicular to the solid lines.

We calculate the projection of the point onto each of the dashed lines. Positive and negative projections are defined as shown in the figure. Consider line 1. All points in sectors 1,2 , and 6 will project onto the positive side of the line while points in sectors 3,4 , and 5 will have negative projections. Each sector can then be uniquely defined by the sign of its projections on the three lines. For each sector the particular sign combination is shown on the figure. 


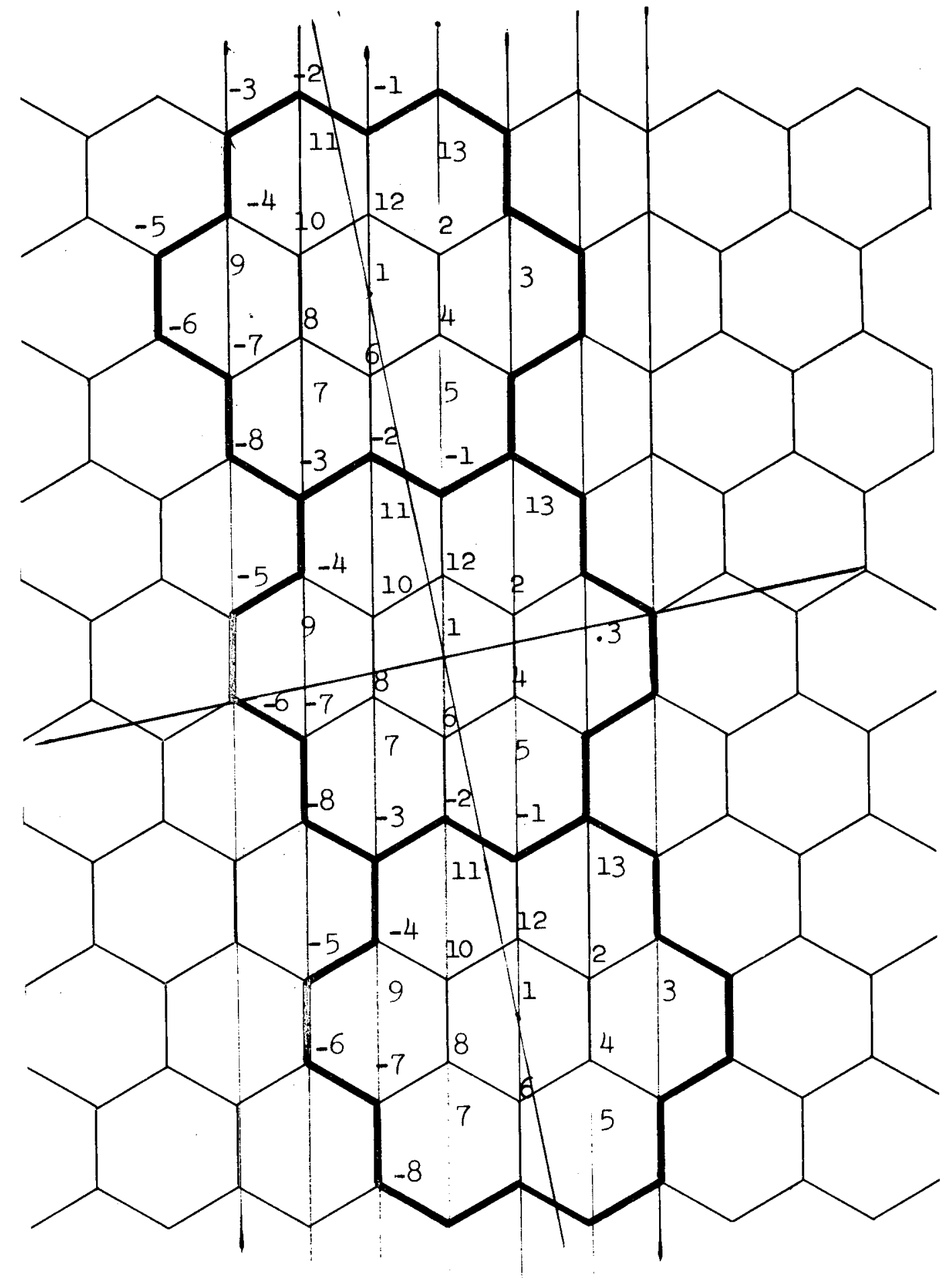

Figure 2. Projections for Three Patches in Same Ring. 


\begin{tabular}{|l|l|l|l|}
\hline$\underbrace{}_{\text {DPSTM-500 }}$ OSHUtle Subroutine: HEXXY & Vol. & $\begin{array}{l}\text { Page } \\
\text { E.2.93 }\end{array}$ \\
\cline { 3 - 5 } & & Rev. & $\begin{array}{c}\text { Date } \\
6 / 73\end{array}$ \\
\hline
\end{tabular}

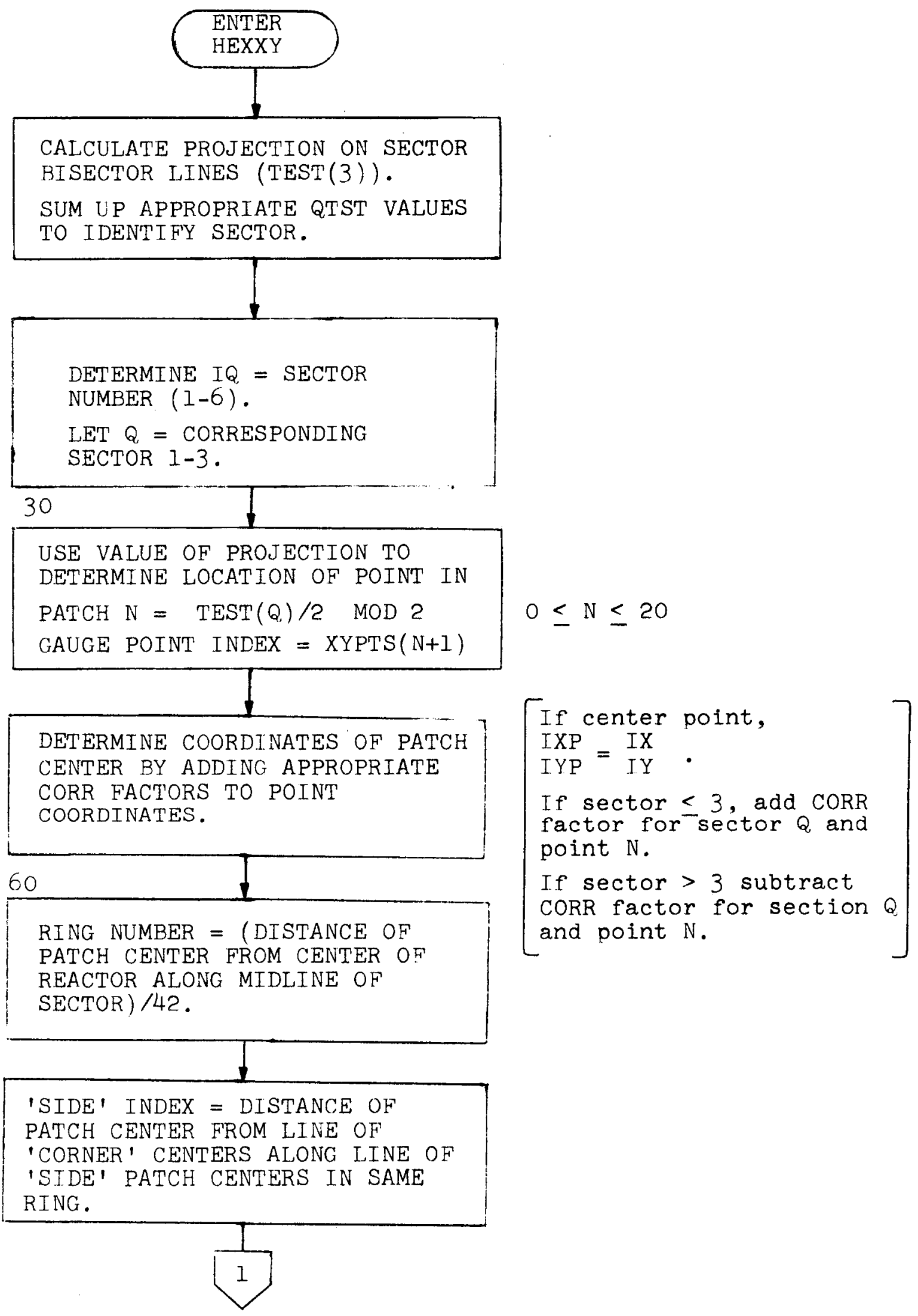




\begin{tabular}{|c|l|l|l|l|}
\hline JOSHUA & Title Subroutine: HEXXY & Vol. & Page \\
DPSTM.500 & & IX & E.2.94 \\
\cline { 3 - 5 } & & Rev. & Date \\
\hline
\end{tabular}

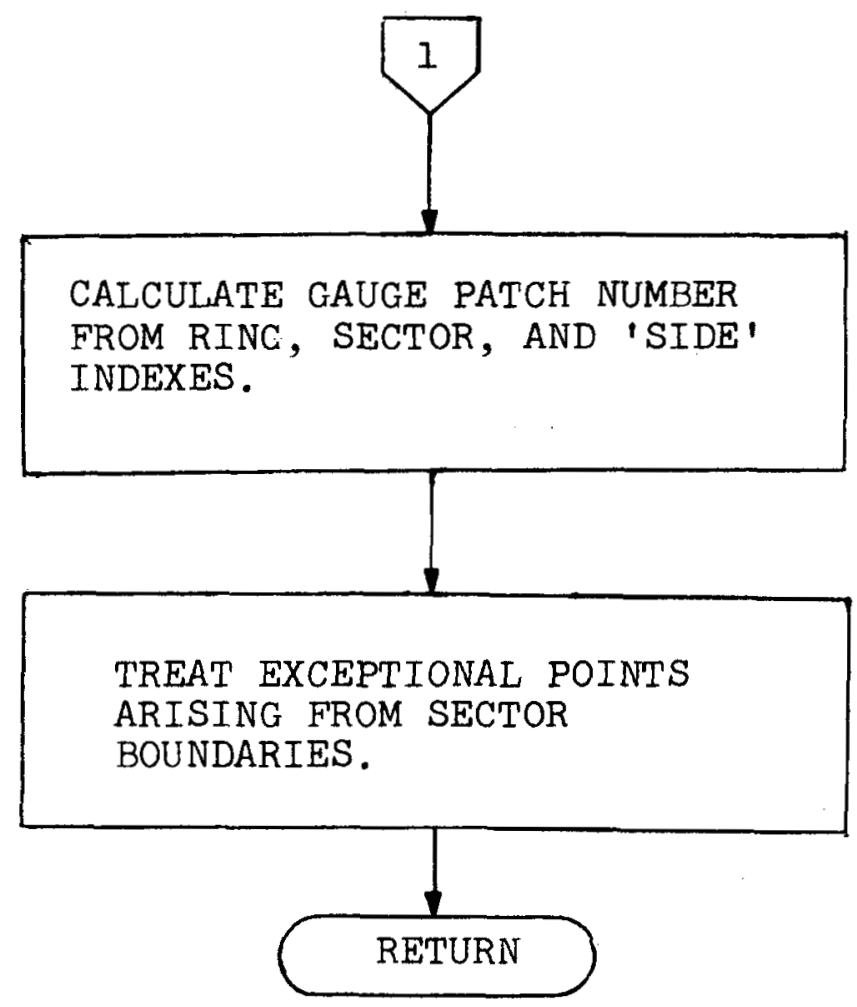




\begin{tabular}{|c|c|c|c|c|c|}
\hline & \multirow{2}{*}{\multicolumn{3}{|c|}{ Title Subroutine: HEXXY }} & Vol. & $\begin{array}{l}\text { Page } \\
\text { E.2.95 }\end{array}$ \\
\hline DPSTM. 500 & & & & Rev. & $\begin{array}{l}\text { Date } \\
6 / 73\end{array}$ \\
\hline
\end{tabular}

Detailed flowchart for exceptional points:

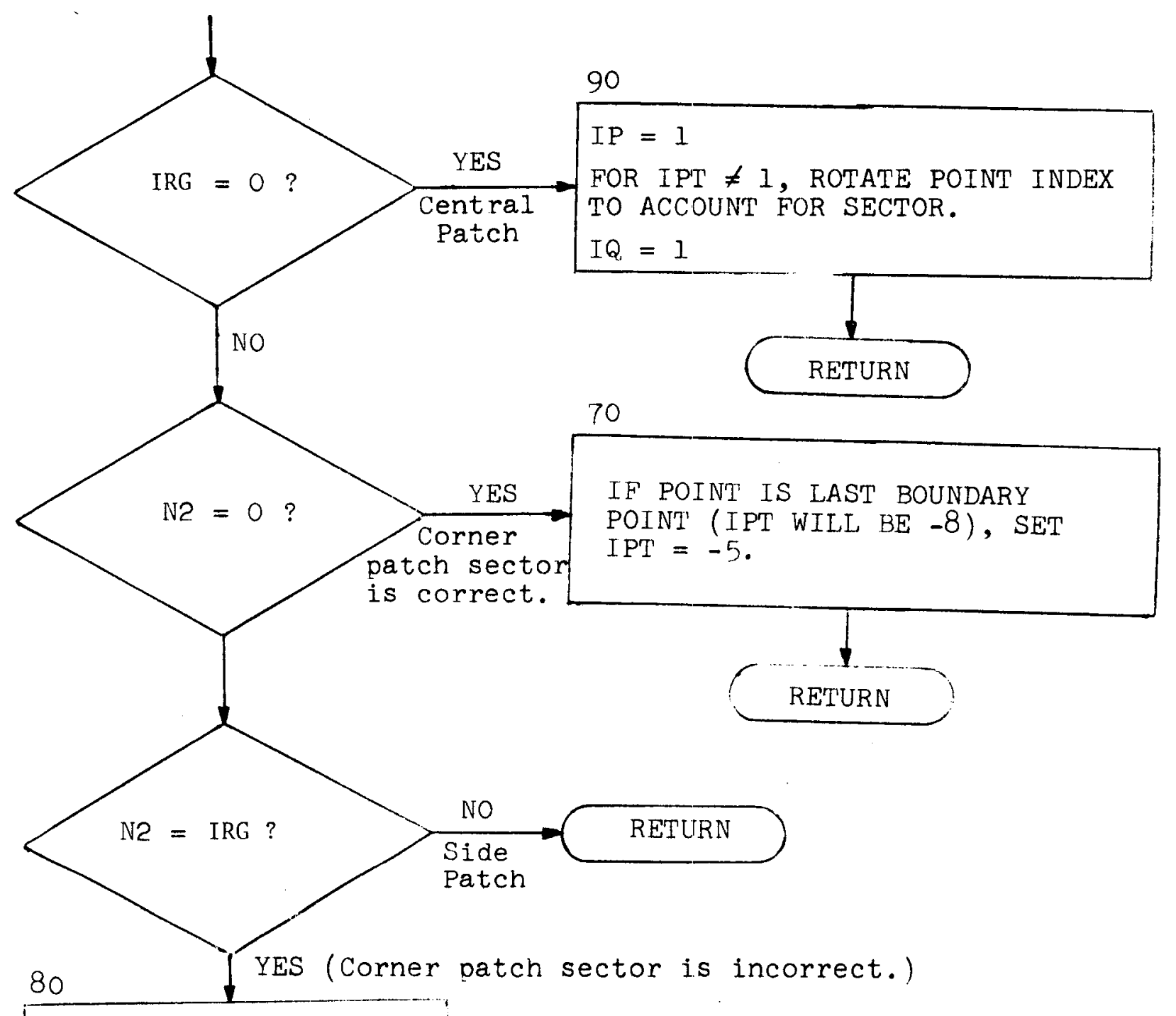

$I Q=(I Q+1)$ MOD 6. ADJUST IP IF NECESSARY,

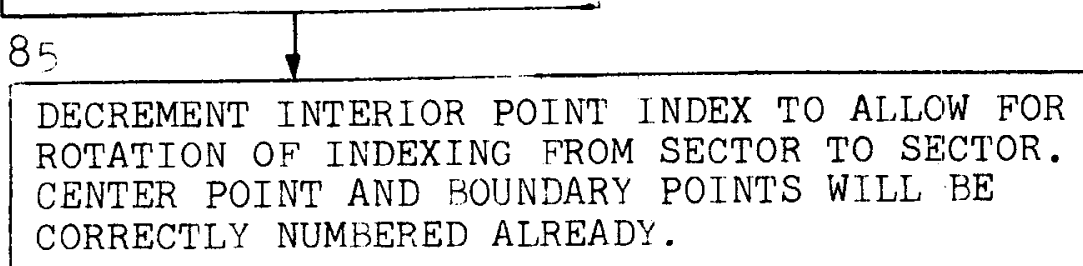

RETURN 


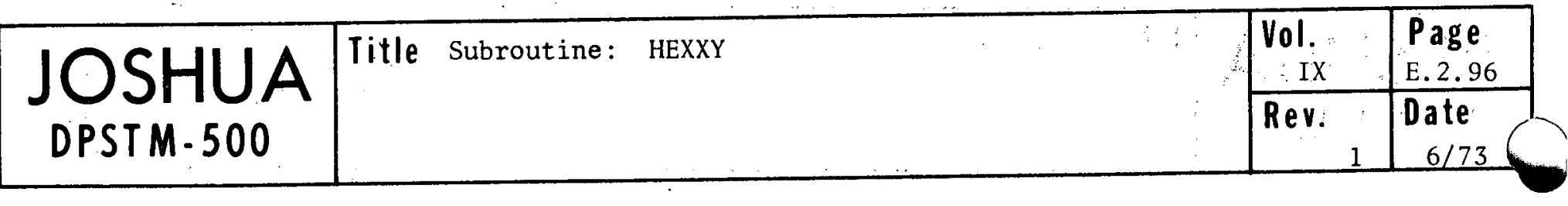




\begin{tabular}{|c|c|c|c|}
\hline & Title & Vol. IX & $\begin{array}{l}\text { Page } \\
E .2 .97\end{array}$ \\
\hline DPSTM. 500 & Subroutine: IBMDATE & ${ }_{1}$ Rev. & $\begin{array}{c}\text { Date } \\
6 / 73\end{array}$ \\
\hline
\end{tabular}

Purpose:

Usage:

To return, as a fixed point value, in both the argument provided and in register 0 (allowing use as a FORTRAN integer function) the day in the form YYDDD, where:

$Y Y$ is the last two digits of the year;

DDD is the day of the year.

The general FORTRAN form for usage is:

[CALL] IBMDATE (L)

Arguments:

Mnemonic

Type

Description

$\mathrm{L}$

Integer*4 Returns the date.

Program Logic:

The date is retrieved in packed decimal form from the OS Communication Vector Table (CVT), converted to fixed point, and returned. in register zero and in $\mathrm{L}$.

Language:

OS/360 Assembler

Author :

R. C. Haywood 


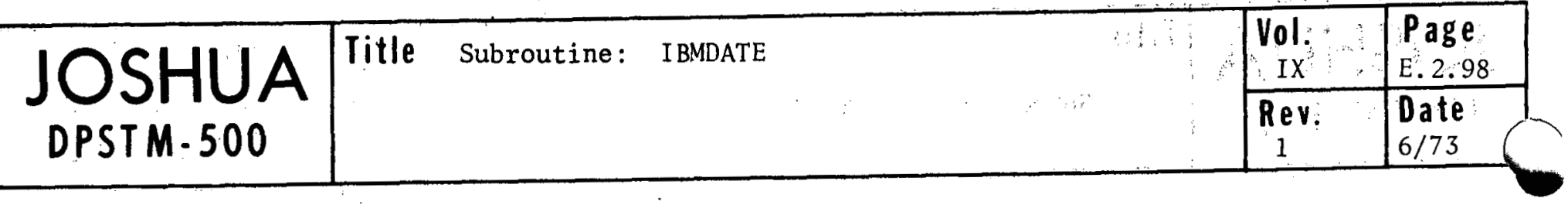

(Blank) 


\begin{tabular}{|c|c|c|c|c|}
\hline 然 & \multirow{2}{*}{\multicolumn{2}{|c|}{ Title Function: IBMJUL }} & Vol IX & $\begin{array}{l}\text { Page } \\
\text { E.2.99 }\end{array}$ \\
\hline DPSTM. 500 & & & Rev. & $\begin{array}{l}\text { Date } \\
6 / 73\end{array}$ \\
\hline
\end{tabular}

Purpose:

Usage:

\section{Arguments:}

Mnemonic

I BMDAT

Program Logic:

Restrictions:

Language:

Author:

To convert a date of the form YYDDD to a Julian date reckoned from March 1 of the preceding centurial year.

As a FORTRAN function

IBMJUL (IBMDAT)

The result is returned in register zero (OS/360 FORTRAN).

Type

Integer*4

\section{Description}

A date of the form YYDDD where:

$Y Y$ is the last two digits of the year. DDD is the day of the year.

- The year is multiplied by 1461 (the number of days in a four year period in the order 365-365-365-366), and then divided by four. The integer result plus the day of the year minus either 59 (normal years) or 60 (leap years) produces the Julian date.

In the current implementation, the centurial year is not a leap year.

OS/360 Assembler

R. S. Wood - R. C. Haywood 


\begin{tabular}{|c|l|l|l|}
\hline JOSHUA & Title Function: IMBJUL & Vol. & Page \\
DPSTM.500 & & Ix & E.2.100 \\
\cline { 3 - 5 } & & Rev. & Date \\
\end{tabular}

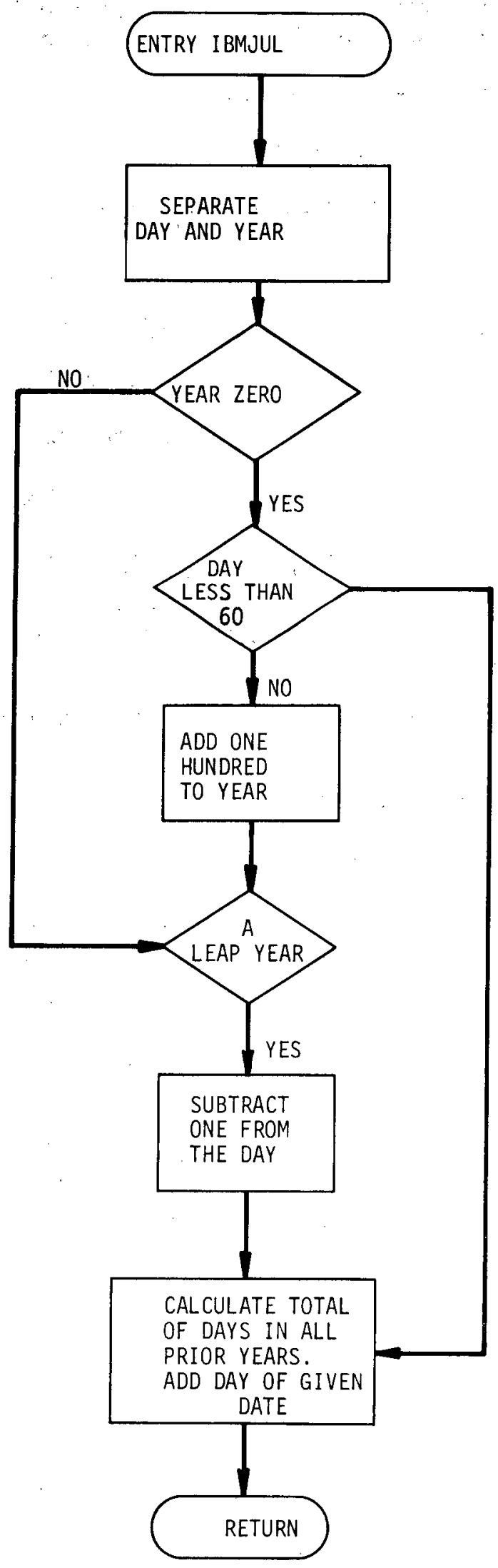




\begin{tabular}{|c|c|c|c|c|}
\hline & \multirow{2}{*}{\multicolumn{2}{|c|}{ Title Subroutine: IPUT }} & Vol. IX & \begin{tabular}{|l|} 
Page \\
E.2.101
\end{tabular} \\
\hline DPSTM. 500 & & & Rev. & \begin{tabular}{|c|} 
Date \\
$6 / 73$ \\
\end{tabular} \\
\hline
\end{tabular}

Purpose:

Usage:

\section{Arguments:}

Mnemonic

BUFFER

LNTH

NDS

NREC

VADD

Subprograms:

Objective:

Program Logic:
To simulate IBCOM sequential write conventions.

CALL IPUT (BUFFER, NDS, NREC)

CALL JPUT (VADD, LNTH)
Type

Logical*1

Integer*4

Integer $* 4$

Integer $* 4$

$\operatorname{Logica1*1}$

Control Section

LINK

MOVEIT

XLOC

\section{Description}

An area provided by the caller which is used as the buffer area. It must be a minimum of 400 contiguous bytes.

Length in bytes of VADD.

The output data set reference (FT) number.

The starting relative record number of the output date set.

The date to be transferred to BUFFER and written.

Entry Point

JTREE

MOVEIT

XLOC
To perform output operations while conforming to the IBCOM convention of leaving slack bytes at the end of a record block rather than divide a logical data unit between two blocks.

- Normal usage is a series of calls to JPUT bounded by an initial and final call to IPUT.

- Entry point IPUT establishes the data set and relative record references numbers, the addressability of the buffer, and sets the buffer location counter to zero. When the location counter is not zero on entry, data remaining in the buffer is written.

- Entry point JPUT effects the transfer of the data to the buffer. If the transfer of the data would overflow the buffer, the data existing in the buffer is written, the record counter incremented and the location counter reset before transfer. 


\begin{tabular}{|c|c|c|c|c|}
\hline & \multirow[t]{2}{*}{ Title } & \multirow[t]{2}{*}{ Subroutine: IPUT } & Vol. IX & $\begin{array}{l}\text { Page } \\
\text { E: } 2.102\end{array}$ \\
\hline DPSTM -500 & & & Rev. & $\begin{array}{l}\text { Date } \\
6 / 73\end{array}$ \\
\hline
\end{tabular}

Remarks:

A RETURN 1 (setting a condition code of 4 ) is taken if $\mathrm{LNTH}>400$.

Language: $\quad$ Fortran IV

Author:

R. C. Haywood 


\begin{tabular}{|l|l|l|l|l|}
\hline JOSHUA & Title Subroutine: IPUT & Vol. & $\begin{array}{l}\text { Page } \\
\text { IX }\end{array}$ \\
\\
\cline { 3 - 5 }
\end{tabular}
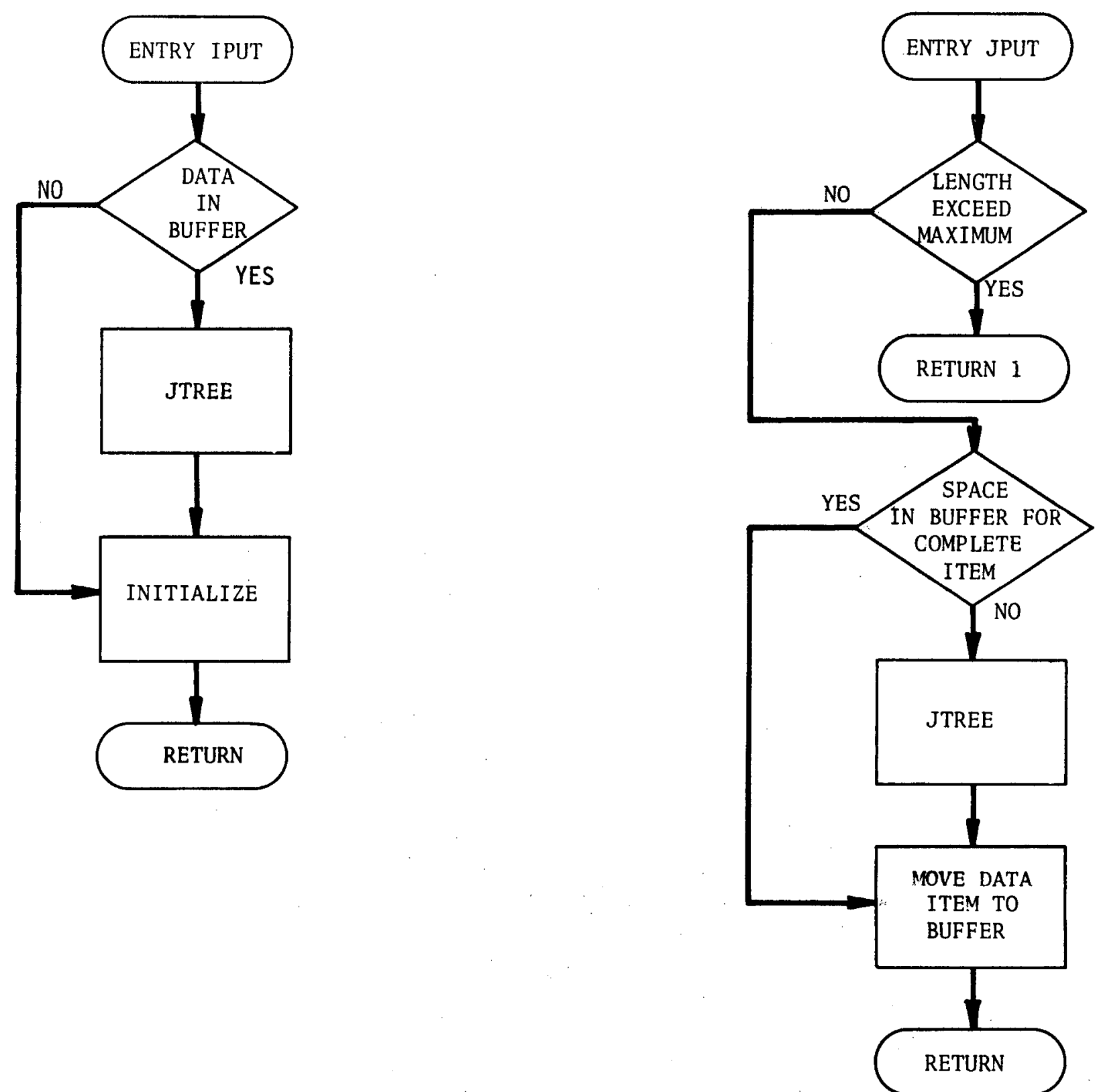


\begin{tabular}{|c|c|c|c|c|}
\hline 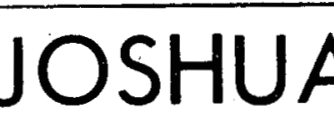 & \multirow[t]{2}{*}{ Title Subroutine: IPUT } & \multirow[t]{2}{*}{ ' } & $\begin{array}{l}\text { Vol. } \\
\text { IX } \\
\end{array}$ & $\begin{array}{l}\text { Page } \\
\text { E.2.104 }\end{array}$ \\
\hline DPSTM -500 & & & $\begin{array}{c}\text { Rev. } \\
1\end{array}$ & $\begin{array}{c}\text { Date } \\
6 / 73\end{array}$ \\
\hline
\end{tabular}




\begin{tabular}{|c|l|l|l|l|}
\hline JOSHUA & Title Subroutine: JOSDEQ & Vol. IX & $\begin{array}{c}\text { Page } \\
\text { E.2.105 }\end{array}$ \\
\cline { 3 - 5 } & & Rer. & $\begin{array}{c}\text { Date } \\
6 / 73\end{array}$ \\
\hline
\end{tabular}

Purpose:

Usage:

External References: DEQ

Program Logic:

ENQ Name:

Referenced by:

Language:

Author:
To deq on the argument name.

CALL (NAME2), where

NAME2 $=$ Enq-Deq Name 2 ( 8 bytes long)

The address of the enq-deq name two is received via the argument 1ist. A DEQ is issued on the name two passed. A return is issued.

JOSYSTEM (Name 2 passed $=$ NAME2)

Calling routines.

Assembler

W. H. Brotherton, Jr. 

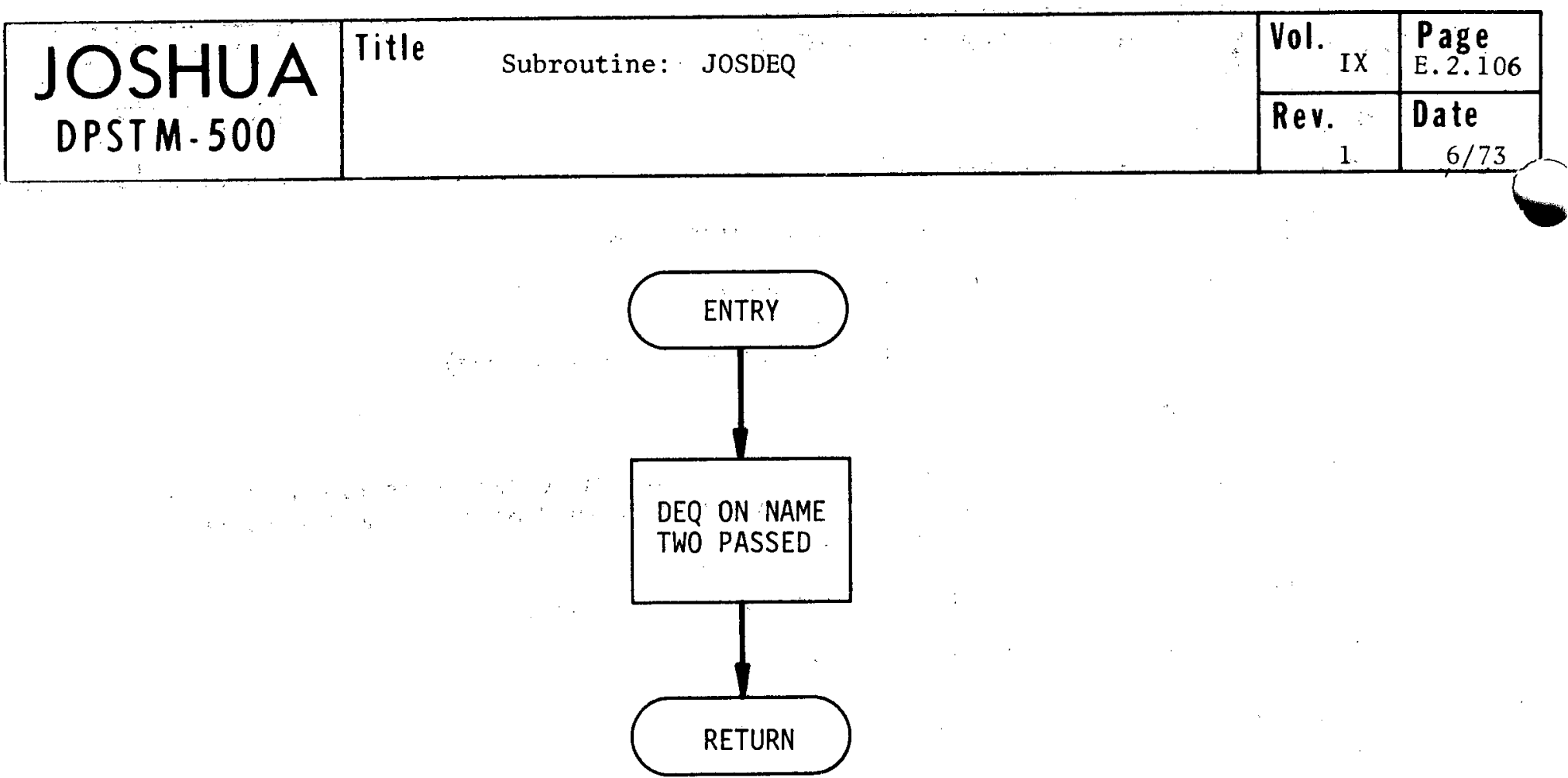


\begin{tabular}{|l|l|l|l|}
\hline JOSHUA & Title Subroutine: JOSENQ & $\begin{array}{l}\text { Vol. } \\
\text { Ix }\end{array}$ & $\begin{array}{l}\text { Page } \\
\text { E.2.107 }\end{array}$ \\
\cline { 3 - 4 } & & Rev. & $\begin{array}{c}\text { Date } \\
6 / 73\end{array}$ \\
\hline
\end{tabular}

Purpose: $\quad$ To enq on the name passed.

Usage: $\quad$ CALL (NAME2,, $\mathrm{qN}^{\mathrm{N}}$ ), where

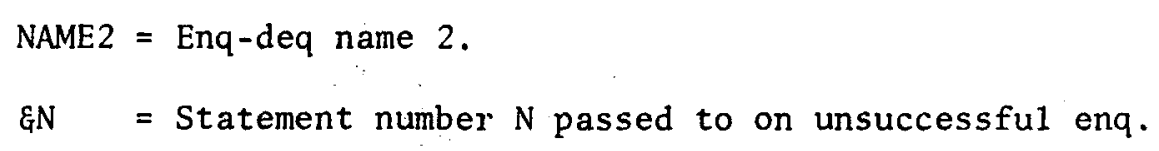

External References: ENQ, STIMER

Program Logic:

ENQ Name:

Referenced by:

Language:

Author:
The address of enq-deq name 2 is recieved via the argument list. An ENQ is issued on the name and a test is made to see if it was successful. If the enq was successful, a return is issued; otherwise, a STIMER is issued and upon end of STIMER the conditional return is set up.

JOSYSTEM (NAME2)

Calling routines.

Assembler

W. H. Brotherton, Jr. 


\begin{tabular}{|c|c|c|c|c|c|}
\hline 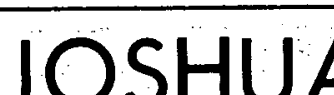 & \multirow{2}{*}{\multicolumn{2}{|c|}{ Title $\quad$ Subroutine: JOSENQ }} & \multirow[t]{2}{*}{. $\quad+\cdots$} & Vol. IX & $\begin{array}{l}\text { Page } \\
\text { E.2.108 }\end{array}$ \\
\hline DPSTM-500 & & & & Rev. & $\begin{array}{c}\text { Date } \\
6 / 73\end{array}$ \\
\hline
\end{tabular}

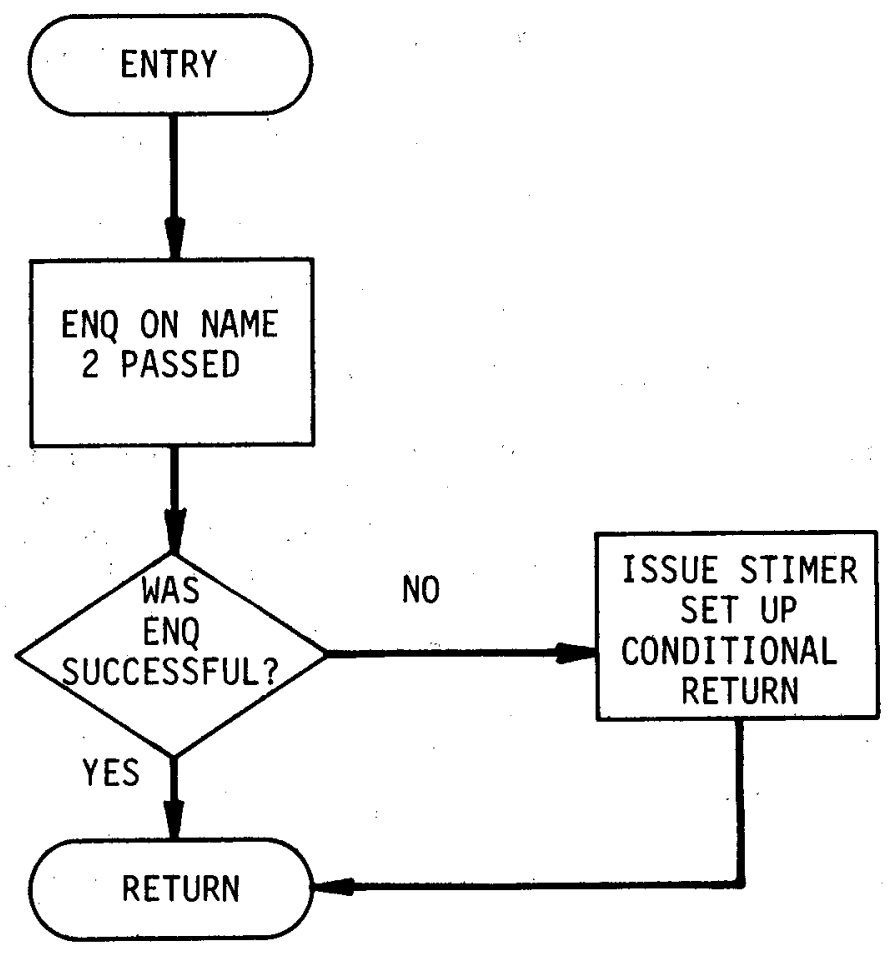




\begin{tabular}{|c|c|c|c|c|}
\hline \multirow{2}{*}{$\begin{array}{l}\text { JOSHUA } \\
\text { DPSTM.500 }\end{array}$} & \multirow{2}{*}{\multicolumn{2}{|c|}{ Subroutine: JSREAD }} & Vol. ${ }_{\text {IX }}$ & \begin{tabular}{|l|} 
Page \\
E.2.109
\end{tabular} \\
\hline & & & Rev. & \begin{tabular}{|c} 
Date \\
$6 / 73$
\end{tabular} \\
\hline
\end{tabular}

Purpose:

Usage:

Arguments:

Mnemonic

FIELD

ELNTH

ELNO

DSREF

DSREC

FLAG

Subprograms:

Objective:

Program Logic:

To simulate IBCOM sequential read conventions.

CALL JSREAD (FIELD, ELNTH, ELNO [,DSREF, DSREC, FLAG], *)

Type

Not restricted

Integer*4

Integer*4

Integer $* 4$

Integer $* 4$

Integer*4

\section{Description}

Area into which data from the buffer is to be transferred.

Length of a logical element of FIELD.

Number of elements to be loaded.

The data set reference (FT) number.

The starting relative record number.

FLAG $=0$ - Starts the transfer at the beginning of record specified by DSREF and DSREC.

FLAG $=1$ - Continues the transfer at point where preceding call left off.

Note: When the option FLAG $=1$ would be used, the last three arguments may be omitted to obtain the same result.

JTREE

To extract data from a record while conforming to the IBCOM convention of skipping the slack bytes at the end of a record block which were produced as a result of the refusal to divide a logical unit between blocks.

- The element length ELNTH is ascertained not to exceed the buffer size.

- When the six argument form has been used, FLAG is checked. If it is zero, the new DSREF and DSREC are established as local variables and the initial record read.

- As many elements of length ELNTH, up to the number requested, ELNO, as remain in the buffer are transferred to FIELD. If the request is not satisfied, DSREC is incremented locally, JTREE called to read the next record, and the transfer resumed. A counter is maintained locally of the number of bytes remaining in a buffer. 


\begin{tabular}{|c|c|c|c|c|}
\hline$\ldots$ & \multirow{2}{*}{\multicolumn{2}{|c|}{ Title Subroutine: JSREAD }} & Vol. IX & $\begin{array}{l}\text { Page } \\
\text { E. } 2.110\end{array}$ \\
\hline DPSTM- 500 & & & $\operatorname{ReV}_{1}$ & $\begin{array}{l}\text { Date } \\
6 / 73\end{array}$ \\
\hline
\end{tabular}

Terminating Conditions:

Register fifteen is set to four (analogous to a RETURN 1) if:

1. the specified data set is not on-line;

2. the value specified by ELNTH exceeds the maximum buffer size allowed.

Restriction:

The buffer area is fixed at four hundred bytes.

Language:

OS/360 Assembler

Author:

R. C. Haywood 


\begin{tabular}{|c|c|c|c|c|}
\hline On: & \multirow{2}{*}{\multicolumn{2}{|c|}{ Title Subroutine: JSREAD }} & Vol. IX & \begin{tabular}{|l} 
Page \\
E.2.111
\end{tabular} \\
\hline DPSTM -500 & & & ${ }_{1}^{R e v .}$ & $\begin{array}{l}\text { Date } \\
6 / 73\end{array}$ \\
\hline
\end{tabular}

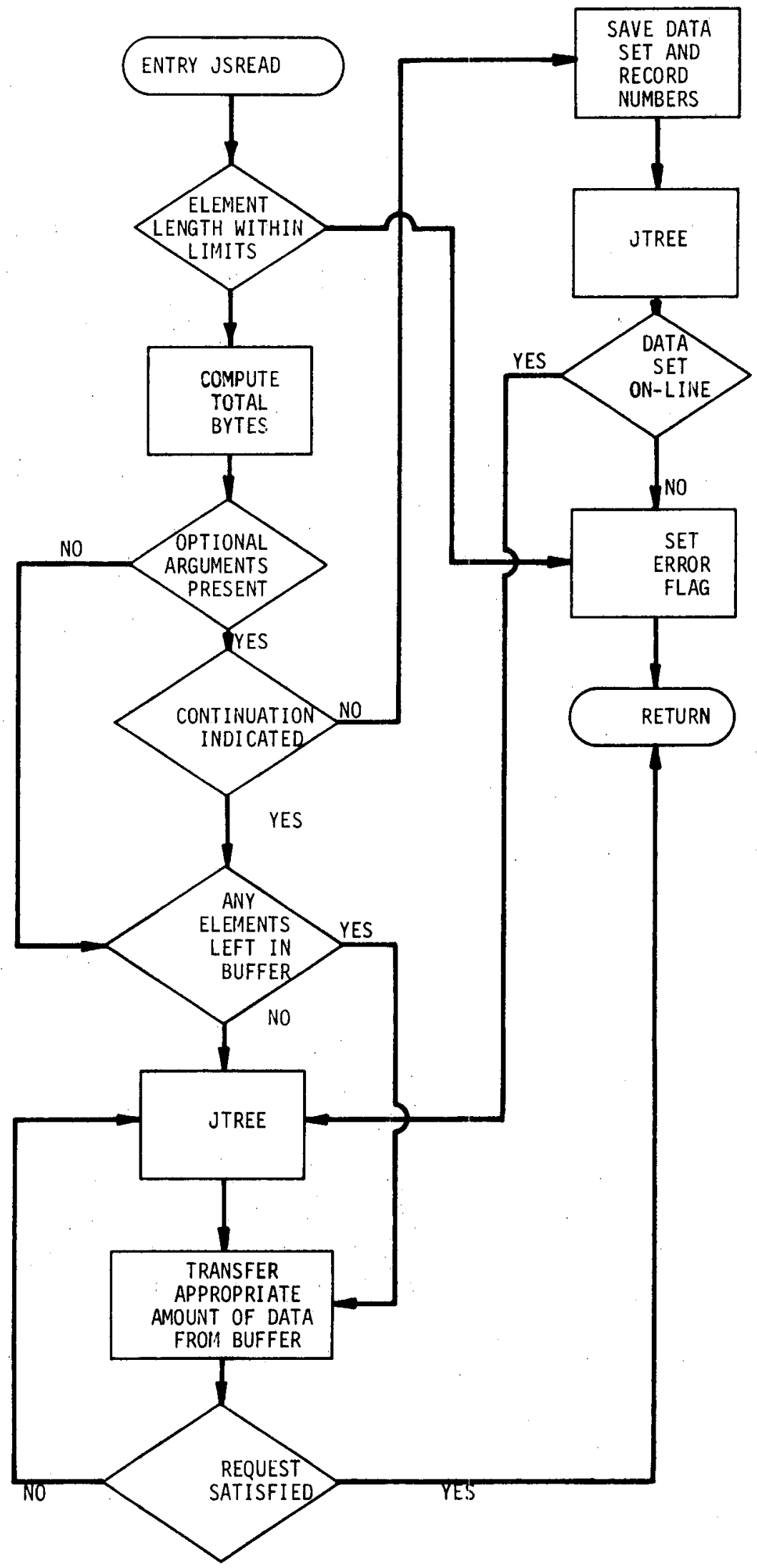




\begin{tabular}{|c|c|c|c|c|}
\hline$\bigcup_{\text {DPSTM-500 }}$ & Title Subroutine: JSREAD & $\begin{array}{c}\text { Vol. } \\
\text { IX }\end{array}$ & $\begin{array}{l}\text { Page } \\
\text { E.2.112 }\end{array}$ \\
\cline { 3 - 5 } & Rev. & Date \\
$6 / 73$
\end{tabular}




\begin{tabular}{|c|l|l|l|}
\hline JOSHUA & Title Subroutine: JTREE & Vol. & Page \\
IX & $E .2 .113$ \\
\cline { 3 - 5 } & & Rev. & Date \\
& $6 / 73$ \\
\hline
\end{tabular}

Purpose: $\quad$ To perform the direct access input/output

Usage: $\quad$ CALL JTREE (OPTION, DSREF, RECNO, BUFFER, \&N)

where

\begin{tabular}{|c|c|c|}
\hline Parameter & Type & Description \\
\hline \multirow[t]{5}{*}{ OPTION } & $I * 4$ & 0 -write record \\
\hline & & 1 - read record \\
\hline & & 2 - close all files \\
\hline & & 5 - open as input and read \\
\hline & & $\begin{array}{l}8 \text { - open only return code of ' } 4 \text { ' if } \\
\text { unsuccessfuly }\end{array}$ \\
\hline DSREF & $I * 4$ & Data set reference number \\
\hline RECNO & $I * 4$ & $\begin{array}{l}\text { Relative record number in } \\
\text { direct access file. }\end{array}$ \\
\hline BUFFER & & Storage for one record \\
\hline \&N & & Returning to statement $\mathrm{N}$ on open er \\
\hline
\end{tabular}

Internal Tables: Mode1 DCB for dirct access data sets.

Table of DCB addresses.

Program Control Block.

External References: GETMAIN, OPEN, CLOSE, READ " WRITE, CHECK, FREEMAIN, ABEND, WTO.

Data Sets: JOS catalog data sets.

Program Logic: The addresses of OPTION, DSREF, RECNO, AND BUFFER are received via the argument 1 ist. Exclusive control of this routine is obtained by issuing an ENQ macro-instruction. If the routine is already in use a. STIMER macro is issued in order to wait a specified time before again issuing the ENQ. This cycle is continued until the usage of the routine is obtained. The OPTION argument is tested for a close request. If a close file is indicated, the $D C B$ pointers and counters are reset and the data sets are closed (CLOSE macro instruction issued). The DCB area is freed up by issuing the FREEMAIN macro instruction and then a return is issued. 


\section{JOSHUA Title" subroutine: JTREE}

\begin{tabular}{|c|c|}
\hline Vol. & Page \\
IX & E.2.114 \\
\hline Rev. & Date \\
1 & $6 / 73$ \\
\hline
\end{tabular}

If the close was not indicated, the record is adjusted for BDAM usage; dynamic area to build a model DCB is obtained by issuing the GETMAIN macro; and the data set is OPENED in the updated mode unless OPTION argument indicated input only. The OPTION argument is then checked to see if a OPEN is the only thing desired; if so, and if the open was successful, a return is issued. An error return option is used if the OPEN was unsuccessful. Otherwise, the OPTION argument is then checked for a write request. If there is a write request, the direct access record (RECNO) is written into the BUFFER area by issuing a WRITE macro instruction and then a return is issued; otherwise, a read request is tested for. If there is a read request, the record is read into the buffer by issuing a READ macro and then a return is issued. If there is neither a read nor a write request, an error flag is set (last byte of OPTION is set to HEX 'FF') and a return is issued. Exclusive control of this routine is released by issuring a DEQ macro instruction immediately before returning to the calling program. (JTREE appropriates storage for a specified number of DCB's). If one DCB is needed after the specified number is taken, the existing DCB's are closed and their storage is cleared leaving space for construction of the same number of new DCB's.

Terminating Conditions:

If there is neither a read, write, nor a close request, an error flag is set and a return is issued.

If there is an $I / 0$ error, an abend is set up with a dump and a code of 24 .

Referenced By: Calling routines.

Language:

Author:

\section{Assembler}

R. L. Boyce, Jr . 


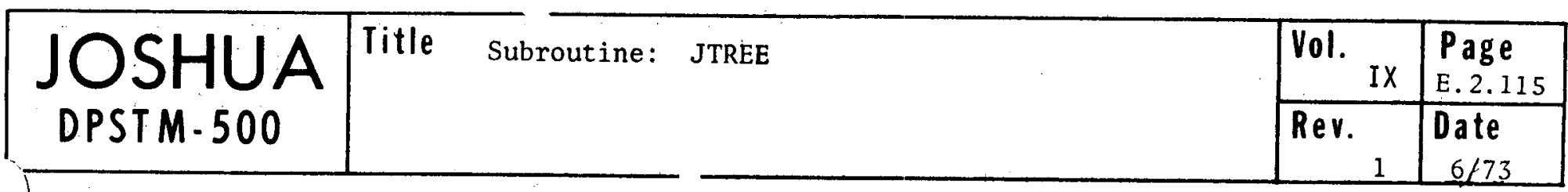

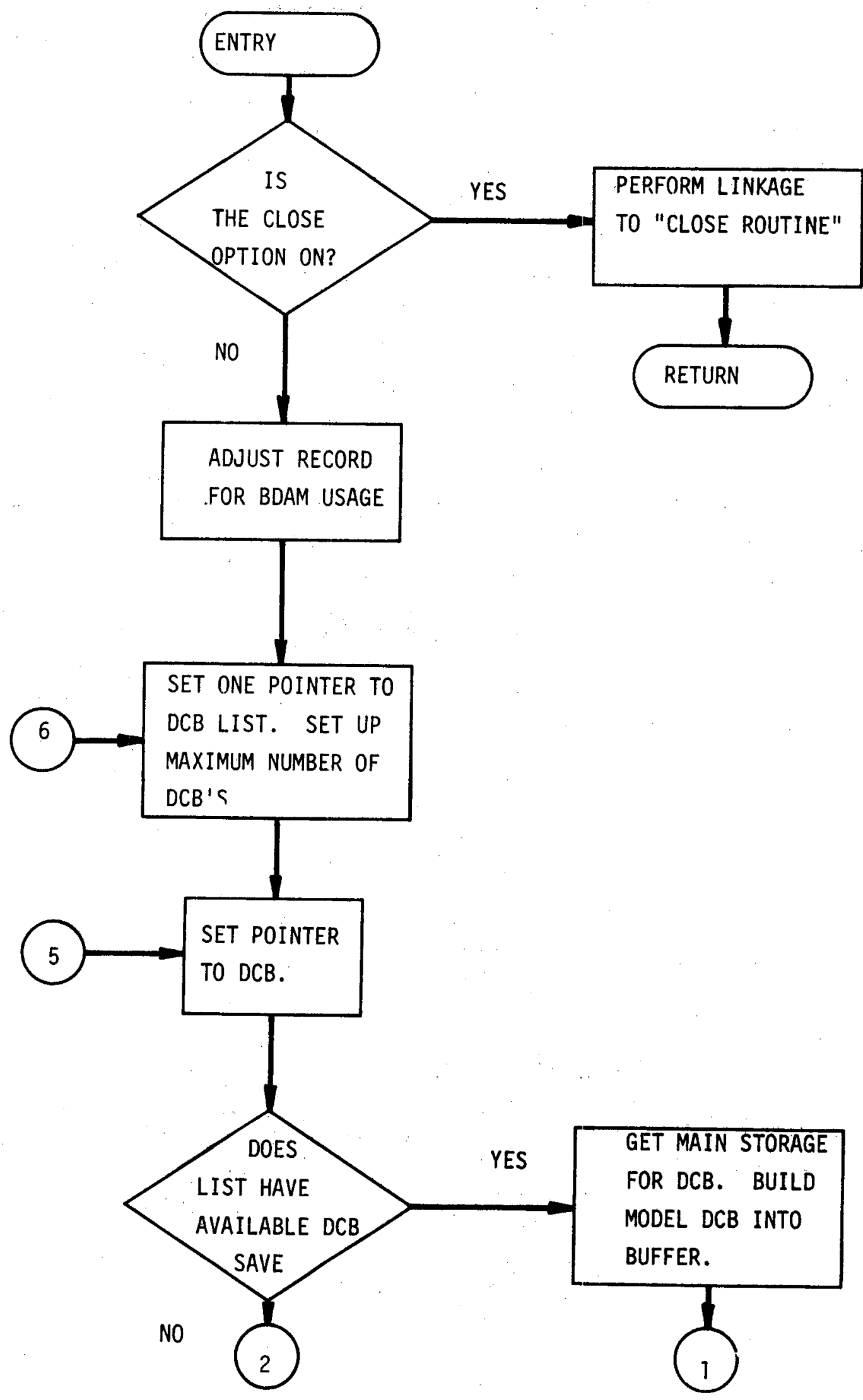




\section{JOSHUA ${ }^{\text {rittle }}$ subroutine: Jreke DPSTM.500}

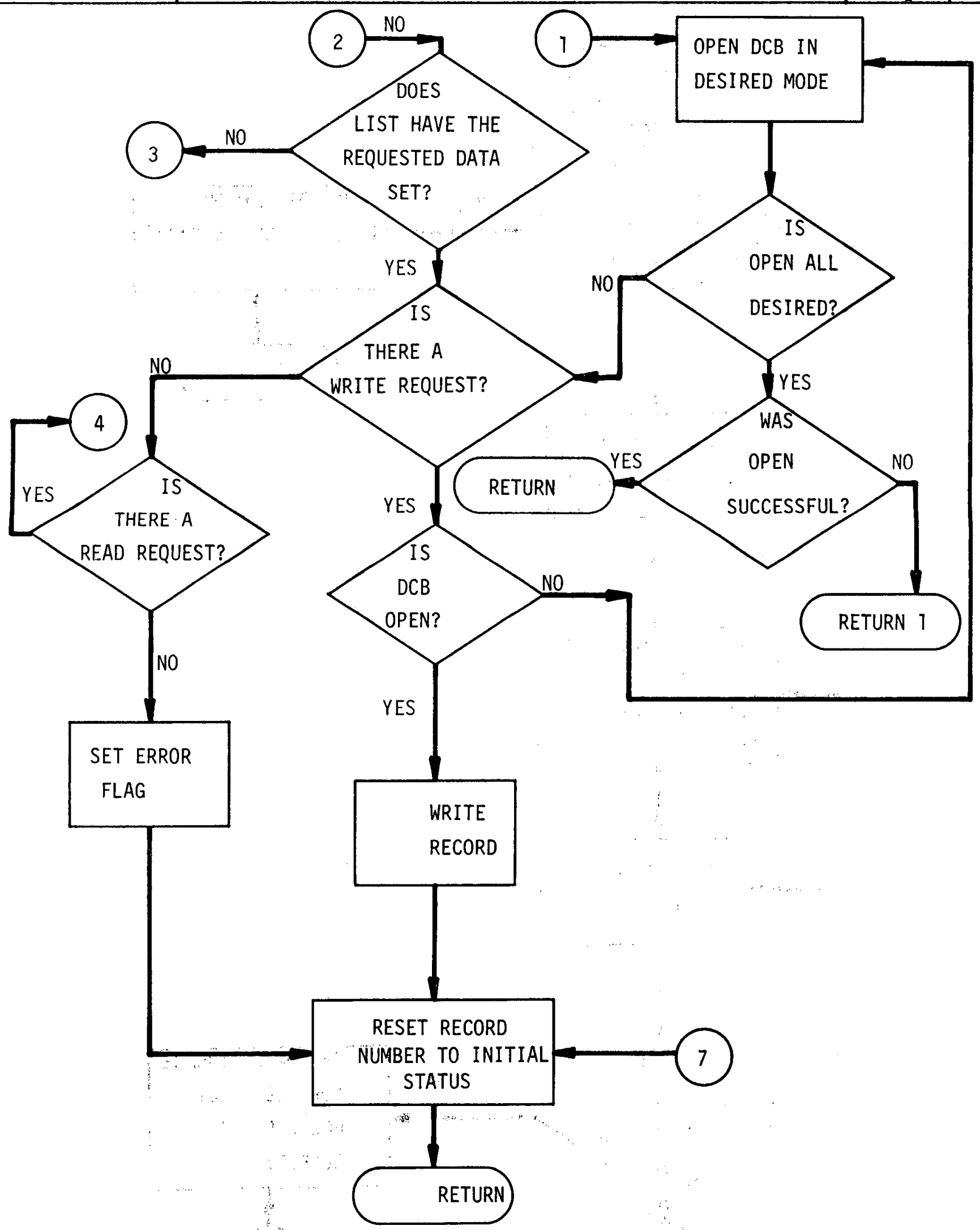



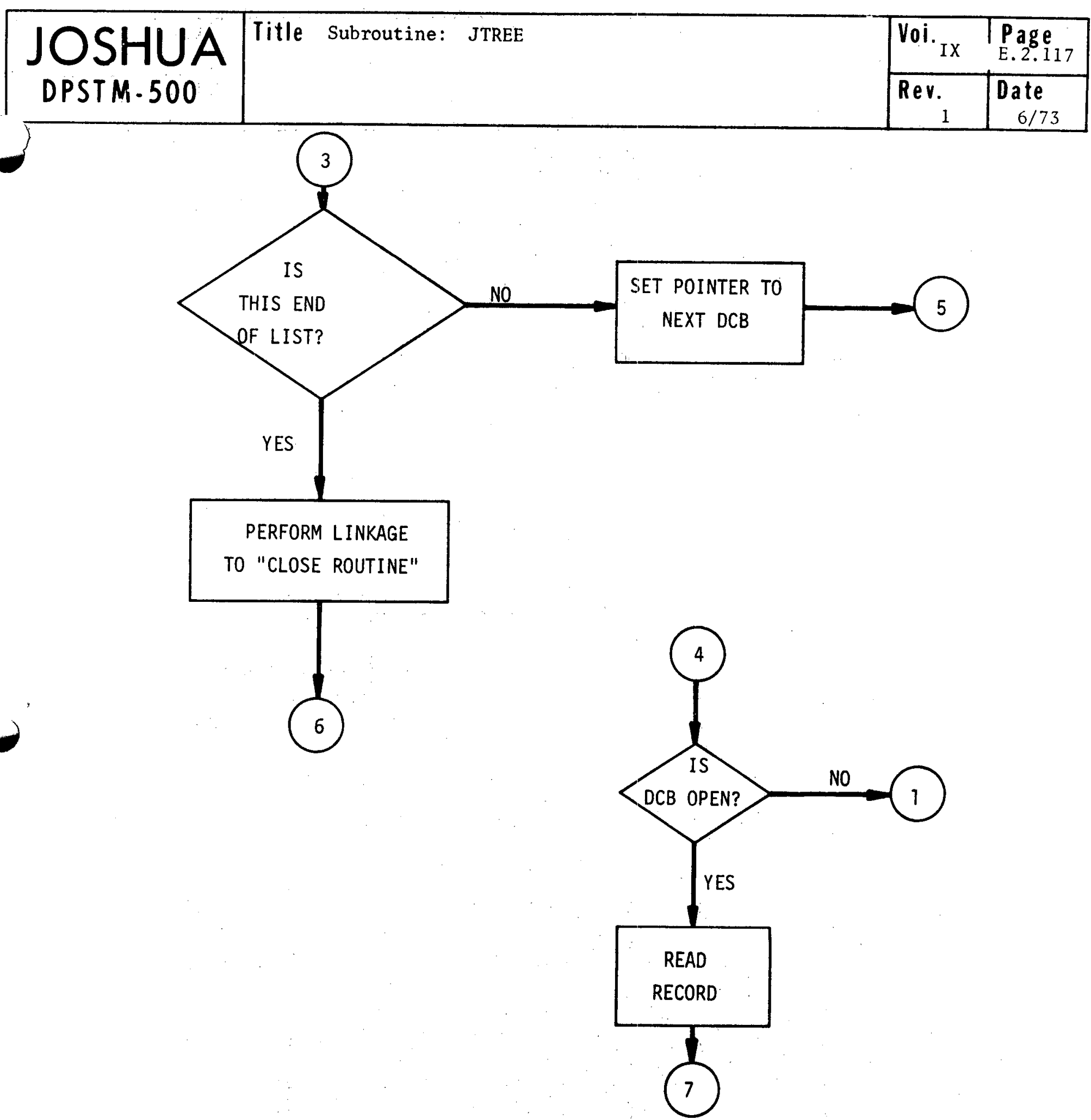
JOSHUA Title subrout ine: JTREE

\begin{tabular}{|c|l|}
\hline Vol. & Page \\
IX & E.2.118 \\
\hline Rev. & Date \\
1 & $6 / 73$ \\
\hline
\end{tabular}

"CLOSE ROUTINE" :

RESET MAXIMUM NUMBER

OF DCB'S, POINTERS,

AND LENGTH OF DCB'S.

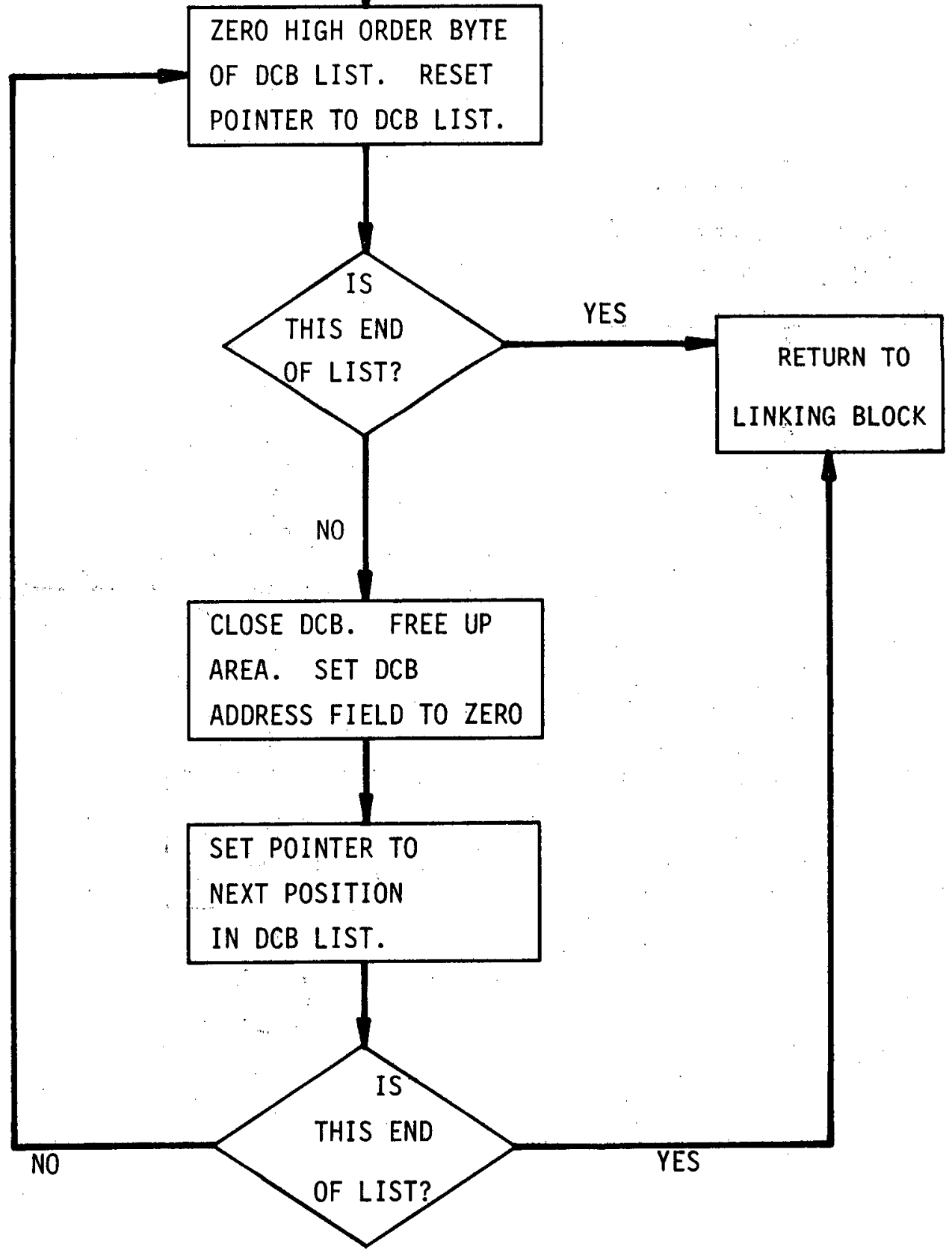




\begin{tabular}{|c|l|l|l|l|}
\hline \multirow{2}{\text{JOSSTM.500}}{} & Title Function: JULDAT & $\begin{array}{l}\text { Vol. Ix } \\
\text { Page } \\
\text { E.2.119 }\end{array}$ \\
\cline { 3 - 5 } & Rev. & $\begin{array}{l}\text { Date } \\
6 / 73\end{array}$ \\
\hline
\end{tabular}

Purpose:

Usage:

\section{Arguments:}

Mnemonic

JULSEQ

Program Logic:

Language:

Author:
To convert to a calendar date a Julian date reckoned from March 1 of the preceding centurial year.

As a FORTRAN function

JULDAT (JULSEQ)

The date is returned as a fixed point value in register zero in the form MMDDYY.

\section{Type}

Description

$$
\text { Integer } * 4
$$

A Julian date.

- The primary factors utilized in the conversion are:

the sequence $365-365-365-366$ of days in the consecutive four-year periods starting March 1, 1900;

the sequence $31-30-31-30-31$ in the two successive five month periods starting with March;

the eleventh month in a twelve month cycle (i.e. January) a1so has 31 days.

0S/360 Assembler

R. S. Wood - R. C. Haywood 


\section{JOSAUA ${ }^{\text {Title }}$ Function: JULDAT DPST $M \cdot 500$}

Page

IX

E. 2.120

\begin{tabular}{l|l} 
Rev. & Date
\end{tabular} 1

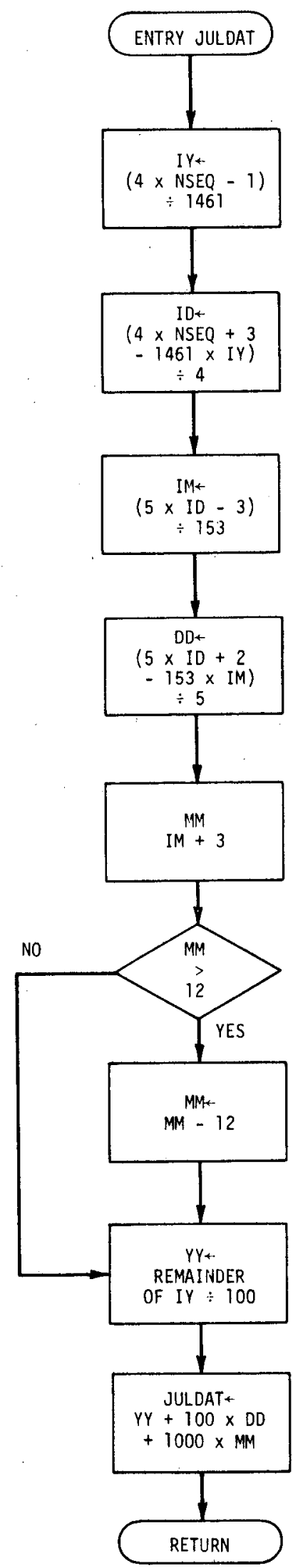


\begin{tabular}{|l|l|l|l|}
\hline \multirow{2}{\text{JPSTM.500}}{ Title Subroutine: LCDINT } & Vol. Ix & $\begin{array}{l}\text { Page } \\
\text { E.2.121 }\end{array}$ \\
\cline { 3 - 5 } & & $\begin{array}{l}\text { Rev. } \\
\text { Date } \\
6 / 73\end{array}$ \\
\hline
\end{tabular}

Purpose:

Attribute:

Entry:

Usage:

Y

Program Logic:

Language:

Author:

Arguments:

Mnemonic
To convert a fixed point number to an edited zoned format.

Nonreusable.

LCDINT for a one byte fixed point value.

HCDINT for a half word fixed point value.

$\$ C D I N T$ for a full word fixed point value.

The general form in Fortran is

as a subroutine CALL $x$ CDINT $(J, K, Y)$

or

as a double-precision function $\operatorname{xCDINT}(J, K, Y)$

Type

Varies with

entry point

Description

The fixed point value for which an

EBCDIC representation is desired.

Integer*4

$|K|$ specifies the width of the field. When positive, leading zeroes are desired; when negative, leading zeroes are to be replaced by blanks. When $K$ is not specified, the width of the field is what is required for the sign (if negative) and the significant digits.

Logica $1 * 1$

The output field whose length is defined by $K$, but will not exceed eight, if the field will not accomodate the result, $Y$ is filled with asterisks.

The fixed point value is converted to decimal and edited. Any minus sign is moved to the leading position of the result field followed by the indicated numerics, including any leading blanks if indicated. The result is loaded into floating point register zero and, when specified, the user's output field.

Should the output field width be inadequately wide, the field is filled with EBCDIC asterisks. The width of the output field will not exceed eight positions. When the width of the field is less than one, $Y$ is left unaltered and floating point register zero returns EBCDIC blanks.

OS/360 Assembler

R. S. Wood 


\begin{tabular}{|c|c|c|c|c|}
\hline & \multirow{2}{*}{\multicolumn{2}{|c|}{ Subroutine: }} & ${ }_{\text {Vol. }}^{\text {IX }}$ & $\begin{array}{l}\text { Page } \\
\text { E.2.122 }\end{array}$ \\
\hline DPSTM-500 & & & Rev. & Date \\
\hline
\end{tabular}

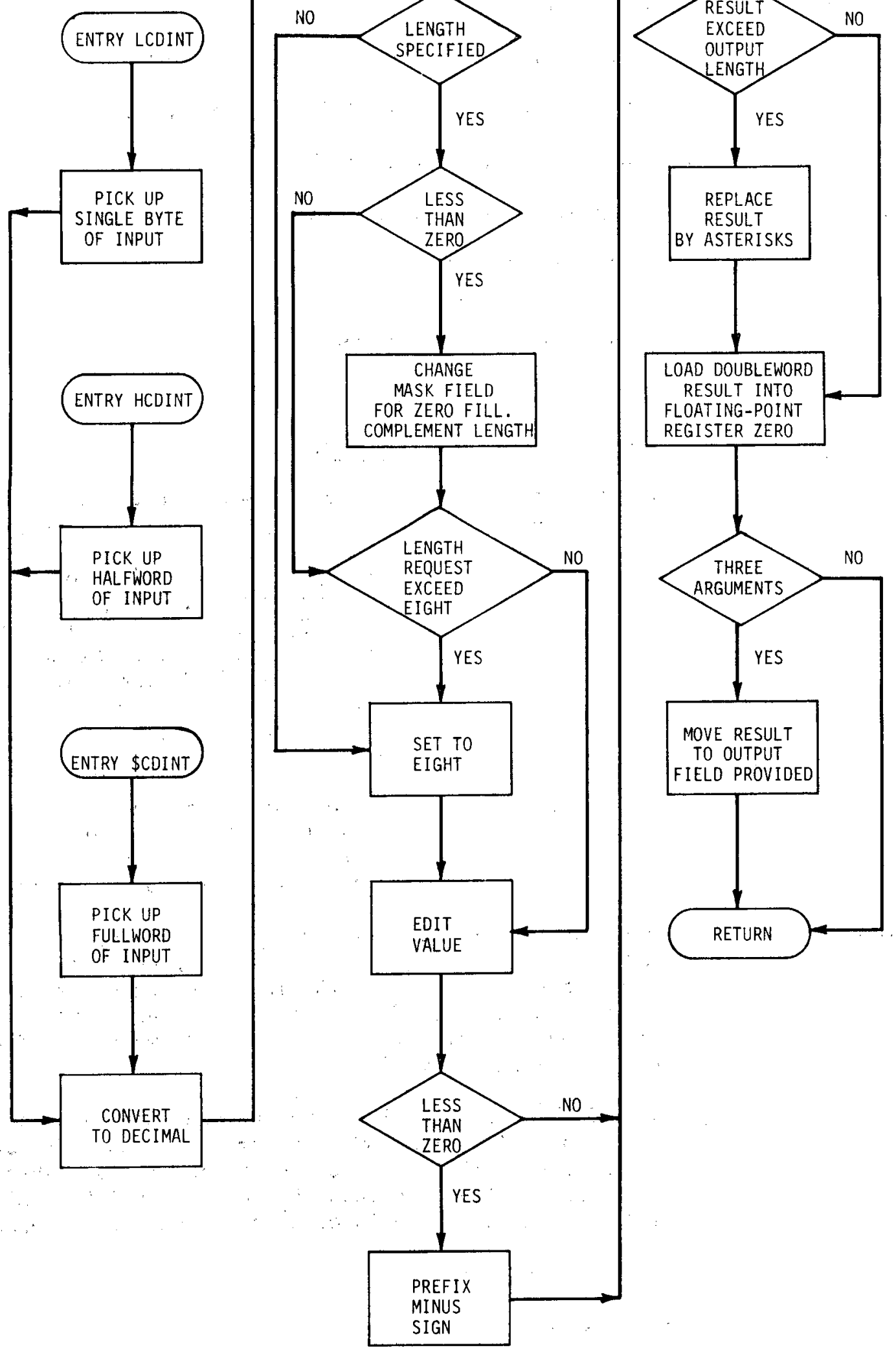




\begin{tabular}{|c|c|c|c|c|}
\hline 1 & Title Subroutine: & LEFTIT & $\begin{array}{l}\text { Vol. } \\
\text { IX }\end{array}$ & \begin{tabular}{|l} 
Page \\
E.2.123
\end{tabular} \\
\hline DPSTM 500 & & & & \begin{tabular}{|c|} 
Date \\
$6 / 73$
\end{tabular} \\
\hline
\end{tabular}

Purpose:

Usage:

Program Logic:

Referenced By:

Language:

Author:
To left adjust a double word.

CALL LEFTIT (DW)

where

$D W=$ pointer to double word.

The double word (DW) address is received via the argument list. The double word name field is tested for all blanks. If it is all blanks, a return is issued; otherwise, the first character is checked for a blank. If the character is a blank, all characters are shifted to the left and a blank character is put on end. This procedure is repeated until the first character is no longer a blank and then a return is issued.

\section{Calling routines.}

Assembler

W. H. Brotherton, Jr. 


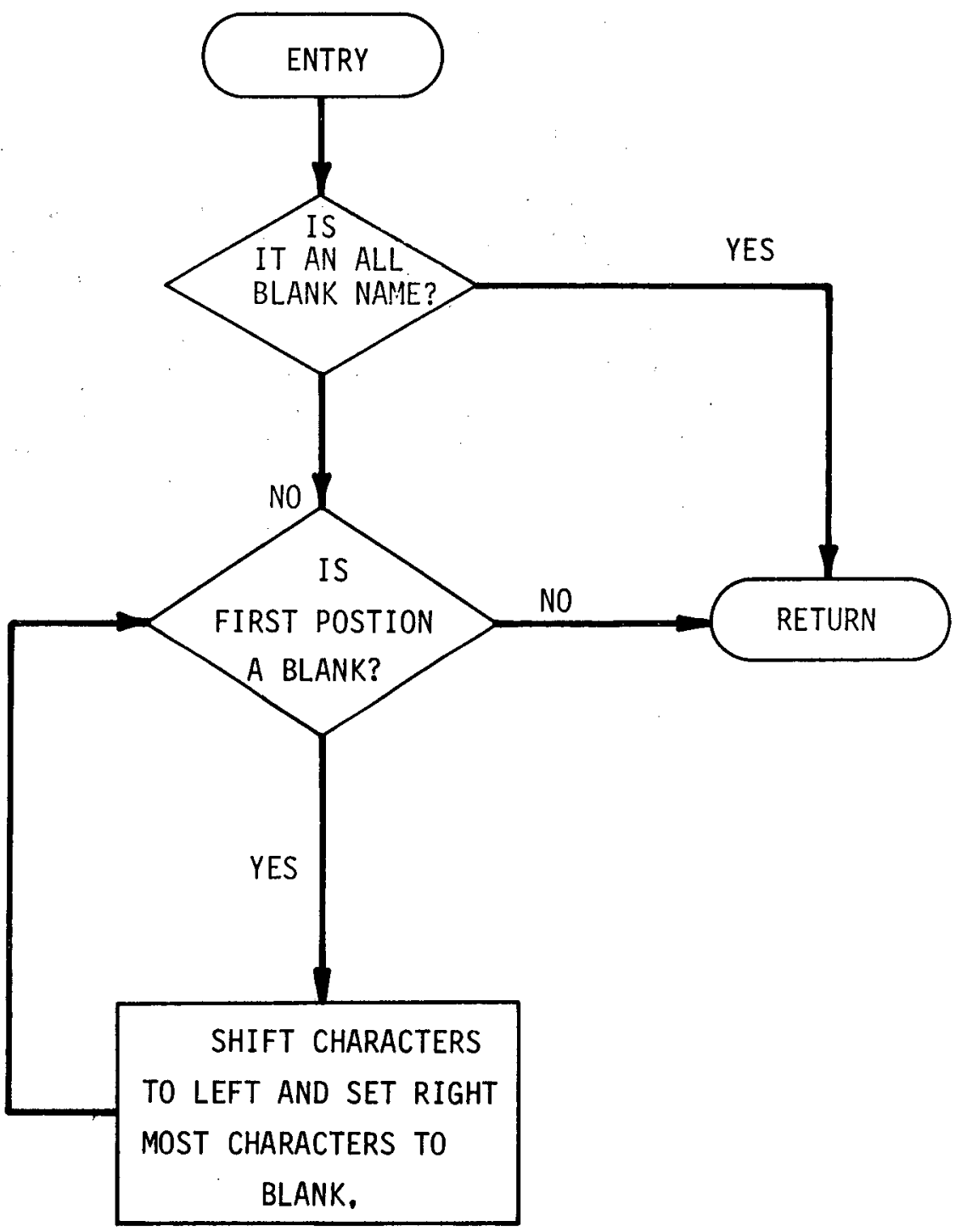




\begin{tabular}{|l|l|l|l|l|}
\hline JOSHUA & Title Function: mDYJUL & Vol. & Page \\
DPSTM.500 & & Ix & E.2.125 \\
\cline { 3 - 5 } & & $\begin{array}{l}\text { Rev. } \\
\text { Date } \\
6 / 73\end{array}$ \\
\hline
\end{tabular}

Purpose: $\quad$ To convert a date of the form MMDDYY to a Julian date with a base date of March 1 of the preceding centurial year.

Usage:

As a FORTRAN function

MDYJUL (MDY)

The Julian date is returned as a fixed point value in register zero (for OS/360 FORTRAN).

Arguments:

Mnemonic

Type

Description

MDY

Integer ${ }^{*}$

A calendar date of the form MMDDY.

Program Logic:

- Conversion utilizes the following elements:

The number of days in each year of the consecutive four-year periods within the effective range produces the sequence $365-365-365-366$;

The number of days in each month of the two consecutive five-month periods beginning with March produces the sequence $31-30-31-30-31$;

The eleventh month of a twelve-month period (i.e. January) also has 31 days.

Language:

OS/360 Assembler

Author:

R. W. Wood - R. C. Haywood 


\begin{tabular}{|c|c|c|c|c|}
\hline & \multirow{2}{*}{\multicolumn{2}{|c|}{ Title Subroutine: MDYJUL }} & Vol. & $\begin{array}{l}\text { Page } \\
\text { E.2.126 }\end{array}$ \\
\hline DPSTM. 500 & & & Rev. & $\begin{array}{l}\text { Date } \\
6 / 73\end{array}$ \\
\hline
\end{tabular}

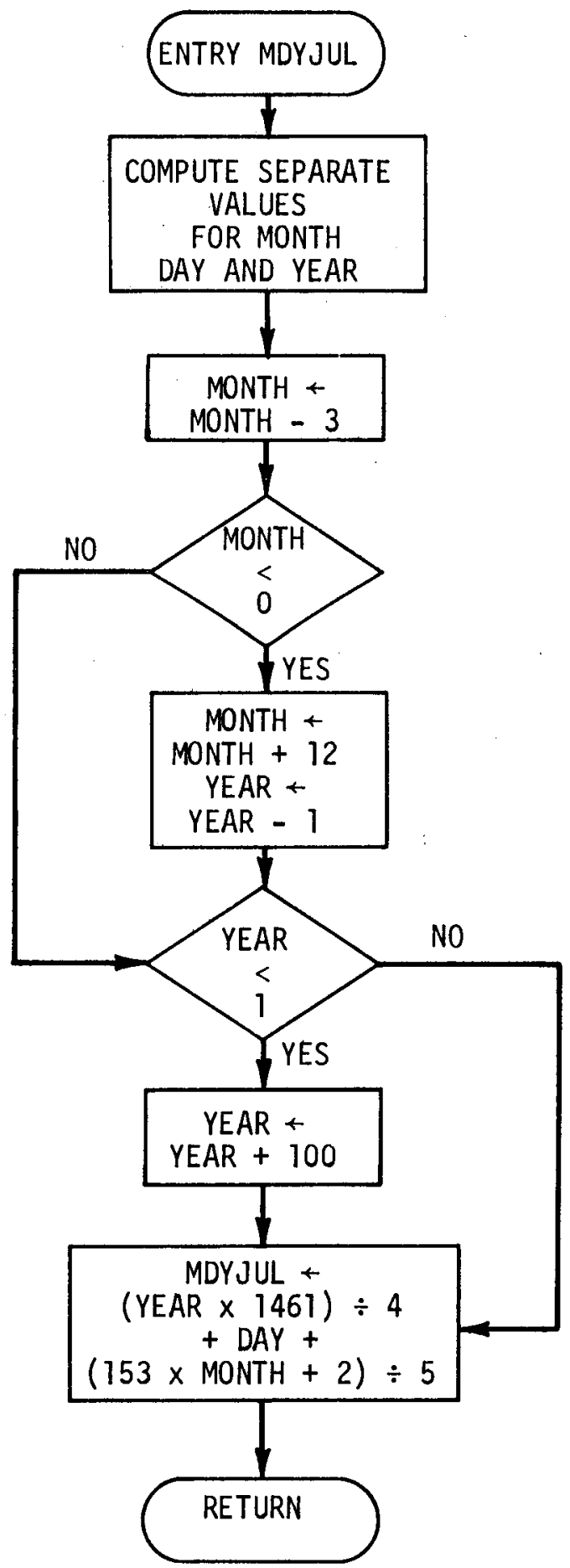




\begin{tabular}{|c|ll|l|l|}
\hline JOSHUA & Title Subroutine: MoveIt & Vol. Ix & $\begin{array}{l}\text { Page } \\
\text { E.2.127 }\end{array}$ \\
\cline { 3 - 3 } & & Rev. & $\begin{array}{c}\text { Date } \\
6 / 73\end{array}$ \\
\hline
\end{tabular}

Purpose:

To set a contiguous string of bytes starting from a specified location in one field equal to a contiguous string of bytes starting at a specified location in another field.

Attribute:

Reusuable

Entry:

MOVEIT

Usage:

The general form in Fortran is

CALL MOVEIT (TO, I, FROM, J, L)

where: To is the receiving field;

I is the relative byte within $\mathrm{TO}$ at which the operation will start;

FROM is the original field;

$\mathrm{J} \quad$ is the relative byte within FROM at which the operation will start;

L is the number of contiguous bytes in both TO and FROM, beginning at relative bytes $I$ and $J$, respectively, involved in the operation.

Program Logic:

- If $L$ is less than one, subroutine execution is terminated.

- The starting points in fields TO and FROM are determined.

- The specified number of bytes from FROM is moved to TO first in as many blocks of 256 bytes as are contained in the number specified and then the remainder.

- The necessary registers are reset and control returned to the calling routine.

Language:

OS/360 Assembler

Author:

R. L. Boyce - R. S. Wood. 


\begin{tabular}{|c|l|c|c|}
\hline JOSHUA & Title Subroutine: MOVEIT & $\begin{array}{c}\text { Vol. } \\
\text { IX }\end{array}$ & $\begin{array}{l}\text { Page } \\
\text { E.2.128 }\end{array}$ \\
\cline { 3 - 4 } & & $\begin{array}{c}\text { Rev. } \\
1\end{array}$ & $\begin{array}{l}\text { Date } \\
6 / 73\end{array}$ \\
\hline
\end{tabular}




\begin{tabular}{|c|l|l|l|l|}
\hline JOSHUA & Title Subroutine: RHAR & Vol. IX & $\begin{array}{l}\text { Page } \\
\text { E.2.129 }\end{array}$ \\
& & Rev. & $\begin{array}{c}\text { Date } \\
6 / 73\end{array}$ \\
\hline
\end{tabular}

Purpose:

To search a byte string for the first occurence of a specified value.

Attribute: $\quad$ Reusable

Entry: $\quad$ CHAR

RHAR

Usage:

The general form in Fortran is

$$
\operatorname{CALL}\{\operatorname{CHAR} \mid \operatorname{RHAR}\}(A, B, L[, I], \& n)
$$

where: A contains the one byte value for which the search is made,

$B$ is the byte string to be searched,

$L$ is the length of $B$,

I is, when a match is found, the relative byte in $B$ at which the match occurred,

$\mathrm{n}$ is the statement number to which control is passed when a match is made or a match is not made depending on entry being made at CHAR or RHAR, respectively.

Program Logic:

- Initialize flag to indicate no match - zero when entering at CHAR, four when entering RHAR.

- Terminate if length of byte string is defined as less than one.

- Sequentially search the byte string for the specified value. When not found, terminate. When found, invert the flag by exclusively ORing with a four, store the relative byte number in the fourth argument if present, and terminate.

- When terminating, load general purpose register fifteen with the flag value.

Language:

Author:
- OS/360 Assembler

A. H. Dobyns - R. S. Wood 


\begin{tabular}{|l|l|l|l|l|}
\hline JOSHUA & Title Subroutine: SHIFTB & Vol. & Page \\
& & Ix & E.2.131 \\
\cline { 3 - 4 } & & Rev. & $\begin{array}{c}\text { Date } \\
6 / 73\end{array}$ \\
\hline
\end{tabular}

Purpose:

Usage:

Program Logic:

Language:

Author:
To pack a name string.

CALL SHIFTB (S,BUF), where

$$
S \quad \text { = name string of double words }
$$

BUF $=$ buffer of packed names

The addresses of the name string (S) and the buffer (BUF) are received via the argument 1ist. The double word argument name in $S$ are moved to the buffer (BUF) such that there is only a period (no blanks between names. The names are moved until a double work of HEX $5^{\prime} s$ is found or until the end of a buffer line is reached; on finding either of these, a return is issued.

Assembler

R. L. Boyce, Jr. 


\begin{tabular}{|c|c|c|c|c|}
\hline & \multirow[t]{2}{*}{ Subroutine: } & \multirow[t]{2}{*}{ SHIFTB } & Vol: IX & $\begin{array}{l}\text { Page } \\
\text { E.2.132 }\end{array}$ \\
\hline DPSTM. 500 & & & Rev. & $\begin{array}{c}\text { Date } \\
6 / 73\end{array}$ \\
\hline
\end{tabular}

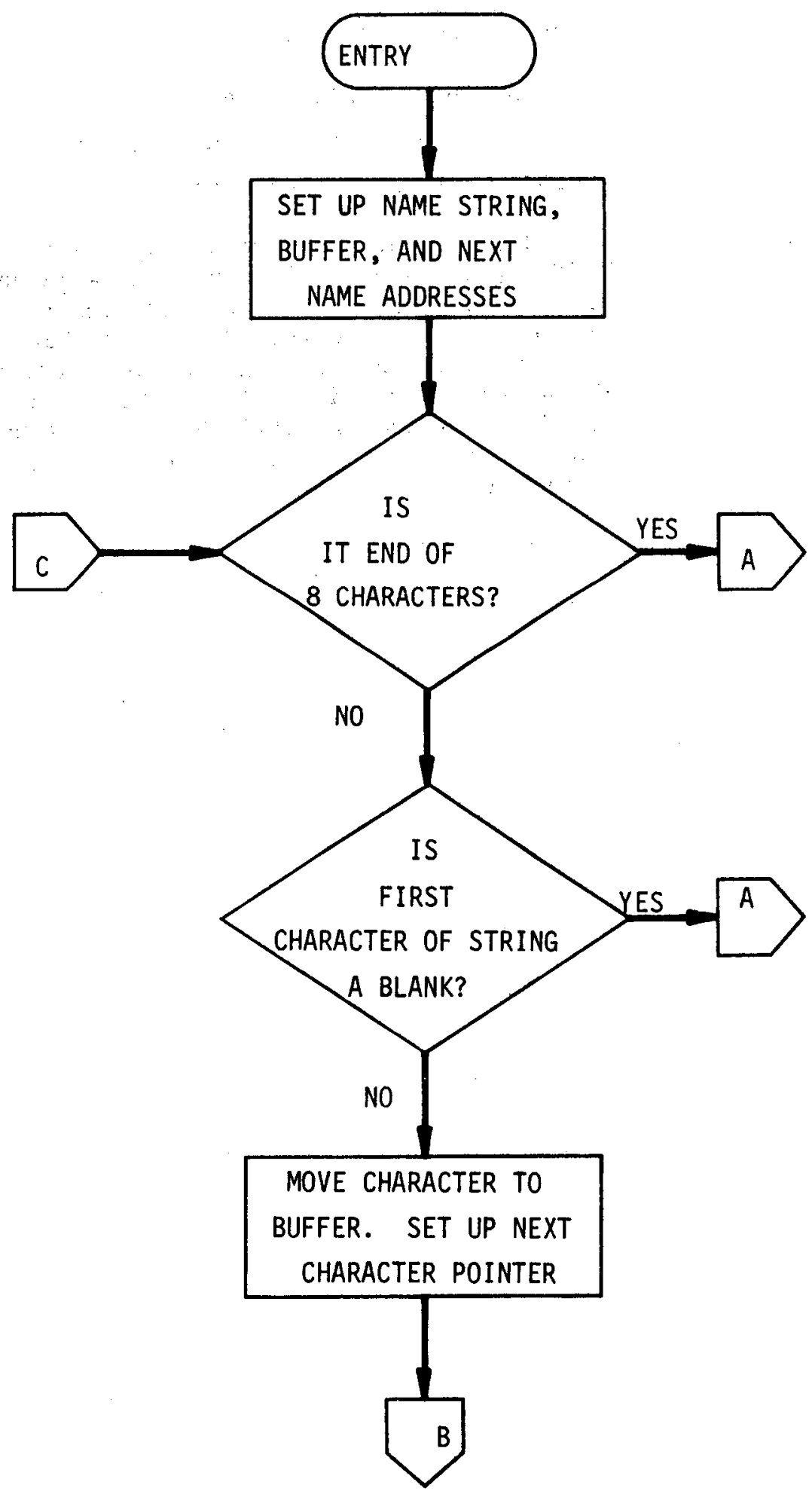




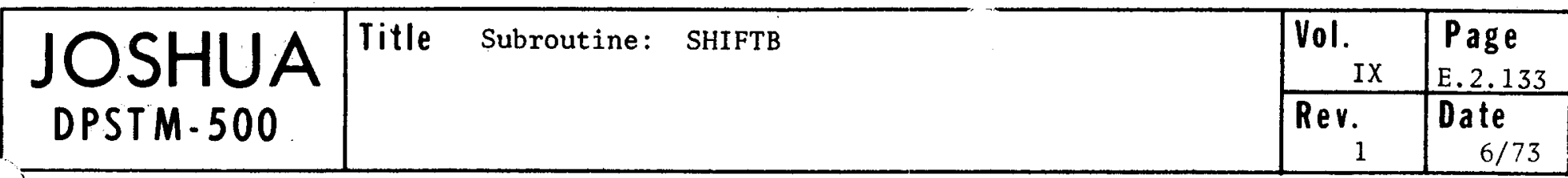

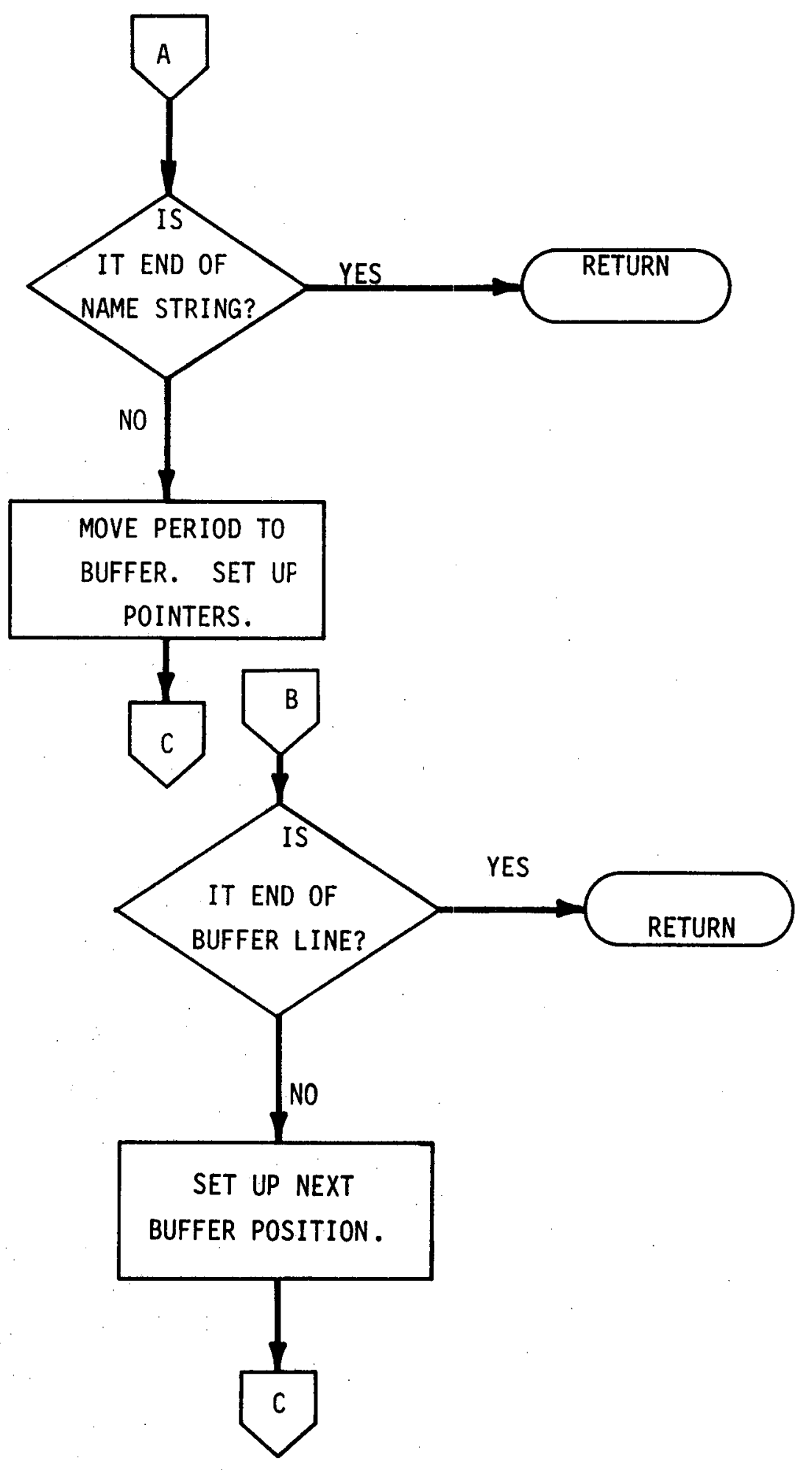




\begin{tabular}{|c|lc|c|c|}
\hline JOSHUA Subroutine: SHIFTB & Title & $\begin{array}{c}\text { Vol. } \\
\text { IX }\end{array}$ & $\begin{array}{c}\text { Page } \\
\text { E.2.134 }\end{array}$ \\
& & $\begin{array}{c}\text { Rev. } \\
\text { Date } \\
6 / 73\end{array}$ \\
\hline
\end{tabular}


Purpose:

To place in contiguous doublewords a series of qualifiers separated by periods.

Usage:

Cal1 SHIFTN (S)

where, $S$ is the string of qualifiers.

The area defined by $S$ should be on a doubleword boundary and be sixteen doublewords in length.

Program Logic:

- The input string is defined

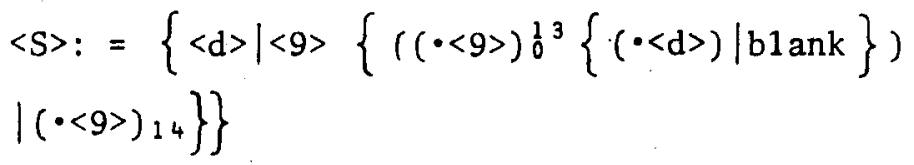

where

$<\mathrm{d}\rangle:=\{\cdot \mid \mathrm{b} l$ ank $\}$

$\langle 9\rangle:=(\langle x\rangle)_{1}^{n}(b 1 \text { ank })_{0}^{8-n}$ where $0<N \leq 8$

$\langle x\rangle:$ : any configuration except blank and period

- The qualifiers are placed in successive doublewords in a local area.

- When all qualifiers have been picked up or when an error is sensed, the doubleword following the last to receive a valid qualifier is filled with hexadecimal 55's.

- Only those doublewords thru the appended one containing hexadecimal $55^{\prime} \mathrm{s}$ are transferred back to $\mathrm{S}$.

- Register 15 returns a zero for normal completion, a four when an error is sensed.

Language:

S/360 Assembler

Author:

R. C. Haywood 


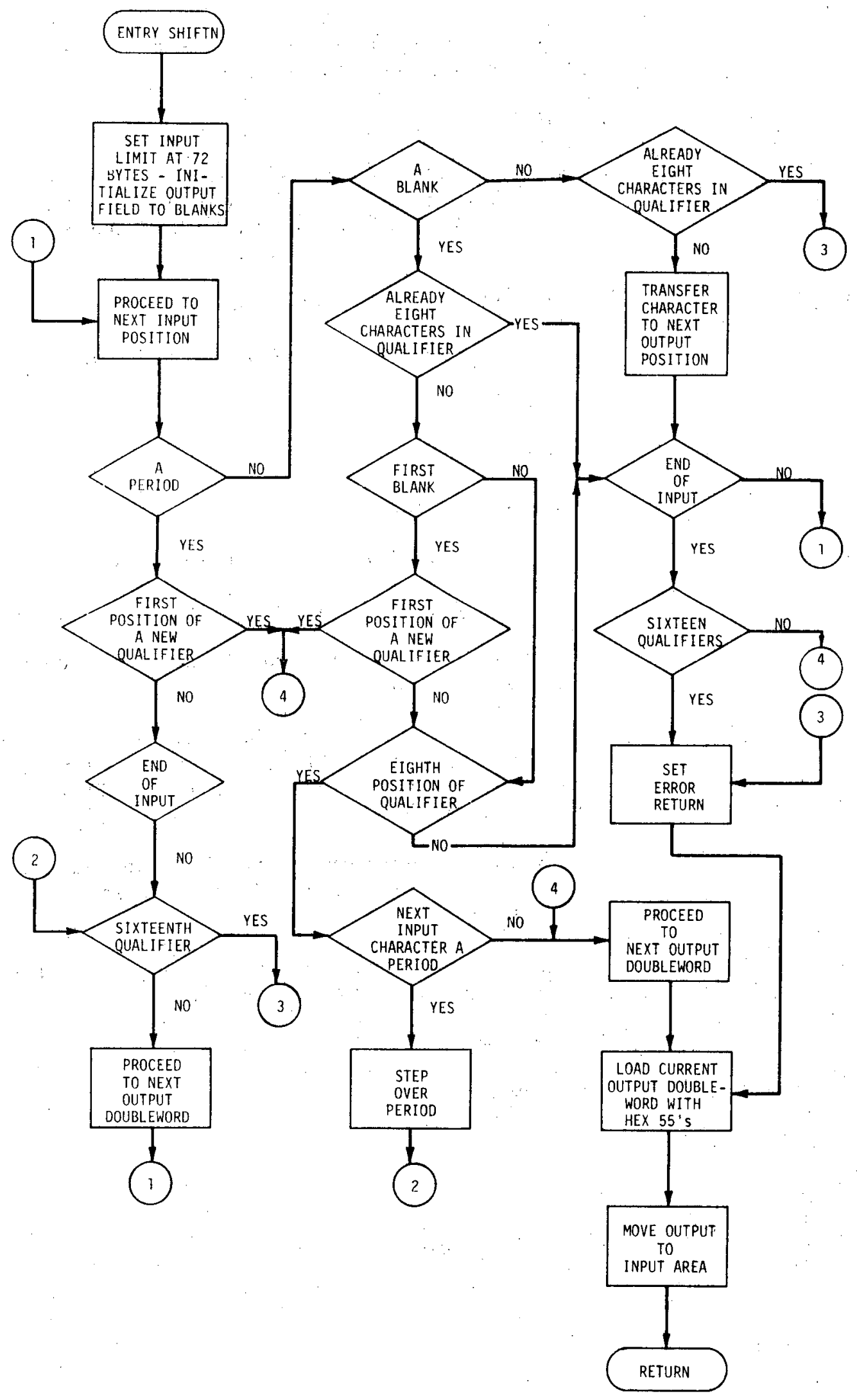




\begin{tabular}{|c|ll|l|l|}
\hline JOSHUA & Title Subroutine: TRNSLT & Vol. & $\begin{array}{l}\text { Page } \\
\text { E.2.137 }\end{array}$ \\
\cline { 3 - 4 } & & Rev. & Date \\
& & $6 / 73$ \\
\hline
\end{tabular}

Purpose: $\quad$ To make value-for-value exchanges in a byte string.

Attribute: $\quad$ Reusable

Usage: The general Fortran usage is:

$$
\text { CALL TRNSLT }(A, B, I, C, K)
$$

where: A is a byte string containing the existing values;

B is a byte string defining the values with which each occurrence of the respectively positioned value defined in $A$ is to be replaced;

I is the number of bytes each in $A$ and $B$.

$C$ is the field in which the translations are to be made; and

$K$ is the length, in bytes, of $C$.

$I$ and $K$ are both integers; $A, B$, and $C$ are not restricted as to type.

Program Logic:

- If either I or $K$ is less than one, control is returned to the caller.

- A translate table is built using the bytes in $B$ as function bytes.

- A translate instruction is executed to cover the number of bytes in $C$ resulting as the division remainder of $\mathrm{K} / 256$. Translation on any remaining bytes is then performed in sets of 256 .

Language:

0S/360 Assembler

Author:

R. C. Haywood 


\begin{tabular}{|l|l|l|l|}
\hline DPSTM-500 & Title Subroutine: TRNSLT & Page & $\begin{array}{c}\text { Page } \\
\text { E.2.138 }\end{array}$ \\
\cline { 3 - 5 } & & Rev. & $\begin{array}{c}\text { Date } \\
6 / 73\end{array}$ \\
\hline
\end{tabular}

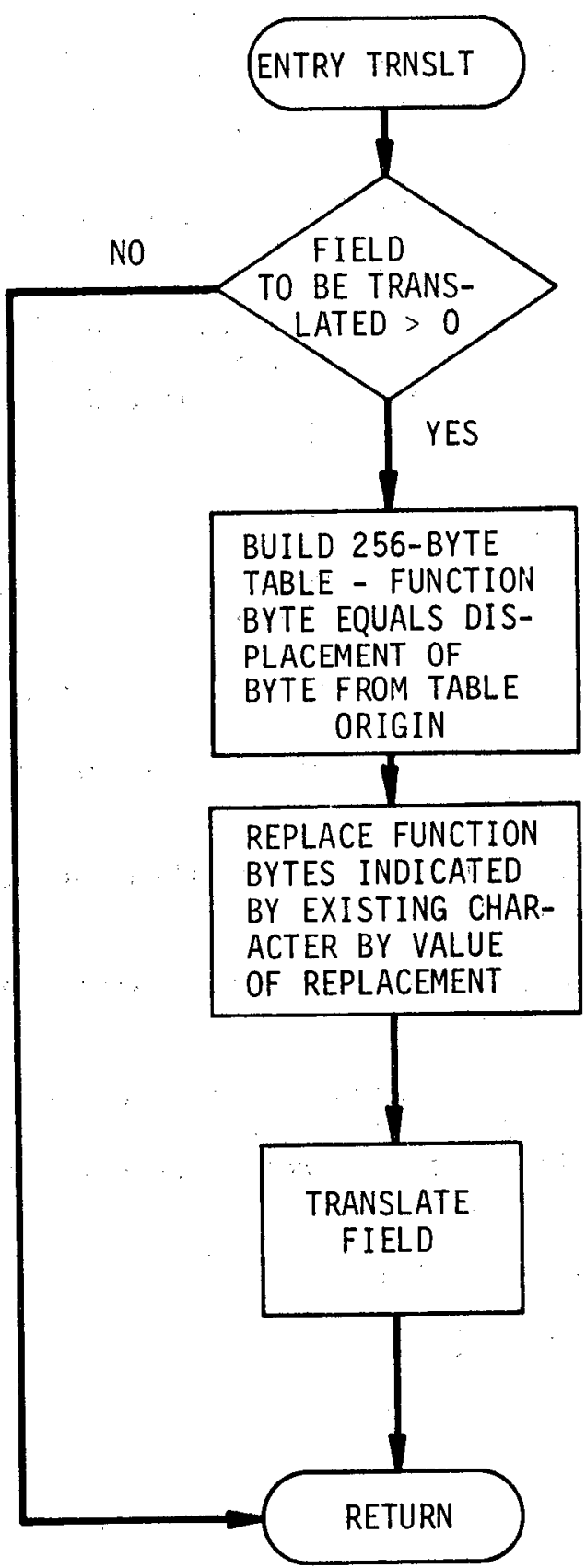




\begin{tabular}{|l|l|l|l|l|}
\hline \multirow{2}{\text{JOSSTM.500}}{} & Title Subroutine: wDUMP & $\begin{array}{l}\text { Vol. Ix } \\
\text { Page } \\
\text { E.2.139 }\end{array}$ \\
\cline { 3 - 5 } & & Rev. & $\begin{array}{l}\text { Date } \\
6 / 73\end{array}$ \\
\hline
\end{tabular}

Purpose: $\quad$ To provide a hexadecimal dump of a core storage area defined in the parameter list.

Usage: $\quad \operatorname{CALL}$ WDUMP $(A, N)$, where

$$
\begin{aligned}
A= & \text { Variable whose address begins dump } \\
N= & \text { Integer } * 4 \text { variable that gives number of } \\
& \text { contiguous bytes to dump }
\end{aligned}
$$

Communication Area: $\quad$ DCB for SYSPRINT Data Set.

Externa1 References: OPEN, WRITE, CHECK

Data Sets: SYSPRINT Data Set.

Program Logic: The addresses of the arguments are received. The contents desired is then written to the SYSPRINT Data Set via the WRITE macro. A translation is done so that the proper characters are designated. After writing last line out, a return is issued.

Referenced by: Calling routine.

Language: Assembler

Author: J. L. Kilpatrick 


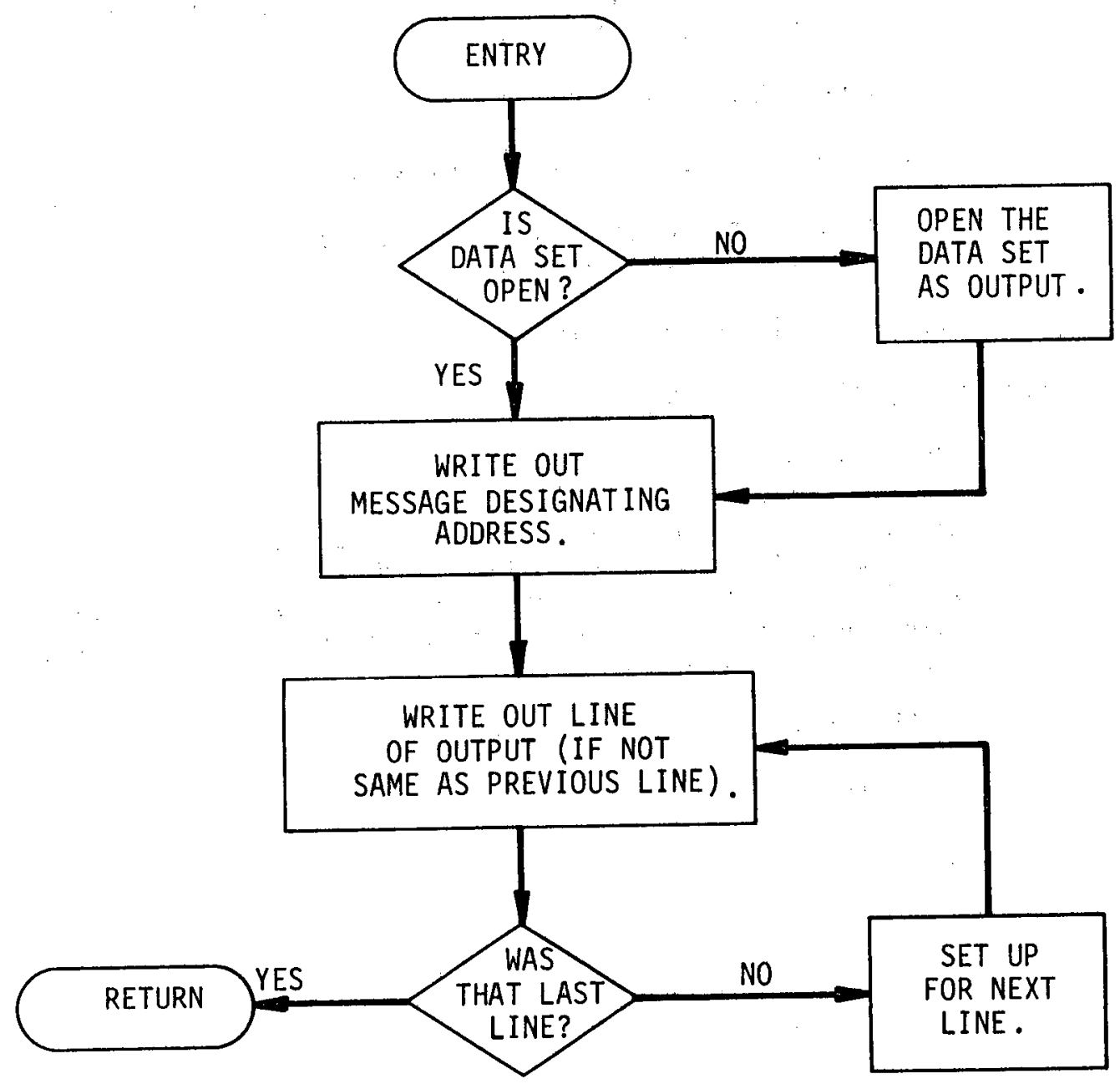




\begin{tabular}{|c|c|c|c|}
\hline 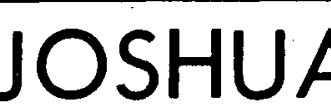 & Title $\quad$ Subroutine: XLIST & ${ }_{\text {IX }}^{\text {Vol. }}$ & \begin{tabular}{|l} 
Page \\
E.2.141
\end{tabular} \\
\hline DPSTM. 500 & & $\begin{array}{r}\text { Rev. } \\
1 \\
\end{array}$ & \begin{tabular}{|c|} 
Date \\
$6 / 73$ \\
\end{tabular} \\
\hline
\end{tabular}

Purpose:

Attribute:

Usage:

Arguments:

Mnemonic

LIMIT

EOL

NLOC

NLOX

MAXCAR

NESTS

NBL

NVMAX

NERR

BOL

LOOPS
To analyze a template $1 / 0$ ist into sets of nested DO-loops, establish loop limits, and define variable.

Nonreusable

CALL XLIST (LIMIT, EOL, NLOC, NLOX, MAXCAR, NESTS, NBL, NVMAX, NERR, BOL, LOOPS, FLAG, CD)
Type

Integer*2

Integer $* 2$

Integer ${ }^{*}$

Integer $* 2$

Integer $* 2$

Integer $* 2$

Integer $* 2$

Integer*2

Integer*2

Integer*2

Integer *2

\section{Description}

Six halfwords per loop. For any 1oop L of a possible twelve loops, LIMIT $(1, L)$ returns the number of variables in that loop.

For any loop L, EOL(L) returns the end point of the loop. For explicitly indexed loops, this is the location of the equal sign preceding the limits of that loop.

For any variable $\mathrm{N}, \mathrm{NLOC}(\mathrm{N})$ returns the starting location of that variable.

For any variable $\mathrm{N}, \mathrm{NLOX}(\mathrm{N})$ returns the ending location of that variable.

Specifies the length of the I/O list. Value will be altered due to the addition of up to two positions to the list.

Returns the number of nests.

Returns the total number of loops.

Returns the total number of variables.

Returns the location of a syntax error in the I/O list.

For any loop L, BOL (L) returns the starting location of that loop. A pseudo-loop-start at BOL $(\mathrm{NBL}+1) \mathrm{de}-$ fines the end of the list (i.e., BOL $(N B L+1)=M A X C A R)$.

For any nest $N$, LOOPS $(N)$ returns the number of loops in that nest. 


\section{JOSHUA ${ }^{\text {Tittle }}$ subroutine: xulsT DPSTM. 500}

\begin{tabular}{|l|l|}
\hline Vol. IX & $\begin{array}{l}\text { Page } \\
\text { E.2.142 }\end{array}$ \\
\hline Rev. & $\begin{array}{c}\text { Date } \\
6 / 73\end{array}$ \\
\hline
\end{tabular}

FLAG Integer*2 On input, it indicates whether a certain syntax error should result in a request for correction or truncation of the list at the point of error. The error is the failure, after a nest has ended, for the continuation to be a comma.

On output, a zero indicates successful execution; a one an error.

CD $\quad$ Logical 1

The template I/O list. It may contain no embedded blanks. It will have two blanks added to the end when returned.

Program Logic:

- The start of the list marks the start of the first loop (and nest). Additional loop starts are determined by the occurrence of a left parenthesis or comma either before any indexing has begun for loops in the same nest or after al1 required indexing to that point has been completed. In the latter case the loop would also mark the start of a new nest.

- Loop ending positions are recorded as either the position immediately preceding the start of a new loop (when ending a loop for which there is no explicit indexing), the equal sign in the indexing parameter, or the end of the list (before blank padding of the list).

- Variables are defined as strings starting with alphabetic characters and ending immediately before the first space, left parenthesis, or comma. Such a string ended by an equal sign is ignored.

Terminating Conditions:

1. Syntax errors.

2. Number of nest exceeding five.

3. Number of loops exceeding twelve.

4. Number of variables exceeding twenty.

Language: . Fortran IV

Author: $\quad$ R. C. Haywood - J. E. Suich 


\begin{tabular}{|c|c|c|c|}
\hline $\mathrm{JOS}$ & Title Subroutine: XLIST & Vol. & $\begin{array}{l}\text { Page } \\
\text { E.2.143 }\end{array}$ \\
\hline DPSTM. 500 & & Rev. & $\begin{array}{c}\text { Date } \\
6 / 73\end{array}$ \\
\hline
\end{tabular}

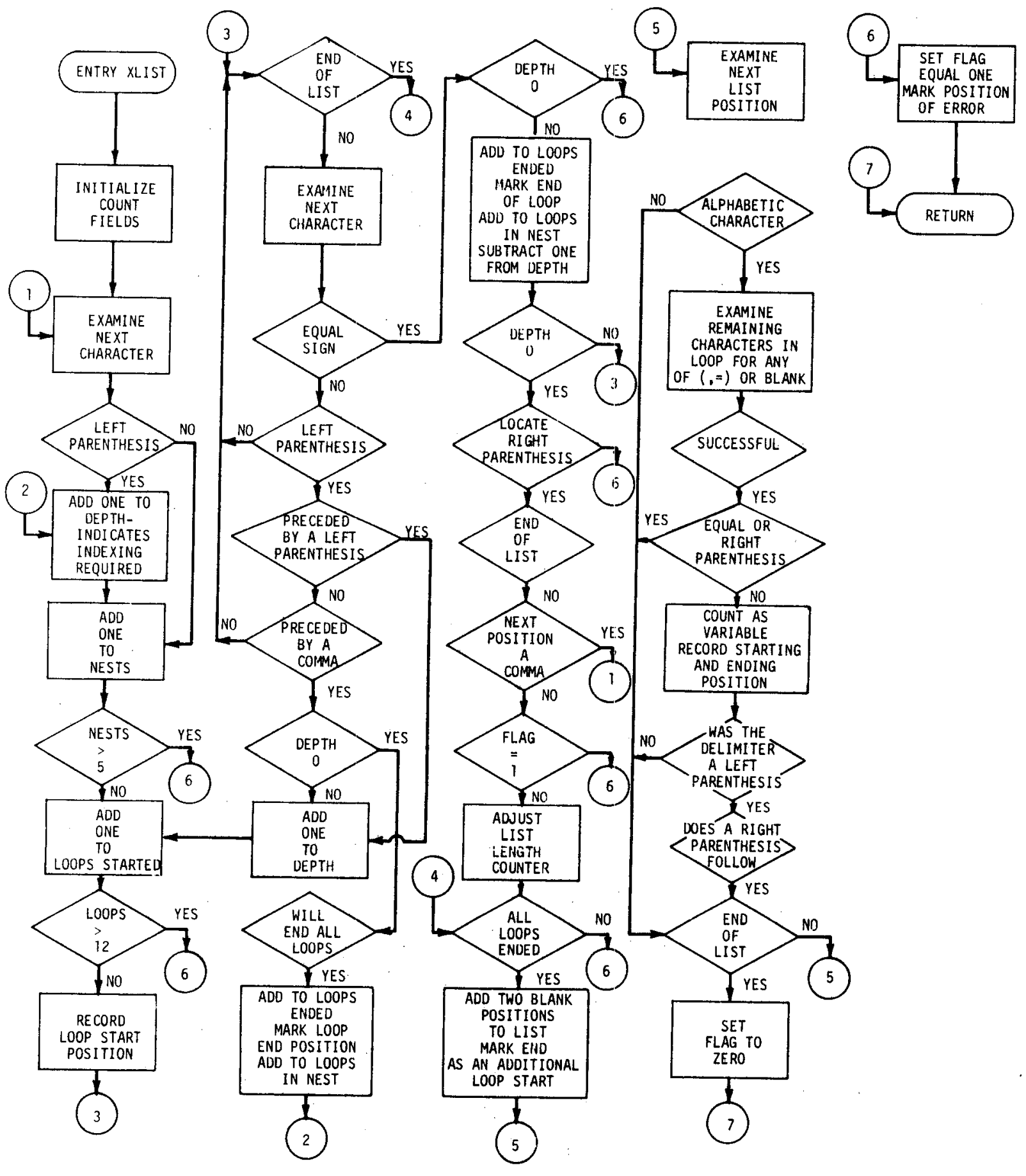




\begin{tabular}{|c|c|c|c|}
\hline. & \multirow[t]{2}{*}{ Title Subroutine: XLIST } & $\begin{array}{l}\text { Vol. } \\
\text { IX }\end{array}$ & $\begin{array}{l}\text { Page } \\
\text { E. } 2.144\end{array}$ \\
\hline DPSTM. 500 & & $\begin{array}{c}\text { Rev. } \\
1\end{array}$ & $\begin{array}{l}\text { Date } \\
6 / 73 \\
\end{array}$ \\
\hline
\end{tabular}




\begin{tabular}{|l|l|l|l|l|}
\hline JOSHUA & Title Subroutine: xLOC & $\begin{array}{l}\text { Vol. IX } \\
\text { DPSTM-500 }\end{array}$ & $\begin{array}{l}\text { Page } \\
\text { E.2.145 }\end{array}$ \\
\cline { 3 - 5 } & & $\begin{array}{l}\text { Rev. } \\
\text { Date } \\
6 / 73\end{array}$ \\
\hline
\end{tabular}

Purpose:

Attribute:

Entry:

Usage:

Program Logic:

Language:

Author:
To provide the absolute address of a variable.

Reusable

XLOC

The general form in Fortran is

$$
L=X \operatorname{LOC}(X)
$$

where: $X$ is the variable whose address is desired,

$\mathrm{L}$ is the vaxiable receiving the address,

XLOC is typed as INTEGER.

The high-order byte of the fullword addressed by register one is cleared and the contents of that word are then loaded into general purpose register zero.

OS/360 Assembler

R. S. Wood - A. H. Dobynis 


\begin{tabular}{c|l|l|l|l|}
\hline \\
DPSTM-500 & Title Subroutine: XLOC & $\begin{array}{c}\text { Vol. } \\
\text { Ix }\end{array}$ & $\begin{array}{c}\text { Page } \\
\text { E.2.146 }\end{array}$ \\
\cline { 3 - 5 } & & $\begin{array}{c}\text { Rev. } \\
\text { Date } \\
6 / 73\end{array}$ \\
\hline
\end{tabular}




\begin{tabular}{|c|ll|l|l|}
\hline JOSHUA & Title Subroutine: xNSTID & Vol. Ix & $\begin{array}{l}\text { Page } \\
\text { E.2.147 }\end{array}$ \\
& & Rev. & $\begin{array}{c}\text { Date } \\
6 / 73\end{array}$ \\
\hline
\end{tabular}

Purpose:

Attribute:

Usage:

Arguments:

Mnemonic

LIST

LITNO

BOL

LOOPS

$\mathrm{CD}$

Program Logic:

Language:

Author:

To place in the last line of the buffer the portion of a template $\mathrm{I} / 0$ list associated with a specified nest.

Nonreusable

CALL XNSTID (LIST, LITNO, BOL, LOOPS, CD)

Type

Logica1*1

Integer*2

Integer $* 2$

Integer *2

$\operatorname{Logica1*1}$

\section{Lescription}

The template I/0 list.

The number of nests preceding the nest of interest.

An array specifying the starting point in LIST of each loop.

An array defining for each nest the number of loops in the nest.

A nine hundred sixty byte field considered to be, but not necessarily, the terminal buffer. The specified portion of the list will be placed in 77 positions starting at byte 883 , truncating when necessary.

- The beginning or ending positions in LIST of the first and last 1oop, respectively, in the nest of interest are determined.

- Bytes 881 - 960 of $\mathrm{CD}$ are blanked.

- The specified portion of the list is placed in CD starting at byte 883. When the segment exceeds 77 bytes, it is truncated to 72 and the literal ',ETC.' loaded starting at byte 956 .

Fortran IV

J. E. Suich 


\begin{tabular}{|c|c|c|c|c|}
\hline$:=$ & \multirow{2}{*}{\multicolumn{2}{|c|}{$\begin{array}{l}\text { Title } \\
\text { Subroutine: XNSTID }\end{array}$}} & Vol. & $\begin{array}{l}\text { Page } \\
\text { E. } 2.148\end{array}$ \\
\hline DPSTM-500 & & & Rev. & $\begin{array}{l}\text { Date } \\
6 / 73\end{array}$ \\
\hline
\end{tabular}

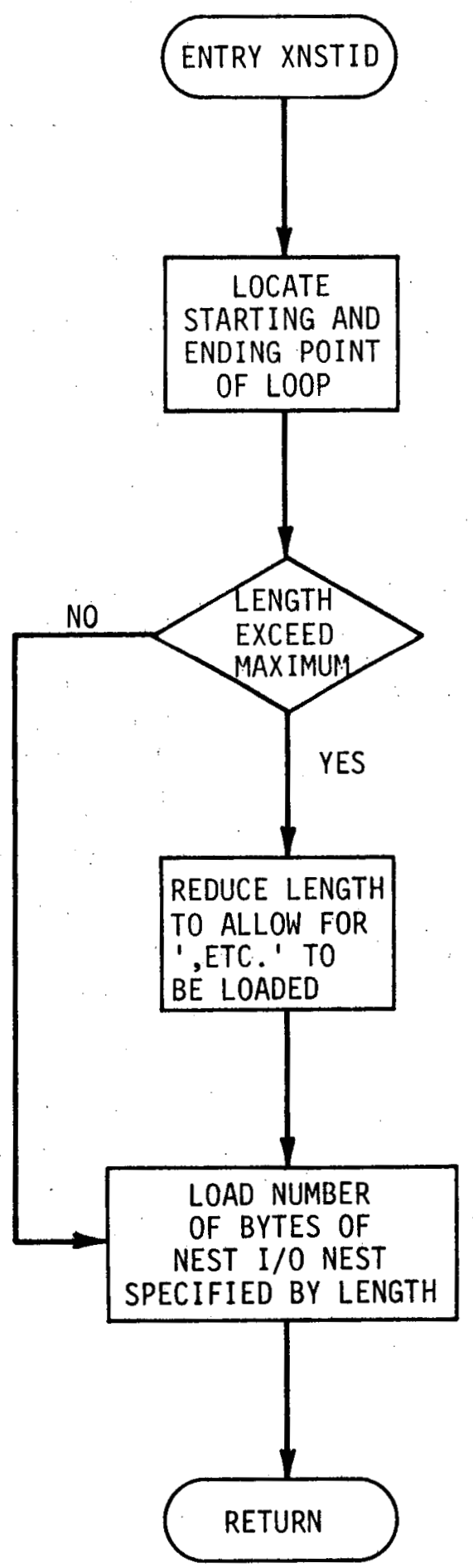




\begin{tabular}{|c|ll|l|l|}
\hline JOSHUA & Title Subroutine: XYHEX & Vol. & $\begin{array}{l}\text { Page } \\
\text { IX } \\
\text { E.2.149 }\end{array}$ \\
& & $\begin{array}{c}\text { Rev. } \\
\text { Date } \\
\end{array}$ \\
\hline
\end{tabular}

Purpose:

To convert from the patch/point representation of a hexagonal lattice (G.AUGE Indexing) to SRP $X, Y$ coordinate representation.

Usage:

CALL XYHEX (IX, IY, IP, IPT, IBC, IR, IQ, IXP, IYP)

where :

IX: $\quad X$ coordinate of the point

IY: $\quad Y$ coordinate of the point

IP: patch number

IPT: point number in patch

IBC: boundary flag (= 1 if 5 point or corner patch; = 0 otherwise)

IR: ring number

IQ: sector number

IXP: $\quad X$ coordinate of patch center

IYP: $\quad$ Y coordinate of patch center

IP and IPT are transmitted to the subroutine; all other varlables are calculated by XYHEX. AlI arguments are integer*4 variables.

The GAUGE indexing scheme used is that in the original code with three points per hex and a full six sectors in the geometry. The interior points of a patch are numbered 1 to 13 as in GAUGE; the boundary points are given negative indexes which will run from -1 to -5 or -8 depending on the patch. T The one point per hex coordinates can also be obtained from XYHEX. If IP and IPT refer to a hex in superpatch coord1nates, then the proper X-coordinate will be -3 . IY and the proper Y-coordinate will be IX. For a problem with only $n$ sectors in the geometry, line 8 in the program should be changed to $\mathrm{N} I=2^{*}(\mathrm{IP}-2) / \mathrm{n}$. ].

The X-Y coordinate system is that used at SRP except that the origin has been translated to the center of the reactor. 


\begin{tabular}{|c|c|c|c|c|}
\hline & \multirow{2}{*}{\multicolumn{2}{|c|}{ Title Subroutine: XYHEX }} & Vol. IX & $\begin{array}{l}\text { Page } \\
\text { E. } 2.150\end{array}$ \\
\hline DPSTM. 500 & & & $\begin{array}{r}\text { Rev. } \\
1 \\
\end{array}$ & $\begin{array}{l}\text { Date } \\
6 / 73 \\
\end{array}$ \\
\hline
\end{tabular}

Data Constants:

PATCHO $(2,6)$ - The vector along the line through the centers of the 'corner' patches; length equal to the spacing from one ring to the next.

$\operatorname{DELTA}(2,6)$ - The vectors from the center of a patch to the center of the next patch in the same ring.

For PATCHO and DELTA, the second subscript is the sector number and the first subscript is the coordinate. For PATCHO and DELTA, $X=1$ and $Y=2$.

QTST(3) .. Values associated with each bisector in using the decision table to determine the sector number.

GAGEPT (13) - Index in the CORR array for each interior point.

GAGEBD(8) - Index in the CORR array for each boundary point.

CORR $(2,20,3)$ - Vector displacement from point to center of patch. First subscript is coordinate $(X=1, Y=2)$, second subscript is point index (in order of XYPTS array (not defined here), with central point omitted), and third subscript is sector (sectors $4-6$ are the negative of $1-3$ ).

Program Logic:

The patch numbers, IP, for the patches in ring IR obey the realtionship

$$
\begin{aligned}
& 3 I R(I R-1)+2 \leq I P<3 I R(I R+1)+2 \\
& I R(I R-1) \leq \frac{I P-2}{3}<I R(I R+1) \\
& (I R)^{2}-I R+\frac{1}{4} \leq \frac{I P-2}{3}+\frac{1}{4}<(I R)^{2}+I R+\frac{1}{4} \\
& (I R-1 / 2)^{2} \leq \frac{4 \cdot I P-5}{12}<\left(I R+\frac{1}{2}\right)^{2} \\
& \text { Therefore, IR } \leq \frac{4 \cdot I P-5}{12}+\frac{1}{2}<I R+1
\end{aligned}
$$




\begin{tabular}{|c|c|c|c|c|c|}
\hline \multirow{2}{*}{$\begin{array}{l}\text { JSHUA } \\
\text { DPSTM.500 }\end{array}$} & \multirow[t]{2}{*}{ Title } & \multirow{2}{*}{\multicolumn{2}{|c|}{ Subroutine: XYHEX }} & \multirow{2}{*}{\begin{tabular}{|l} 
Vol. \\
Rev.
\end{tabular}} & \begin{tabular}{|l} 
Page \\
E.2.151
\end{tabular} \\
\hline & & & & & \begin{tabular}{|c|} 
Date \\
$6 / 73$
\end{tabular} \\
\hline
\end{tabular}

This formula is true for real numbers. Using an approximation which works for integers as long as IR $<10$, the ring number is determined. Once the ring index is known, it is fairly simple to determine $I Q$, the sector number, and IN3, the index of location in the sector. Simply subtract the number of patches up to ring IR and divide the result by IR. The quotient (plus I) w1ll be IQ and the remainder will be IN3. $0<$ IN3 < IR. If IN3 $=0$, the patch is a 'corner' or' '5-point' patch and the boundary flag, $I B C$, is set to 1 .

Next the $X-Y$ coordinates of the center of the patch are determined. The patch centers lie on a triangular mesh. In each sector, the centers of the 'corner' patches lie at equal distances on a straight line out from the origin. See Figure 1. The vectors denoting a unit distance on each of these lines are contained in the data array PATCHO. The center of the corner patch in the same ring as the desired patch then has coordinates:

$$
\begin{aligned}
& I X P_{C}=I R \operatorname{PATCHO}(1, I Q) \\
& I Y P_{C}=I R \operatorname{PATCHO}(2, I Q)
\end{aligned}
$$

From the 'corner' patch, the centers of the 'side' patches in the same ring lie on another stralght line, which makes a $60^{\circ}$ angle with the line of 'corner' patch centers. The vector denoting the unit on this line is stored in the data array DELTA.

* IR $=(\mathrm{N} 2+25+478 \mathrm{~N} 1 / \mathrm{N} 2) / 44$

where:

$$
\mathrm{N} 1=\frac{4 \cdot \mathrm{IP}-5}{12} \text { and } \mathrm{N} 2=\text { ? } \mathrm{N} 1+51
$$




\section{JOSHUA ${ }^{\text {Title }}$ subroutine: XYHEX DPSTM 500}

\begin{tabular}{|l|l|}
\hline Vol. & $\begin{array}{l}\text { Page } \\
\text { IX } 2.152\end{array}$ \\
\hline Rev. & $\begin{array}{c}\text { Date } \\
\text { I }\end{array}$ \\
\hline
\end{tabular}

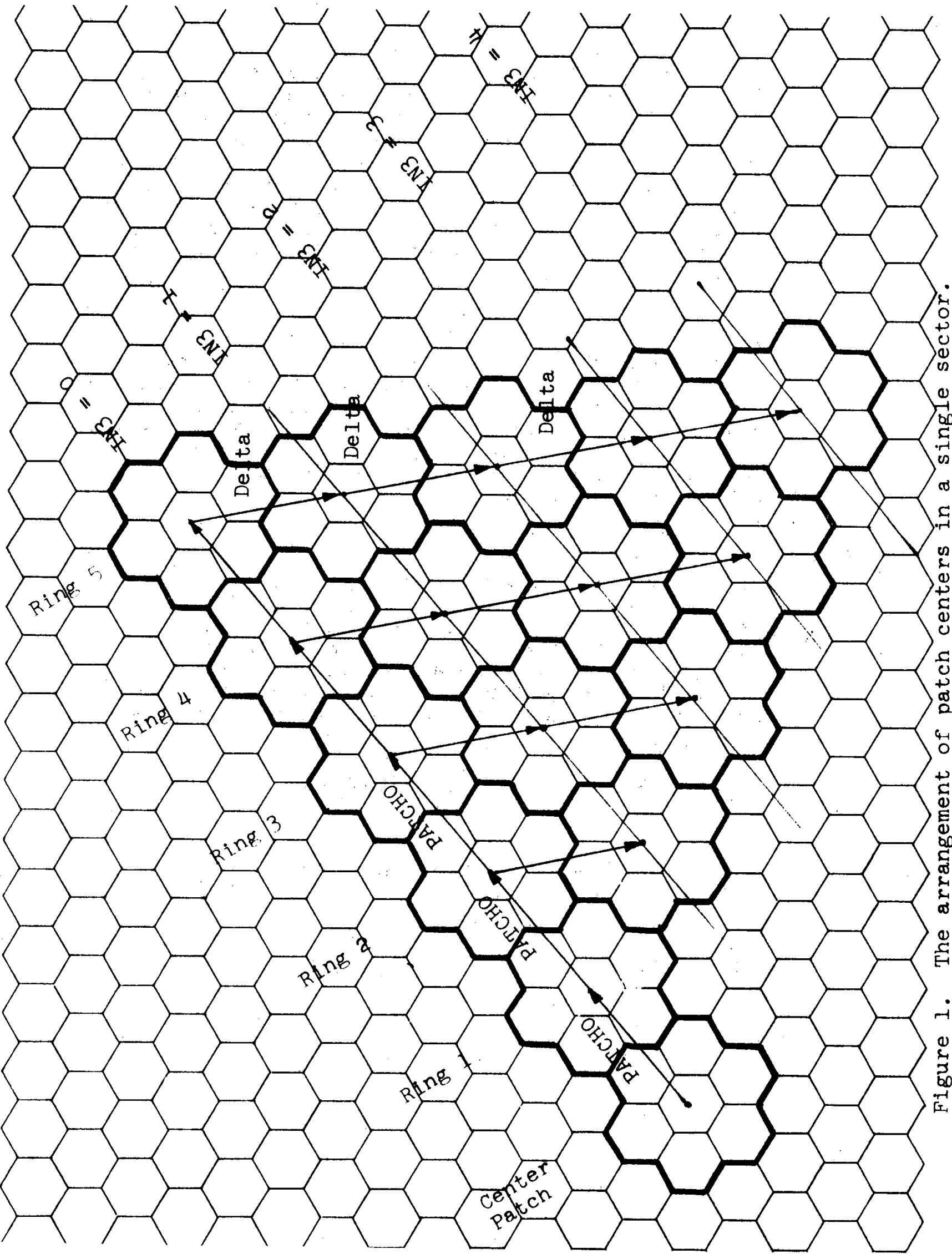




\begin{tabular}{|c|lc|c|c|} 
JOSHUA & Title Subroutine: XYHEX & $\begin{array}{l}\text { Vol. } \\
\text { IX }\end{array}$ & $\begin{array}{l}\text { Page } \\
\text { E.2.153 }\end{array}$ \\
& & $\begin{array}{c}\text { Rev. } \\
1\end{array}$ & $\begin{array}{l}\text { Date } \\
6 / 73\end{array}$ \\
\hline
\end{tabular}

The coordinates of the desired patch center are then:

$$
\begin{aligned}
& I X P=I X P_{c}+I N 3 \operatorname{DELTA}(1, I Q) \\
& I Y P=I Y P_{c}+I N 3 \operatorname{DELTA}(2, I Q)
\end{aligned}
$$

From the center of the patch, the various points in the patch lie at distances which are fixed for all patches in the same sector (and rotate $60^{\circ}$ from one sector to the next). A table lookup is used to determine the difference in coordinates from the patch center to the desired point. Advantage is taken of the symmetry to reduce the table size by two, as the coordinate vectors for the last three sectors are the negative of those for the first three sectors. To further reduce the size of tables stored, the CORR array needed for the HEXXY routine is also used in XYHEX for the table of coordinates from the patch center to the individual point. This necessitates doing the table lookup in two steps. First a table lookup (using GAGEPT and GAGEBD) translates the point number from the GAUGE indexing scheme to the order used in the CORR array. Then the values in the CORR array are added to the coordinates of the patch center to get the coordinates of the particular point.

Language: Fortran IV

Author:

J. E. Suich

Restrictions: The approximation used to replace the square root in determining the ring index limits the routine to less than ten rings in the reactor lattice. 


\begin{tabular}{|c|ll|l|l|}
\hline JOSHUA & Title Subroutine: XYHEX & $\begin{array}{l}\text { Vol. } \\
\text { IX }\end{array}$ & $\begin{array}{l}\text { Page } \\
\text { E..2.154 }\end{array}$ \\
& & $\begin{array}{c}\text { Rev. } \\
\text { Date } \\
6 / 73\end{array}$ \\
\hline
\end{tabular}

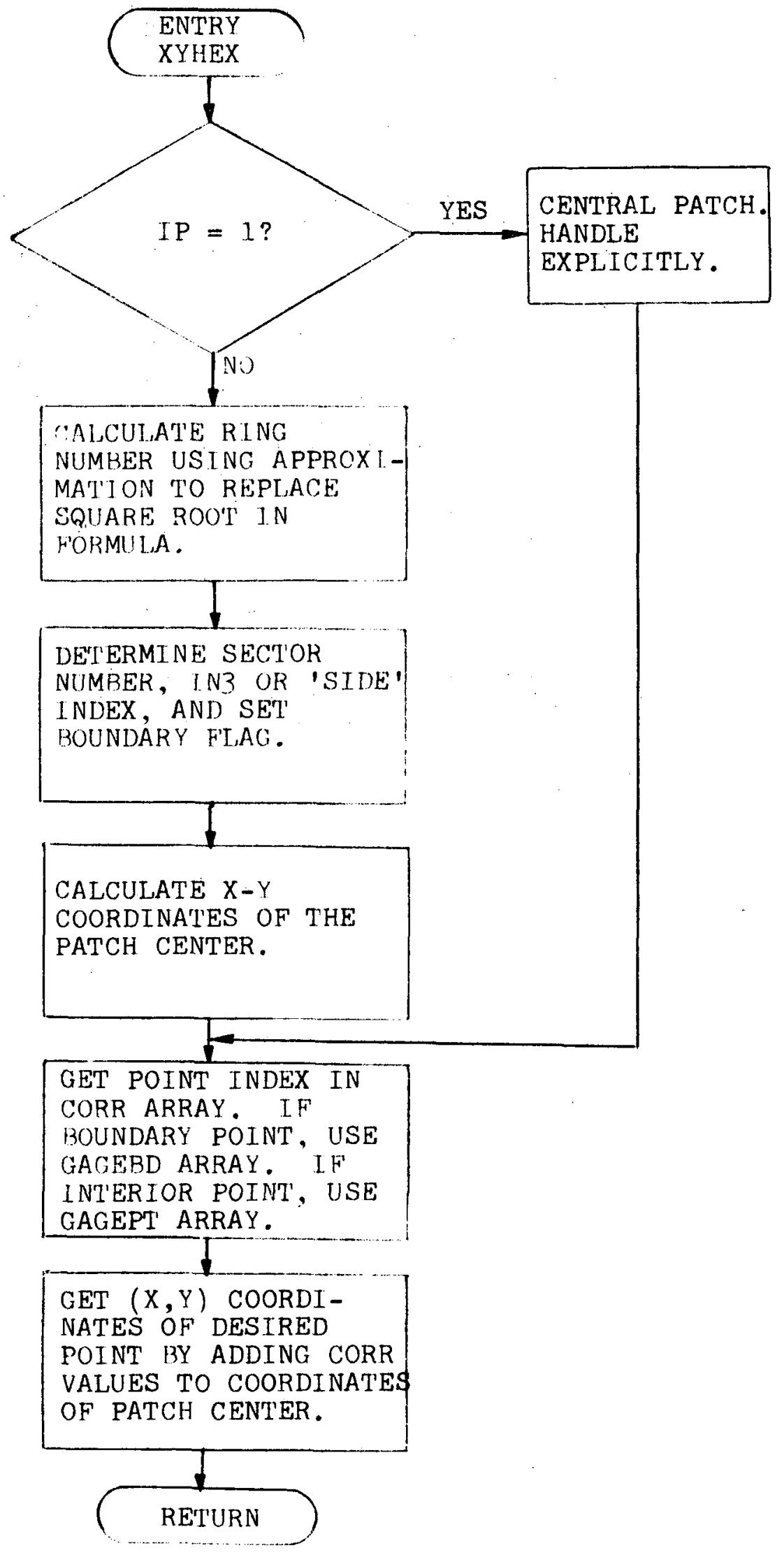




\begin{tabular}{|c|c|c|c|c|}
\hline 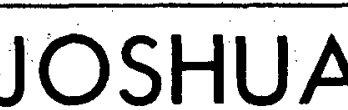 & \multirow{2}{*}{\multicolumn{2}{|c|}{ Title Subroutine: zCOMP }} & Vol. IX & Page \\
\hline DPSTM.500 & & & Rev. $_{1}$ & $\begin{array}{l}\text { Date } \\
6 / 73\end{array}$ \\
\hline
\end{tabular}

Purpose:

Attribute:

Entry:

Usage:

Program Logic:

Language:

Author:
To perform a logical compare of two fields of equal length.

Reusable.

ZCOMP

The general form in FORTRAN is

CALL $Z$ COMP $(A, B, L, I[, N[, M]])$

where: A is the first field for the comparison,

$B$ is the second field,

$\mathrm{L}$ is the number of contiguous bytes in each field participating in the test,

I indicates the result of the test as follows:

1. $A<B$

2. $A=B$

3. $A>B$

$\mathrm{N}$ is the relative byte in fields $\mathrm{A}$ and $\mathrm{B}$ which the comparison is to start,

$M \quad$ is the relative byte in field $B$ at which the comparison is to start thus overriding $\mathrm{N}$ as it relates to field $B$.

- The starting points in fields A and B are established.

- If the length of the comparison is defined as less than one, the return code is set to two and the subroutine is terminated.

- The two fields are compared first in blocks of 256 bytes until less than 256 bytes remain and then the remainder are tested. After all but the final test, if the result. shows A less than B or A greater than B the return code is set and the subroutine terminated. After the final compare, the proper return code is set and the subroutine terminated.

OS/360 Assembler

R. S. Wood - L. F. Zimnerman 


\begin{tabular}{|c|c|c|c|}
\hline & \multirow[t]{2}{*}{ Title Subroutine: ZCOMP } & \multicolumn{2}{|c|}{ 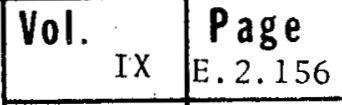 } \\
\hline DPSTM 500 & & Rev. & $\begin{array}{l}\text { Date } \\
6 / 73\end{array}$ \\
\hline
\end{tabular}

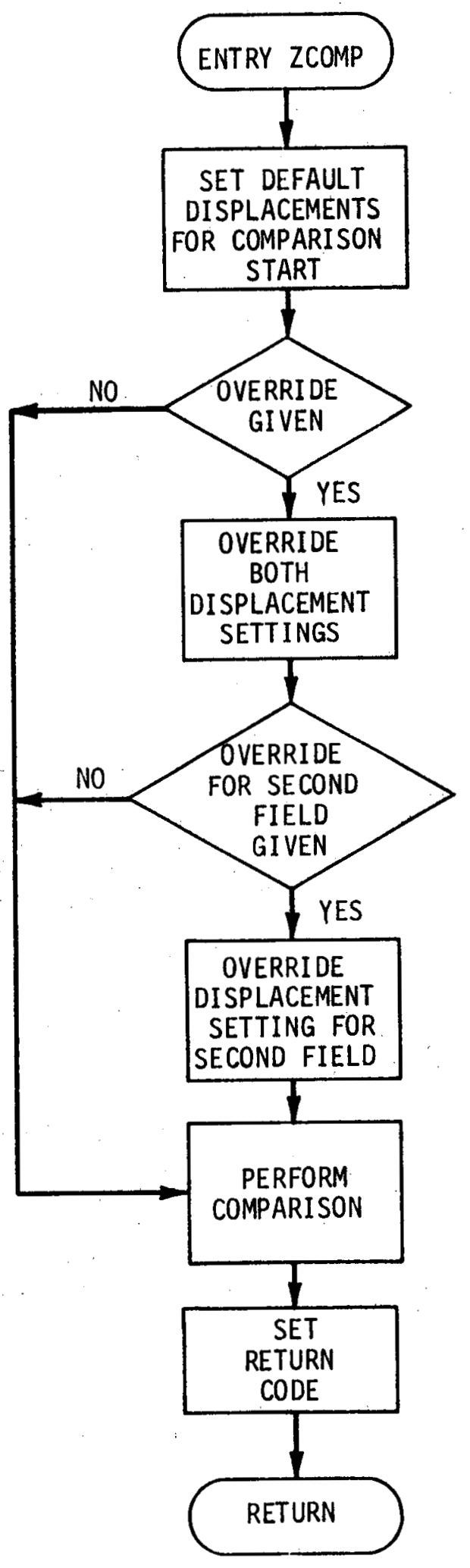


DPSTM-500

Vol. $9.3 \quad 6 / 74$

\section{DISTRIBUTION}

3. C. M. Brown $-706 \mathrm{C}$

5. T. B. Niland - AEC

6. D. N. Bridges - AEC

7. M. M. Anderson - 773A

8. C. W. Farmer, Jr. - AEC

9. C. A. McCharen - AEC

10. J. W. Croach - Wilm.

11. F. E. Kruesi - Wilm.

12. J. H. Carswel1 - 773A

13. R. F. Gambill, Jr. $-703 \mathrm{~A}$

14. J. H. Hightower $-773 \mathrm{~A}$

15. L. W. Patrick $-706 \mathrm{C}$

16. R. E. Cooper - 773A

17. 0. A. Towler $-706 \mathrm{C}$

18. D. A. Ward $-706 \mathrm{C}$

19. C. J. Temple $-706 \mathrm{C}$

20. R. L. Carson - 703A

21. J. N. Wilson $-703 \mathrm{~A}$

22. C. D. Kern - 773A

23. B. G. Kingery $-706 \mathrm{C}$

24. J. W. Wade $-773 \mathrm{~A}$

25. H. C. Honeck - 773A

26. J. M. Sicilian - 773A

27. W. R. Hartshorn $-773 \mathrm{~A}$

28. J. C. Jensen $-773 \mathrm{~A}$

29. R. S. Wood - 773A

31. D. R. Finch $-773 \mathrm{~A}$

32. W. H. Hightower $-773 \mathrm{~A}$

33. J. H. Maddox - 773A

34. R. C. Haywood - 773A

35. J. W. Stewart $-773 \mathrm{~A}$

36. B. P. Compton - 773A

37. W. E. Graves - 773A

38. D. A. Sharp - 773A

39. F. J. McCrosson - 773A

40. P. L. Ames $-706 \mathrm{C}$

41. D. E. Hostetler $-777 \mathrm{M}$

42. J. E. Beach - 773A

43. R. M. Wallace $-773 \mathrm{~A}$

44. H. K. Clark - 773A

45. F. R. Field - 773A

46. H. E. Wingo $-773 \mathrm{~A}$

48. R. L. Kare1 - 732A

50. A. N. Mallen $-773 \mathrm{~A}$

51. 777M File Point

52. J. D. Spencer $-777 \mathrm{M}$

53. M. B. Stroud $-777 \mathrm{M}$

55. W. H. Brotherton, Jr. - 773A
56. Helen P. Thompson - CE

57. F. D. Knight $-773 \mathrm{~A}$

58. F. D. King - 773A

59. W. V. Baxter $-773 \mathrm{~A}$

60. R. J. Pryor - 773A

61. M. R. Buckner - 773A

62. J. P. Church - 773A

63. B. Toppel - ANL

64. Richard Ehrich - KAPL

65. D. Vondy - ORNL

66. C. W. Craven, Jr. - ORNL

67. R. L. Howell - ORNL

68. M. Levine - BNL

69. Neal Carter - BMI

70. G. H. Best - LASL

71. R. A. Danne1s - WAPD

72. D. Roy - B\&W

73. P. G. Aline - GE

74. B. Hutchins - GE

75. Alleen Thompson - GE

76. H. Alter - AI

78. Martin Becker - RPD

79. D. S. Craig - AECL

80. D. S. Craig - AECL

81. L. A. Heinrich - 773A

82. Mrs. Margaret Butler - ANL

85. R. L. Hellens - CEI

92. Kent F. Hansen - MIT

93. R. J. Mullin - TVA

94. H. Toffer - DUN

95. George Minton - PWR

96. J. E. Suich - Wilm.

97. Orlando Lopez - IN

98. David S. Selengut - KAPH

100. Vital Records File

\section{TIS File:}

* Master Copy

$1,2,4,30,47,49,54,77$, $83,84,86-91, * 99$. 